UNIVERSIDAD POLITECNICA DE VALENCIA DEPARTAMENTO DE INGENIERIA HIDRAULICA Y MEDIO AMBIENTE

\title{
CARACTERIZACIÓN ECOLÓGICAY Y ESTABLECIMIENTO DE LOS CRITERIOS PARA DETERMINAR EL POTENCIAL ECOLÓGICO EN LAS SALINAS DE LA COMUNIDAD VALENCIANA
}

\author{
TESIS DOCTORAL \\ CARMEN Ma MARTÍ INSA \\ DIRECTORA \\ DRA. INMACULADA ROMERO GIL
}

VALENCIA, OCTUBRE 2010 



\section{Agradecimientos}

La realización de esta tesis doctoral no hubiera sido posible sin la ayuda de muchas personas. En primer lugar quisiera agradecer a Dña. Inmaculada Romero Gil, directora de esta tesis, y a D. Julio González del Río Rams, profesor responsable del grupo hasta la fecha y que tanto ha confiado en mí. A ambos muchas gracias. Ni que decir tiene que esta tesis no hubiera visto la luz sin su ayuda.

Al Instituto de Ingeniería del Agua y Medio Ambiente (IIAMA) y a la Conselleria de Medio Ambiente, Agua, Urbanismo y Vivienda de la Comunidad Valenciana cuya financiación ha hecho posible realizar esta tesis doctoral.

También quisiera agradecer a mis compañer@s del Grupo de Evaluación de Impacto Ambiental. Tanto a los que llevamos o pasamos más tiempo juntos como María, Reme, Zuri, Isabel y Patricia, como a los nuev@s Cinta, Jaime, Fran, Iñaqui, Noemí y Virginia. Todos me habéis ayudado en mayor o menor medida, algunos con las analíticas, otros con los muestreos o los mapas, o simplemente "aguantándome".

En especial quiero agradecer a María, que ha sido mi compañera de proceso de tesis porque este proceso "nos tocó" vivirlo a las dos a la vez y no se cómo hubiera hecho durante los meses más difíciles sin su ayuda. A Reme por sus sabios consejos como asesora de imagen de la tesis y sobre todo en el laboratorio. A Zuri porque los quebraderos de cabeza de las muestras salinas nos los "hemos comido" juntas. Y de nuevo a Inma porque no sólo le he de agradecer como tutora sino también por las pequeñas (y no tan pequeñas) cosas del día a día en las que me ha ayudado aún cuando no tenía por qué hacerlo. Gracias.

Gracias también a todas aquellas personas que han pasado por el grupo como Cristina, Laia, María Miralles, Germà, Jorge...con las que tan buenos momentos he vivido.

Gracias a mis amig@s a quienes tan abandonad@s he tenido especialmente durante el último año. Bueno aunque parecía que nunca iba a llegar el día, por fin la tesis está finalizada!!

Gracias a mi familia por su paciencia conmigo y les pido disculpas por no haber podido pasar más tiempo con ellos durante el último año, a Andrés, Dalia, Matilde y Aurelio.

Y muy especialmente agradezco y dedico esta tesis a las dos personas que más han estado conmigo ayudándome y apoyándome durante el último año. A mi madre, Matilde, y a Constantin. Sin ellos sí que no hubiera sido posible este trabajo. Muchas gracias. 



\section{Resumen}

Las salinas son masas de agua situadas normalmente en el litoral, cuyo objeto es la obtención de sal a través de la evaporación del agua de mar (o en algunos casos de aguas salinas continentales). Generalmente están constituidas por un sistema de balsas someras cuya salinidad es mayor que la del agua marina y su ubicación, modo de explotación y la salinidad de las balsas, especialmente las que se dan al final del circuito, marcan la pauta para el desarrollo de las condiciones ambientales. Las elevadas concentraciones salinas hacen que estos sistemas presenten unas condiciones ambientales extremas a las que sólo unos pocos organismos especializados han podido adaptarse.

En la presente tesis doctoral se realiza un estudio exhaustivo de los principales parámetros físico-químicos de estos ecosistemas tan extremos de la Comunidad Valenciana (salinas de Santa Pola, La Mata-Torrevieja y Calpe) que en gran medida están determinados por las condiciones de gestión humana:

- La salina de Santa Pola es un sistema salinero convencional donde se hace circular el agua de mar por una serie de estanques someros para obtener mediante evaporación una progresiva concentración de las sales y finalmente su precipitación. En este sistema el rango de salinidades es muy amplio y va desde niveles algo mayores a los del agua de mar a niveles próximos al punto de precipitación (en los cristalizadores).

- La salina de La Mata-Torrevieja es un sistema formado por dos grandes estanques. La laguna de La Mata que presenta concentraciones más variables ya que funciona como un gran calentador y la laguna de Torrevieja, con valores muy homogéneos puesto que actúa como un gran cristalizador. Torrevieja además de recibir las aguas de La Mata también recibe las aguas de salmuera procedentes del lavado de la sal del yacimiento de El Pinoso.

- La salina de Calpe actualmente no se encuentra en explotación, si bien recibe periódicamente bombeos de agua marina con el fin de mantener la lámina de agua y la biodiversidad en el sistema, por lo que la salinidad de sus aguas es mayor que la marina aunque sin llegar a superar los niveles de un calentador.

El principal parámetro considerado en el estudio de estos sistemas lógicamente es la salinidad, que presenta diferencias significativas entre las salinas dadas las condiciones particulares de cada una de ellas. Además, se estudia el comportamiento de diversos parámetros físico-químicos ( $\mathrm{pH}$, amonio, nitrito, nitrato, NID, PSR, relación NID/PSR, PT y ácido ortosilícico) así como las variaciones que estos parámetros presentan estacionalmente, a lo largo del gradiente salino, e incluso en diferentes zonas dentro de una misma salina. Se revisa si el estado de los diferentes parámetros físico-químicos deriva del sistema de explotación salinero o de causas distintas, y se realiza una comparación entre salinas con el fin de determinar si existen pautas de comportamiento similares entre ellas, o por el contrario, particularidades propias de cada una.

Finalmente, se procede a revisar los principales criterios a tener en cuenta para el establecimiento del potencial ecológico en las salinas de la Comunidad Valenciana en aplicación de la Directiva Marco del Agua (2000/60/CE). Esta Directiva establece el marco 
europeo para la protección de las aguas superficiales continentales, de transición, costeras y subterráneas para prevenir o reducir su contaminación, promover su uso sostenible, proteger el medio ambiente, mejorar el estado de los ecosistemas acuáticos y atenuar los efectos de las inundaciones y sequías. El objetivo de la DMA es que todas las masas de agua alcancen un "estado ecológico bueno" en el año 2015.

Las salinas de la Comunidad Valenciana, en el ámbito de la DMA, pertenecen al grupo de aguas de transición y han sido designadas como masas de agua muy modificadas (MAMM). En el caso de las MAMM, la DMA establece la obligatoriedad de determinar el "potencial ecológico" y no el "estado ecológico". Esto supone la asunción de determinadas condiciones de excepcionalidad entre las que se encuentra la reducción de las exigencias ambientales, manteniendo al mismo nivel los objetivos de protección y mejora de la calidad.

Previamente al establecimiento del potencial ecológico, es necesario realizar un proceso de intercalibración entre los diferentes Estados Miembros de las distintas metodologías propuestas para su determinación. Actualmente, el proceso de intercalibración en aguas de transición se encuentra poco avanzado puesto que son masas de agua complejas y condicionadas por un amplio número de factores. A esta complejidad se añade, en el caso de las MAMM, que no pueden verse alteradas las funciones para las que sirven. Dado que el proceso de intercalibración no se encuentra actualmente definido, no se está en condiciones de establecer el potencial ecológico de las salinas, aunque en la presente tesis doctoral se propone una metodología para llegar a determinar el potencial ecológico de los sistemas salineros de la Comunidad Valenciana.

La metodología propuesta se basa en criterios físico-químicos y no biológicos ya que, dadas las condiciones tan extremas para la vida en las salinas, no hay un elemento biológico que pueda ser aplicado como índice de calidad en todas ellas. Por ello se propone un modelo teórico basado en el comportamiento del $\mathrm{P}_{50}$ del PT frente al $\mathrm{P}_{50}$ de la salinidad, aplicado en la salina de Santa Pola, que es por sus características y por su amplio rango salino, la salina considerada como más representativa. También se proponen una serie de medidas de mitigación para la mejora de la calidad de las aguas en aquellas salinas donde se hace necesario, sin alterar los usos a los que éstas son destinadas. 


\section{Abstract}

Solar salterns are water bodies normally situated along the coast and whose object is the obtainment of salt through the evaporation of seawater (or, in some cases, saline continental waters). They are generally composed of a system of shallow ponds with salinities exceeding that of seawater. Their location and manner of exploitation, coupled with the salinity of the ponds (particularly those situated at the end of the circuit), together set the standard for the development of environmental conditions. The elevated saline concentrations lead these systems to present extreme environmental conditions to which only a few specialized organisms have been able to adapt.

In the present doctoral thesis, an exhaustive study is carried out on the principal physicochemical parameters of these highly extreme ecosystems within the Valencian Community (the salterns of Santa Pola, La Mata-Torrevieja and Calpe), which are determined to a great extent by conditions linked to human activities:

- The Santa Pola solar saltern is a conventional flow-through system where seawater is circulated through a series of shallow ponds to obtain, via evaporation, a progressive concentration of salts, and finally their precipitation. The range of salinities in this system is very extensive, encompassing levels somewhat greater than those found in seawater to levels near the precipitation point (in the crystallizers).

- The saltern at La Mata-Torrevieja is a system composed of two large lagoons. The smaller of the pair, La Mata, presents more variable concentrations due to its role as a great heating pond. The Torrevieja lagoon exhibits very homogenous values since it acts as a great crystallizer. In addition to the water from La Mata, Torrevieja also receives saturated brines piped down from the salt deposit at El Pinoso.

- $\quad$ The Calpe saltern is not currently in use, although it does periodically receive influxes of seawater, which in turn maintain the water level and biodiversity in the system. Consequently, the salinity of these waters is greater than seawater, but does not exceed the levels of a heating pond.

The principal parameter considered in the study of these systems is, logically, salinity. It exhibits significant differences between solar salterns, given the particular conditions of each. Likewise studied are the behaviours of diverse physicochemical parameters $(\mathrm{pH}$, ammonium, nitrite, nitrate, DIN, SRP, the ratio DIN/SRP, TP and orthosilicic acid), as well as the variations these parameters exhibit seasonally, along the saline gradient, and even in different zones within the same saltern. The different physicochemical parameters are examined to see if their status is attributable to the solar saltern exploitation system or to other causes. Additionally, the salterns are compared to determine shared behaviour patterns or, on the contrary, particularities specific to each.

Finally, a revision is subsequently carried out of the principal criteria to be taken into account when establishing the ecological potential of the Valencian Community salterns, in application of the Water Framework Directive (2000/60/CE). This Directive establishes the European framework for the protection of surface, continental, transitional, coastal and 
subterranean waters so as to prevent or mitigate their contamination, promote their sustainable use, protect the environment, improve the status of aquatic ecosystems and attenuate the effects of flooding and droughts. The overall objective of the WFD is to have all water bodies achieve a "good quality status" by 2015.

Within the scope of the WFD, the solar salterns of the Valencian Community belong to the transitional-waters group, and have been designated as Heavily Modified Water Bodies (HMWB). Regarding HMWB, the WFD establishes as obligatory the determination of their "ecological potential," and not their "ecological status." This supposes the assumption of certain exceptional conditions, among which include the reduction of environmental requirements, maintaining at the same level the goals of protection and quality improvement.

Prior to establishing the ecological potential, an intercalibration exercise of the different proposed methodologies must first be conducted by the various Member States. To date, the intercalibration exercise for transitional waters has advanced little, as these water bodies are complex and conditioned by a large number of factors. This complexity is further exacerbated in the case of the HMWB, as their specified functions cannot be modified. Given that the intercalibration exercise remains currently undefined, the ecological potential of the solar salterns is not ready to be established. Nevertheless, a methodology is proposed in the present thesis for eventually determining the ecological potential for the Valencian saltern systems.

The proposed methodology is based on physicochemical, not biological, criteria. Given the extremely harsh conditions for life in the solar salterns, there is no biological element capable of being applied as a quality measurement of all three. For this reason, a theoretical model is proposed based on the behaviour of the $\mathrm{P}_{50}$ of TP versus the $\mathrm{P}_{50}$ of salinity. This model is applied to the Santa Pola saltern, considered the most representative saltern for its characteristics and broad saline range. A series of mitigation measures are additionally proposed to improve water quality in those salterns requiring such actions, though without altering their specified use. 


\section{Resum}

Les salines són masses d'aigua situades normalment en el litoral, l'objecte de les quals és l'obtenció de sal per mitjà de l'evaporació de l'aigua de mar (o en alguns casos d'aigües salines continentals). Generalment es troben constituïdes per un sistema de basses someres amb una salinitat major que la de l'aigua de mar i la seua ubicació, manera d'explotació i la salinitat de les basses, especialment les que es troben al final del circuit, marquen la pauta per al desenvolupament de les condicions ambientals. Les elevades concentracions salines fan que aquests sistemes presenten unes condicions ambientals extremes, per la qual cosa, només uns pocs organismes especialitzats han pogut adaptar-se.

En la present tesi doctoral es realitza un estudi exhaustiu dels principals paràmetres fisicoquímics d'aquests ecosistemes tan extrems de la Comunitat Valenciana (salines de Santa Pola, La Mata-Torrevieja i Calp) que en gran mesura es troben determinats per les condicions de gestió humana:

- La salina de Santa Pola és un sistema saliner convencional on es fa circular l'aigua de mar per una sèrie d'estanys superficials per tal d'obtindre mitjançant l'evaporació, una progressiva concentració de les sals i finalment la seua precipitació. En aquest sistema, el rang de salinitats és molt ampli i oscil·la des de nivells un poc majors als de l'aigua de mar a nivells pròxims al punt de precipitació (en els cristalitzadors).

- La salina de La Mata-Torrevieja és un sistema format per dos grans estanys. La llacuna de La Mata que presenta concentracions més variables ja que funciona com a un gran escalfador i, d'altra banda, la llacuna de Torrevieja, amb valors molt homogenis perque actua com a un gran cristalitzador. Torrevieja, a més de rebre les aigües de La Mata també rep les aigües de salmorra que procedeixen del rentat de la sal del jaciment de El Pinòs.

- La salina de Calp actualment no es troba en explotació, encara que rep periòdicament bombatges d'aigua marina amb la finalitat de mantindre el nivell d'aigua i la biodiversitat dins del sistema. D’aquesta manera, la salinitat de les seues aigües és major que la marina però així i tot, sense arribar a superar els nivells d'un escalfador.

El principal paràmetre considerat en l'estudi d'aquestos sistemes és lògicament la salinitat, que presenta diferències significatives entre les salines per les condicions particulars de cadascuna d'elles. A més, s'estudia el comportament de diversos paràmetres fisicoquímics (pH, amoni, nitrit, nitrat, NID, PSR, relació NID/PSR, PT i àcid ortosilícic) així com les variacions que aquests paràmetres presenten estacionalment al llarg del gradient salí, i fins i tot, en diferents zones dins d'una mateixa salina. Es revisa si l'estat dels diferents paràmetres fisicoquímics procedeix del sistema d'explotació salinera o de causes diferents. També, es realitza una comparació entre les diferents salines, per tal de determinar si existeixen pautes de comportament similars entre elles, o per contra, particularitats pròpies de cadascuna.

Finalment, es procedeix a revisar els principals criteris a tindre en compte per a l'establiment del potencial ecològic en les salines de la Comunitat Valenciana en aplicació 
de la Directiva Marc de l'Aigua (2000/60/CE). Aquesta Directiva estableix el marc europeu per a la protecció de les aigües superficials continentals, de transició, costaneres i subterrànies per a previndre o reduir la seua contaminació, promoure el seu ús sostenible, protegir el medi ambient, millorar l'estat dels ecosistemes aquàtics i atenuar els efectes de les inundacions i sequeres. L'objectiu de la DMA és que totes les masses d'aigua arriben a un “estat ecológic bo” l’any 2015.

Les salines de la Comunitat Valenciana, en l'àmbit de la DMA, pertanyen al grup d'aigües de transició i han estat designades com a masses d'aigua molt modificades (MAMM). En el cas de les MAMM, la DMA estableix l'obligatorietat de determinar el "potencial ecològic" i no "l'estat ecològic". Açò suposa l'assumpció de determinades condicions d'excepcionalitat dins les quals es troba la reducció de les exigències ambientals i el manteniment al mateix nivell dels objectius de protecció i millora de la qualitat.

Prèviament a l'establiment del potencial ecològic, és necessari realitzar un procés d'intercalibració entre els Estats Membres de les diferents metodologies proposades per a la seua determinació. Actualment, el procés d’intercalibració en aigües de transició es troba poc avançat degut a que són masses d'aigua complexes i condicionades per un ampli nombre de factors. A aquesta complexitat cal afegir, en el cas de les MAMM, que aquestes no poden veure alterades les funcions per a les quals serveixen. Atès que el procés d'intercalibració no es troba actualmente definit, no s'està en condicions d'establir el potencial ecològic de les salines. Tanmateix, en la present tesi doctoral es proposa una metodologia per a arribar a determinar el potencial ecològic dels sistemes saliners de la Comunitat Valenciana.

La metodologia propasada es basa en criteris físic-químics i no biològics, ja que donades les condicions tan extremes per a la vida en les salines, no hi ha un element biològic que puga ser aplicat com índex de qualitat en totes elles. Per això es proposa un model teòric basat en el comportament del $\mathrm{P}_{50}$ del PT davant el $\mathrm{P}_{50}$ de salinitat, aplicat en la salina de Santa Pola, que és per les seues característiques i pel seu ampli rang salí, la salina considerada com a més representativa. També es proposen una sèrie de mesures de mitigació per a la millora de la qualitat de les aigües en aquelles salines on es fa necessari, sense alterar els usos als quals aquestes són destinades. 


\section{ÍNDICE GENERAL}

CAPÍTULO 1. INTRODUCCIÓN 1

1.1. Principales características de las salinas 1

1.1.1. Las salinas 1

1.1.2. Funcionamiento de las explotaciones salineras 1

1.1.3. Salinidad y rangos de salinidad en las explotaciones salineras 3

1.1.4. Los nutrientes en los sistemas acuáticos 3

1.1.4.1. Nitrógeno 3

1.1.4.2. Fósforo

1.1.4.3. Silicio

1.1.4.4. Nutrientes y fitoplancton 6

1.1.4.5. La limitación por nutrientes $\quad 7$

1.1.5. Los nutrientes en las explotaciones salineras. Estudios previos 8

1.1.6. El sistema carbónico - carbonato en los ambientes hipersalinos 13

1.1.7. Biota 15

1.1.7.1. Características generales de la biota en los ambientes 15 hipersalinos

1.1.7.2. Principales organismos 16

1.1.7.3. La coloración de las salinas $\quad 19$

$\begin{array}{ll}\text { 1.1.8. El ecosistema en las salinas } & 19\end{array}$

1.2. Las salinas en el ámbito de la Directiva Marco del Agua 21

1.2.1. La Directiva Marco del Agua 21

1.2.2. Caracterización y tipologías de las masas de agua superficiales 22

1.2.3. Indicadores ecológicos y condiciones de referencia 23

1.2.4. Periodicidad de los controles de vigilancia 24

1.2.5. Las aguas de transición en la Comunidad Valenciana 25

1.2.6. Las masas de agua muy modificadas (MAMM) según la DMA 26

1.2.7. Las salinas según la Directiva Marco del Agua 26

1.2.8. El potencial ecológico 27

1.2.9. El ejercicio de intercalibración. Establecimiento del potencial 28 
ecológico en MAMM. Situación actual del proceso

1.2.9.1. El ejercicio de intercalibración 28

1.2.9.2. Establecimiento del potencial ecológico en MAMM 29

1.2.9.3. Situación actual de proceso 30

1.3. Objetivos

CAPÍTULO 2. ÁREA DE ESTUDIO 33

2.1. El litoral mediterráneo 33

2.1.1. Los humedales costeros 34

2.1.2. Las lagunas costeras 36

2.2. Marco legal y administrativo 36

2.2.1. Marco legal 36

2.2.2. Marco administrativo 38

2.3. Principales características del medio físico 39

2.3.1. Climatología 39

2.3.2. Geología 39

2.3.3. Edafología 39

2.4. Las salinas de la Comunidad Valenciana 41

2.4.1. Salina de Calpe $\quad 42$

2.4.2. Salina de La Mata-Torrevieja 43

2.4.3. Salina de Santa Pola 44

2.4.3.1. Características del circuito salinero de Bonmatí 45

2.4.3.2. Circulación de las aguas en el circuito de Bonmatí 47

CAPÍTULO 3. MATERIAL Y MÉTODOS 49

3.1. Muestreos $\quad 49$

3.1.1. Campañas de muestreo 49

3.1.2. Descripción de los muestreos $\quad 50$

3.1.3. Toma de muestras de agua 57

3.2. Tratamiento y análisis de las muestras $\quad 57$

$\begin{array}{ll}\text { 3.2.1. Cadena de custodia de las muestras } & 57\end{array}$ 
3.2.2. Métodos analíticos 58

3.2.2.1. Análisis de conductividad, salinidad, $\mathrm{pH}$ y clorofila $a \quad 58$

3.2.2.2. Análisis de nutrientes $\quad 59$

3.3. Tratamiento estadístico 61

3.3.1. Análisis de componentes principales $\quad 61$

3.3.2. Análisis de conglomerados o clusters 62

CAPÍTULO 4. RESULTADOS Y DISCUSIÓN 63

4.1. Salina de Calpe 63

4.1.1. Análisis de los parámetros físico-químicos 63

4.1.1.1. Salinidad 63

$\begin{array}{ll}\text { 4.1.1.2. } \mathrm{pH} & 67\end{array}$

4.1.1.3. Amonio 68

$\begin{array}{ll}\text { 4.1.1.4. Nitrito } & 70\end{array}$

4.1.1.5. Nitrato 72

4.1.1.6. Nitrógeno Inorgánico Disuelto 73

4.1.1.7. Fósforo Soluble Reactivo $\quad 74$

4.1.1.8. Relación NID/PSR

4.1.1.9. Fósforo Total 76

4.1.1.10. Ácido ortosilícico $\quad 77$

4.1.2. Análisis multivariable de la salina de Calpe 79

4.2. Salina de La Mata $\quad 82$

4.2.1. Análisis de los parámetros físico-químicos 82

4.2.1.1. Salinidad 82

4.2.1.2. $\mathrm{pH}$

4.2.1.3. Amonio 88

4.2.1.4. Nitrito 90

$\begin{array}{ll}\text { 4.2.1.5. Nitrato } & 91\end{array}$

4.2.1.6. Nitrógeno Inorgánico Disuelto 93

4.2.1.7. Fósforo Soluble Reactivo 94

4.2.1.8. Relación NID/PSR 96 
4.2.1.9. Fósforo Total

4.2.1.10. Ácido ortosilícico 98

4.2.2. Análisis multivariable de la laguna de La Mata 100

\subsection{Salina de Torrevieja 103}

4.3.1. Análisis de los parámetros físico-químicos 103

$\begin{array}{ll}\text { 4.3.1.1. Salinidad } & 103\end{array}$

$\begin{array}{ll}\text { 4.3.1.2. } \mathrm{pH} & 104\end{array}$

4.3.1.3. Amonio 105

$\begin{array}{ll}\text { 4.3.1.4. Nitrito } & 107\end{array}$

$\begin{array}{ll}\text { 4.3.1.5. Nitrato } & 108\end{array}$

4.3.1.6. Nitrógeno Inorgánico Disuelto 109

4.3.1.7. Fósforo Soluble Reactivo 110

4.3.1.8. Relación NID/PSR 112

4.3.1.9. Fósforo Total 113

4.3.1.10. Ácido ortosilícico 114

4.3.2. Análisis multivariable de la laguna de Torrevieja 116

\subsection{Circuito salinero de Santa Pola 119}

4.4.1. Análisis de los parámetros físico-químicos 119

4.4.1.1. Salinidad 119

4.4.1.2. $\mathrm{pH}$

4.4.1.3. Amonio 125

$\begin{array}{ll}\text { 4.4.1.4. Nitrito } & 127\end{array}$

$\begin{array}{ll}\text { 4.4.1.5. Nitrato } & 129\end{array}$

4.4.1.6. Nitrógeno Inorgánico Disuelto 130

4.4.1.7. Fósforo Soluble Reactivo 132

4.4.1.8. Relación NID/PSR 134

4.4.1.9. Fósforo Total 135

4.4.1.10. Ácido ortosilícico 137

4.4.2. Análisis multivariable de la salina de Santa Pola 139

4.4.3. Problemática del NID y de sus variaciones de concentración a lo 144 largo del circuito salinero 
4.4.3.1. Estudio de las solubilidades

4.4.3.2. Factores de concentración de los nitratos en los cristalizadores

4.5. Diferencias y semejanzas entre las tres salinas

4.5.1. Análisis de los parámetros físico-químicos en todas las salinas

4.5.1.1. Salinidad

4.5.1.2. $\mathrm{pH}$

4.5.1.3. Amonio

4.5.1.4. Nitrito

4.5.1.5. Nitrato

4.5.1.6. Nitrógeno Inorgánico Disuelto

4.5.1.7. Fósforo Soluble Reactivo

4.5.1.8. Relación NID/PSR

4.5.1.9. Fósforo Total

4.5.1.10. Ácido ortosilícico

4.5.2. Análisis multivariable de los parámetros físico-químicos

4.6. Establecimiento de los criterios para determinar el potencial ecológico 161 en las salinas de la Comunidad Valenciana

4.6.1. Indicadores de calidad en las salinas

4.6.2. Masas de agua de referencia

4.6.3. El proceso de establecimiento del potencial ecológico

4.6.4. Medidas de mitigación propuestas

\section{CAPÍTULO 5. CONCLUSIONES}

5.1. Conclusiones generales del conjunto de las salinas

5.2. Conclusiones respecto a los criterios para determinar el potencial ecológico de las salinas 



\section{ÍNDICE DE TABLAS}

Tabla 1.1: Concentraciones de nutrientes inorgánicos documentadas en 11 explotaciones salineras de todo el mundo. Traducción de la tabla 3 de Oren (2009)

Tabla 1.2: Tipos de masas de agua de transición según la Orden ARM/2656/2008 22

Tabla 1.3: Definición de las diferentes clases de potencial ecológico 28

Tabla 3.1: Fechas de los muestreos efectuados en las salinas 49

Tabla 3.2: Coordenadas de las estaciones de muestreo de la salina de Calpe 50

Tabla 3.3: Coordenadas de las estaciones de muestreo de la salina de La Mata- 52 Torrevieja

Tabla 3.4: Coordenadas de las estaciones de muestreo del circuito de Bonmatí en 54 Santa Pola durante el año 2008

Tabla 3.5: Coordenadas de las estaciones de muestreo del circuito de Bonmatí en 54 Santa Pola durante el año 2009

Tabla 4.1: Tabla de pesos de los componentes del ACP para los parámetros físicoquímicos de Calpe

Tabla 4.2: Valores de $\mathrm{P}_{50}$ de salinidad $(\mathrm{g} / \mathrm{kg})$ en las diferentes estaciones de La Mata para las campañas de 2008-2009

Tabla 4.3: Tabla de pesos de los componentes del ACP para los parámetros físicoquímicos de La Mata

Tabla 4.4: Tabla de pesos de los componentes del ACP para los parámetros físicoquímicos de Torrevieja

Tabla 4.5: Coeficientes de variación de la salinidad (\%) en las diferentes estaciones de Santa Pola para las campañas de 2008

Tabla 4.6: Tabla de pesos de los componentes del ACP para los parámetros físicoquímicos de Santa Pola

Tabla 4.7: Valores de $\mathrm{P}_{50}$ de salinidad (g/kg) en las diferentes estaciones de Santa Pola en las campañas de 2008

Tabla 4.8: a) $\mathrm{P}_{50}$ de los nitratos en los concentradores y b) $\mathrm{P}_{50}$ de los nitratos en los cristalizadores de Santa Pola junto con estimaciones teóricas del rango inferior y superior de nitratos calculados a partir del aumento en la concentración salina

Tabla 4.9: Tabla de pesos de los componentes del ACP para los parámetros físicoquímicos

79

85

100

116

123

139

141

145

Tabla 4.10: $\mathrm{P}_{50}$ de la salinidad y de los parámetros físico-químicos para las diferentes tipologías de Santa Pola así como para las playas más próximas a las entradas de agua durante el año 2008 
Tabla 4.11: Contenido en PT para cada EQR establecido con el índice Phymed

Tabla 4.12: Concentraciones de PT del circuito salinero según diferentes niveles de 168 eutrofia en las aguas de entrada

Tabla 4.13: Rectas que establecen las clases de potencial ecológico para los 169 diferentes niveles de salinidad

Tabla 4.14: Composición físico-química de la muestra para el lavado de sal gema 170 en El Pinoso 


\section{ÍNDICE DE FIGURAS}

Figura 1.1: Compuestos de nitrógeno y reacciones que tienen lugar entre ellos

Figura 1.2: Composición de las salmueras de Exportadora de Sal (ESSA) durante 13 el transcurso del proceso de evaporación (Javor, 1983)

Figura 1.3: Porcentajes de dióxido de carbono, ión bicarbonato e ión carbonato en 14 función del $\mathrm{pH}$ a $0^{\circ} \mathrm{C}$ (Riley y Chester, 1971)

Figura 1.4: Imagen de Dunaliella salina

Figura 1.5: Esquema para establecer los EQR en masas de agua costeras y de 24 transición

Figura 1.6: Estructura organizativa de la Estrategia Común de Implementación de 29 la DMA (WFD CIS, 2004)

Figura 2.1: Perfil idealizado de una costa arenosa (WWF/Adena, 2002)

Figura 2.2: Imágenes tomadas en la laguna costera de La Mata

Figura 2.3: Mapa de localización de las salinas de la Comunidad Valenciana

Figura 2.4: a) Imagen de la salina de Torrevieja donde se aprecia la coloración rosada de sus aguas y b) Salida de la tubería con salmueras procedentes de El Pinoso

Figura 2.5: a) Estanques cristalizadores del circuito salinero de Bonmatí en Santa Pola y b) Pilas de sal

Figura 2.6: Flujo de circulación del agua en el circuito salinero de Bonmatí

Figura 3.1: Ubicación de las estaciones de muestreo en la salina de Calpe

Figura 3.2: Ubicación de las estaciones de muestreo en la salina de La Mata - 53 Torrevieja

Figura 3.3: Ubicación de las estaciones de muestreo del circuito de Bonmatí dentro del Parque Natural de las Salinas de Santa Pola

Figura 3.4: Detalle de las estaciones de muestreo estudiadas en el circuito salinero 56 de Bonmatí

Figura 3.5: Cadena de custodia de las muestras y conservación de las distintas 58 alícuotas

Figura 3.6: Salinómetro Portasal modelo 8410A

Figura 3.7: a) Autoanalizador de flujo contínuo segmentado por aire y b) 60 Autoclave

Figura 4.1: Ubicación de las estaciones de muestreo en la salina de Calpe

Figura 4.2: Precipitaciones diarias $(\mathrm{mm})$ en la estación Benissa Convento durante 65 el período 2008-2009 
Figura 4.3: Salinidades registradas en la salina de Calpe durante las campañas de 65 2008-2009

Figura 4.4: Valores de $\mathrm{pH}$ registrados en la salina de Calpe durante las campañas de 2008-2009

Figura 4.5: a) Comportamiento del $\mathrm{pH}$ respecto a la salinidad y b) Comportamiento del $\mathrm{pH}$ respecto a la temperatura en la salina de Calpe durante 2008-2009

Figura 4.6: Concentraciones de amonio registradas en la salina de Calpe durante las campañas de 2008-2009

Figura 4.7: a) Comportamiento del amonio respecto a la salinidad; b) 70 Comportamiento del amonio respecto al $\mathrm{pH}$ y c) Comportamiento del amonio respecto a la temperatura en la salina de Calpe durante 2008-2009

Figura 4.8: Concentraciones de nitrito registradas en la salina de Calpe durante las campañas de 2008-2009

Figura 4.9: a) Comportamiento del nitrito respecto a la salinidad; b) 71 Comportamiento del nitrito respecto al $\mathrm{pH}$ y c) Comportamiento del nitrito respecto a la temperatura en la salina de Calpe durante 2008-2009

Figura 4.10: Concentraciones de nitrato registradas en la salina de Calpe durante las campañas de 2008-2009

Figura 4.11: a) Comportamiento del nitrato respecto a la salinidad; b) 73 Comportamiento del nitrato respecto al $\mathrm{pH}$ y c) Comportamiento del nitrato respecto a la temperatura en la salina de Calpe durante 2008-2009

Figura 4.12: Concentraciones de NID registradas en la salina de Calpe durante las campañas de 2008-2009

Figura 4.13: a) Comportamiento del NID respecto a la salinidad; b) 74 Comportamiento del NID respecto al $\mathrm{pH}$ y c) Comportamiento del NID respecto a la temperatura en la salina de Calpe durante 2008-2009

Figura 4.14: Relación NID/PSR en la salina de Calpe durante las campañas de 2008-2009

Figura 4.15: a) Comportamiento de la relación NID/PSR respecto a la salinidad; b) Comportamiento de la relación NID/PSR respecto al pH y c) Comportamiento de la relación NID/PSR respecto a la temperatura en la salina de Calpe durante 20082009

Figura 4.16: Concentraciones de PT registradas en la salina de Calpe durante las campañas de 2008-2009

Figura 4.17: a) Comportamiento del PT respecto a la salinidad; b) Comportamiento 73 del PT respecto al $\mathrm{pH}$ y c) Comportamiento del PT respecto a la temperatura en la salina de Calpe durante 2008-2009

Figura 4.18: Concentraciones de ácido ortosilícico registradas en la salina de Calpe 78 durante las campañas de 2008-2009 
Figura 4.19: a) Comportamiento del ácido ortosilícico respecto a la salinidad; b) 78 Comportamiento del ácido ortosilícico respecto al pH y c) Comportamiento del ácido ortosilícico respecto a la temperatura en la salina de Calpe durante 2008-2009

Figura 4.20: Gráfico de pesos de los componentes del ACP para los parámetros físico-químicos de Calpe

Figura 4.21: Diagrama de dispersión de los componentes 1 y 2 del ACP para los parámetros físico-químicos de la salina de Calpe

Figura 4.22: Conglomerado jerárquico con la agrupación de las estaciones para cada una de las campañas muestreadas en la salina de Calpe

Figura 4.23: Precipitaciones diarias $(\mathrm{mm})$ en la estación Laguna de Torrevieja durante el período 2008-2009

Figura 4.24: Ubicación de las estaciones de muestreo en la salina de La Mata Torrevieja

Figura 4.25: Salinidades registradas en la laguna de La Mata durante las campañas de 2008-2009

Figura 4.26: a) Pruebas $\mathrm{pH}$ sin difusor y b) Pruebas $\mathrm{pH}$ con difusor en muestras de La Mata - Torrevieja

Figura 4.27: Valores de $\mathrm{pH}$ registrados en la laguna de La Mata durante las campañas de 2008-2009

Figura 4.28: a) Comportamiento del $\mathrm{pH}$ respecto a la salinidad y b) 88 Comportamiento del $\mathrm{pH}$ respecto a la temperatura en la laguna de La Mata durante 2008-2009

Figura 4.29: Concentraciones de amonio registradas en la laguna de La Mata durante las campañas de 2008-2009

Figura 4.30: a) Comportamiento del amonio respecto a la salinidad; b) 79 80 81 82 83 Comportamiento del amonio respecto al $\mathrm{pH}$ y c) Comportamiento del amonio respecto a la temperatura en la laguna de La Mata durante 2008-2009

Figura 4.31: Concentraciones de nitrito registradas en la laguna de La Mata durante las campañas de 2008-2009

Figura 4.32: a) Comportamiento del nitrito respecto a la salinidad; b) 91 Comportamiento del nitrito respecto al $\mathrm{pH}$ y c) Comportamiento del nitrito respecto a la temperatura en la laguna de La Mata durante 2008-2009

Figura 4.33: Concentraciones de nitrato registradas en la laguna de La Mata durante las campañas de 2008-2009

Figura 4.34: a) Comportamiento del nitrato respecto a la salinidad; b) 92 Comportamiento del nitrato respecto al $\mathrm{pH}$ y c) Comportamiento del nitrato respecto a la temperatura en la laguna de La Mata durante 2008-2009

Figura 4.35: Concentraciones de NID registradas en la laguna de La Mata durante las campañas de 2008-2009 
Figura 4.36: a) Comportamiento del NID respecto a la salinidad; b) 94 Comportamiento del NID respecto al $\mathrm{pH}$ y c) Comportamiento del NID respecto a la temperatura en la laguna de La Mata durante 2008-2009

Figura 4.37: Concentraciones de PSR registradas en la laguna de La Mata durante 95 las campañas de 2008-2009

Figura 4.38: a) Comportamiento del PSR respecto a la salinidad; b) 95 Comportamiento del PSR respecto al $\mathrm{pH}$ y c) Comportamiento del PSR respecto a la temperatura en la laguna de La Mata durante 2008-2009

Figura 4.39: Relación NID/PSR de la laguna de La Mata durante las campañas de 96 2008-2009

Figura 4.40: a) Comportamiento de la relación NID/PSR respecto a la salinidad; b) Comportamiento de la relación NID/PSR respecto al pH y c) Comportamiento de la relación NID/PSR respecto a la temperatura en la laguna de La Mata durante 20082009

Figura 4.41: Concentraciones de PT registradas en la laguna de La Mata durante las campañas de 2008-2009

Figura 4.42: a) Comportamiento del PT respecto a la salinidad; b) Comportamiento del PT respecto al pH y c) Comportamiento del PT respecto a la temperatura en la laguna de La Mata durante 2008-2009

Figura 4.43: Concentraciones de ácido ortosilícico registradas en la laguna de La Mata durante las campañas de 2008-2009

Figura 4.44: a) Comportamiento del ácido ortosilícico respecto a la salinidad; b) Comportamiento del ácido ortosilícico respecto al $\mathrm{pH}$ y c) Comportamiento del ácido ortosilícico respecto a la temperatura en la laguna de La Mata durante 20082009

Figura 4.45: Gráfico de pesos de los componentes del ACP para los parámetros físico-químicos en la laguna de La Mata

Figura 4.46: Diagrama de dispersión para los componentes 1 y 2 del ACP para los parámetros físico-químicos de la laguna de La Mata

Figura 4.47: Conglomerado jerárquico con la agrupación de las estaciones para cada una de las campañas muestreadas en la laguna de La Mata

Figura 4.48: Salinidades registradas en la laguna de Torrevieja durante las campañas de 2008-2009

Figura 4.49: Valores de $\mathrm{pH}$ registrados en la laguna de Torrevieja durante las campañas de 2008-2009

Figura 4.50: a) Comportamiento del $\mathrm{pH}$ respecto a la salinidad; b) 105 Comportamiento del $\mathrm{pH}$ respecto a la temperatura en la laguna de Torrevieja durante 2008-2009

Figura 4.51: Concentraciones de amonio registradas en la laguna de Torrevieja 106 durante las campañas de 2008-2009 
Figura 4.52: a) Comportamiento del amonio respecto a la salinidad; b) 106 Comportamiento del amonio respecto al $\mathrm{pH}$ y c) Comportamiento del amonio respecto a la temperatura en la laguna de Torrevieja durante 2008-2009

Figura 4.53: Concentraciones de nitrito registradas en la laguna de Torrevieja 107 durante las campañas de 2008-2009

Figura 4.54: a) Comportamiento del nitrito respecto a la salinidad; b) 108 Comportamiento del nitrito respecto al $\mathrm{pH}$ y c) Comportamiento del nitrito respecto a la temperatura en la laguna de Torrevieja durante 2008-2009

Figura 4.55: Concentraciones de nitrato registradas en la laguna de Torrevieja 108 durante las campañas de 2008-2009

Figura 4.56: a) Comportamiento del nitrato respecto a la salinidad; b) 109 Comportamiento del nitrato respecto al $\mathrm{pH}$ y c) Comportamiento del nitrato respecto a la temperatura en la laguna de Torrevieja durante 2008-2009

Figura 4.57: Concentraciones de NID registradas en la laguna de Torrevieja 110 durante las campañas de 2008-2009

Figura 4.58: a) Comportamiento del NID respecto a la salinidad; b) 110 Comportamiento del NID respecto al $\mathrm{pH}$ y c) Comportamiento del NID respecto a la temperatura en la laguna de Torrevieja durante 2008-2009

Figura 4.59: Concentraciones de PSR registradas en la laguna de Torrevieja durante las campañas de 2008-2009

Figura 4.60: a) Comportamiento del PSR respecto a la salinidad; b) 111 Comportamiento del PSR respecto al $\mathrm{pH}$ y c) Comportamiento del PSR respecto a la temperatura en la laguna de Torrevieja durante 2008-2009

Figura 4.61: Relación NID/PSR de la laguna de Torrevieja durante las campañas de 2008-2009

Figura 4.62: a) Comportamiento de la relación NID/PSR respecto a la salinidad; b) 113 Comportamiento de la relación NID/PSR respecto al $\mathrm{pH}$ y c) Comportamiento de la relación NID/PSR respecto a la temperatura en la laguna de Torrevieja durante 2008-2009

Figura 4.63: Concentraciones de PT registradas en la laguna de Torrevieja durante las campañas de 2008-2009

Figura 4.64: a) Comportamiento del PT respecto a la salinidad; b) Comportamiento del PT respecto al $\mathrm{pH}$ y c) Comportamiento del PT respecto a la temperatura en la laguna de Torrevieja durante 2008-2009

Figura 4.65: Concentraciones de ácido ortosilícico registradas en la laguna de Torrevieja durante las campañas de 2008-2009

Figura 4.66: a) Comportamiento del ácido ortosilícico respecto a la salinidad; b) 114 Comportamiento del ácido ortosilícico respecto al $\mathrm{pH}$ y c) Comportamiento del ácido ortosilícico respecto a la temperatura en la laguna de Torrevieja durante 2008-2009 
Figura 4.67: Gráfico de pesos para los componentes 1 y 2 del ACP para los 117 parámetros físico-químicos en la laguna de Torrevieja

Figura 4.68: Diagrama de dispersión para los componentes 1 y 2 del ACP para los 117 parámetros físico-químicos en la laguna de Torrevieja

Figura 4.69: Conglomerado jerárquico con la agrupación de las estaciones para cada una de las campañas muestreadas en la laguna de Torrevieja

Figura 4.70: Precipitaciones diarias $(\mathrm{mm})$ en la estación Elche durante el período 2008-2009

Figura 4.71: Salinidades registradas en la salina de Santa Pola durante las 120 campañas de 2008-2009

Figura 4.72: Rangos de distribución de los $\mathrm{P}_{50}$ de salinidad en los distintos estanques

Figura 4.73: Valores de $\mathrm{pH}$ registrados en la salina de Santa Pola durante las campañas de 2008-2009

Figura 4.74: a) Comportamiento del pH respecto a la salinidad; b) Comportamiento del $\mathrm{pH}$ respecto a la temperatura en la salina de Santa Pola durante las campañas de 2008-2009

Figura 4.75: Concentraciones de amonio registradas en la salina de Santa Pola durante las campañas de 2008-2009

Figura 4.76: a) Comportamiento del amonio respecto a la salinidad; b) 118 Comportamiento del amonio respecto al $\mathrm{pH}$ y c) Comportamiento del amonio respecto a la temperatura en la salina de Santa Pola durante 2008-2009

Figura 4.77: Concentraciones de nitrito registradas en la salina de Santa Pola durante las campañas de 2008-2009

Figura 4.78: a) Comportamiento del nitrito respecto a la salinidad; b) 128 Comportamiento del nitrito respecto al $\mathrm{pH}$ y c) Comportamiento del nitrito respecto a la temperatura en la salina de Santa Pola durante 2008-2009

Figura 4.79: Concentraciones de nitrato registradas en la salina de Santa Pola durante las campañas de 2008-2009

Figura 4.80: a) Comportamiento del nitrato respecto a la salinidad; b) 130 Comportamiento del nitrato respecto al $\mathrm{pH}$ y c) Comportamiento del nitrato respecto a la temperatura en la salina de Santa Pola durante 2008-2009

Figura 4.81: Concentraciones de NID registradas en la salina de Santa Pola durante las campañas de 2008-2009

Figura 4.82: a) Comportamiento del NID respecto a la salinidad; b) 131 Comportamiento del NID respecto al $\mathrm{pH}$ y c) Comportamiento del NID respecto a la temperatura en la salina de Santa Pola durante 2008-2009

Figura 4.83: Concentraciones de PSR registradas en la salina de Santa Pola durante 133 las campañas de 2008-2009 
Figura 4.84: a) Comportamiento del PSR respecto a la salinidad; b) Comportamiento del PSR respecto al $\mathrm{pH}$ y c) Comportamiento del PSR respecto a la temperatura en la salina de Santa Pola durante 2008-2009

Figura 4.85: Relación NID/PSR de la salina de Santa Pola durante las campañas de 2008-2009

Figura 4.86: a) Comportamiento de la relación NID/PSR respecto a la salinidad; b) Comportamiento de la relación NID/PSR respecto al pH y c) Comportamiento de la relación NID/PSR respecto a la temperatura en la salina de Santa Pola durante 2008-2009

Figura 4.87: Concentraciones de PT registradas en la salina de Santa Pola durante las campañas de 2008-2009

Figura 4.88: a) Comportamiento del PT respecto a la salinidad; b) Comportamiento del PT respecto al pH y c) Comportamiento del PT respecto a la temperatura en la salina de Santa Pola durante 2008-2009

Figura 4.89: Concentraciones de ácido ortosilícico registradas en la salina de Santa Pola durante las campañas de 2008-2009

Figura 4.90: a) Comportamiento del ácido ortosilícico respecto a la salinidad; b) Comportamiento del ácido ortosilícico respecto al pH y c) Comportamiento del ácido ortosilícico respecto a la temperatura en la salina de Santa Pola durante 20082009

Figura 4.91: Gráfico de pesos de los componentes del ACP para los parámetros físico-químicos en la laguna de Santa Pola

Figura 4.92: Diagrama de dispersión para los componentes 1 y 2 del ACP para los parámetros físico-químicos de la laguna de Santa Pola

Figura 4.93: Conglomerado jerárquico con la agrupación de las estaciones para cada una de las campañas muestreadas en la salina de Santa Pola durante el 2008

Figura 4.94: Conglomerado jerárquico con la agrupación de las estaciones con $\mathrm{P}_{50}$ de salinidad $<140 \mathrm{~g} / \mathrm{kg}$ en la salina de Santa Pola durante el 2008

Figura 4.95: Nuevos rangos de distribución de los $\mathrm{P}_{50}$ de salinidad en los distintos estanques

Figura 4.96: a) Comportamiento del $\mathrm{pH}$ respecto a la salinidad y b) 150 Comportamiento del $\mathrm{pH}$ respecto a la temperatura en todas las salinas durante 2008-2009

Figura 4.97: a) Comportamiento del amonio respecto a la salinidad y b) 152 Comportamiento del amonio respecto al pH en todas las salinas durante 2008-2009

Figura 4.98: Comportamiento del PT respecto a la salinidad en todas las salinas durante 2008-2009

Figura 4.99: Gráfico de pesos de los componentes 1 y 2 del ACP para los 156 parámetros físico-químicos de todas las salinas durante 2008 
Figura 4.100: Gráfico de pesos de los componentes 1 y 3 del ACP para los 158 parámetros físico-químicos de todas las salinas durante 2008

Figura 4.101: Diagrama de dispersión para los componentes 1 y 2 del ACP para los 158 parámetros físico-químicos de todas las salinas durante 2008

Figura 4.102: Diagrama de dispersión para los componentes 1 y 3 del ACP para los parámetros físico-químicos de todas las salinas durante 2008

Figura 4.103: Conglomerado jerárquico con la agrupación de las estaciones de todas las salinas (excepto STT014) a partir de los $\mathrm{P}_{50}$ de los parámetros físicoquímicos estudiados durante el 2008

Figura 4.104: Localización de las estaciones DP118 y DP119, así como de las entradas de agua de mar en el circuito salinero

Figura 4.105: Relación entre el $\mathrm{P}_{50}$ de cada parámetro físico-químico y el $\mathrm{P}_{50}$ de la salinidad en el circuito salinero de Santa Pola y en las estaciones DP118 y DP119 para el año 2008

Figura 4.106: Valores de PT estimados a partir de distintos niveles de eutrofia en 168 las aguas de entrada que corresponderían a un EQR de 1; 0,75; 0,50; 0,25 y 0 en el circuito de Santa Pola y concentraciones de PT en La Mata, Torrevieja y Calpe 


\section{CAPÍTULO 1}

\section{INTRODUCCIÓN}

\subsection{PRINCIPALES CARACTERÍSTICAS DE LAS SALINAS}

\subsubsection{Las salinas}

Las salinas son masas de agua, situadas normalmente en el litoral, cuyo objeto es la obtención de sal a través de la evaporación del agua de mar (o en otros casos de aguas salinas continentales). Tienen las siguientes características particulares:

1. Están constituidas en su mayor parte por un sistema de balsas someras.

2. La salinidad de sus aguas es mayor que la del agua marina. Esto es debido a que para llevar a cabo el proceso de explotación salinera se produce una evaporación del agua de mar que se va concentrando conforme atraviesa el circuito salinero hasta que tiene lugar la precipitación de la sal. Éste es a fin de cuentas el objetivo de la instalación.

3. En función de su ubicación geográfica y de las características climatológicas del lugar, pueden funcionar todo el año o sólo durante la época estival y su ubicación, modo de explotación y salinidad de las balsas, especialmente las que se dan al final del circuito, marcan la pauta para el desarrollo de las condiciones ambientales.

4. Estas elevadas concentraciones salinas hacen que el sistema tenga unas condiciones ambientales extremas a las que sólo unos pocos organismos especializados han podido adaptarse.

\subsubsection{Funcionamiento de las explotaciones salineras}

En una explotación salinera típica, el agua de mar es introducida por bombeo o gravedad a través de una serie de estanques de evaporación. En primer lugar, entra en los "calentadores" que son estanques relativamente poco profundos (de aproximadamente $1 \mathrm{~m}$ ) donde comienza el proceso de concentración del agua de mar. De ahí, es conducida a los estanques intermedios o "concentradores" donde la concentración salina del agua aumenta considerablemente. En los concentradores se pretende eliminar por precipitación otros compuestos presentes en las aguas cargadas en sales, como carbonato de calcio $\left(\mathrm{CaCO}_{3}\right)$ y yeso $\left(\mathrm{CaSO}_{4} \cdot 2 \mathrm{H}_{2} \mathrm{O}\right)$, de tal manera que en los estanques finales o "cristalizadores" únicamente tenga lugar la precipitación del cloruro de sodio $(\mathrm{NaCl})$. Los cristalizadores son estanques muy someros (de unos $30 \mathrm{~cm}$ de profundidad) que constituyen la parte final del circuito salinero y donde se produce la precipitación y extracción de la sal.

Normalmente este tipo de salinas se sitúa en lugares próximos a la costa, en climas cálidos con precipitaciones muy escasas y con altas tasas de insolación, lo que favorece el desarrollo de estas actividades (Folch, 1992), tal y como ocurre con las salinas objeto de estudio que son las salinas de Santa Pola, La Mata-Torrevieja y Calpe. Aunque como ya se 
ha mencionado anteriormente también existen salinas continentales ubicadas en zonas donde hay aguas con elevadas concentraciones en sales.

El proceso de precipitación y extracción de la sal en una explotación salinera convencional es el siguiente:

La salinidad del agua aumenta progresivamente conforme se avanza en los estanques del circuito debido a que éstos son poco profundos (generalmente $<1 \mathrm{~m}$ ) y presentan una elevada relación superficie-volumen, lo que aumenta la tasa de evaporación. De esta manera, se pretende permitir la precipitación de las sales minerales marinas menos solubles (principalmente $\mathrm{CaCO}_{3}$ y $\mathrm{CaSO}_{4} \cdot 2 \mathrm{H}_{2} \mathrm{O}$ (yeso)) de modo que en los estanques de cristalización solamente precipite el $\mathrm{NaCl}$. Según Lazar et al. (1983), el $\mathrm{CaCO}_{3}$ precipita cuando el agua de mar se concentra entre unas 2,5 - 4 veces. La mayoría de los cationes de $\mathrm{Ca}^{+2}$ precipitan en forma de yeso, el cual forma una dura corteza en el fondo de estos estanques. El yeso comienza a precipitar cuando el agua de mar se concentra unas 4,5 veces. Una vez que el agua de mar ha evaporado más del $90 \%$ de su contenido en agua y casi todo el $\mathrm{Ca}^{+2}$ ha precipitado, comienza a precipitar el $\mathrm{NaCl}$. Es en este punto, cuando las salmueras son bombeadas o conducidas a los cristalizadores.

En algunos sistemas, las sales de potasa que contienen diversas combinaciones de $\mathrm{Na}^{+}$, $\mathrm{Mg}^{+2}, \mathrm{~K}^{+}, \mathrm{Cl}^{-}$y $\mathrm{SO}_{4}^{-}$alcanzan la saturación en las salmueras más concentradas. Estas salmueras pueden ser descartadas o procesadas para cosechar potasa u otras sales.

El agua de salmuera situada por encima de la sal es retirada periódicamente hasta que se deposita en el fondo de las balsas una corteza de sal de entre unos $5-20 \mathrm{~cm}$. Cuando esto se produce, la sal es cosechada, lavada y apilada durante un tiempo para reducir su carga contaminante y posteriormente es comercializada. Este proceso puede producir sal cuya pureza puede superar el 99,7\% (Davis, 2000).

Todos estos fenómenos de evaporación y precipitación de sales, están íntimamente relacionados con los procesos biológicos que tienen lugar en cada estanque de las salinas solares (Herrmann et al., 1973; Krumbein, 1985), por lo que el sistema biológico puede ayudar o dañar la producción salinera (Sammy, 1983; Davis, 1993; Davis, 2000).

Según Javor (2002) existen organismos que pueden influir en el rendimiento del circuito salinero y son considerados "positivos" o "negativos" para el proceso de producción de sal. Por ejemplo, serían "organismos positivos" aquellos microorganismos productores de carotenoides en los cristalizadores, ya que pueden contribuir a la absorción solar; los crustáceos de aguas salobres que se alimentan de algas planctónicas y contribuyen a clarificar los estanques reduciendo la turbidez, etc. Mientras que algunos organismos contraproducentes para la producción de sal son por ejemplo, las densas poblaciones de algas planctónicas y bacterias o las proliferaciones o "blooms" de fitoplancton que pueden ocasionar condiciones anaeróbicas en el sistema. Especialmente nocivos son las proliferaciones de la cianobacteria Aphanothece halophytica que en los concentradores, a aproximadamente unos $100 \mathrm{~g} / \mathrm{kg}$ de salinidad, excretan un polisacárido mucilaginoso de masa viscosa que flota hacia los cristalizadores e inhibe la cristalización de la sal (Baha AlDeen y Baha Al-Deen, 1972). 


\subsubsection{Salinidad y rangos de salinidad en las explotaciones salineras}

Las aguas salinas se dividen en talasohalinas (las procedentes de la evaporación del agua de mar) o atalasohalinas (las que no tienen un origen marino sino continental). El agua de origen marino se diferencia de la de origen continental, no sólo en el contenido en sales totales disueltas, sino también en la composición iónica y en las proporciones (Alcocer y Escobar, 1993).

En cuanto a la salinidad del agua de mar, ésta depende de un amplio número de factores como ubicación, estación, temperatura y dilución por las descargas de los ríos (influencia continental) y es menor en las orillas y estuarios que en alta mar. Aunque un aspecto a destacar del agua de mar es que aunque la salinidad puede variar, la proporción relativa de los elementos disueltos es la misma en todo el mundo, independientemente de la estación (Venkatesh, 1982). Para el caso concreto del Mar Mediterráneo, éste presenta una salinidad media mayor que la de otros mares u océanos como el Atlántico $(37,9 \mathrm{~g} / \mathrm{kg}$ en el Mediterráneo y 36,15 g/kg en el Atlántico) (Rodríguez, 1982; Romero, 2004).

En una explotación salinera típica, la salinidad aumenta conforme el agua marina pasa por las diferentes balsas desde los calentadores a los cristalizadores, alcanzando en estos últimos unas concentraciones salinas muy altas y próximas, lógicamente, al punto de precipitación del $\mathrm{NaCl}$. Por tanto, el rango de salinidades que abarca es muy amplio y oscila entre el propio del agua de mar $(37,9 \mathrm{~g} / \mathrm{kg})$ hasta el encontrado en los cristalizadores $(>250 \mathrm{~g} / \mathrm{kg}$ ) siendo las variables físico-químicas de cada estanque muy estables a lo largo de los años debido al clima semiárido y a las estrictas condiciones de funcionamiento impuestas por las empresas productoras de sal (Toumi et al., 2005).

\subsubsection{Los nutrientes en los sistemas acuáticos}

Existe numerosa bibliografía relacionada con el estudio de los nutrientes y sus ciclos biogeoquímicos en los sistemas acuáticos, tanto en sistemas marinos como estuarinos, como los trabajos de Riley y Chester (1971), Nixon (1981), Webb (1981), Rodríguez (1982), Herbert (1999), Romero (2004), etc., si bien existen muy pocos estudios sobre nutrientes en sistemas acuáticos de explotaciones salineras, tal y como posteriormente se verá en el apartado 1.1.5.

Según los estudios anteriormente citados, las distintas formas o compuestos de los diferentes elementos esenciales para la vida de los organismos (nutrientes) van pasando a través de la cadena trófica, entre los organismos que están presentes en un ecosistema. Los principales nutrientes que se pueden encontrar en los sistemas acuáticos y los principales procesos asociados a dichos nutrientes son los que se describen a continuación:

\subsubsection{Nitrógeno}

El nitrógeno es un elemento que posee diferentes estados de oxidación, que van desde $+5 \mathrm{a}$ -3 , pudiéndose encontrar en una gran variedad de compuestos en la naturaleza. Además del $\mathrm{N}_{2}$ molecular disuelto, se pueden encontrar importantes cantidades de distintos compuestos de nitrógeno, tanto orgánicos como inorgánicos. Según Kennedy (1986), gran parte del nitrógeno presente en los ecosistemas se encuentra en forma orgánica dentro de los organismos vivos o en la materia orgánica del agua y los sedimentos, mientras que una proporción variable está en forma inorgánica, disponible para ser usado por los productores 
primarios. Las principales formas de nitrógeno inorgánico asimilable son nitrato $\left(\mathrm{NO}_{3}^{-}\right)$, nitrito $\left(\mathrm{NO}_{2}^{-}\right)$y amonio $\left(\mathrm{NH}_{3} / \mathrm{NH}_{4}^{+}\right)$.

La utilización del nitrógeno por los agentes biológicos puede dividirse en procesos asimiladores (asimilación de nitrato, fijación de nitrógeno y asimilación de amonio) y no asimiladores (nitrificación, desnitrificación y amonificación) (ver figura 1.1). Aunque todos estos procesos son reacciones de oxidación-reducción que se encuentran muy influenciadas por las condiciones físico-químicas existentes en el medio (Herbert, 1999).

\section{Procesos asimiladores}

- Reducción asimilatoria de nitrato (proceso 7). Se lleva a cabo a través de la reducción de las especies oxidadas de nitrógeno a amonio, que es incorporado a aminoácidos, proteínas y polinucleótidos. En este proceso intervienen dos enzimas, la nitratoreductasa que participa en la reducción de nitrato a nitrito y la nitritoreductasa que participa en la reducción de nitrito a amonio.

Hay que mencionar que bajo algunas condiciones, tales como poca luz o aumento en la concentración de amonio cuando el fitoplancton está utilizando nitrato, compuestos intermedios como el nitrito pueden ser exudados al exterior por el organismo (Webb, 1981).

- Fijación de nitrógeno (proceso 3). Algunos organismos son capaces de reducir el $\mathrm{N}_{2}$ atmosférico a $\mathrm{NH}_{3} / \mathrm{NH}_{4}^{+}$y posteriormente asimilarlo. Este proceso es inhibido por la presencia de oxígeno.

- Asimilación de amonio (proceso 1). En este proceso el $\mathrm{NH}_{3}$ o el $\mathrm{NH}_{4}{ }^{+}$es tomado y asimilado por un organismo para entrar a formar parte de su biomasa en la forma de compuestos orgánicos nitrogenados.

\section{Procesos no asimiladores}

- $\quad$ Nitrificación (proceso 6). En este proceso se produce la oxidación del amonio a nitrito y nitrato. La oxidación de amonio a nitrito es llevado a cabo principalmente por bacterias del género Nitrosomonas, mientras que la oxidación de nitrito a nitrato lo realizan fundamentalmente las bacterias del género Nitrobacter (aunque no son las únicas bacterias que realizan estos procesos).

Tanto la temperatura como la presencia de amonio y oxígeno disuelto en el medio tienen un efecto positivo sobre el proceso, pero además otros factores físicoquímicos y biológicos son importantes. Éstos son el pH, $\mathrm{CO}_{2}$ disuelto, salinidad, presencia de compuestos inhibidores, luz, actividad de la macrofauna y presencia de raíces de macrófitos (Herbert, 1999).

- Desnitrificación (proceso 5), reducción no-asimilatoria de nitrato (proceso 8) y amonificación de nitrato (proceso 4). Todos ellos son procesos anaeróbicos de reducción mediante los cuales las bacterias utilizan el nitrato como un aceptor terminal de electrones en la respiración y lo reducen a sus productos gaseosos (desnitrificación) o a amonio (amonificación del nitrato) (Webb, 1981; Herbert, 1999).

- Amonificación. Se trata de una reacción de mineralización por la que las macromoléculas de nitrógeno de la materia viva (ácidos nucléicos, proteínas, 
aminoácidos, etc.) quedan disponibles para los organismos descomponedores cuando se produce la muerte celular. Las bacterias heterótrofas son las principales responsables de este proceso. Utilizan compuestos orgánicos de plantas muertas o materia animal como fuente de carbono y liberan $\mathrm{NH}_{3}$ y $\mathrm{NH}_{4}{ }^{+}$.

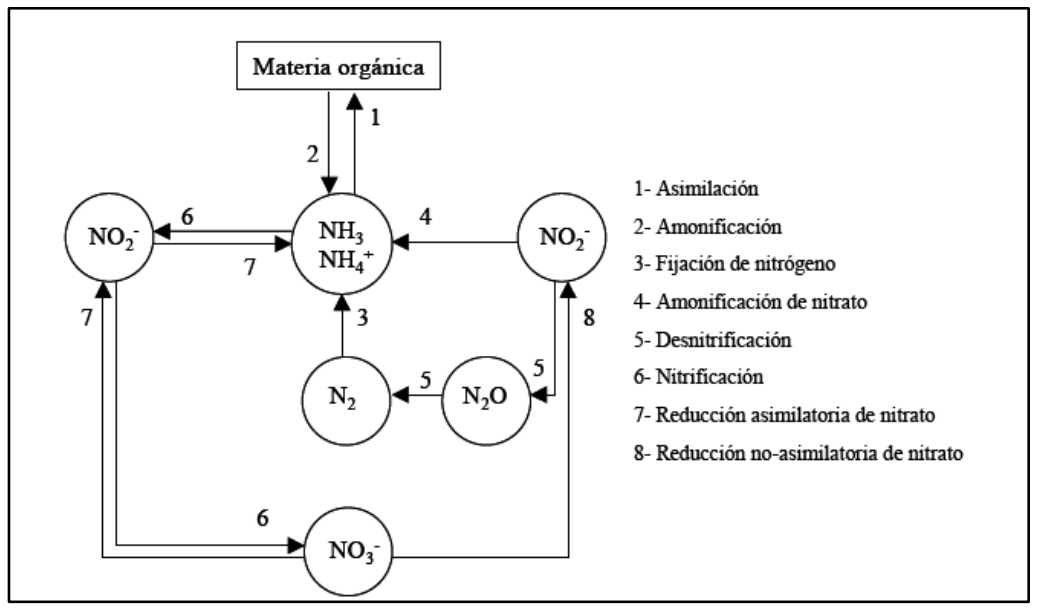

Figura 1.1: Compuestos de nitrógeno y reacciones que tienen lugar entre ellos

\subsubsection{Fósforo}

Los distintos compuestos de fósforo que se pueden encontrar en un ecosistema acuático se agrupan en formas inorgánicas y orgánicas, disueltas o particuladas.

El fósforo es un nutriente esencial para los seres vivos, cuyo ciclo se diferencia del ciclo del nitrógeno en que no hay cantidades importantes de compuestos de fósforo gaseoso en la atmósfera y en que no se dan cambios del estado de oxidación del fósforo a lo largo de su ciclo biogeoquímico. El fósforo en el medio acuático aparece casi exclusivamente en forma pentavalente, en estado de oxidación +5 , encontrándose como fosfato $\left(\mathrm{PO}_{4}^{-3}\right)$. Prácticamente todas las formas disueltas y particuladas de fósforo son formas combinadas, complejadas o modificadas ligeramente de este ión (ortofosfato, pirofosfato, largas cadenas de polifosfatos, etc). Por lo que en general, el ciclo biogeoquímico del fósforo es similar al del fosfato (Correll, 1998).

La principal reserva de fósforo es de tipo sedimentario. Además, parte del fósforo que interviene en el ciclo queda inmovilizado en los sedimentos al precipitar en forma de fosfato cálcico cuando el $\mathrm{pH}$ es elevado, o férrico cuando se oxida el ión ferroso. Si estos sedimentos vuelven a estar en condiciones de ambiente reductor, puede producirse la redisolución del fósforo. Aunque una fracción importante de los fosfatos precipitados queda inmovilizada de forma irreversible y casi permanente en los sedimentos.

\subsubsection{Silicio}

En los ecosistemas acuáticos el silicio puede encontrarse tanto en forma disuelta como particulada. La sílice disuelta en el agua se encuentra como ácido ortosilícico monomérico $\mathrm{Si}(\mathrm{OH})_{4}$ que es mayor en las aguas continentales que en las marinas. La sílice biogénica es sílice particulada de origen biológico que forma parte de las frústulas de las diatomeas u 
otros organismos, tanto vivos como muertos. Finalmente la sílice particulada mineral se encuentra en la columna de agua formando parte del material en suspensión.

El ciclo del silicio es considerablemente distinto al del nitrógeno o al del fósforo desde un punto de vista biológico ya que según Webb (1981) la utilización del silicio es biológica y la mineralización es un proceso de solución química. Destacan dos procesos:

- La utilización del silicio por las diatomeas. Las diatomeas poseen un exoesqueleto compuesto de formas no cristalinas de sílice hidratado (Riley y Chester, 1971) y pueden absorber y almacenar el silicio.

- Regeneración. Cuando las diatomeas mueren sus esqueletos se disuelven rápidamente (Riley y Chester, 1971), siendo el pH un factor fundamental en dicha redisolución.

Debido a estos procesos, la sílice (mineral y biogénica) puede precipitar y caer en los sedimentos o disolverse proporcionando $\mathrm{Si}(\mathrm{OH})_{4}$. Una vez en los sedimentos puede llegar a resuspenderse. $\mathrm{El} \mathrm{Si}(\mathrm{OH})_{4}$ disuelto en el agua puede ser absorbido por las diatomeas y otros organismos que con sus excreciones o su muerte proporcionarán de nuevo sílice biogénica suspendida, además sus frústulas pueden disolverse proporcionando $\mathrm{Si}(\mathrm{OH})_{4}$.

\subsubsection{Nutrientes y fitoplancton}

El fitoplancton constituye la base de las cadenas tróficas pelágicas y por tanto, cualquier cambio cuantitativo o cualitativo en éste, puede afectar a la dinámica de los niveles tróficos superiores debido a la variabilidad en su biomasa y producción. La luz, la temperatura, la disponibilidad de nutrientes y el consumo herbívoro son los cuatro factores más importantes que regulan la producción y biomasa del fitoplancton (Shiah et al., 1996). De estos cuatro factores, el elemento que normalmente condiciona la producción primaria del fitoplancton es la disponibilidad de "sales nutritivas" (compuestos de nitrógeno, fósforo, silicio). Hay que mencionar que no solo es necesaria la existencia de dichas "sales nutritivas" sino también que éstas se encuentren disponibles para el fitoplancton.

- $\quad$ Nitrógeno y fitoplancton: Según Smayda (1983) las formas preferenciales por el fitoplancton son por este orden: amonio, urea, nitrato, nitrito y otros compuestos orgánicos diferentes a la urea. El amonio y la urea son preferenciales porque no necesitan reducirse previamente, mientras que las formas oxidadas (nitrato y nitrito) deber ser reducidas previamente mediante la acción de las enzimas nitratoreductasa (reduce el nitrato a nitrito) y nitritoreductasa (reduce el nitrito a amonio). Además hay que tener en cuenta que el amonio puede llegar a absorberse "en tromba" (de una manera rápida y en gran cantidad) aunque no el nitrato.

- Fósforo y fitoplancton: En el agua de mar, una gran variedad de compuestos orgánicos e inorgánicos de fósforo pueden ser asimilados por los organismos vivos y aunque hay muchas especies de fitoplancton capaces de utilizar compuestos orgánicos disueltos (Riley y Chester, 1971), la forma preferida por el fitoplancton es el ortofosfato (Migon y Sandroni, 1999).

El fitoplancton normalmente satisface sus necesidades de fósforo por asimilación directa de ortofosfato. Hay que mencionar que se pueden encontrar dos tipos de absorción. Una está regulada por los procesos internos y se da en células sin deficiencia de fósforo. La otra se produce "en tromba" en células con deficiencias 
de fósforo, cuando los acúmulos internos están vacíos y no se encuentra regulada por procesos internos. Este segundo tipo de absorción se realiza en una tasa muy elevada, superando las necesidades de la célula, por lo que se considera como un mecanismo adaptativo en células deficitarias en fósforo para aprovechar al máximo un incremento en la concentración exterior.

- Silicio y fitoplancton: Como ya se ha mencionado anteriormente, el $\mathrm{Si}(\mathrm{OH})_{4}$ disuelto en el agua puede ser absorbido por las diatomeas y otros organismos que con sus excreciones o su muerte proporcionarán de nuevo sílice biogénica suspendida, además sus frústulas pueden disolverse proporcionando $\mathrm{Si}(\mathrm{OH})_{4}$.

El crecimiento del fitoplancton en primavera causa una rápida disminución de la concentración de sílice mientras que la regeneración de la sílice producida por la muerte y posterior disolución de las frústulas de las diatomeas comienza en verano, cuando el crecimiento del fitoplancton disminuye y continúa hasta un valor máximo a principios del invierno.

\subsubsection{La limitación por nutrientes}

Los procesos metabólicos que son la base de la dinámica del ecosistema acuático, en términos de transformaciones de masas, están gobernados por principios estequiométricos relativamente simples (Vollenweider et al., 1996). La composición elemental del fitoplancton, zooplancton, las bacterias, etc., engloba una gran variedad de elementos. Por término medio el $\mathrm{C}, \mathrm{N}, \mathrm{P}$ y $\mathrm{S}$ en estos organismos se encuentra aproximadamente en una proporción 106:16:1:1, llamada relación de Redfield. Generalmente se supone que las células fitoplanctónicas absorben los nutrientes en proporciones atómicas aproximadamente constantes y similares a las que se encuentran en los organismos vivos (C:N:P:Si = 106:16:1:16).

Según Vollenweider et al. (1996), los elementos o compuestos que podrían llegar a limitar el crecimiento del fitoplancton serían carbono, azufre, nitrógeno, fósforo, silicio e incluso ciertos elementos como el hierro, manganeso, cobalto y molibdeno. Pero en el agua tanto dulce como marina, el $\mathrm{C}$ y el $\mathrm{S}$ se encuentran normalmente en exceso relativo respecto al $\mathrm{N}$ $\mathrm{y}$ al $\mathrm{P}$, por lo que es difícil que tanto el $\mathrm{C}$ como el $\mathrm{S}$ sean los nutrientes limitantes.

Los criterios para la limitación estequiométrica de nutrientes se basan normalmente en la relación atómica Si:N:P del fitoplancton que es aproximadamente 16:16:1 (relación de Redfield). Las desviaciones de esta relación indican limitación de N, P ó Si para el fitoplancton. Cuando las aguas receptoras tienen una limitación de $\mathrm{P}$, la biomasa fitoplanctónica tiene una relación N/P bastante superior que la de Redfield (15-16) pero cuando el $\mathrm{N}$ es el limitante, la relación es más baja (Correll, 1998).

El nutriente limitante para el crecimiento del fitoplancton varía según la zona de estudio y las condiciones ambientales que en ella se den. Por ejemplo, en el caso particular del Mar Mediterráneo, que es un mar oligotrófico con una carga de $\mathrm{N}$ y $\mathrm{P}$ baja en comparación con otros mares u oceános, la relación molar N/P está entre 21-23 frente a los 15 que suele encontrarse en la mayoría de los océanos (Bethoux et al., 1992).

Según Justic et al. (1995) existirá limitación de fósforo cuando NID:P $>22$ y Si:P $>22$, existirá limitación de nitrógeno cuando NID:P $<10$ y Si:NID $>1$ y existirá limitación de $\mathrm{Si}$ cuando Si:P $<10$ y Si:NID $<1$. 


\subsubsection{Los nutrientes en las explotaciones salineras. Estudios previos}

Existen grandes diferencias en la concentración de nutrientes de las distintas salinas, por lo que algunos autores las clasifican en función de su contenido en nutrientes en oligotróficas, mesotróficas o eutróficas tal y como se clasificaría cualquier otro ambiente acuático (Javor, 1989). Por ejemplo, Pedrós-Alió et al. (2000) en el estudio de las salinas de La Trinitat en el Delta del Ebro y de las salinas de Bras del Port en Santa Pola clasificación ambas salinas como eutróficas.

Independientemente de su carga en nutrientes, cada parámetro estudiado puede presentar una pauta diferente. Por ello, algunos parámetros presentan un comportamiento similar con el aumento de la salinidad, como el oxígeno, que tiende a disminuir con la saturación de sales; mientras que otros presentan un comportamiento variable, como los fosfatos, cuya mayor o menor presencia conforme aumenta la salinidad varía según el sistema salinero objeto de estudio.

A continuación se va a analizar el contenido y la pauta de comportamiento de algunos de los principales parámetros físico-químicos presentes en las explotaciones salineras según algunos estudios previos. Dichos estudios no son muy numerosos ya que tal y como mencionan Stiller y Nissembaum (1999), al contrario de lo que sucede con la gran cantidad de información sobre los ciclos de los nutrientes en los ambientes de agua dulce, los estudios biogeoquímicos en los ambientes hipersalinos en los que la salinidad es superior a $\operatorname{los} 120 \mathrm{~g} / 1$ es muy poco conocida.

Hay que mencionar que la cantidad de estudios en los que se analiza la composición físicoquímica de las aguas en las explotaciones salineras no solamente es muy reducida sino que además (en la mayor parte de los casos) han sido realizados de forma complementaria al estudio de las comunidades biológicas de las explotaciones salineras y de sus adaptaciones a medios tan extremos y no como un fin en sí mismos, de ahí que sean tan escasos.

\section{- pH - Oxígeno - Temperatura}

El $p H$ y el contenido en oxígeno de las salmueras de las salinas solares dependen de la salinidad y de la productividad biológica. El pH en estas aguas se encuentra normalmente entre 7,5 - 8,5 aunque en salmueras altamente concentradas se pueden alcanzar valores de $\mathrm{pH}$ incluso menores (Javor, 1989).

La concentración de oxígeno puede experimentar fluctuaciones a lo largo del día pero tiende a disminuir cuanto mayor es la cantidad de sales ya que entonces es menor la capacidad de solubilidad del oxígeno en el agua, siendo muy común la sobresaturación de oxígeno en muchos de los estanques (Pedrós-Alió et al., 2000). Kinsman et al. (1974) determinaron los valores de saturación del oxígeno para aguas de mar muy concentradas y aunque las salinas cargadas de $\mathrm{NaCl}$ se encuentran saturadas con unos $2 \mathrm{mg} \mathrm{O} / \mathrm{L}$, se ha detectado muy poco o incluso nada de oxígeno en los cristalizadores (Sammy, 1983; Javor, 1989). Esta situación ocurre probablemente porque la respiración sobrepasa la tasa de productividad primaria en salinas extremadamente cargadas de sales.

La temperatura del agua por lo general aumenta conforme aumenta la salinidad debido a la mayor capacidad calorífica de las aguas salinas (Pedrós-Alió et al., 2000). 


\section{- Amonio}

Las concentraciones de amonio pueden variar ampliamente según la salina estudiada, en los distintos estanques de las explotaciones salineras, a diferentes salinidades y a lo largo del ciclo anual (Javor, 2002) por lo que no existe una pauta de comportamiento del amonio extrapolable a todas las salinas.

Joint et al. (2002) en sus estudios realizados en el circuito salinero de Bras del Port en Santa Pola encontraron valores de amonio inferiores a los de nitrato, que mostraron pocas variaciones a lo largo del gradiente salino y que oscilaron entre $1,5-2,4 \mu \mathrm{M}$ en las salinidades bajas e intermedias y entre $1-3,9 \mu \mathrm{M}$ en las salinidades más altas.

Estos resultados contrastan con los obtenidos por Pedrós-Alió et al. (2000) en las mismas salinas, donde el amonio fue el nutriente inorgánico más abundante, alcanzando valores entre $40-230 \mu \mathrm{M}$ en calentadores y concentradores y entre $150-230 \mu \mathrm{M}$ en los cristalizadores. Mientras que en el mismo estudio de Pedrós-Alió en La Trinitat (Delta del Ebro) se dieron valores entre $3-13 \mu \mathrm{M}$ en calentadores y concentradores y entre $3-4 \mu \mathrm{M}$ en los cristalizadores.

Por otra parte, Javor (1983 a y b) encontró concentraciones muy bajas de amonio en los calentadores y concentradores de ESSA (Exportadora de Sal, S.A. en Baja California Sur, México) con valores $<5 \mu \mathrm{M}$ y también bajos en los cristalizadores (entre $5-10 \mu \mathrm{M}$ ). Aunque observó una considerable acumulación de amonio en los estanques más salinos con valores de hasta $50 \mu \mathrm{M}$. Por el contrario, en las salinas de Western Salt (USA) el amonio alcanzó valores entre $2-20 \mu \mathrm{M}$.

Como se puede observar a partir de estos estudios, el amonio es un compuesto que experimenta una gran variabilidad de concentraciones entre las diferentes salinas, e incluso en las mismas salinas a lo largo del tiempo, observándose en algunas salinas acumulaciones de este parámetro en los cristalizadores. A pesar de ello, Javor (2002) estableció unos rangos de concentraciones típicos de amonio para las salinas solares eutróficas con valores entre $1-50 \mu \mathrm{M}$ en los estanques de precipitación del yeso y entre $5-50 \mu \mathrm{M}$ en los cristalizadores; y de entre $0-7 \mu \mathrm{M}$ en los estanques de precipitación del yeso y entre $0-7$ $\mu \mathrm{M}$ en los cristalizadores de las salinas oligotróficas.

\section{- Nitritos}

El contenido en nitritos en muchas de las salinas estudiadas es prácticamente nulo a lo largo de los circuitos salineros, tal y como sucede en los estudios en ESSA de Javor (1983b), así como en los de La Trinitat de Pedrós-Alió et al. (2000), si bien en el mismo estudio en Bras del Port fue de $8 \mu \mathrm{M}$ en todo el circuito salinero.

\section{- Nitratos}

La concentración de nitratos en el estudio de Joint et al. (2002) en Bras del Port es de 3 - 4 $\mu \mathrm{M}$ en las salinidades bajas e intermedias y de $6,2 \mu \mathrm{M}$ en las salinidades más elevadas. En cambio, en el estudio de Pedrós-Alió et al. (2000) en Bras del Port los nitratos alcanzaron valores entre $0-4 \mu \mathrm{M}$ en los calentadores y concentradores, y entre $4-18 \mu \mathrm{M}$ en los cristalizadores; mientras que en La Trinitat se encontraron valores entre $0-3 \mu \mathrm{M}$ en calentadores y concentradores, y entre $0-38 \mu \mathrm{M}$ en los cristalizadores.

Javor (1983 a y b) no detectó concentraciones de nitratos en los calentadores y concentradores de ESSA $(<1 \mu \mathrm{M})$ mientras que en los cristalizadores los rangos de 
concentraciones oscilaron entre $10-20 \mu \mathrm{M}$. Las concentraciones en las salinas de Western Salt, oscilaron entre 2- $36 \mu \mathrm{M}$.

Por lo general, la concentración de nitratos según la bibliografía consultada, es muy baja o no detectable en los sistemas de explotación salinera. Sin embargo, en numerosos estudios se observa un ligero aumento de la concentración de nitratos con la salinidad, especialmente en los cristalizadores donde puede producirse un aumento brusco de este parámetro.

\section{- Fosfatos}

La concentración de fosfatos varía conforme aumenta la salinidad en los diferentes sistemas salineros.

En el estudio de Pedrós-Alió et al. (2000), las pautas de comportamiento del fosfato fueron diferentes en cada una de las salinas estudiadas, ya que en Bras del Port se observó un ligero aumento con el incremento de la concentración salina, mientras que en La Trinitat se observó un ligero descenso con la salinidad, si bien los valores no fueron en ningún caso superiores a los $10 \mu \mathrm{M}$.

En los estudios de Javor (1983 a y b) en ESSA, el fosfato se mantuvo en niveles no detectables durante todo el circuito salinero si bien aumentó en los cristalizadores $(2-5$ $\mu \mathrm{M})$ y particularmente en los estanques más salinos donde se alcanzaron valores de hasta $10 \mu \mathrm{M}$. En Western Salt, los valores de fosfato oscilaron entre $0-3,5 \mu \mathrm{M}$.

Javor (2002) estableció como rangos de valores típicos para los fosfatos de las salinas solares eutróficas, entre $1-10 \mu \mathrm{M}$ en los estanques de precipitación del yeso, y entre $2-$ $60 \mu \mathrm{M}$ en los cristalizadores; mientras que en las oligotróficas estableció valores $<1 \mu \mathrm{M}$ en los estanques de precipitación del yeso, y oscilan entre $0-2 \mu \mathrm{M}$ en los cristalizadores.

Oren (2009) como parte de su estudio sobre los procesos de producción primaria en condiciones hipersalinas, en particular sobre la disponibilidad de los nutrientes inorgánicos para las comunidades fotosintéticas microbianas de las explotaciones salineras, elaboró una tabla-resumen (tabla 1.1) donde se presentan las concentraciones de los principales nutrientes documentados en las explotaciones salineras a lo largo del gradiente salino.

Oren en esta tabla-resumen convierte los valores de salinidad de los distintos estudios: $\mathrm{g} / \mathrm{l}$, $\mathrm{g} / \mathrm{kg}$, moles/l (para soluciones de $\mathrm{NaCl}$ ), \%, \%o y ${ }^{\circ}$ Bé (grados Baumé) a g/l, siempre que esto es posible. Aunque hay que destacar que los valores presentados en la tabla en $\mathrm{g} / \mathrm{l}$ en el caso de aguas altamente concentradas no son equivalentes a $\mathrm{g} / \mathrm{kg}$, que es la unidad con la que se trabaja en la presente tesis doctoral, y que la conversión está en función de la densidad de las muestras.

Con el fin de conocer la densidad de las muestras, en esta tesis doctoral se han pesado volúmenes conocidos de muestras con distintas salinidades. Según éstos resultados aguas con salinidades en torno a $130 \mathrm{~g} / \mathrm{kg}$ (La Mata) presentan densidades de $1,1 \mathrm{~kg} / 1$, mientras aguas con salinidades en torno a $250 \mathrm{~g} / \mathrm{kg}$ (Torrevieja) presentan densidades de $1,2 \mathrm{~kg} / \mathrm{l}$. Por ejemplo, un agua con $255 \mathrm{~g} / \mathrm{kg}$ de salinidad equivaldría a un agua con $306 \mathrm{~g} / \mathrm{l}$. 


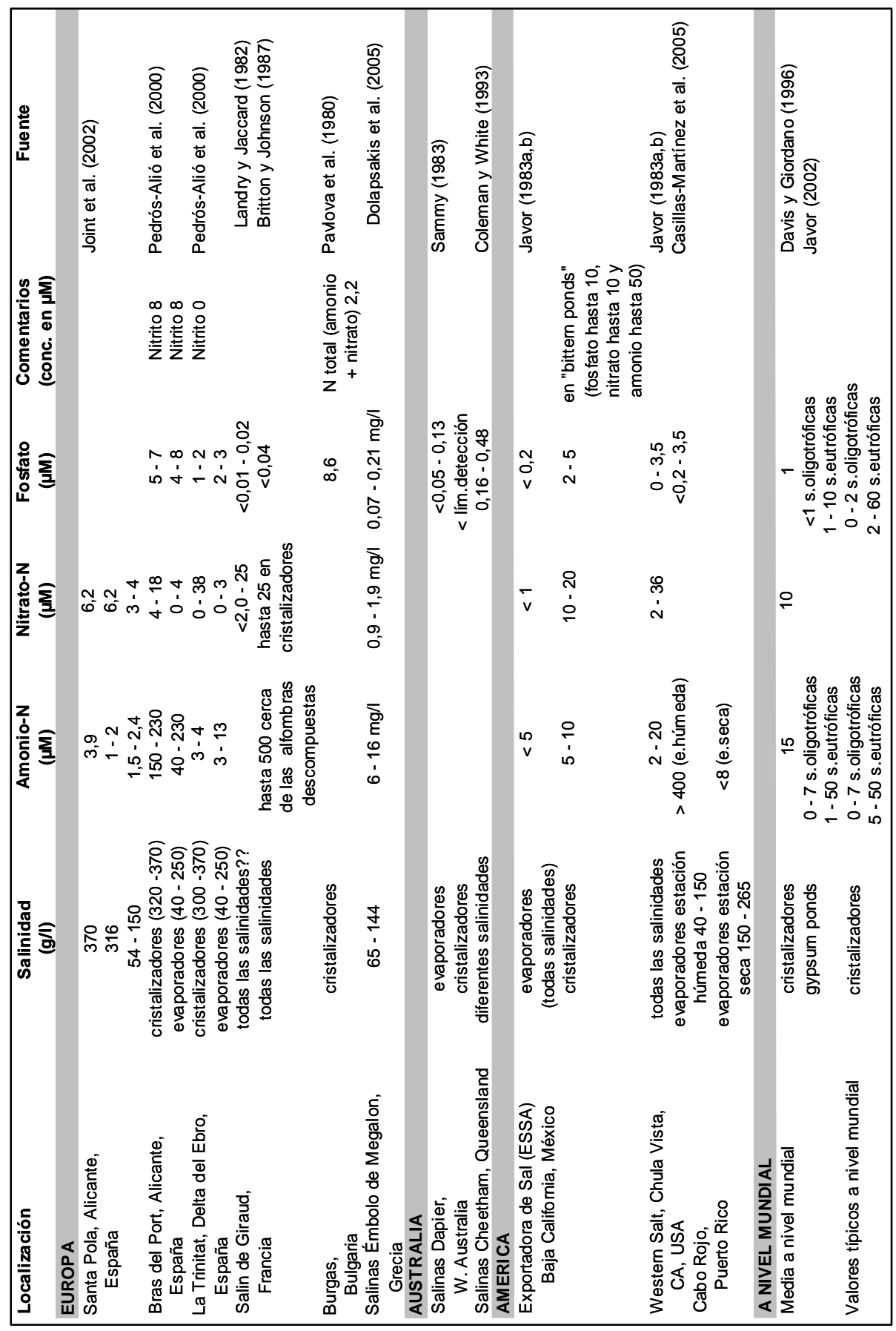

Tabla 1.1: Concentraciones de nutrientes inorgánicos documentadas en explotaciones salineras de todo el mundo. Traducción de la tabla 3 de Oren (2009) 
Según Javor (1983b), se cree que el aumento en la concentración de fosfatos, nitratos y amonio observado en los cristalizadores y en las aguas más cargadas de sales, son debidos a la descomposición de las bacterias y a una mayor concentración de las salmueras. Aunque se sabe que las halobacterias producen amonio (Dundas y Halvorson, 1966), los pasos que conducen a la producción de nitratos en el sistema aún no han sido explorados.

Esta circunstancia también es abordada más recientemente por Oren (2009) quien menciona que el hecho de que las concentraciones de nitrato sean mayores en los cristalizadores (a menudo mucho mayores de las esperadas por la concentración del agua de mar en sí misma) y que normalmente sobrepasan las concentraciones de amonio, permanece todavía inexplicado. Ya que según este autor la nitrificación autótrofa, responsable de la oxidación del amonio a través de los nitritos a nitratos, no es operativa en concentraciones salinas por encima de los 100 - $150 \mathrm{~g} / 1$ (Oren 1999, 2001).

También hay que mencionar, que algunos procesos microbianos están ausentes (p.e. nitrificación) o no han sido estudiados (p.e. fijación de $\mathrm{N}_{2}$ ) en ambientes extremadamente hipersalinos, mientras que otros procesos se encuentran relativamente atenuados por la elevada concentración de sales (p.e. sulfatorredución y metanogénesis). Por el contrario, otras actividades microbianas no se encuentran prácticamente afectadas por la hipersalinidad (p.e. degradación de aminoácidos) (Javor, 1989).

\section{- Minerales evaporíticos. Cationes y aniones principales de las aguas}

Los minerales evaporíticos o evaporitas son aquellos que se han formado como resultado de la evaporación y posterior precipitación de las sales tanto de origen marino (talásicos) como no marino (atalásicos). Hardie (1984) identificó algunas de las principales características que diferencian las evaporitas talásicas de las atalásicas, entre ellas los tipos de minerales primarios y secundarios.

En función del origen del sistema estudiado, la composición de las aguas será diferente, ya que la concentración total de iones en el agua de mar es mucho mayor que la del agua dulce, puesto que contiene grandes cantidades de sales disueltas. Las especies predominantes en el agua de mar son los iones sodio y cloruro aunque también se puede encontrar magnesio, potasio, sulfuro y, en menor medida, calcio y bromo. Estos iones se pueden asociar formando sales (Venkatesh, 1982; Baird, 2001).

Durante el proceso de evaporación y concentración del agua de mar en las salinas solares, se produce una precipitación de minerales según la solubilidad de los mismos. Cuando las aguas cargadas en sal se van concentrando, los principales minerales precipitan en el siguiente orden: $\mathrm{CaCO}_{3}$ (calcita o aragonita), $\mathrm{CaSO}_{4} \cdot 2 \mathrm{H}_{2} \mathrm{O}$ (yeso), $\mathrm{NaCl}$ (halita), y ciertos minerales de $\mathrm{K}-\mathrm{Mg}\left(\mathrm{MgSO}_{4}, \mathrm{MgCl}_{2}, \mathrm{NaBr}\right.$ y finalmente $\left.\mathrm{KCl}\right)$ (Sonnenfeld, 1984). Aunque hay que mencionar que en los sistemas de origen marino, la halita es la sal mayoritaria y puede constituir el $80 \%$ en peso de las sales totales en el agua de mar (Venkatesh, 1982).

A menudo la sucesión teórica de minerales y la sucesión observada son diferentes especialmente en las fases de potasa (Dean, 1978; Harvie et al., 1980), ya que la solubilidad de algunos minerales se encuentra fuertemente afectada por el efecto iónico común y la complejación iónica (Holser, 1979) así como el carbono orgánico disuelto en algunos casos. 
Además, una serie de factores pueden complicar la predicción de las secuencias de precipitación de los minerales como contacto con agua menos salina o con salmueras de diferente composición; contacto con rocas solubles y sedimentos; reflujos o salmueras más densas procedentes de la cuenca de evaporación; actividad biológica o carbono orgánico disuelto; y condiciones no fijas (Javor, 1989).

En el estudio llevado a cabo por Javor (1983a) en las salinas de Exportadora de Sal (ESSA) se puede observar la composición de las aguas de salmuera durante el transcurso de la precipitación:

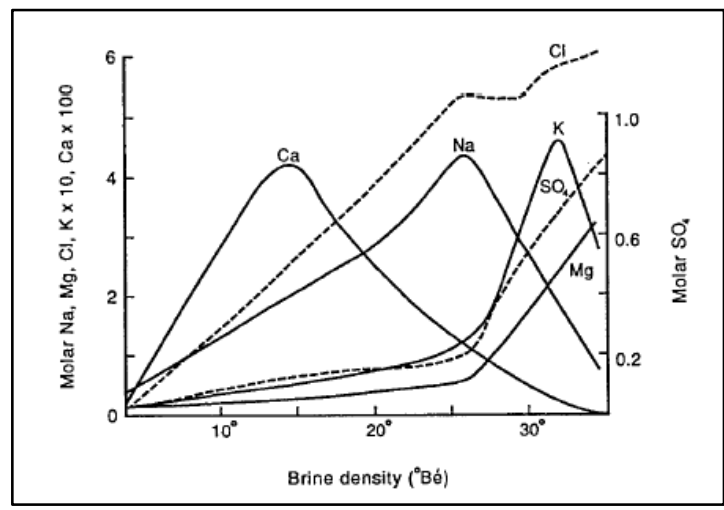

Figura 1.2: Composición de las salmueras de Exportadora de Sal (ESSA) durante el transcurso del proceso de evaporación (Javor, 1983)

\subsubsection{El sistema carbónico - carbonato en los ambientes hipersalinos}

\section{- El sistema carbónico-carbonato}

La química de los procesos ácido-base de muchos sistemas acuosos naturales está dominada por la interacción del ión carbonato $\left(\mathrm{CO}_{3}{ }^{-2}\right)$, base moderadamente fuerte, con el ácido carbónico $\left(\mathrm{H}_{2} \mathrm{CO}_{3}\right)$. Este ácido se forma por la disolución del dióxido de carbono atmosférico en el agua y a partir de la descomposición de la materia orgánica; existiendo habitualmente un equilibrio entre el gas y el ácido acuoso (Baird, 2001):

$$
\mathrm{CO}_{2}(\mathrm{~g})+\mathrm{H}_{2} \mathrm{O}(\mathrm{ac}) \leftrightarrow \mathrm{H}_{2} \mathrm{CO}_{3}(\mathrm{ac})
$$

El ácido carbónico en el medio acuoso está, también en equilibrio con el ión bicarbonato $\mathrm{HCO}_{3}{ }^{-}$), y con el ión hidrógeno:

$$
\mathrm{H}_{2} \mathrm{CO}_{3} \stackrel{\mathrm{K}_{1}}{\leftrightarrow} \mathrm{H}^{+}+\mathrm{HCO}_{3}^{-}
$$

Además, el ión bicarbonato está en equilibrio con el ión carbonato y con el ión hidrógeno:

$$
\mathrm{HCO}_{3}^{-} \stackrel{\mathrm{K}_{2}}{\leftrightarrow} \mathrm{H}^{+}+\mathrm{CO}_{3}^{-2}
$$

El origen predominante del ión carbonato son las rocas calizas, las cuales están constituidas predominantemente de carbonato de calcio, $\mathrm{CaCO}_{3}$. Aunque esta sal es insoluble, se disuelve una pequeña cantidad cuando las aguas están en contacto con ella:

$$
\mathrm{CaCO}_{3}(\mathrm{~s}) \leftrightarrow \mathrm{Ca}^{+2}+\mathrm{CO}_{3}^{-2}
$$


Debido a que $\mathrm{CO}_{2}(\mathrm{ac}), \mathrm{HCO}_{3}, \mathrm{HCO}_{3}{ }^{-} \mathrm{y} \mathrm{CO}_{3}{ }^{-2}$, se encuentran en concentraciones relativamente altas en todas las aguas naturales y por el importante papel que juega el $\mathrm{CO}_{2}$ en los procesos de fotosíntesis - respiración, el sistema carbónico-carbonato presenta un gran interés en el estudio del medio acuático, por ser extremadamente importante para la regulación del pH en las aguas naturales (Westall y Stumm, 1980).

En la figura 1.3 se muestra la relación entre el $\mathrm{pH}$ y las diferentes proporciones relativas de las distintas formas de carbono inorgánico $\mathrm{CO}_{2}, \mathrm{HCO}_{3}{ }^{-}$y $\mathrm{CO}_{3}{ }^{-2}$ para el agua destilada (línea continua) y para el agua de mar (línea discontinua) según Riley y Chester (1971). Como se puede observar en aguas salinas las curvas de los tres componentes se desplazan hacia valores menores de $\mathrm{pH}$.

Según Margalef (1983), a valores de $\mathrm{pH}>6,5$ predomina el bicarbonato; a valores de $\mathrm{pH}>$ 10,5 la concentración de carbonato supera a la de bicarbonato. De la misma manera, cuando el valor de $\mathrm{pH}$ es de 8,5 la fracción de carbonato empieza a nivelar a la fracción de carbónico. El valor preciso de $\mathrm{pH}(6,5 ; 8,5$ y 10,5$)$ depende de la temperatura, salinidad y otras condiciones y sirven bastante bien para situar las proporciones de las distintas formas de carbono orgánico con el pH.

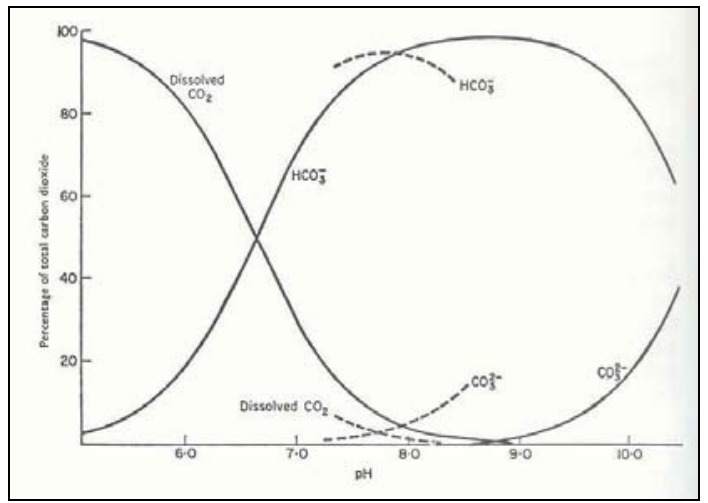

Figura 1.3: Porcentajes de dióxido de carbono, ión bicarbonato e ión carbonato en función del $\mathrm{pH}$ a $0^{\circ} \mathrm{C}$ (Riley y Chester, 1971)

\section{- El sistema carbónico-carbonato en ambientes hipersalinos}

En condiciones naturales, el agua de mar presenta una gran capacidad de neutralizar protones y, por tanto, de amortiguar las variaciones del pH (Stumm y Morgan, 1981). Sin embargo, conforme el agua de mar se evapora y se convierte en hipersalina, tienen lugar una serie de cambios físicos que afectan al sistema carbónico - carbonato y, por consiguiente, al $\mathrm{pH}$. Esto da lugar a que el comportamiento del sistema de carbonato en las aguas hipersalinas sea marcadamente diferente al del agua de mar o las aguas dulces.

En estos sistemas, el pH experimenta un descenso conforme el agua de mar se concentra que ha sido documentado por numerosos investigadores (Sass y Ben-Yaakov, 1977). Esto es debido a que la solubilidad del $\mathrm{CO}_{2}$ disminuye cuando aumenta la salinidad, y las constantes de disociación del ácido carbónico $\left(\mathrm{K}_{1} \mathrm{y} \mathrm{K}_{2}\right)$ así como el producto de 
solubilidad del $\mathrm{CaCO}_{3}$ varían cuando cambia la composición iónica y la fuerza iónica a lo largo de la secuencia de evaporación (Lazar et al., 1983). Las constantes de disociación del sistema carbonato fueron medidas de forma precisa por Sass y Ben-Yaakov (1977) y descubrieron que conforme aumentaba el contenido en sales, $\mathrm{K}_{1}$ y $\mathrm{K}_{2}$ disminuían progresivamente.

Además, Krumgalz (1981) mencionó el efecto salino sobre la actividad de los coeficientesaniónicos divalentes presentes en las aguas, específicamente carbonato.

Uno de los sistemas hipersalinos en los que más ampliamente ha sido estudiado el descenso de los valores de $\mathrm{pH}$ conforme aumenta la concentración salina es en el Mar Muerto, donde los valores de $\mathrm{pH}$ son excepcionalmente bajos (entre 5,9 y 6,5). Algunos autores como Nissenbaum (1969) y Amit y Bentor (1971) concluyeron que el responsable del descenso del pH en el Mar Muerto era el sistema carbonato. Marcus (1989) afirmó que el elevado descenso de la actividad del anión divalente carbonato con el aumento de la salinidad era, el principal responsable del descenso del $\mathrm{pH}$ de valores de 8,1 en aguas del Mediterráneo oriental a 6,0 en el interior del Mar Muerto.

Más recientemente, Soetaert et al. (2007), en un exhaustivo estudio sobre el $\mathrm{pH}$ en aguas naturales, mencionaron que el $\mathrm{pH}$ de las aguas puede verse condicionado por una serie de reacciones ácido-base, que pueden afectar tanto al $\mathrm{pH}$ como a las constantes termodinámicas y al equilibrio de las concentraciones. En particular, el proceso de calcificación (por el cual el $\mathrm{Ca}^{+2}$ y los iones carbonato o bicarbonato precipitan para formar cristales minerales de carbonato de calcio, como la calcita o la aragonita) tiene el efecto de disminuir el $\mathrm{pH}$.

Esto es debido a que a lo largo del proceso de evapotranspiración, se produce una precipitación en primer lugar del $\mathrm{CaCO}_{3}$ y posteriormente del $\mathrm{CaSO}_{4} \cdot 2 \mathrm{H}_{2} \mathrm{O}$ (yeso) que provoca un descenso del contenido en calcio de la columna de agua y, por tanto, reduce la capacidad del sistema de regular la concentración de carbónico - carbonato a través de la precipitación del $\mathrm{CaCO}_{3}$, y por tanto de tamponar el efecto sobre el $\mathrm{pH}$ del aumento de las entradas de $\mathrm{CO}_{2}$ al sistema.

\subsubsection{Biota}

\subsubsection{Características generales de la biota en los ambientes hipersalinos}

Existen muchos organismos que habitan en el agua de mar capaces de tolerar salinidades ligeramente elevadas, pero sólo las especies halófilas o halotolerantes pueden prosperar en aquellos hábitats caracterizados por una hipersalinidad extrema.

Muchos ambientes hiperhalinos son perjudiciales para los macroorganismos y por este motivo habitualmente no se observan peces por encima de $40-50 \mathrm{~g} / \mathrm{kg}$ de salinidad (Litchfield y Gillevet, 2002), aunque existen excepciones como el fartet (Aphanius iberus) especie considerada en peligro de extinción y localizada entre otros lugares en las salinas de Santa Pola (Planelles-Gomis, 1999) y en las salinas de Marchamalo y San Pedro del Pinatar en Murcia (Torralva et al., 2001). Sin embargo, éstos son los hábitats preferidos para una gran variedad de microorganismos, por lo que existe una extensa comunidad microbiana (Oren 1993; Ollivier et al., 1994; Ventosa et al., 1998; Litchfield et al., 1999).

En las salinas solares, cada uno de los estanques contiene una biota característica adaptada a la concentración salina predominante, desde el agua de mar hasta la saturación del $\mathrm{NaCl}$. 
Dado que el proceso industrial de fabricación de la sal se encuentra extendido por todo el mundo, según Litchfield et al. (2000) se asume que las diferencias entre poblaciones microbianas de las explotaciones salineras son mínimas.

Oren (1993) también afirma que los estudios sobre la biología de las salinas solares en diversas partes del mundo son muy similares en cuanto a su microbiología y que pueden darse algunas diferencias como resultado de cambios en la radiación incidente, temperatura, disponibilidad de nutrientes, tiempo de residencia en los estanques, etc. Javor (1983 a y b) menciona que los sistemas salineros de diferentes localizaciones geográficas, a menudo son distintos en cuanto a la densidad de las comunidades microbianas, probablemente debido a la variabilidad en los niveles de nutrientes inorgánicos.

Los microorganismos (tanto eucariotas como procariotas) han desarrollado una gran variedad de adaptaciones bioquímicas que les han permitido soportar el estrés iónico y osmótico, los cambios de temperatura, los ambientes con luminosidad variable, y las variaciones en las concentraciones de oxígeno y sulfuro propias de los sistemas hipersalinos (Javor, 1989).

\subsubsection{Principales organismos}

Según Javor (2002) a lo largo de un sistema de explotación salinera convencional se pueden encontrar diferentes comunidades biológicas. Cuando el agua de mar (en torno a 35 $\mathrm{g} / \mathrm{kg}$ de salinidad) se concentra unas dos veces, la flora y la fauna son las que se encontrarían en cualquier estuario eurihalino. Sin embargo, tal y como el agua de mar se concentra más, la fauna queda dominada por el género Artemia, que es ampliamente halotolerante a lo largo de la mayor parte de los sistemas salineros. La flora se encuentra dominada por microorganismos moderadamente halófilos (hasta aproximadamente unos $150 \mathrm{~g} / \mathrm{kg}$ de salinidad) y extremadamente halófilos (hasta la saturación del $\mathrm{NaCl}$, con más de $250 \mathrm{~g} / \mathrm{kg}$ de salinidad).

La mayor parte de los grupos fisiológicos de bacterias pueden ser identificados tanto en rangos de salinidad moderados como extremadamente halófilos, incluyendo fotótrofos (cianobacterias y bacterias fototróficas), quimioautótrofos (bacterias oxidantes del azufre) y heterótrofos (aeróbicos, fermentadores anaeróbicos, sulfato reductores, etc). Entre las Archeas se pueden diferenciar tanto halobacterias como metanogénicas.

\section{- Fitoplancton}

En el fitoplancton de los ambientes hipersalinos se pueden encontrar organismos tanto eucariotas como procariotas:

\section{- $\underline{\text { Procariotas }}$}

Entre las procariotas destacan las cianobacterias, que son habituales en los hábitats hiperhalinos. Algunas de las encontradas a salinidades mayores son Aphanothece halophytica y Schizothrix arenaria), siendo la primera una de las más conocidas (Javor, 1989).

\section{- Eucariotas}

Existen una serie de factores que restringen la presencia de algas eucariotas en muchos ambientes hiperhalinos como la incapacidad para la osmorregulación bajo ciertas condiciones, la incapacidad de asimilar nutrientes que pueden ser escasos, y la exclusión de 
aquellos hábitats en los que la temperatura aumenta por encima de 40 - $45^{\circ} \mathrm{C}$ (Javor, 1989). Las desecaciones periódicas también pueden restringir la presencia de algunas algas eucariotas. Entre las eucariotas existen diversas especies halotolerantes aunque de entre todas ellas, las más destacadas son las pertenecientes al género Dunaliella.

- Dunaliella spp.

El género Dunaliella pertenece a la división Chlorophyta (algas verdes) al orden Volvocal. Dentro de este género, $D$. salina y $D$. viridis han sido documentadas en numerosos ambientes marinos hipersalinos y atalásicos. Se trata de un microorganismo unicelular, fotótrofo y aeróbico, y es el organismo eucariota más conocido y extendido en estos ambientes (ver figura 1.4). Puede crecer en un amplio rango de salinidades y aunque $D$. salina crece mejor a salinidades en torno a $120 \mathrm{~g} / \mathrm{kg}$ tolera bien salinidades mucho mayores. Existe numerosa bibliografía sobre Dunaliella en ambientes hiperhalinos respecto a su fisiología general, ecología y cultivo, mecanismos de osmorregulación y composición lipídica, con referencias particulares a su contenido en $\beta$-carotenos, ya que $D$. salina puede ser una de las mejores y más importantes fuentes biológicas de $\beta$-caroteno que existen (Fraser y Bramley, 2004).

El éxito de Dunaliella en los ambientes hiperhalinos recae en las numerosas adaptaciones que presenta al estrés osmótico. Estas adaptaciones incluyen cambios en el volumen de la célula, en la concentración celular de iones, en la concentración intracelular de glicerol y en la expresión de algunos genes inducidos por la sal (Chen y Jiang, 2009). Según Oren (2005) Dunaliella no solamente puede adaptarse a un amplio espectro de concentraciones salinas por osmorregulación (acumulando glicerol como osmolito) sino también dirigir su metabolismo hacia la formación de proteínas específicas en relación con cambios en la salinidad del medio. Además, al no presentar pared celular, las células están encerradas en un plasma delgado que les permite cambiar rápidamente su volumen y tamaño como respuesta a los cambios hipo- e hiper-osmóticos (Sadka et al., 1989).

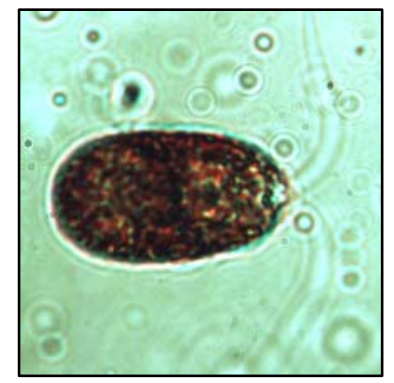

Figura 1.4: Imagen de Dunaliella salina

- Diatomeas

Aunque se encuentran presentes de forma habitual en los ambientes hipersalinos, nunca parecen dominar en los mismos (Javor, 1989). Se sabe poco acerca de la fisiología y ecología de las diatomeas en este tipo de hábitats y según Davis (1978) son comunes en las salinas solares hasta salinidades en torno a $210 \mathrm{~g} / \mathrm{kg}$ aunque se observa una tendencia a que disminuya su diversidad conforme aumenta la salinidad (Clavero et al., 2000). 


\section{- Zooplancton}

\section{- Invertebrados}

De entre el zooplancton de los ambientes hipersalinos, destaca el crustáceo Artemia salina (clase Crustacea, orden Anostraca). Existen varias especies de Artemia ampliamente repartidas por todo el mundo y que se pueden encontrar, entre otros hábitats, en las salinas costeras de origen marino. Se pueden encontrar numerosos estudios sobre las poblaciones de Artemia en la Península Ibérica y se constata su presencia en las salinas de Calpe, en las de Santa Pola tanto en Bonmatí como en Bras del Port y en la laguna de La Mata (Amat, 1983; Barata et al., 1996).

\section{- $\underline{\text { Protozoos }}$}

La gran variedad de protozoos que se encuentran en los ambientes hipersalinos confirma el relativo éxito adaptativo de este grupo de microorganismos en estos hábitats (Javor, 1989). Se pueden encontrar a lo largo de todo el gradiente salino y algunos géneros están fisiológicamente adaptados a las salinidades más altas. Uno de los ciliados más destacados es Fabrea salina que puede competir por los recursos con Artemia salina tal y como muestra el estudio realizado por Elloumi et al. (2006) en las salinas solares de Sfax (Túnez).

\section{- Bacterias}

Las comunidades bacterianas presentan una gran importancia en los ambientes extremos propios de las salinas solares y son los regímenes de salinidad y de temperatura los principales factores que imponen las distribuciones de cada una de ellas.

Existen numerosos estudios sobre las bacterias halófilas y halotolerantes: aquellos que describen la variedad de tipos metabólicos y los ratios de actividad en los hábitats hipersalinos; investigaciones sobre bacterias aisladas que describen sus requerimientos en cuanto a crecimiento y tolerancia a la salinidad; e investigaciones que detallan aspectos específicos del metabolismo, osmorregulación y bioquímica de las bacterias (Javor, 1989).

Algunos de los géneros más comunes de bacterias no fotótrofas (no emplean la luz como fuente de energía y, por tanto, no realizan la fotosíntesis) aislados en salinas solares son pertenecientes a los géneros: Pseudomonas, Alteromonas o Alcaligenes; mientras que algunos de los más comunes de bacterias fotótrofas (emplean la luz a través de la fotosíntesis) son: Aphanothece, Ectothiorhodospira o Rhodospirillum.

Los ambientes hipersalinos son especialmente adecuados para la proliferación de las bacterias. Dentro de las salinas solares destacan los tapices microbianos, en su mayor parte compuestos por diferentes grupos de microorganismos estratificados horizontalmente como cianobacterias, bacterias del azufre, bacterias sulfato-reductoras, distribuidas a lo largo de microgradientes verticales de oxígeno, sulfuro y luz (Revsbech et al., 1983; Van Gemerden, 1993). Por ejemplo, en el estudio de los tapices microbianos en las Salins-deGiraud (Francia) se ha observado que los principales componentes son las cianobacterias, además de diatomeas y otras algas. Existen también grupos de bacterias relacionados con el ciclo del sulfuro como las bacterias sulfato-reductoras, las oxidantes del azufre y las fotótrofas anoxigénicas (Fourçans et al., 2004).

Los tapices microbianos se encuentran en aquellos estanques con salinidades elevadas aunque por debajo de la saturación del yeso. Algunos de los nutrientes que alimentan los 
tapices son procedentes de las aguas de salmuera que se encuentran por encima. Hay que destacar que este tipo de tapices no se desarrollan sobre la superficie de las gruesas cortezas de yeso de los cristalizadores aunque pueden desarrollarse por debajo de éstas sobre los sedimentos (los cuales pueden utilizar como fuente de nutrientes y elementos traza) (Javor, 2002).

\section{- Arqueas halófilas o Haloarqueas}

Pertenecen al dominio Archaea. Son extremadamente halófilas y en la mayoría de los casos requieren como mínimo un $120-150 \mathrm{~g} / \mathrm{kg}$ de salinidad para su crecimiento. A menudo son altamente pigmentadas y se diferencian del resto de arqueas por la presencia de bacteriorrodopsina, si bien el color rojo típico de la mayoría de halobacterias es debido a los carotenoides $\beta$-caroteno y bacterioruberina. Destacan los géneros Halobacterium y Haloferax. Una de las especies más conocidas es Haloferax mediterranei que tiene en las salinas Santa Pola uno de sus hábitats naturales (Martínez-Espinosa, 2003).

\section{- Hongos y levaduras}

Parece ser que tanto hongos como levaduras están bien adaptados a vivir en hábitats con un alto contenido en sales (ambos pueden ser halotolerantes aunque no necesariamente halófilos). Existen muy pocos estudios sobre hongos y levaduras en ambientes extremadamente hipersalinos. Uno de ellos, es el efectuado por Gunde-Cimerman et al. (2000) en las salinas de Secovlje (Slovenia) en el que demuestran la existencia de hongos halotolerantes y halófilos del grupo de las levaduras negras.

\subsubsection{La coloración de las salinas}

Las explotaciones salineras (al menos en sus balsas con mayor salinidad) se caracterizan por una coloración rojiza. Dos tipos de microorganismos ricos en carotenoides han sido normalmente los responsables del origen de la coloración rojiza en las explotaciones salineras: las arqueas halófilas de la familia Halobacteriaceae y el alga unicelular Dunaliella salina. Los principales pigmentos de las Halobacteriaceae son carotenoides C50 , principalmente $\alpha$-bacterioruberina y sus derivados (de color rojo) mientras que Dunaliella acumula cantidades masivas de $\beta$-caroteno (de color naranja).

Sin embargo, Oren y Rodríguez-Valera (2001) en un estudio en Bras del Port (Santa Pola) sobre el análisis de los pigmentos extraídos en los cristalizadores, observaron que entre un $5-7,5 \%$ de la absorbancia del pigmento de las procariotas podía atribuirse a un nuevo compuesto carotenoide. Este pigmento era idéntico al pigmento exclusivo de Salinibacter ruber (Salinibacter ruber es un importante componente de la comunidad microbiana en los estanques salinos españoles). Por ello, el color rojizo de los cristalizadores en estas salinas podría ser debido no solo a la coloración roja de las Archaeas halófilas y a los $\beta$-carotenos de Dunaliella spp. como previamente era asumido.

\subsubsection{El ecosistema en las salinas}

Los ecosistemas salinos presentan unas salinidades tan elevadas que son muy pocos los organismos que han podido adaptarse a estas condiciones tan extremas y no existen organismos superiores que habiten en ellas. De ahí que estos ambientes sean hábitats básicamente microbianos (Grant, 2004). 
En el estudio llevado a cabo por Javor (2002) se observó un cambio en la composición tanto de las aguas como del sedimento en los ecosistemas salinos conforme aumentaba la salinidad, con una simplificación de los mismos.

Existen diversos estudios sobre la cadena trófica microbiana y la composición de las poblaciones de bacterias y Archaea de las salinas de Santa Pola (Rodríguez-Valera, 1988; Benlloch et al., 1995; Antón et al., 2000; Casamayor et al., 2000; Pedrós-Alió et al., 2000).

Según el estudio de Pedrós-Alió et al. (2000), la cadena trófica microbiana tiende a hacerse más simple tal y como la concentración salina aumenta, con una tendencia al descenso en la abundancia, en la riqueza de especies y en la diversidad de los organismos acuáticos. En dicho estudio se observaron unas estructuras y flujos que experimentaban cambios muy dramáticos a lo largo del gradiente salino:

- Las comunidades con salinidades con una composición más similar a las del ecosistema marino costero no fueron consideradas en dicho estudio. Aunque existen numerosos estudios relacionados con la cadena trófica en los ecosistemas costeros y acuáticos como los de Nixon (1981) y Vollenweider et al. (1996).

- Las comunidades situadas en las salinidades intermedias (calentadores), presentaban una cadena intrincada, incluyendo el bentos y una gran variedad de taxones fitoplanctónicos y macroorganismos. La biomasa fitoplanctónica estaba formada básicamente por cianobacterias, algas verdes y diatomeas, y la producción primaria era elevada.

- Conforme aumentaba la salinidad (concentradores), la estructura se veía dramáticamente simplificada. y solamente había un productor primario Dunaliella salina y un predador Artemia salina, formando una cadena clásica corta, simple y lineal. En esta comunidad, los depredadores de las bacterias desaparecían y los virus jugaban un pequeño papel. Hay que mencionar que si bien Pedrós-Alió et al. (2000) dicen que solamente hay un productor y un predador, no se ha de confundir el que ambas poblaciones estén dominadas por una especie con que sea la única especie presente.

- Finalmente, en las salinidades más altas (cristalizadores), la actividad era debida fundamentalmente a organismos del dominio Archaea. No había productores primarios ni predadores, únicamente dos o tres tipos de procariotas y hasta los virus crecían lentamente. Ramos-Cormenzana (1991) y Oren (2002) también mencionan que solamente unas pocas especies, principalmente organismos procariotas sobreviven en las salinidades más altas a lo largo del gradiente salino.

Como se puede observar, los estanques de los circuitos salineros constituyen un ecosistema en el que se pueden desarrollar cadenas tróficas con diferentes grados de complejidad, y la salinidad es el parámetro que más va a condicionar las condiciones ambientales de los sistemas salineros. Elloumi et al. (2006) en sus estudios llevados a cabo en las salinas de Sfax (Túnez), afirman que la salinidad es el factor que controla la distribución general de los taxones a lo largo de la secuencia de estanques, mientras que otros factores como la predación, competencia y nutrientes controlan el esquema estacional de las comunidades planctónicas en cada estanque. 


\subsection{LAS SALINAS EN EL ÁMBITO DE LA DIRECTIVA MARCO DEL AGUA}

\subsubsection{La Directiva Marco del Agua}

La Directiva Marco del Agua (2000/60/CE), de 23 de octubre de 2000, denominada comúnmente DMA, es el texto legal de ámbito Comunitario con el que se establece el marco europeo para la protección de las aguas superficiales continentales, de transición, costeras y subterráneas para prevenir o reducir su contaminación, promover su uso sostenible, proteger el medio ambiente, mejorar el estado de los ecosistemas acuáticos y atenuar los efectos de las inundaciones y sequías. Esta Directiva surge de la necesidad, dentro de la Unión Europea, de tomar medidas para proteger las aguas tanto en cantidad como en calidad y garantizar que todas las masas de agua alcancen un "estado ecológico bueno" en el año 2015.

Algunos de los principales conceptos de la DMA que serán utilizados a lo largo de la presente tesis doctoral son:

- Aguas costeras: aguas superficiales situadas hacia tierra desde una línea cuya totalidad de puntos se encuentra a una distancia de una milla náutica mar adentro desde el punto más próximo de la línea de base que sirve para medir la anchura de las aguas territoriales y que se extienden, en su caso, hasta el límite exterior de las aguas de transición.

- Aguas de transición: masas de agua superficial próximas a la desembocadura de los ríos que son parcialmente salinas como consecuencia de su proximidad a las aguas costeras, pero que reciben una notable influencia de flujos de agua dulce.

- Masa de agua artificial: masa de agua superficial creada por la actividad humana.

- Masa de agua muy modificada: masa de agua superficial que, como consecuencia de alteraciones físicas producidas por la actividad humana, ha experimentado un cambio sustancial en su naturaleza, y ha sido designada como tal por el Estado Miembro según el Anexo II de la DMA “Caracterización, presiones e impactos, condiciones de referencia”.

- Estado de las aguas superficiales: expresión general del estado de una masa de agua superficial, determinado por el peor valor de su estado ecológico y de su estado químico.

- Estado ecológico: expresión de la calidad de la estructura y el funcionamiento de los ecosistemas acuáticos asociados a las aguas superficiales.

- Buen Estado ecológico: estado de una masa de agua superficial clasificado como tal según el Anexo V “estados de las masas de agua” de la DMA.

- Buen Potencial ecológico: estado de una masa de agua muy modificada o artificial clasificado como tal según el Anexo V de la DMA.

- Máximo Potencial Ecológico: máxima calidad ecológica que puede ser alcanzada por una masa de agua muy modificada o una masa de agua artificial, una vez que todas las medidas de mitigación, que no tienen impactos negativos significativos sobre su uso específico o sobre el medio ambiente en general, han sido aplicadas. 


\subsubsection{Caracterización y tipologías de las masas de agua superficiales}

La aplicación de la DMA se realiza a nivel de cuenca hidrográfica y debe ser tenida en cuenta en el plan hidrológico de cada cuenca. Según el Anexo II de la DMA (“Caracterización, presiones e impactos, condiciones de referencia”), las masas de agua superficial dentro de cada demarcación hidrográfica se clasificarán en una de las siguientes categorías de masas de agua superficiales: ríos, lagos, aguas de transición, aguas costeras, masas de agua artificial o masas de agua muy modificadas.

Según Heiskanen et al. (2004) cada una de las categorías de masas de agua superficiales se clasificará por tipos, que deben ser caracterizados en base a factores geográficos, morfológicos y físicos. Por tanto, la tipología debe agrupar sitios donde las condiciones biológicas naturales sean similares.

En España, la Instrucción de Planificación Hidrológica Nacional (Orden ARM/2656/2008), que constituye un instrumento de aplicación de la DMA y de los Planes Hidrológicos de Cuencas, también establece que las masas de agua superficial de cada categoría se clasificarán en tipos.

Para las masas de agua de transición serán los representados en la tabla 1.2 donde como se puede observar las salinas son tipología en sí mismas dentro del grupo de masas de agua de transición.

\begin{tabular}{|ll|}
\hline Uso & Denominación \\
\hline 1) & Estuario mediterráneo micromareal sin cuña salina \\
\hline 2) & Estuario mediterráneo micromareal con cuña salina \\
\hline 3) & Bahía estuárica mediterránea \\
\hline 4) & Laguna costera mediterránea con aportes bajos de agua dulce \\
\hline 5) & Laguna costera mediterránea con aportes medios de agua dulce \\
\hline 6) & Laguna costera mediterránea con aportes altos de agua dulce \\
\hline 7) & Salinas \\
\hline 8) & Estuario atlántico intermareal con dominancia de río sobre el \\
\hline 9) & Estuario \\
\hline 10) & Estuario atlántico intermareal con dominancia marina submareal \\
\hline 11) & Zonas de transición atlánticas lagunares \\
\hline 12) & Estuario atlántico mesomareal con descargas irregulares de río \\
\hline 13) & Estuario Tinto-Odiel \\
\hline
\end{tabular}

Tabla 1.2: Tipos de masas de agua de transición según la Orden ARM/2656/2008

La clasificación de cada masa en un determinado tipo se realiza en función de los valores que presentan para cada masa en condiciones naturales las variables que definen la tipología y que se encuentran en el Anexo II de la Orden ARM/2656/2008:

- $\quad$ amplitud de la marea; salinidad media anual

- $\quad$ superficie emergida / sumergida 
- $\quad$ exposición al oleaje

- $\quad$ características de la mezcla de agua

- $\quad$ tasa de renovación del agua

- $\quad$ permanencia / temporalidad

- $\quad$ tipo de conexión con el mar: directa /restringida

En el caso de las masas de agua superficial artificiales y muy modificadas, la clasificación se llevará a cabo de conformidad con los descriptores correspondientes a cualquiera de las categorías de aguas superficiales que más se parezca a la masa de agua muy modificada o artificial de que se trate, en este caso las aguas de transición.

\subsubsection{Indicadores ecológicos y condiciones de referencia}

Para poder conocer el estado ecológico o el potencial ecológico de una masa de agua, en primer lugar es necesario definir los elementos de calidad o indicadores (elementos del medio que presenten una respuesta a las presiones) que van a ser utilizados.

Los elementos de calidad o indicadores del estado ecológico para las masas de agua de transición, según el Anexo V apartado 1.1.3. de la DMA son los siguientes (son los mismos que para las masas de agua costeras salvo que en este caso se incluyen los peces):

- Indicadores biológicos

- composición, abundancia y biomasa del fitoplancton

- composición y abundancia de otra flora acuática

- composición y abundancia de fauna invertebrada béntica

- composición y abundancia de peces

- Indicadores hidromorfológicos

- condiciones morfológicas: variación de la profundidad; cantidad, estructura y sustrato del lecho; estructura de la zona intermareal

- $\quad$ régimen de mareas: flujo de agua dulce y exposición a las olas

- Indicadores químicos y físico-químicos

- generales: transparencia, condiciones térmicas, oxigenación, salinidad y condiciones de los nutrientes

- contaminantes específicos: contaminación por sustancias prioritarias que se descargan en la cuenca o subcuenca y por otros contaminantes que se descargan en cantidades significativas en la cuenca o subcuenca

Para el caso de las masas de agua artificiales o muy modificadas, según el Anexo V apartado 1.1.5. de la DMA, pueden ser los aplicables a cualquiera de las categorías de masas de agua superficiales a las que más se parezca la masa de agua en cuestión (aguas de transición). 
Posteriormente, se han de determinar cuáles son las condiciones de referencia para cada elemento indicador de calidad. Esto permitirá conocer cuál es el objetivo de calidad ecológica a mantener o restablecer.

Las condiciones de referencia para una masa de agua son una descripción de los elementos de calidad biológica que existen o existirían en el estado prístino prácticamente con ninguna o muy pocas alteraciones derivadas de las actividades humanas. La DMA en el Anexo II apartado 1.3 identifica cuatro opciones para establecer las condiciones de referencia:

- $\quad$ utilizando una base espacial

- utilizando modelos (modelos de predicción o métodos de análisis a posteriori, utilizando los datos disponibles: históricos, paleológicos y/o de otro tipo)

- derivados de la combinación de ambos métodos

- $\quad$ en caso de no existir ninguno de los tres anteriores, juicio de expertos

Una vez decididos qué parámetros estadísticos hay que utilizar para establecer las condiciones de referencia en cada elemento de calidad ambiental, se calcula el Cociente de Calidad Ambiental (EQR: Environmental Quality Ratio), que para las masas de aguas costeras y de transición es el que se muestra en la figura 1.5:

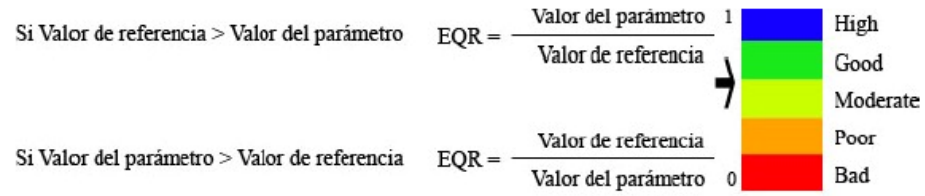

Figura 1.5: Esquema para establecer los $\mathrm{EQR}$ en masas de agua costeras y de transición

\subsubsection{Periodicidad de los controles de vigilancia}

La Directiva Marco del Agua establece la periodicidad con la que se han de realizar los controles de vigilancia. Según la DMA, se optará por una periodicidad que tenga en cuenta el carácter variable de los parámetros debido a las condiciones ambientales y antropogénicas. Los Estados Miembros establecerán la periodicidad de los controles operativos requeridos para cada parámetro, de manera que se proporcione la información suficiente para hacer una evaluación segura del estado del indicador de calidad correspondiente (Directiva 2000/60/CE).

Para las masas de agua artificiales o muy modificadas, categoría en la que están incluidas las salinas, según el Anexo V de la DMA, se aplican los elementos de calidad de cualquiera de las cuatro categorías de aguas superficiales naturales (ríos, lagos, aguas de transición o aguas costeras) a la que más se parezca la masa de agua superficial o muy modificada de que se trate, en este caso, aguas de transición. El Anexo V establece que para las aguas de transición se ha de realizar un seguimiento sobre una serie de indicadores biológicos, hidromorfológicos, físico-químicos y contaminantes específicos. 
La normativa de la DMA en cuanto a periodicidad de los controles (Anexo V apartado 1.3.4) establece una periodicidad mínima anual de seguimiento para aguas de transición de 3 meses para los parámetros físico-químicos. Además puntualiza que para el período de controles de vigilancia, los parámetros correspondientes a los indicadores de calidad físicoquímicos se controlarán con la periodicidad establecida, salvo en caso de que se justifiquen intervalos mayores en función de los conocimientos técnicos y la apreciación de los especialistas.

\subsubsection{Las aguas de transición en la Comunidad Valenciana}

La DMA define las aguas de transición como las masas de agua superficial próximas a la desembocadura de los ríos que son parcialmente salinas como consecuencia de su proximidad a las aguas costeras, pero que reciben una notable influencia de flujos de agua dulce. En la región ecológica mediterránea las mareas pueden ser consideradas despreciables $(<1 \mathrm{~m})$ y en la mayoría de los casos la escasa penetración del agua salina reduce la extensión de las aguas de transición. Por otro lado, los ríos mediterráneos en general no presentan aportaciones suficientes de agua dulce que generen la formación de plumas que se extiendan mar adentro.

La delimitación de las aguas de transición ha estado basada en el límite competencial entre el dominio público hidráulico y el dominio público marítimo terrestre. Este límite según la Ley de Costas se extiende aguas arriba por las márgenes de los ríos hasta donde se haga sensible el efecto de las mareas. Para el caso del ámbito territorial de la Comunidad Valenciana, las masas de agua superficiales definidas como "aguas de transición" por la Conselleria de Medio Ambiente, Agua, Urbanismo y Vivienda (Ministerio de Medio Ambiente, 2007) son:

- Salinas: con un gradiente salino que puede ir desde aguas salobres hasta las aguas de cristalización: Salina de Calpe; Salina de Santa Pola y Salina de La Mata - Torrevieja

- Sistemas estuarinos con cuña salina: Estany Gran de Cullera y Estuario del Júcar

La mayor parte de humedales, estanques y lagunas del litoral de la Comunidad Valenciana (especialmente al norte del Cabo de San Antonio) son claramente de agua dulce, por lo que aún siendo sistemas litorales no entrarían dentro de la clasificación de aguas de transición. Según Serra (2005) el Cabo San Antonio es un punto de ruptura desde el punto de vista de las cuencas fluviales y los aportes continentales. En la zona norte las cuencas son mayores y reciben aportes continentales, bien en forma de río o de acequias, mientras que al sur del cabo las cuencas fluviales son menores y los ríos existentes en el territorio no llevan agua en su salida al mar. 


\subsubsection{Las masas de agua muy modificadas (MAMM) según la DMA}

Las masas de agua muy modificadas son las que, como consecuencia de alteraciones físicas producidas por la actividad humana, han experimentado un cambio sustancial en su naturaleza, y cumplen los criterios establecidos en el arículo 4.3 de la DMA. En dicho artículo se establece que:

"Los Estados miembros podrán calificar una masa de agua como artificial o muy modificada cuando:

a) los cambios en las características hidromorfológicas de dicha masa necesarios para alcanzar su buen estado ecológico impliquen considerables repercusiones negativas en:

- el entorno en sentido amplio,

- la navegación, incluidas las instalaciones portuarias, o las actividades recreativas,

- las actividades para las que se almacena el agua, tales como el suministro de agua potable, la producción de energía o el riego,

- la regulación del agua, la protección contra las inundaciones, el drenaje de terrenos,

- otras actividades de desarrollo humano sostenible igualmente importantes;

b) los beneficios derivados de las características artificiales o modificadas de la masa de agua no puedan alcanzarse razonablemente, debido a las posibilidades técnicas o a costes desproporcionados, por otros medios que constituyan una opción medioambiental significativamente mejor.

Tal calificación y sus motivos se mencionarán específicamente en los planes hidrológicos de cuenca y se revisarán cada seis años”.

\subsubsection{Las salinas según la Directiva Marco del Agua}

Las salinas de la Comunidad Valenciana en el ámbito de la DMA pertenecen al grupo de aguas de transición tal y como se ha explicado en el apartado 1.2.5. Sin embargo, estas masas de agua (junto con los puertos) han sido designadas como masas de agua muy modificadas siguiendo el Documento Guía ${ }^{\circ} 4$ de la UE (WFD CIS Guidance Document $\mathrm{n}^{\circ} 4,2003$ ) al cumplir alguno de los requisitos descritos anteriormente en el apartado 1.2.6 (Ministerio de Medio Ambiente, 2009).

En el caso de las salinas, las condiciones de excepcionalidad vienen dadas por la introducción de cambios profundos en las condiciones hidrodinámicas debido al manejo humano del sistema, lo que ha dado lugar a una serie de cambios en las condiciones ambientales que limitan la calidad ecológica máxima que pueden alcanzar. Las razones de esta designación según Ministerio de Medio Ambiente (2007) son:

- $\quad$ Las Salinas de Santa Pola y las salinas de La Mata - Torrevieja son humedales litorales que fueron transformados para su explotación salinera, por lo que los flujos de agua están regulados en función de los objetivos de producción de sal. Ambas presentan, por tanto, un elevado nivel de gestión antrópica de los flujos de agua en función de los intereses de las respectivas explotaciones salineras. Las condiciones se alejan de las "naturales" y no cabe esperar conseguir un buen estado ecológico. 
- La Salina de Calpe no tiene en estos momentos explotación comercial, pero su hidrodinámica fue cambiada con tal fin con una comunicación con el mar que aún persiste. Actualmente todavía se realizan aportes de agua de mar que junto a la evapotranspiración convierten las aguas de la salina en hipersalinas la mayor parte del año. En este caso, las condiciones también se alejan por tanto de las "naturales" y no cabe esperar conseguir un buen estado ecológico.

En este caso, la DMA establece la obligatoriedad de determinar el "potencial ecológico" y no el "estado ecológico". Esta calificación supone la asunción de determinadas condiciones de excepcionalidad entre las que se encuentra la reducción de las exigencias ambientales, manteniendo al mismo nivel los objetivos de protección y mejora de la calidad necesarios para que estas masas de agua alcancen un potencial ecológico calificado como "bueno", que también debe ser alcanzado para el año 2015.

\subsubsection{El potencial ecológico}

En las MAMM, se han de establecer otros objetivos más apropiados para el control de las presiones (incluyendo presiones físicas que no se encuentran asociadas con su uso específico) para asegurar que los efectos ecológicos adversos que la alteración física puede provocar son convenientemente mitigados sin dañar los beneficios para los que sirven.

Los objetivos se establecen en relación a unas condiciones de referencia o máximo potencial ecológico (MPE), que es la máxima calidad ecológica que puede ser alcanzada por una masa de agua muy modificada (o artificial), una vez que todas las medidas de mitigación, que no tienen impactos negativos significativos sobre su uso específico o sobre el medio ambiente en general, han sido aplicadas. El MPE es, por tanto, el estado biológico que refleja, en la medida de lo posible, la masa de agua más próxima con la que se puede comparar la MAMM teniendo en cuenta sus propias características.

Según el informe del Ministerio de Medio Ambiente (2009) se prevé la clasificación de las masas de agua según su potencial ecológico en tipos, para lo que se usarán los descriptores correspondientes a la categoría de agua superficial a la que más se parezca (en el caso de las salinas, los correspondientes a las aguas de transición) y para cada uno de ellos habrá que establecer los valores de los indicadores correspondientes al máximo potencial ecológico (WFD CIS Guidance Document nº4, 2003).

Los criterios que se deben aplicar para establecer el MPE son los siguientes:

a) Se utilizarán, en la medida de lo posible, los mismos elementos de calidad que se establezcan para la categoría de agua superficial a la que más se parezca a la masa de agua artificial o muy modificada de que se trate.

b) Los valores de los indicadores de los elementos de calidad hidromorfológicos serán los correspondientes a la situación resultante de aplicar todas las medidas mitigadoras posibles, una vez admitidas las alteraciones físicas identificadas en el proceso de designación.

c) Los valores de los indicadores de los elementos de calidad físico-químicos se basarán en los del tipo que resulte más semejante, una vez asumidas las condiciones hidromorfológicas anteriores.

d) Los valores de los indicadores de los elementos de calidad biológicos se basarán en los del tipo que resulte más semejante, una vez asumidas las condiciones hidromorfológicas y físico-químicas anteriores. 
e) Los tipos en los que se basen los valores de los indicadores de los elementos de calidad físicoquímicos y biológicos podrán corresponder a masas de agua naturales o ser específicos de masas artificiales o muy modificadas.

Las clases de potencial ecológico definidas a partir del MPE son las que se muestran en la tabla 1.2 (el BPE y el MPE para la elaboración de informes y mapas se combinan en una sola clase):

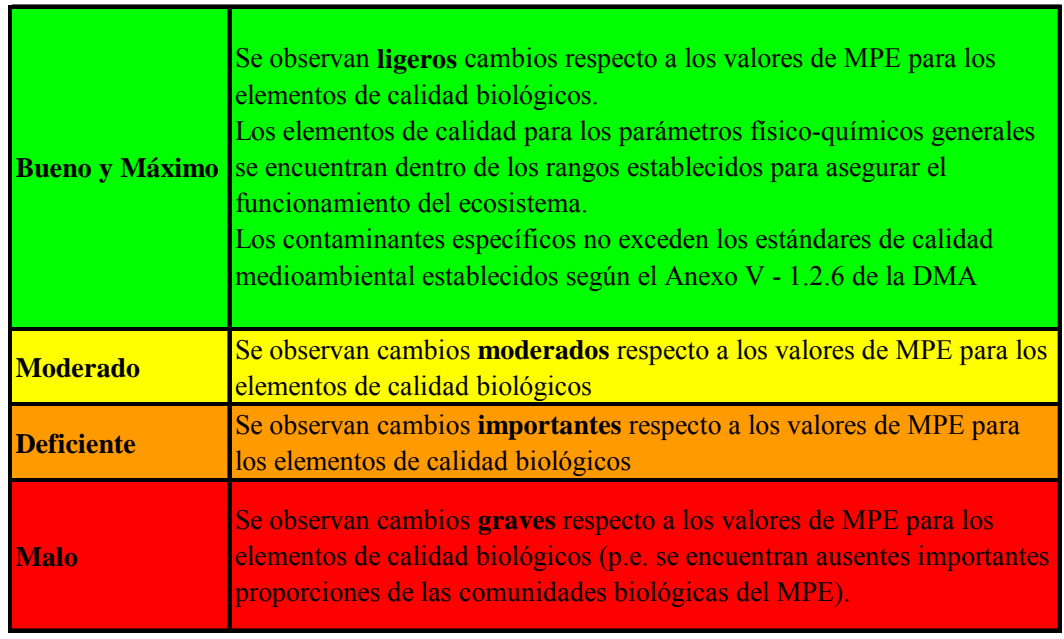

Tabla 1.3: Definición de las diferentes clases de potencial ecológico

\subsubsection{El ejercicio de intercalibración. Establecimiento del potencial ecológico en MAMM. Situación actual del proceso}

\subsubsection{El ejercicio de intercalibración}

La complejidad de la DMA hizo necesario el establecimiento entre todos los Estados Miembros de una Estrategia Común de Implementación (CIS) aprobada en mayo de 2001, que ayudara a la implementación de la DMA (WFD CIS, 2001).

La estructura organizativa actual de la Estrategia Común de Implementación (ver figura 1.6) establece que el grupo A Ecological Estatus (ECOSTAT) lleve a cabo el ejercicio de intercalibración (WFD CIS, 2004). 


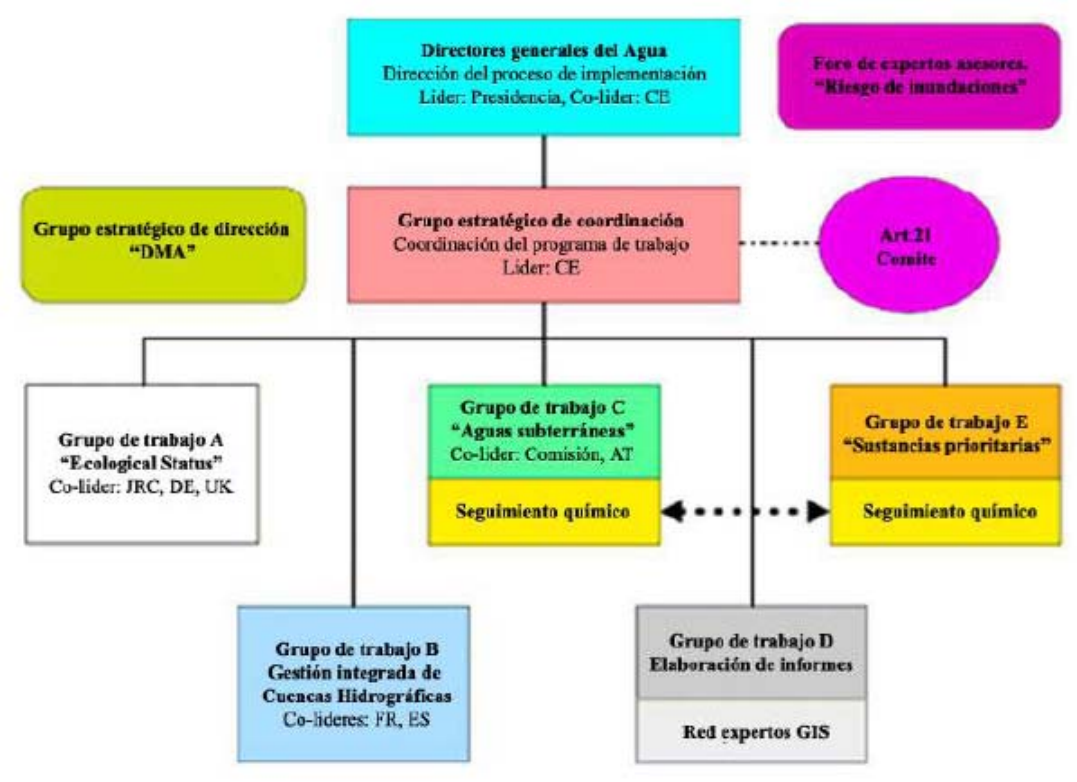

Figura 1.6: Estructura organizativa de la Estrategia Común de Implementación de la DMA (WFD CIS, 2004)

Para desarrollar la intercalibración, se crean, dentro del ECOSTAT, para las distintas categorías de aguas superficiales, una serie de subgrupos internacionales de trabajo. La Comunidad Valenciana participa en el Grupo de Intercalibración del Mediterráno (MedGIG) y sus masas de agua se rigen por las decisiones tomadas en el ejercicio de intercalibración por este grupo.

El proceso de intercalibración es un proceso importante, puesto que previamente al establecimiento del potencial ecológico, es necesario realizar un proceso de intercalibración entre los diferentes Estados Miembros de las distintas metodologías propuestas para su determinación.

\subsubsection{Establecimiento del potencial ecológico en MAMM}

El documento de referencia más reciente que existe en la actualidad es el surgido a partir de la reunión de expertos celebrada en marzo de 2009 en Bruselas, el "European Workshop on Heavily Modified Water Bodies (HMWB)" (WFD CIS, 2009), con la finalidad de asesorar sobre el establecimiento de medidas y objetivos para conseguir un "buen potencial ecológico" en las MAMM.

En la actualidad, para el establecimiento del Buen Potencial Ecológico (BPE) en MAMM se reconocen dos métodos (WFD CIS, 2009):

- Basado en las condiciones de referencia biológicas. Es el establecido inicialmente por la DMA en el Documento Guía $\mathrm{n}^{\circ} 4$ sobre MAMM (WFD-CIS Guidance Document $\left.\mathrm{n}^{\circ} 4,2003\right)$, cuyos indicadores de calidad han sido descritos en el apartado 1.2.3. 
-Basado en las medidas de mitigación (o "Prague approach"). En este método surgido posteriormente, existen varias formas de describir los objetivos ecológicos: con simples descripciones cualitativas, con valores modificados de EQRs entre límites de clases, etc. Por ejemplo, para derivar un objetivo ecológico se puede:

1. Medir el EQR para cada elemento relevante de la calidad ecológica en la masa de agua.

2. Aplicar medidas de mitigación que no tengan impactos negativos significativos sobre su uso específico o sobre el medio ambiente en general.

3. Estimar la mejora en el valor del EQR resultante tras aplicar las medidas de mitigación. Los valores revisados de los EQR representan la calidad ecológica resultante de las medidas de mitigación y por tanto los EQRs del BPE.

\subsubsection{Situación actual del proceso}

El porcentaje medio de masas de agua designadas por los Estados Miembros como MAMM es aproximadamente de un $15 \%$ y los usos por los que han sido clasificadas como tales son variables: suministros hidroeléctricos, suministro y almacenamiento de agua potable, defensa contra inundaciones, navegación en aguas interiores, puertos de navegación, minería y explotaciones salineras, etc. Las explotaciones salineras se encuentran incluidas dentro del grupo de "Otras actividades de desarrollo humano sostenibles igualmente importantes" (WFD CIS, 2009).

En la actualidad, el proceso de establecimiento del potencial ecológico a nivel europeo (al contrario de lo que sucede con el establecimiento del estado ecológico en las masas de agua costeras) se encuentra muy poco avanzado y los pocos estudios llevados existentes en MAMM han sido desarrollados por países que no pertenecen al Med-GIG y están más bien relacionados con ríos y presas. Como el trabajos de Ibrekk y Pedersen (2005) en la cuenca del río Suldal (Noruega) con 113 masas de agua clasificadas como MAMM debido la producción hidroeléctrica o el de Lammens et al. (2008) en los lagos del área de IJsselmeer (Países Bajos) con altas cargas de nutrientes, proliferaciones de fitoplancton y pesca intensiva.

A nivel estatal, según el informe del Ministerio de Medio Ambiente (2009) en la mayor parte de las Comunidades Autónomas (CCAA) el proceso está poco avanzado tanto en la designación de las masas, como en la evaluación del potencial ecológico y su clasificación, que están actualmente en desarrollo y estudio. La situación actual en la materia, por tanto, es la siguiente:

- En la mayor parte de las CCAA (y aunque el nivel de desarrollo del trabajo puede ser diferente), el efecto del potencial ecológico en aguas de transición y costeras, no ha sido clasificado todavía.

- El máximo potencial ecológico (MPE) no ha sido establecido todavía aunque existen valores a nivel nacional para algunos puertos.

- No existe todavía un procedimiento establecido para evaluar el potencial ecológico. 
- En algunos casos están en desarrollo o en estudio procedimientos para evaluar las condiciones biológicas utilizando indicadores similares a los empleados en las masas de agua naturales (los mismos o adaptados). En este caso en algunas CCAA se están recopilando datos de fitoplancton (composición, abundancia, etc.) y de invertebrados bénticos (según la región y los usos), que son los elementos de calidad biológicos elegidos para las aguas de transición.

- No existen valores específicos de los indicadores en condiciones de máximo potencial ecológico (de referencia) por lo que no se ha procedido a la clasificación de las masas en función de su potencial ecológico.

- Tampoco se han podido fijar objetivos menos rigurosos ni prórrogas para estas masas de agua.

El estado tan poco avanzado del proceso de establecimiento del potencial ecológico, no solamente en nuestro país, sino también en el resto de países del Med-GIG, parece ser debido no solamente a que las masas de agua estudiadas son complejas, sino también a que se encuentran condicionadas por un amplio número de factores. A la complejidad intrínseca de las aguas de transición se añade, en el caso particular de las MAMM, que no pueden verse alteradas las funciones para las que sirve cada una de ellas. Esto unido a la gran variedad de usos que presentan las MAMM hace que sea aún más difícil establecer unos criterios comunes a seguir y llevar a cabo el proceso de intercalibración entre los Estados Miembros.

Debido a que el proceso de intercalibración no se encuentra actualmente definido, no se está todavía en condiciones de establecer el potencial ecológico de las salinas, ya que para ello el proceso de intercalibración debería de encontrarse en un estado más avanzado. Sin embargo, se pueden caracterizar estos sistemas, para posteriormente proponer una serie de criterios a tener en cuenta y una metodología adecuada para el establecimiento del potencial ecológico en las salinas de la Comunidad Valenciana. 


\subsection{OBJETIVOS}

El objetivo general de la presente tesis doctoral es el de caracterizar el comportamiento de las variables físico-químicas de los sistemas salineros de la Comunidad Valenciana y proponer una serie de criterios que permitan establecer el potencial ecológico de las salinas de la Comunidad Valenciana tal y como requiere la Directiva Marco del Agua (2000/60/CE).

Para ello se proponen unos objetivos específicos que son los siguientes:

- Estudiar la salinidad y el comportamiento de una serie de parámetros físico-químicos ( $\mathrm{pH}$, amonio, nitrito, nitrato, NID, PSR, relación NID/PSR, PT y ácido ortosilícico) en las salinas de la Comunidad Valenciana. En un circuito salinero representativo de Santa Pola (el circuito salinero de Bonmatí), en el sistema bilagunar La Mata-Torrevieja y en la salina de Calpe.

- Analizar las pautas estacionales, las pautas a lo largo del gradiente salino y las posibles zonificaciones en cada una de las salinas.

- Determinar cuáles de estas condiciones derivan del sistema de explotación salinero y cuáles pueden deberse a causas distintas.

- Realizar una comparación entre las distintas salinas para determinar si existen pautas de comportamiento similares entre ellas, o por el contrario, particularidades propias de cada salina.

- Establecer una tipología de clasificación de las aguas en función de la de salinidad.

- Proponer una metodología a seguir para un posterior establecimiento del potencial ecológico en las salinas de la Comunidad Valenciana.

La presente tesis doctoral pretende contribuir no solamente a un mayor conocimiento de los sistemas salineros en general, y de la Comunidad Valenciana en particular, desde el punto de vista de su caracterización físico-química, sino también al desarrollo y aplicación de la Directiva Marco del Agua en las masas de agua muy modificadas de la Comunidad Valenciana. 


\section{CAPÍTULO 2}

\section{ÁREA DE ESTUDIO}

La presente tesis doctoral abarca el estudio de las salinas litorales de la Comunidad Valenciana, las cuales son:

- Salina de Calpe

- $\quad$ Salina de La Mata - Torrevieja

- $\quad$ Salina de Santa Pola

En este capítulo se describe en primer lugar las principales características del litoral mediterráneo, en especial de los humedales costeros, por la singularidad e importancia de este tipo de ecosistemas en los que se engloban las salinas; el marco legal y administrativo de las salinas de la Comunidad Valenciana; las principales características del medio físico y finalmente las características particulares de cada salina.

\subsection{EL LITORAL MEDITERRÁNEO}

La zona litoral es aquella donde confluyen e interaccionan el medio marino y el medio terrestre creando una franja de territorio que, aunque en algunos casos cuenta con pocos kilómetros, presenta unas características geomorfológicas y biológicas únicas. En particular en la franja litoral mediterránea se pueden encontrar numerosos tipos de ecosistemas: humedales costeros, playas y cordones dunares, acantilados y fondos rocosos, etc. que albergan una gran cantidad de endemismos (tanto de flora como de fauna), y que son extraordinariamente frágiles ante cualquier tipo de agresión.

En el litoral mediterráneo se encuentran dos modelos básicos de costa según la naturaleza del sustrato: la costa de arenas y fondos blandos, y la costa de acantilados y fondos duros. Las salinas se sitúan sobre costas de arena con fondos blandos. Este tipo de costas se caracterizan porque son costas bajas y arenosas, donde dominan los procesos de acumulación de sedimentos. El sedimento arrastrado por las corrientes marinas es depositado a lo largo del litoral en zonas en las que los efectos de las corrientes están más atenuados. Estos sedimentos están constituidos principalmente por arenas, limos y gravas.

Las formaciones más características de estas zonas son las playas, las dunas y cordones dunares y los humedales costeros. Las playas de arena tienden a formar ensenadas y bahías. Si las bahías y los golfos son poco profundos, los sedimentos pueden cerrarlos, mediante la creación de una barra de arena sobre el fondo que emerge dando lugar a un cordón dunar.

En el interior se forma una laguna de poca profundidad comunicada con el mar mediante un canal de paso. El aporte de aguas continentales en el interior de la laguna y la progresiva colmatación con sedimentos dará lugar a una albufera (como la Albufera de Valencia). Si los aportes de agua dulce son escasos o nulos, los sedimentos de origen marino rellenarán 
la laguna, quedando ésta bajo la influencia del nivel freático marino y dando lugar a saladares como los de las Salinas de Torrevieja en Alicante (WWF/Adena, 2002).

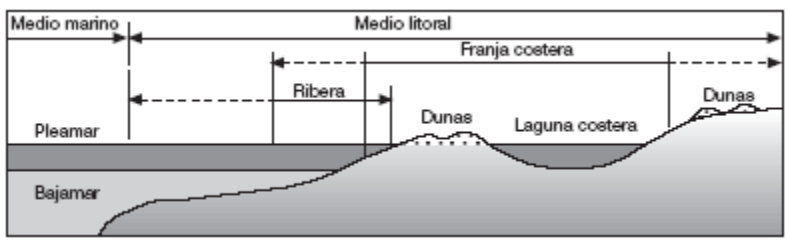

Figura 2.1: Perfil idealizado de una costa arenosa (WWF/Adena, 2002)

\subsubsection{Los humedales costeros}

Los humedales costeros son uno de los principales ecosistemas del litoral mediterráneo por su importancia ecológica. Anteriormente se propiciaba la desecación de los humedales, motivada por dos consideraciones: eran insalubres, fuente de enfermedades; y podían ser susceptibles de rendimiento económico, transformándolos en terreno de cultivo agrícola. Por ello, se fomentó su desecación y su paso a propiedad privada.

Sin embargo, en la actualidad, esta visión de los humedales ha cambiado y diversas modificaciones en la legislación estatal han propiciado una mayor protección de estos ecosistemas:

- La Ley 29/1985 de Aguas, cambió respecto a la desecación de los humedales y esto permitió el reemplazo del viejo concepto de humedal como "zona de deshecho" a un nuevo concepto de humedal mucho más acorde a la protección de estos ecosistemas (Morillo y Gómez-Campo, 2000).

- La Ley 22/1988 de Costas, derogó aquellos artículos que sobre esta materia quedaban en la Ley de Puertos, reconociendo explícitamente el gran valor biológico de estas zonas costeras. Además, intentó prevenir la destrucción y la privatización que ya existía en tantos lugares de las costas españolas y que amenazaba con expandirse aún más a lo largo de los $7.880 \mathrm{~km}$ de costas españolas. Hay que tener en cuenta que en el Estado Español un 35 \% de la población vive en la costa, siendo la población de las zonas costeras cuatro veces mayor que la de zonas interiores, con picos poblacionales importantes durante la temporada turística (Morillo y Gómez-Campo, 2000).

Estos cambios en la legislación estatal estuvieron precedidos por el Convenio Ramsar relativo a la conservación de los humedales de importancia internacional.

Según la Declaración de Ramsar (1971), humedales son: “las extensiones de marismas, pantanos turberas o superficies cubiertas de agua, sean éstas de régimen natural o artificial, permanentes o temporales, estancadas o corrientes, dulces, salobres o saladas, incluidas las extensiones de agua marina cuya profundidad en marea baja no exceda de seis metros. Además, podrán comprender zonas de bordes fluviales o de costas adyacentes al humedal, así como las islas o extensiones de agua marina de una profundidad superior a los seis metros en marea baja, cuando se encuentren dentro del humedal”.

En todo el Estado Español se encuentran incluidos en el Convenio Ramsar un total de 35 humedales que ocupan 157.857 ha, de los cuales 6 humedales se localizan en la Comunidad 
Valenciana y son los siguientes: Lagunas de la Mata y Torrevieja (3.700 ha); Marjal de Pego-Oliva (1.290 ha), Pantano de El Hondo (2.387 ha), Salinas de Santa Pola (2.496 ha), Prat de Cabanes-Torreblanca (812 ha) y la Albufera de Valencia (21.000 ha) lo que hacen un total de 31.685 ha (un 20,07 \% del total del Estado Español).

Los humedales están considerados como uno de los ecosistemas más complejos y productivos del mundo $\mathrm{y}$, además, la dependencia biológica de los humedales para determinadas especies de fauna y flora es extrema.

Seguidamente se presentan algunas de las principales funciones que desempeñan los humedales así como los principales problemas que amenazan estos ecosistemas.

- Principales funciones de los humedales:

$>$ Almacenamiento de agua dulce.

$>$ Descarga y recarga de acuíferos.

$>$ Purificación de las aguas.

$>$ Atenuación de los efectos producidos por las inundaciones.

$>$ Control de la erosión.

> Caracterización de las condiciones climáticas locales.

$>$ Estabilización del litoral.

Además los humedales ofrecen al ser humano importantes beneficios sociales y económicos en campos como la agricultura, la pesca, el abastecimiento de agua o el turismo.

- Principales problemas que amenazan los humedales costeros:

$>$ Pérdida de la integridad física de los humedales por usos agrícolas y turísticos y en menor grado industriales.

> Alteraciones geomorfológicas, principalmente por procesos erosivos y sedimentarios anómalos: colmatación de zonas húmedas, erosión deltáica, etc.

$>$ Alteraciones del funcionamiento hídrico de los humedales: déficit hídrico por exceso de uso del recurso agua, actuaciones costeras que han roto la dinámica hídrica con el mar, etc.

> Pérdida de calidad de los recursos hídricos por contaminación marina y terrestre (pesticidas, fertilizantes, vertidos industriales y urbanos).

> Alteraciones de las comunidades florísticas y faunísticas de los humedales.

$>$ Abandono y cambios en los usos tradicionales del suelo e intensificación de usos perdiendo sus valores naturales.

Por ello cualquier actividad que se emprenda en los humedales tendrá que considerar el mantenimiento de los procesos morfohidrodinámicos y ecológicos esenciales y los procesos vitales de estos ecosistemas (Viñals, 2004). 


\subsubsection{Las lagunas costeras}

Las lagunas costeras son un tipo de humedal costero y están reconocidas como hábitat prioritario para su conservación según el Anexo I de la Directiva Hábitats (Directiva 92/43/CEE).

Son extensiones de agua salada de origen marino, parcial o totalmente separadas del mar; de profundidad variable aunque suelen ser bastante someras. La salinidad del agua puede variar desde salobre a hipersalina y pueden estar conectados al mar mediante pasos, golas o bocanas que en el Mediterráneo no son de tipo mareal y casi no son funcionales en el sentido mar - tierra. El abastecimiento hídrico es variado: aguas continentales superficiales y subterráneas, aguas marinas y lluvia; mientras que las salidas de agua se realizan mediante canales hacia el mar, por evapotranspiración o por alimentación a otros acuíferos.

Entre la enorme variedad de lagunas costeras se encuentran además de las albuferas, que suelen tener comunicación directa con el mar a través de un canal, algunos tipos de marisma, en función de su componente de delta o estuario. También son consideradas como lagunas costeras las salinas, ya que su origen suele estar en una antigua laguna o encharcamiento salino.

Por lo general, la evolución natural de lagunas y albuferas es la colmatación, salvo que exista algún factor de rejuvenecimiento de la morfología (subsidencia, elevación del nivel marino, etc.).
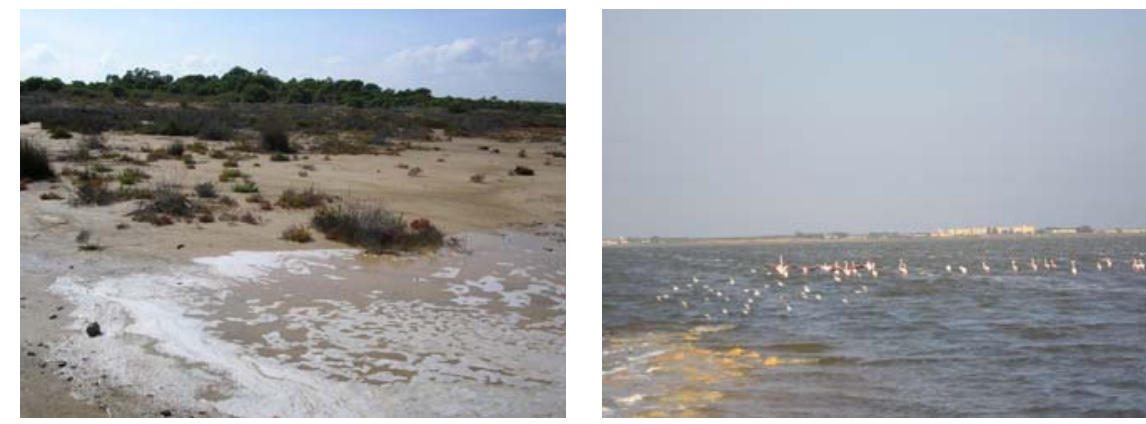

Figura 2.2: Imágenes tomadas en la laguna costera de La Mata

\subsection{MARCO LEGAL Y ADMINISTRATIVO}

\subsubsection{Marco legal}

La principal referencia legal para el litoral español recae en la Ley de Costas (Ley 22/1988) que da distinto tratamiento a los diferentes componentes del litoral y diferencia entre:

- Parte marítima. La parte marítima es de dominio público, tal y como establece la Constitución Española en su artículo 132.2: “Son bienes de dominio público español los que determine la ley y en todo caso, la zona marítimo-terrestre, las playas, el mar territorial y los recursos naturales de la zona económica y la plataforma continental”. En esta parte se distinguen 4 zonas: aguas interiores (aguas marinas situadas entre salientes y que marcan 
las líneas de base); el mar territorial hasta 12 millas náuticas de anchura desde las líneas de base, la zona contigua (entre las 12 y las 24 millas); la zona económica exclusiva (200 millas desde la línea de base); y la plataforma continental.

- Parte marítimo-terrestre. Esta parte también es de dominio público y comprende:

a) “el espacio comprendido entre la línea de bajamar escorada o máxima viva equinoccial, y el límite hasta donde alcanzan las olas en los mayores temporales conocidos o, cuando lo supere, el de la línea de pleamar máxima viva equinoccial.”

b) "las playas o zonas de depósito de materiales sueltos tales como arena, gravas y guijarros, incluyendo escarpes, bermas y dunas, tengan o no vegetación, formadas por la acción del mar o del viento marino, u otras causas naturales o artificiales.”

- Parte terrestre. La propiedad puede ser privada, excepto en los bordes de la costa (dominio público marítimo-terrestre), y en defensa de los intereses generales se establecen zonas de servidumbre: tránsito, de 6 metros de ancho, y protección, de 100 metros de ancho (en las zonas urbanas se reduce a $20 \mathrm{~m}$ ), en las que está prohibido usos como edificaciones y vías de transporte, y de influencia, de 500 metros, donde se regulan ciertos usos.

Como se puede observar, la parte terrestre queda pobremente recogida en la Ley de Costas, por lo cual se hacen necesarias otras figuras de protección legal para preservar aquellos espacios litorales de mayor interés ambiental.

Algunas de las principales figuras de protección que presentan las salinas de la Comunidad Valenciana son de carácter internacional y/o europeo mientras que otras son de carácter autonómico:

- ZONAS RAMSAR. Se declaran a partir de la Convención Internacional para la protección de los Humedales celebrada en Ramsar (Irán) en 1971. Relativa a los humedales de importancia internacional, particularmente como hábitats de aves acuáticas. En la Comunidad Valenciana hay seis humedales incluidos en el convenio RAMSAR entre los que se encuentran las Salinas de Santa Pola y las Lagunas de La Mata - Torrevieja.

- LICs (Lugares de Importancia Comunitaria). Abarca todos aquellos ecosistemas protegidos con objeto de contribuir a garantizar la biodiversidad mediante la conservación de los hábitats naturales y de la fauna y flora silvestres en un territorio tal y como establece la Directiva 92/43/CEE ó Directiva Hábitats. En cumplimiento de esta Directiva 92/43/CEE se han declarado una serie de LICs en la Comunidad Valenciana entre los que se encuentran las Salinas de Santa Pola y las Lagunas de La Mata - Torrevieja.

- ZONAS ZEPA (Zonas de Especial Protección para las Aves). Comprende los territorios más adecuados en número y en superficie para garantizar la conservación de las especies incluidas en el Anexo I de la Directiva 79/409/CEE relativa a la conservación de las aves silvestres. En la Comunidad Valenciana hay 7 zonas ZEPA ubicadas en humedales entre las que se encuentran las Salinas de Santa Pola y las Lagunas de La Mata - Torrevieja.

- PARQUES NATURALES. Esta figura de protección surge en cumplimiento de la Ley 11/1994 de Espacios Naturales Protegidos de la Comunidad Valenciana dentro de la categoría de Espacios Naturales protegidos en régimen general. En el litoral de la Comunidad Valenciana entre otros se encuentran las Salinas de Santa Pola y las Lagunas de La Mata - Torrevieja. 
- ZONAS HÚMEDAS DE LA COMUNIDAD VALENCIANA. Esta figura de protección surge en cumplimiento de la Ley 11/1994 de Espacios Naturales Protegidos de la Comunidad Valenciana dentro del apartado "Protección de otras áreas”, en el que se sitúan las zonas húmedas. En el catálogo de zonas húmedas (GVA, 2002) constan hasta 48 zonas húmedas catalogadas. Dentro de estas se establecen diferentes grupos: albuferas y marjales litorales, ambientes fluviales y litorales asociados, manantiales, lagunas y humedales de interior, saladares litorales y embalses de fluctuación escasa. Dentro del grupo de saladares litorales se encuentran todas las salinas de la Comunidad Valenciana: la Laguna de Calpe, el Parque Natural de las Salinas de Santa Pola y el Parque Natural de las Lagunas de La Mata - Torrevieja.

\subsubsection{Marco administrativo}

El litoral es un espacio complejo donde confluyen una serie de competencias que se reparten entre tres Administraciones: el Estado, las Comunidades Autónomas (CC.AA.) y los Ayuntamientos.

El Estado tiene la titularidad del dominio público marítimo-terrestre y su protección que comprende: la defensa de su integridad, el control de los usos de interés general a que está destinado, la preservación de sus características y elementos naturales y la prevención de las perjudiciales consecuencias de las obras e instalaciones. Las servidumbres de protección y tránsito de acceso al mar en cuanto sirven para proteger la integridad del dominio público marítimo-terrestre. Por ello, el Estado tiene la mayor parte de las competencias en tutela y gestión del litoral, estableciendo únicamente menciones genéricas a las Comunidades Autónomas.

Las Comunidades Autónomas tienen competencias en materia de ordenación territorial y del litoral, puertos, urbanismo, vertidos al mar y demás atribuidas en sus Estatutos.

Las competencias de los Ayuntamientos adquieren competencias en deslindes, solicitudes para ocupaciones del dominio público marítimo - terrestre y servicios de limpieza y salubridad.

En este marco, el Estatuto de Autonomía de la Comunidad Valenciana, atribuye la competencia exclusiva a la Generalitat en materia de "Ordenación del territorio y del litoral, urbanismo y vivienda”. El President de la Generalitat, asignó a la Consellería de Medio Ambiente, Agua, Urbanismo y Vivienda las competencias en materia de medio ambiente, y en particular, "el control de la calidad de las aguas y el ejercicio de las competencias autonómicas en materia de vertidos y de protección y control del litoral”. En particular, según el artículo 16 del mismo Decreto, es al Área de Calidad Ambiental a la que corresponde "el control de la calidad de las aguas y del litoral”.

Es, por tanto, la Generalitat Valenciana la encargada de velar por la aplicación de la Directiva Marco del Agua (Directiva 2000/60/CE), así como por la consecución de los objetivos que ésta plantea para las aguas costeras y de transición, incluidas las salinas, en el territorio de la Comunidad Valenciana. 


\subsection{PRINCIPALES CARACTERÍSTICAS DEL MEDIO FÍSICO}

\subsubsection{Climatología}

El clima de la Comunidad Valenciana es de tipo mediterráneo. Particularmente, las salinas estudiadas se encuentran localizadas, desde el punto de vista climatológico, en el sector litoral meridional de Orihuela. Este sector climático se sitúa al sur de las cordilleras Béticas (norte de la provincia de Alicante) que actúan como divisoria climática y al este del sector climático más continental de Villena. Se trata del sector más árido de la Comunidad Valenciana. El período seco centrado en el verano, se extiende a algunos meses de primavera y otoño, alcanzando una gran duración (5 - 6 meses) e intensidad. Las lluvias medias anuales son escasas, a veces inferiores a $300 \mathrm{~mm}$ y los máximos otoñales y primaverales son poco acusados. Las temperaturas medias anuales son elevadas (en torno a los $18^{\circ} \mathrm{C}$ ) a causa, sobre todo, de las benignas temperaturas invernales (Armengot y PérezCuevas, 1989).

\subsubsection{Geología}

La Comunidad Valenciana participa de tres grandes cordilleras: Costero-Catalana, Ibérica y Bética. La zona que nos ocupa se incluye dentro del área estructural Bética, que abarca toda la provincia de Alicante y el sur de la de Valencia. Dentro del sistema Bético se distinguen las zonas Prebética, Subbética y Bética (Sanchis et al., 1989).

En la zona Prebética dominan los pliegues de dirección noreste-suroeste con un sistema de fallas paralelas y otros dos de dirección NO-SO y NNE-SSO. En esta zona, concretamente en la unidad geológica Prebética meridional se encuentra enclavada la salina de Calpe. Este sector reaccionó de manera diversa frente a los empujes de la orogenia alpina, pero en la zona de estudio se produjo un ascenso diapírico (Serra de Oltà) que contribuyó al hundimiento de los alrededores. La salina de Calpe se encuentra ubicada en el sinclinal de Benissa - Calpe donde se aprecia una tectónica flexible.

Las salinas de Santa Pola y La Mata - Torrevieja se localizan en la unidad geológica de la Vega del Segura. Esta área constituye una verdadera fosa tectónica que ha sido rellenada por materiales neógenos, correspondientes al Mioceno, Plioceno y Cuaternario. Estructuralmente, la zona corresponde a una fosa tectónica que está sufriendo en la actualidad un reajuste. Rodríguez - Estrella (1982) apunta la existencia de una neotectónica en esta zona, basándose en datos de hidroquímica y geofísica. Esto se ve apoyado por la existencia de las lagunas salinas próximas a la costa que, a diferencia de otras lagunas costeras o albuferas, no se han colmatado a pesar de ser pequeñas cuencas endorréicas, por lo que hay que pensar en la existencia de una subsidencia simultánea a la sedimentación. El hecho de que pequeños sismos hayan acaecido en el fondo de las lagunas, parece avalar estas afirmaciones. Además el eje mayor de estas pequeñas cuencas alargadas cuaternarias tiene una dirección NO-SE, en franca contraposición a la directriz de las Béticas (Sanchis et al., 1989).

\subsubsection{Edafología}

Las salinas se localizan en llanuras litorales del Cuaternario. Las rocas sedimentadas durante este período ocupan considerables extensiones en toda la Comunidad Valenciana, especialmente en las llanuras costeras donde se ha producido una deposición de los 
materiales erosionados en las montañas circundantes. La génesis de los depósitos es muy variada, pudiendo ser tanto de origen marino como continental o mixto.

La salina de Calpe está constituida por margas miocenas burdigalienses con escasas intercalaciones arenosas. Sobre ellas y recubriéndolas en las zonas más deprimidas, se encuentran los materiales cuaternarios, principalmente de origen continental que tapizan las laderas y fondos de los torrentes, así como la planicie lagunar (Box, 1987). En la acumulación de materiales cuaternarios también han influido de forma importante el suministro eólico y marino. El origen de la salina de Calpe se debe a una laguna residual tombólica que se encuentra prácticamente colmatada.

Las salinas de Santa Pola antiguamente se situaban en una zona constituida por un gran golfo (Sinus ilicitanus) que ocupaba toda la llanura de Elche. Se trata de una gran depresión tectónica, subsidente desde el Mioceno. La progresiva colmatación de este gran golfo se fue produciendo debido a los aportes de los ríos Segura y Vinalopó, así como de los múltiples barrancos que descienden desde las alineaciones periféricas (Agencia de Medio Ambiente, 1990).

Las lagunas de La Mata - Torrevieja son unas lagunas exorréicas, de origen sedimentario marino y que estuvieron directamente comunicadas con el mar de forma natural hasta el Cuaternario. Ambas quedan enmarcadas en el interior de la cuenca neo-cuaternaria conformada por los relieves correspondientes al grupo de fallas del Baix Segura, al norte, y de San Miguel de Salinas al sur (Agencia de Medio Ambiente, 1990). 


\subsection{LAS SALINAS DE LA COMUNIDAD VALENCIANA}

Las salinas de la Comunidad Valenciana se localizan en la provincia de Alicante, tal y como se muestra en la figura 2.3:

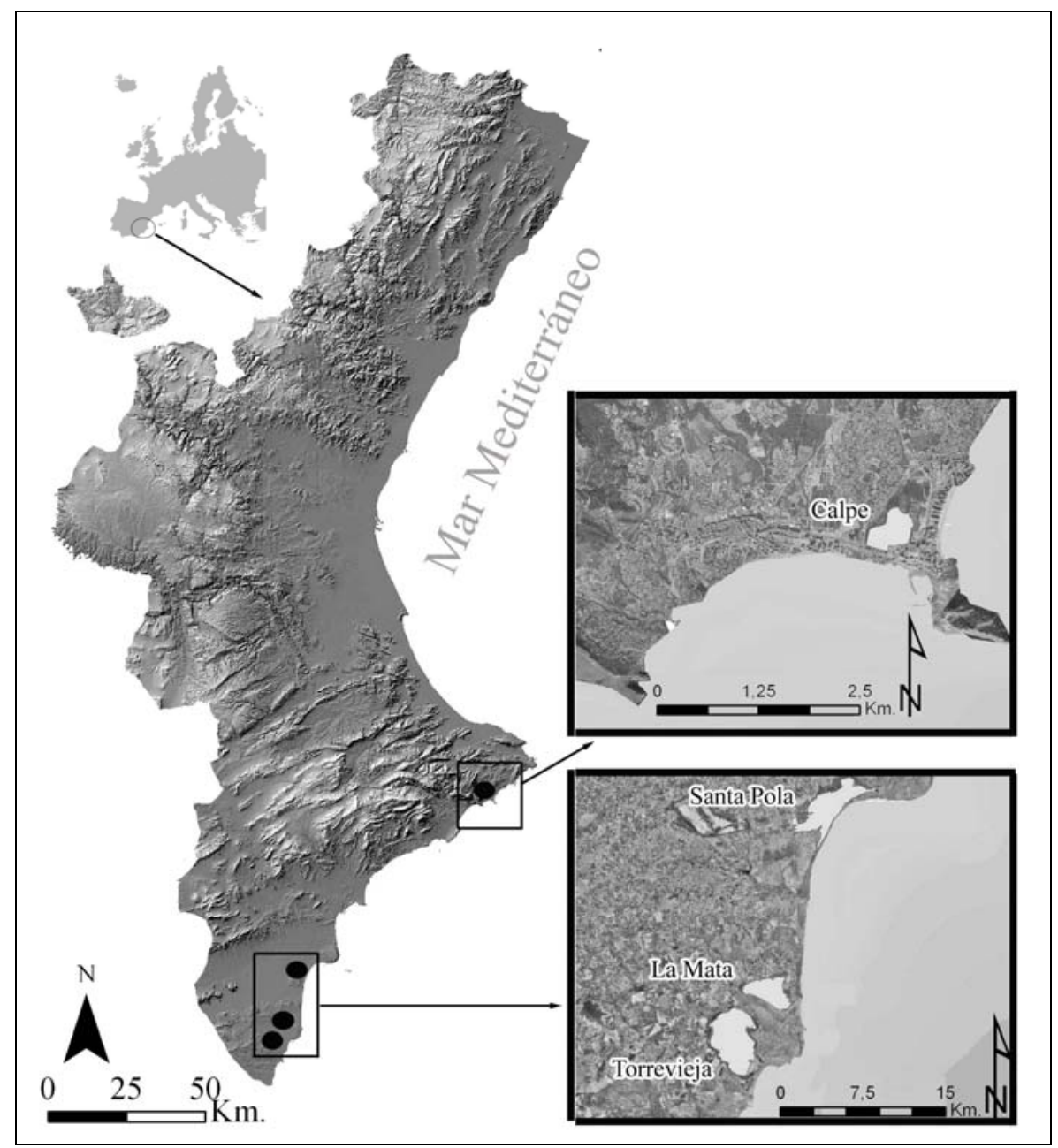

Figura 2.3: Mapa de localización de las salinas de la Comunidad Valenciana

A continuación se explican las características particulares de cada salina en cuanto a sus figuras de protección legal, modo de explotación (si lo hay) y funcionamiento de cada sistema salinero. 


\subsubsection{Salina de Calpe}

La salina de Calpe es las más pequeña de las tres salinas estudiadas con una extensión de 40,79 ha, y se localiza en el término municipal de Calpe (Alicante). Está incluida en el Catálogo de Zonas Húmedas de la Comunidad Valenciana. El uso del suelo está clasificado como suelo no urbanizable protegido.

Este sistema salino no se encuentra en explotación en la actualidad. Antiguamente, tuvo un considerable desarrollo en la Edad Media y posteriormente fue abandonado tal y como ya mencionó Cavanilles en 1795 en su obra "Observaciones sobre la historia natural, geografía, agricultura, población y frutos del Reyno de Valencia” (Lacarra et al., 1996): “...En la llanura contigua á las raices de Hifác habia unas salinas que se abandonáron estos últimos años por creerse causa de calenturas intermitentes que solian padecerse. Lo cierto es que en años lluviosos se juntan muchas aguas en el recinto llamado Saladár, y no hallando salida forman pantanos, y se corrompen en verano...”.

Tras un largo período de inactividad en el que la salina fue un foco importante de paludismo por el estancamiento de sus aguas (Miró, 1998), en el año 1918, se reanudó la explotación salinera cuya actividad se mantuvo hasta mediados de los años ochenta, en que fueron definitivamente abandonadas. En la actualidad, toda la superficie que ocupa la salina y sus alrededores están dentro de la partida de El Saladar y son de titularidad privada (Martí, 2000).

La cuenca vertiente es muy reducida (unos $4,3 \mathrm{~km}^{2}$ ) y el agua recogida en esta cuenca se canaliza principalmente en dos barrancos, el llamado barranco de Ortega y el barranco de Carrió, que al entrar en el llano cuaternario, se unen y dan lugar al barranco de la Merced, el cual termina en un canal que rodea las salinas. Este canal se realizó durante el periodo de explotación de las salinas para evitar que el agua dulce se internara en ella (Box, 1987), aunque en la actualidad están interconectados en varios puntos.

El proceso de explotación que se llevaba a cabo era el siguiente: el agua de mar se introducía en las salinas a través de un canal subterráneo desde la playa dels Banys de la Reina mediante una motobomba. Por gravedad llegaba a la laguna donde se distribuía en una serie de compartimentos separados por diques de tierra llamados calentadores y cuya finalidad era la de conseguir la graduación suficiente de las salmueras mediante la progresiva evaporación de las aguas. Después, las salmueras se trasvasaban a cuatro depósitos concentradores en los que tenía lugar la precipitación del cloruro sódico y la posterior cristalización.

Actualmente, la salina está en desuso pero sigue siendo alimentada de modo artificial por el canal anteriormente mencionado (el que une la salina con el mar por la playa dels Banys de la Reina) que continúa permitiendo la entrada del agua de mar por bombeo en el sistema. Esta entrada de agua es muy importante porque, junto con los aportes proporcionados por las precipitaciones, permiten el mantenimiento de la lámina de agua durante todo el año y, por tanto, el mantenimiento de la flora y la fauna asociadas a la laguna. Durante los meses de verano es vital el bombeo de agua desde el mar pues de no hacerse la laguna se desecaría de forma natural por evaporación (Martí, 2000).

La entrada de agua de mar se produce en verano prácticamente a diario, llegando a funcionar incluso durante 18 horas al día durante los meses más secos, a un caudal de unos 25 l/s. El período aproximado de funcionamiento es de mayo a septiembre (varía según las precipitaciones). 


\subsubsection{Salina de La Mata - Torrevieja}

Está incluida dentro del Parque Natural de las Lagunas de La Mata - Torrevieja, que presenta una extensión de 3.700 ha en la comarca de la Vega Baja del Segura, en los términos municipales de Torrevieja, Guardamar del Segura y Los Montesinos (Alicante). La salina de la Mata - Torrevieja cuenta con las siguientes figuras de protección legal: Parque Natural, zona ZEPA, RAMSAR y LIC; y presenta valores bióticos y de recursos económicos relevantes según el Catálogo de Zonas Húmedas de la Comunidad Valenciana.

La laguna de La Mata (700 ha) está separada de la laguna de Torrevieja (1.400 ha) por el anticlinal del Chaparral que actúa de divisoria de aguas entre ambas. Aunque no se observan cauces de agua permanentes que drenen en estas lagunas, en ellas desembocan las ramblas y barrancos de los relieves periféricos. A esta cuenca, y principalmente a la Laguna de Torrevieja, debido a la proximidad de los relieves de la sierra de San Miguel de Salinas, vierten un conjunto de ramblas y barrancos de régimen intermitente. Estos barrancos son de naturaleza margosa, lo que da lugar a un importante transporte de sedimentos que al llegar a la laguna de Torrevieja originan formaciones deltáicas que cubren amplias zonas (Folch, 1992).

El sistema de explotación de esta salina no es nada convencional. Se trata de un sistema de explotación anual donde la laguna de La Mata actúa como calentador mientras que la precipitación y la extracción de la sal se efectúa en la laguna de Torrevieja. La Mata está conectada con el mar por un canal que permite la entrada de agua de mar en el sistema para la preconcentración de la sal. Ambas lagunas están comunicadas entre sí por el Canal de Las Salinas. Dicho canal funciona según las necesidades de la industria salinera y permite en época de estiaje, mediante el trasvase de aguas desde La Mata a Torrevieja, mantener los niveles adecuados de esta última laguna. Por otra parte, cuando entran cantidades importantes de agua procedente de escorrentías, la laguna de Torrevieja es vaciada dirigiendo estas aguas más dulces hacia la laguna de La Mata. Además, existe un canal conocido como "El Acequión” que une la salina de Torrevieja con el mar y es utilizado para tomar agua del mar aunque únicamente para el lavado de la sal.

La explotación salinera se mantiene por un lado por la entrada de agua de mar a La Mata donde la sal se concentra debido a la elevada evapotranspiración, ya que La Mata actúa como calentador. Por otra parte, y para aumentar la producción salinera, a esta entrada se une la entrada artificial de aguas de salmuera desde el domo salino de El Pinoso, que se introduce con el fin de conseguir un fuerte incremento de la concentración salina acelerando así el proceso de cristalización. Las salmueras son transportadas por un salmueroducto de casi medio metro de diámetro durante $52 \mathrm{~km}$ de distancia.

En este yacimiento de El Pinoso se realiza la extracción de sal gema que se disuelve para obtener salmueras. Las salmueras se obtienen por disolución del depósito salino, se proyecta un chorro de agua a presión contra la sal gema para ir disolviéndola, obteniendo una salmuera con una altísima concentración salina, muy por encima de la del agua de mar y próxima al punto de cristalización de la sal común. La capacidad de evaporación de la laguna de Torrevieja se emplea más bien en la cristalización de la salmuera y no en la concentración del agua de mar. La introducción de las salmueras de El Pinoso en el sistema de explotación aporta grandes beneficios económicos ya que reduce la dependencia de la climatología y permite duplicar la producción. 
Las salinas son propiedad del Estado con un régimen de arrendamiento conjunto con la "Nueva Compañía Arrendataria de las Salinas de Torrevieja, S.A.” que comprende la explotación conjunta de las Salinas de Torrevieja y La Mata y los yacimientos de sal gema de El Pinoso (R.D. 1060/2007). Estas salinas constituyen la primera industria salinera del estado español en cuanto a volumen de producción (entre unas 700.000 y 750.000 toneladas anuales).

Se trata de un espacio natural donde se compagina la actividad económica con la conservación del medio. Además, es importante destacar que tanto la propiedad estatal como el hecho de que las lagunas estén dedicadas a la explotación salinera han sido dos factores que han permitido su preservación, evitando otros usos que habrían comportado probablemente su degradación.
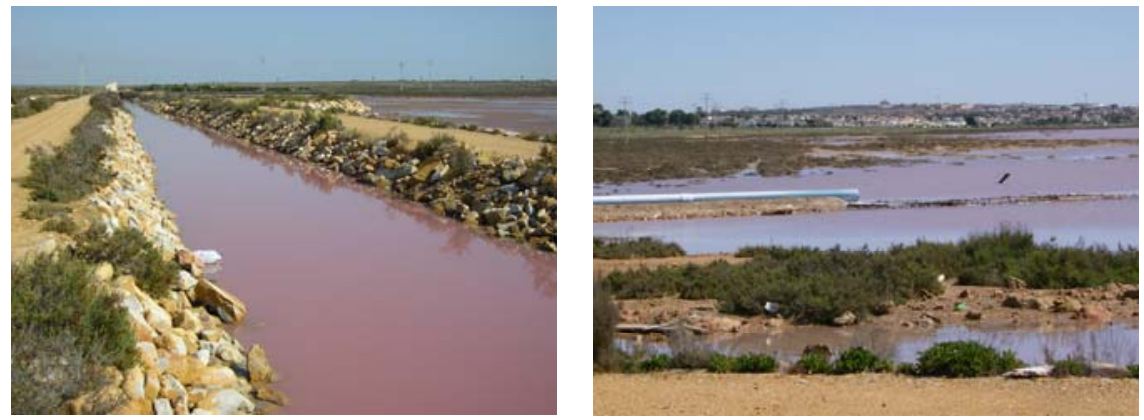

Figura 2.4: a) Imagen de la salina de Torrevieja donde se aprecia la coloración rosada de sus aguas y b) Salida de la tubería con salmueras procedentes de El Pinoso

\subsubsection{Salina de Santa Pola}

Las salinas de Santa Pola se encuentran dentro del Parque Natural de las Salinas de Santa Pola que abarca una extensión de 2.496,74 ha de las cuales 1.100 ha han sido transformadas en salinas, y se localiza en los términos municipales de Santa Pola y Elche. Al igual que en las salinas de La Mata - Torrevieja, cuenta con las siguientes figuras de protección legal: Parque Natural, zona ZEPA, RAMSAR y LIC.

La zona de explotación salinera se encuentra integrada por un conjunto de cuatro circuitos artificiales: dos en la salina de Bras del Port y otros dos en la salina de Bonmatí. Estas salinas fueron creadas artificialmente a finales del S. XIX - principios del S. XX, con una adaptación previa del terreno, formándose amplias balsas de escasa profundidad y gran superficie, con fondos elevados sobre el nivel freático para evitar la contaminación de sus aguas con las aguas subterráneas.

Se trata de un sistema de explotación salinera convencional. La dinámica de las salinas consiste en hacer circular el agua marina por un circuito de balsas para obtener una progresiva concentración en sales como consecuencia de la evaporación. La precipitación se consigue de tal modo que las salmueras vayan precipitando sus sales en solución hasta llegar al punto en que precipite la sal desprovista de impurezas. Estas salinas también presentan una gran importancia a nivel nacional.

El gran interés biológico de las salinas mediterráneas estriba en que la circulación del agua no se detiene durante el invierno. Las balsas, que ocupan una extensa superficie, suelen ser 
poco profundas (menos de 1 metro de profundidad) y permanecen inundadas durante todo el año por lo que el ecosistema de extraordinaria importancia, se mantiene. Únicamente se produce la desecación de los cristalizadores en el momento de la cosecha de la sal.

El espacio es un ejemplo de compaginación entre actividad económica y conservación del medio natural puesto que la explotación salinera garantiza la entrada de agua por bombeo en el sistema y de este modo se mantiene el hábitat de numerosas especies que habitan de forma temporal o permanente en la laguna.

Dentro de la salina de Santa Pola se va a estudiar de manera representativa uno de los circuitos de explotación salinera de Bonmatí.
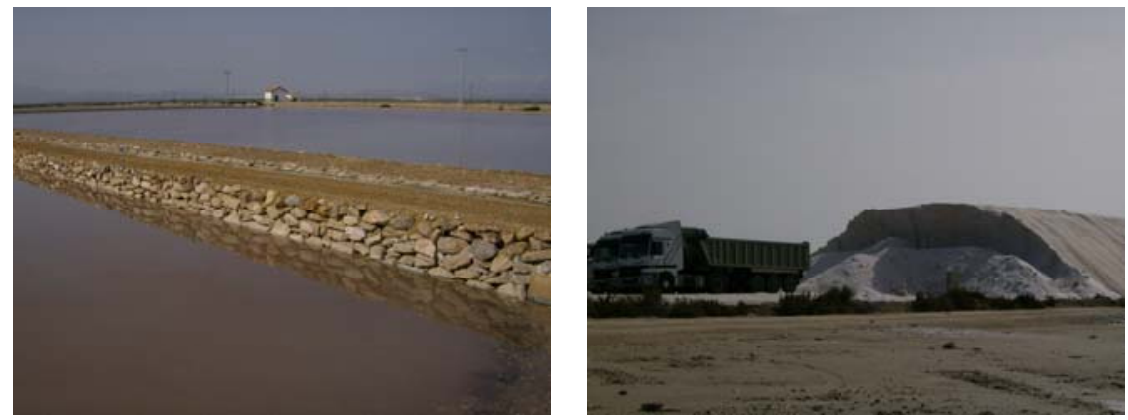

Figura 2.5: a) Estanques cristalizadores del circuito salinero de Bonmatí en Santa Pola y b) Pilas de sal

\subsubsection{Características del circuito salinero de Bonmatí}

La salina de Bonmatí es la explotación salinera más antigua dentro de las salinas de Santa Pola y anteriormente era conocida como Salinas de Pinet. En la actualidad, la mayor parte del circuito es de propiedad privada a excepción de una pequeña parte, el "Circuito A" situado en el extremo sur del circuito de Bonmatí según la figura 2.6, que es de propiedad pública (Conselleria de Medio Ambiente de la Generalitat Valenciana).

El circuito salinero consiste en una serie de balsas por las que se hace circular el agua de mar para obtener una progresiva concentración en sales como consecuencia de la evaporación. Según el grado de concentración de las sales se distinguen los calentadores, los concentradores y los cristalizadores. La circulación del agua se asegura bombeando el agua de mar y forzándola a seguir el recorrido previsto. La circulación entre balsas se realiza por gravedad, al tener éstas niveles progresivamente inferiores. El agua de mar es transferida de un estanque a otro conforme el proceso de evaporación avanza, de tal modo que la precipitación y la recogida de la sal solamente tiene lugar en unos pocos estanques (los cristalizadores) al final del verano (ver figura 2.6). 


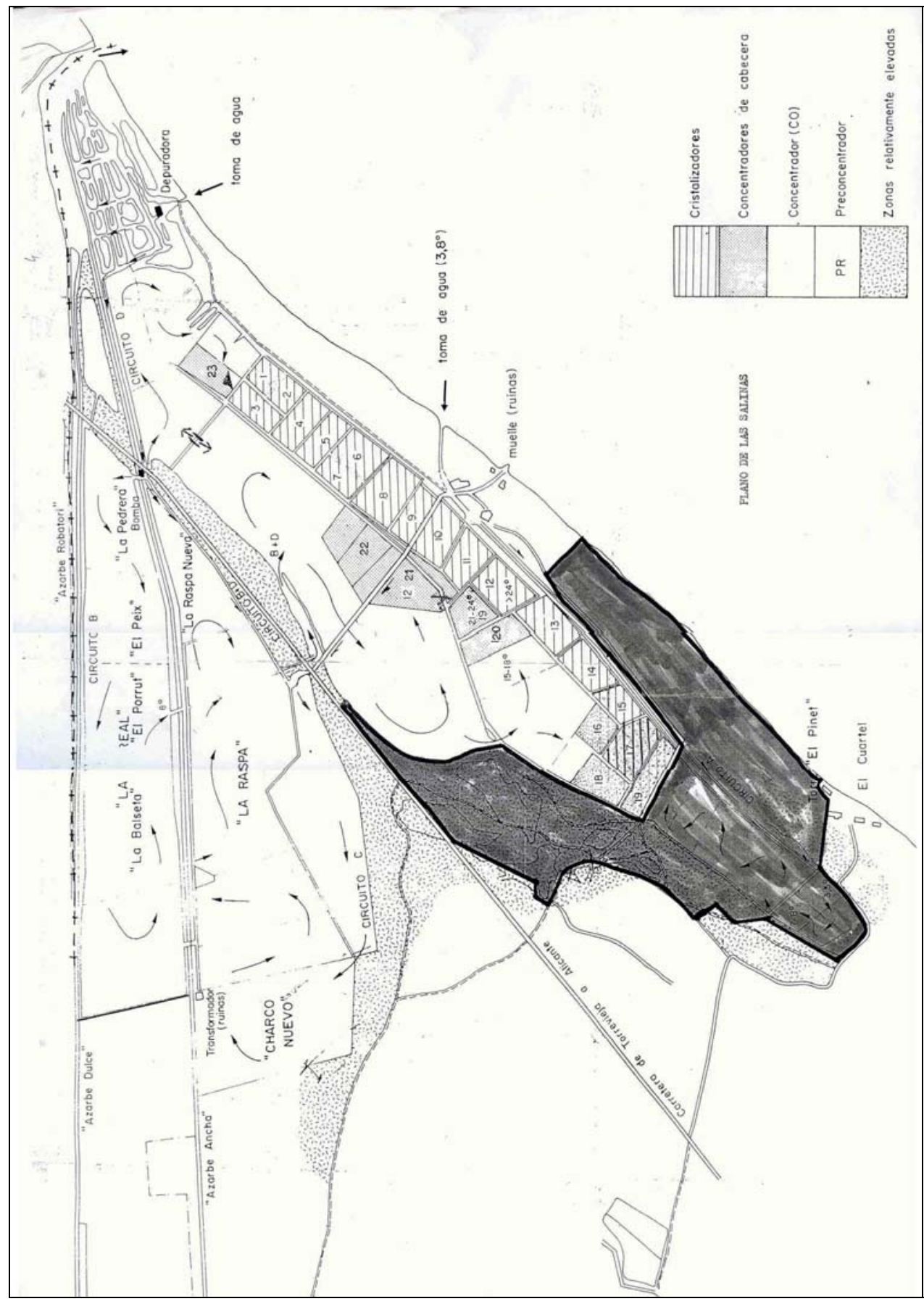

Figura 2.6: Flujo de circulación del agua en el circuito salinero de Bonmatí 


\subsubsection{Circulación de las aguas en el circuito de Bonmatí}

Existen dos entradas de agua de mar en el circuito salinero de Bonmatí, la situada al norte en las proximidades de la depuradora (2), y la entrada principal situada en las proximidades del muelle en ruinas en la zona intermedia del circuito (1) (ver figura 2.6).

\section{1) Entrada de agua próxima al muelle en ruinas.}

El agua de mar entra por bombeo en el circuito donde toma dos caminos:

1.a.) Una parte del agua de mar se dirige hacia el extremo sur del circuito hacia las balsas de propiedad pública que aparecen sombreadas en el mapa, el denominado "Circuito A". Anteriormente estas balsas estaban incomunicadas con el resto del circuito pero en la actualidad el agua puede circular de esta zona al concentrador 19 sur donde se junta con las aguas procedentes del norte tal y como a continuación se explica.

1.b.) Otra parte del agua de mar de esta entrada es dirigida hacia el "Circuito C", desde donde se divide y parte del agua va al "Charco Nuevo" y otra parte hacia "La Raspa”. De estas balsas se conduce a la parte situada más al norte del circuito, el "Circuito B" donde se encuentra "La Real” y va pasando de oeste a este dirigiéndose a "La Balseta”, "El Porrut” y "El Peix" y "La Pedrera". De este conjunto de balsas se conduce a "La Raspa" desde donde es introducida en el circuito "B+D”. Una vez en este circuito el agua se bifurca, una parte se dirige al concentrador 22 y otra parte se dirige al sur a los concentradores de cabecera 21, 20, 19 norte, 16, 18 y 19 sur. Es en esta balsa 19 sur donde se junta con el agua procedente del "circuito A".

Una vez el agua ha llegado a los concentradores de cabecera, ésta es dirigida hacia los cristalizadores: 17, 15, 14, 13, 12, 11, 10 de la parte sur del circuito ó 9, 8, 7, 6, 5, 4, 3, 2 y 1 , de la parte norte del circuito. Las estaciones de muestreo están situadas en la parte sur del circuito, siendo esta zona la que se estudiará de forma representativa con mayor grado de detalle.

Hay que mencionar que la dirección que toma el agua desde los concentradores a los cristalizadores no está previamente establecida y varía según las necesidades de la explotación salinera, ya que el agua de mar es transferida de un estanque a otro tal y como el proceso de evaporación avanza. El agua de los concentradores no tiene por qué dirigirse a los cristalizadores más próximos sino que puede dirigirse al cristalizador donde sea más necesaria la entrada de agua. Por ejemplo, del concentrador 22 se puede dirigir el agua a la balsa de cristalización 12 y del concentrador 20 se puede dirigir el agua a la balsa 14 ó 5 aunque físicamente no sean las más próximas.

\section{2) Entrada de agua situada más al norte del circuito y próxima a la depuradora.}

Por esta entrada no entra agua de mar habitualmente ya que normalmente se encuentra obstruida por las algas. Sin embargo es utilizada una vez al año durante unos 10 - 20 días, en condiciones de mar de fondo, cuando la entrada queda libre. En este momento se aprovecha y es dirigida hacia el "Circuito D" desde donde es elevada mediante una bomba hacia "La Raspa Nueva”. Ahí se junta con el agua procedente de la entrada 1.b. y continúa por el recorrido mencionado anteriormente para esta zona ("La Raspa”, "Charco Nuevo" y “La Real”, etc.). 



\section{CAPÍTULO 3}

\section{MATERIAL Y MÉTODOS}

\subsection{MUESTREOS}

\subsubsection{Campañas de muestreo}

Se han llevado a cabo una serie de campañas de muestreo en las tres salinas de la Comunidad Valenciana estudiadas:

\begin{tabular}{|c|c|c|c|c|}
\hline Muestreo & Campaña & S. Calpe & S. Mata-Torrevieja & S. Sta. Pola \\
\hline Muestreo 0 & Octubre 2007 & $28 / 09 / 07$ & $15 / 10 / 07$ & $23 / 10 / 07$ \\
\hline Muestreo 1 & Febrero 2008 & $13 / 02 / 08$ & $13 / 02 / 08$ & $25 / 02 / 08$ \\
\hline Muestreo 2 & Abril 2008 & $15 / 04 / 08$ & $17 / 04 / 08$ & $17 / 04 / 08$ \\
\hline Muestreo 3 & Julio 2008 & $23 / 07 / 08$ & $23 / 07 / 08$ & $22 / 07 / 08$ \\
\hline Muestreo 4 & Octubre 2008 & $21 / 10 / 08$ & $21 / 10 / 08$ & $22 / 10 / 08$ \\
\hline Muestreo 5 & Febrero 2009 & $19 / 02 / 09$ & $17 / 02 / 09$ & $17 / 02 / 09$ \\
\hline Muestreo 6 & Mayo 2009 & $12 / 05 / 09$ & $12 / 05 / 09$ & $20 / 05 / 09$ \\
\hline Muestreo 7 & Julio 2009 & $8 / 07 / 09$ & $8 / 07 / 09$ & $7 / 07 / 09$ \\
\hline
\end{tabular}

Tabla 3.1: Fechas de los muestreos efectuados en las salinas

Hay que mencionar que la campaña efectuada en octubre del 2007 se trata de un muestreo preliminar cuya finalidad era la de permitir la puesta apunto de las técnicas analíticas con muestras "reales", ya que la elevada salinidad de algunas de las muestras dificultaba en gran medida las mediciones. Por ello, de esta campaña no se considerarán posteriormente los resultados.

Como se ha comentado en la introducción, la DMA establece una periodicidad mínima anual de seguimiento para aguas de transición de 3 meses para los parámetros físicoquímicos. Tal y como se puede observar en la tabla de muestreos (tabla 3.1) las muestras se tomaron estacionalmente con una periodicidad de unos 3 meses, con un total de 4 muestreos durante el 2008 y 3 muestreos durante el 2009, por lo que se cumple la periodicidad de muestreos establecida por la DMA. 


\subsubsection{Descripción de los muestreos}

En cada una de las salinas se han establecido una serie de estaciones de muestreo para la toma de muestras de agua.

\section{- MUESTREOS EN LA SALINA DE CALPE}

Se han tomado muestras en 4 estaciones situadas en diferentes zonas de la laguna, cuya localización se presenta en la tabla 3.2 y en la figura 3.1:

\begin{tabular}{|c|c|c|c||}
\hline \multicolumn{4}{|c|}{ SALINA DE CALPE } \\
\hline Estación & Nomenclatura & UTM X & UTM Y \\
\hline 1 & SCT002 & 766977 & 4281902 \\
\hline 2 & SCT005 & 766814 & 4281876 \\
\hline 3 & SCT008 & 766705 & 4281896 \\
\hline 4 & SCT00J & 767039 & 4282186 \\
\hline
\end{tabular}

Tabla 3.2: Coordenadas de las estaciones de muestreo de la salina de Calpe

Las estaciones SCT005 y SCT008 se encuentran próximas a la entrada por bombeos de agua marina procedente de la playa dels Banys de la Reina, mientras que las estaciones SCT002 y SCT00J se localizan más hacia el interior de la salina, especialmente SCT00J, tal y como se puede observar en la figura 3.1. 


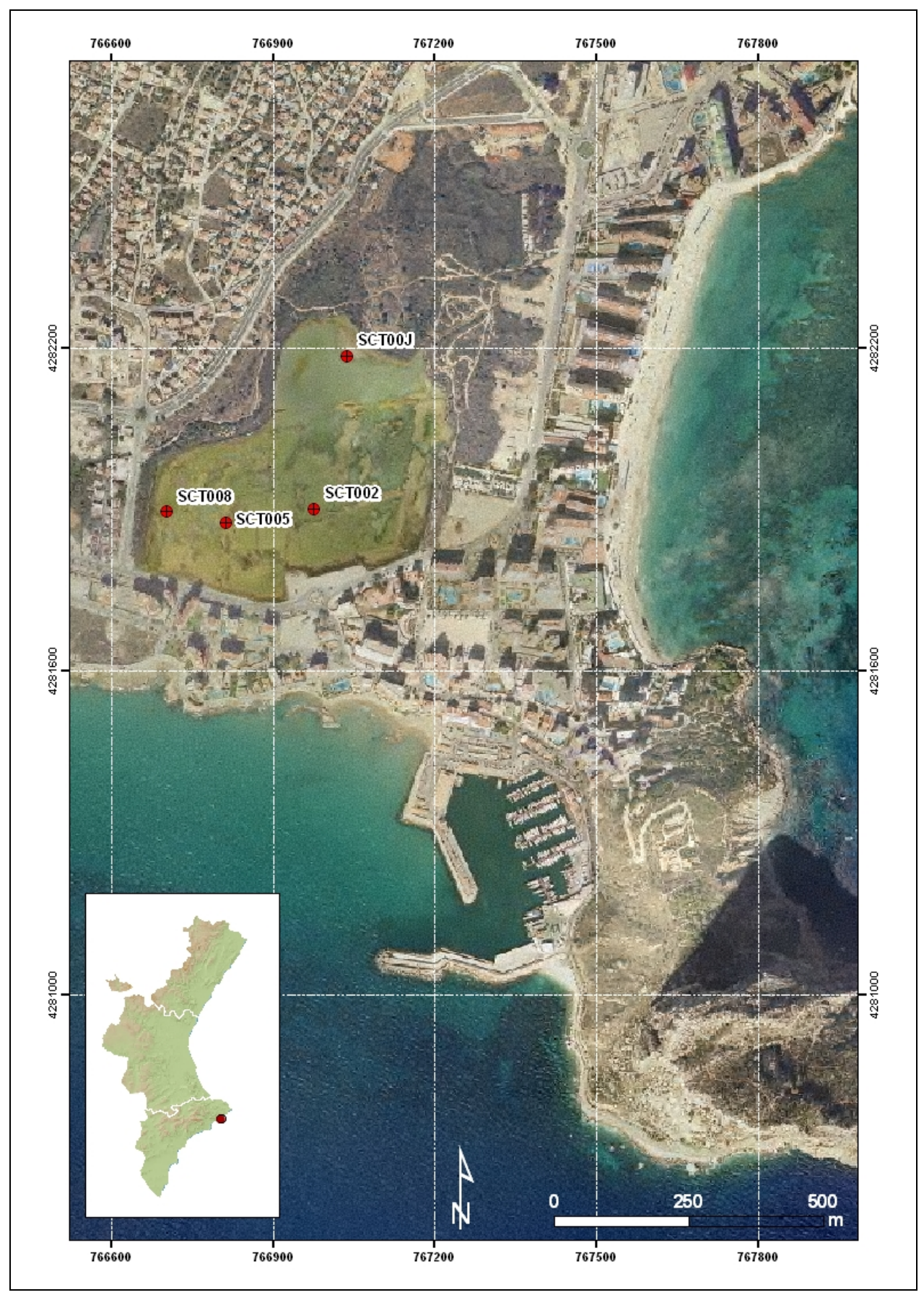

Figura 3.1: Ubicación de las estaciones de muestreo en la salina de Calpe 


\section{- MUESTREOS EN LA SALINA DE LA MATA-TORREVIEJA}

Se han tomado muestras en 6 estaciones en la laguna de La Mata y en 2 estaciones de la laguna de Torrevieja, así como 1 muestra a la salida del salmueroducto de El Pinoso. La localización de las estaciones de muestreo se puede observar en la tabla 3.3 y en la figura 3.2:

\begin{tabular}{|c|c|c|c|}
\hline \multicolumn{5}{|c|}{ SALINA DE LA MATA - TORREVIEJA } \\
\hline Estación & Nomenclatura & UTM X & UTM Y \\
\hline 1 & STM002 & 704112 & 4210842 \\
\hline 2 & STM005 & 702423 & 4213438 \\
\hline 3 & STM008 & 701086 & 4212438 \\
\hline 4 & STM010 & 702715 & 4211692 \\
\hline 5 & STM011 & 704448 & 4213322 \\
\hline 6 & STM012 & 703517 & 4213563 \\
\hline 7 & STT012 & 699330 & 4208517 \\
\hline 8 & STT013 & 699398 & 4208511 \\
\hline 9 & STT014 & 700105 & 4211036 \\
\hline \hline
\end{tabular}

Tabla 3.3: Coordenadas de las estaciones de muestreo de la salina de La Mata- Torrevieja

Las estaciones de La Mata se encuentran distribuidas en diferentes zonas de la laguna, siendo STM002 la estación más próxima al canal que permite la entrada de agua de mar a la laguna y STM008 la más próxima al canal que comunica La Mata con Torrevieja.

Las estaciones de Torrevieja STT012 y STT013 se encuentran muy próximas entre sí en el centro de la laguna, si bien se encuentran separadas por una mota quedando STT013 del lado donde vierten las aguas de El Pinoso y STT012 del lado opuesto. Por otra parte, STT014 representa las aguas a la salida de la tubería con salmueras procedentes del lavado de sal gema de El Pinoso. 


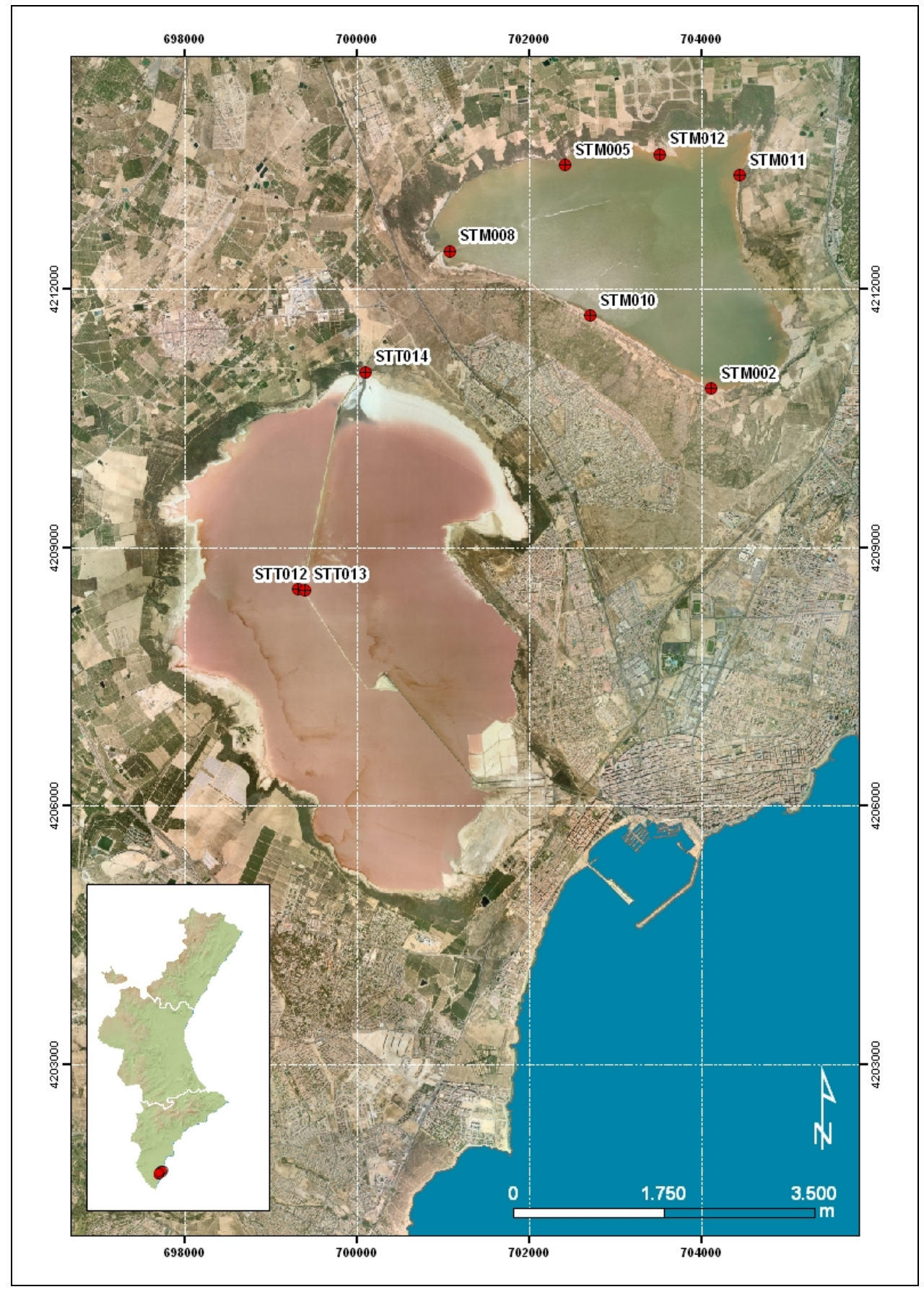

Figura 3.2: Ubicación de las estaciones de muestreo en la salina de La Mata - Torrevieja 


\section{- MUESTREOS EN EL CIRCUITO SALINERO DE BONMATÍ (SANTA POLA)}

Durante el año 2008 se tomaron muestras en 26 estaciones que comprenden buena parte de las balsas que componen el circuito de Bonmatí y cuya localización se presenta en la tabla 3.4 y en las figuras 3.3 (general) y 3.4 (detalle):

\begin{tabular}{||c|c|c|c|c|c|c|c||}
\hline \multicolumn{7}{|c|}{ SALINA DE SANTA POLA- CIRCUITO SALINERO DE BONMATÍ. 2008. } \\
\hline Estación & Nomenclatura & UTM X & UTM Y & Estación & Nomenclatura & UTM X & UTM Y \\
\hline 1 & SPN001 & 706763 & 4227981 & 14 & SPN014 & 707777 & 4225783 \\
\hline 2 & SPN002 & 707889 & 4227575 & 15 & SPN015 & 707804 & 4225799 \\
\hline 3 & SPN003 & 707905 & 4227599 & 16 & SPN016 & 707785 & 4225809 \\
\hline 4 & SPN004 & 708250 & 4227219 & 17 & SPN017 & 707934 & 4226062 \\
\hline 5 & SPN005 & 708259 & 4227222 & 18 & SPN018 & 708041 & 4226413 \\
\hline 6 & SPN006 & 708297 & 4226910 & 19 & SPN019 & 708126 & 4226603 \\
\hline 7 & SPN007 & 708243 & 4226819 & 20 & SPN020 & 708115 & 4226608 \\
\hline 8 & SPN008 & 708214 & 4226768 & 21 & SPN021 & 708227 & 4226761 \\
\hline 9 & SPN009 & 708155 & 4226672 & 22 & SPN022 & 708305 & 4226894 \\
\hline 10 & SPN010 & 707887 & 4226456 & 23 & SPN023 & 708348 & 4227100 \\
\hline 11 & SPN011 & 707945 & 4226425 & 24 & SPN024 & 708364 & 4227093 \\
\hline 12 & SPN012 & 707911 & 4226317 & 25 & SPN025 & 708513 & 4227117 \\
\hline 13 & SPN013 & 707917 & 4226313 & 26 & SPN026 & 708572 & 4227223 \\
\hline \hline
\end{tabular}

Tabla 3.4: Coordenadas de las estaciones de muestreo del circuito de Bonmatí en Santa Pola durante el año 2008

En el 2009 se redujo considerablemente el número de estaciones de muestreo porque, dentro del programa de la DMA en la que se enmarca el trabajo, se consideró que tras un primer año de estudio en detalle se podía reducir el número de estaciones seleccionando 4 balsas representativas de los procesos que tenían lugar en el circuito, dado que eran muestras bastante uniformes. Estas balsas abarcan todo el rango salino, desde la entrada de agua de mar (SPN002), a los calentadores (SPN003), concentradores (SPN008) y cristalizadores (SPN021). Las coordenadas son las que se muestran a continuación:

\begin{tabular}{|c|c|c|c||}
\hline \multicolumn{4}{|c||}{$\begin{array}{c}\text { SALINA DE SANTA POLA- CIRCUITO } \\
\text { SALINERO DE BONMATÍ. 2009. }\end{array}$} \\
\hline Estación & Nomenclatura & UTM X & UTM Y \\
\hline 1 & SPN002 & 707889 & 4227575 \\
\hline 2 & SPN003 & 707905 & 4227599 \\
\hline 3 & SPN008 & 708214 & 4226768 \\
\hline 4 & SPN021 & 708227 & 4226761 \\
\hline \hline
\end{tabular}

Tabla 3.5: Coordenadas de las estaciones de muestreo del circuito de Bonmatí en Santa Pola durante el año 2009 


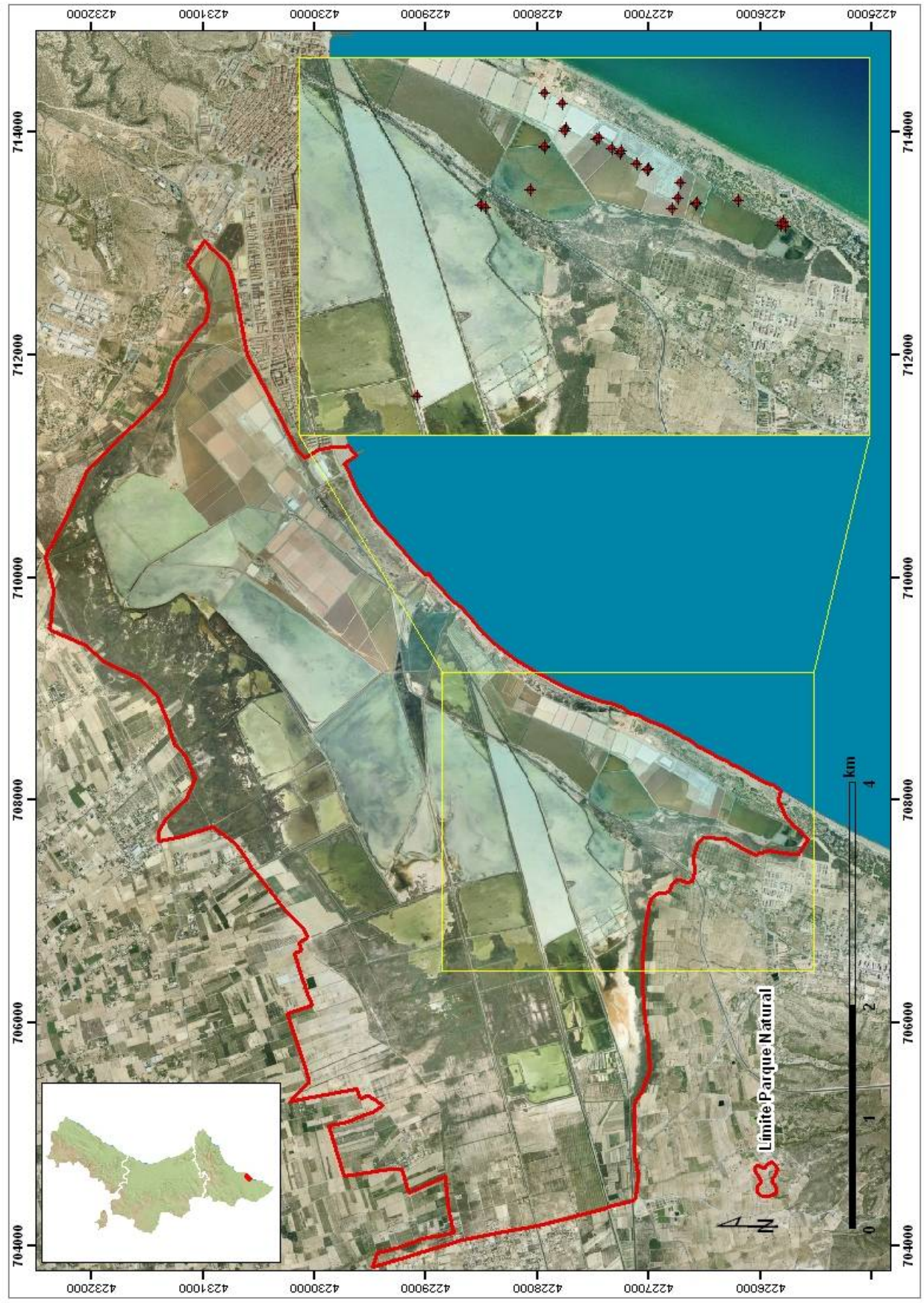

Figura 3.3: Ubicación de las estaciones de muestreo del circuito de Bonmatí dentro del Parque Natural de las Salinas de Santa Pola 


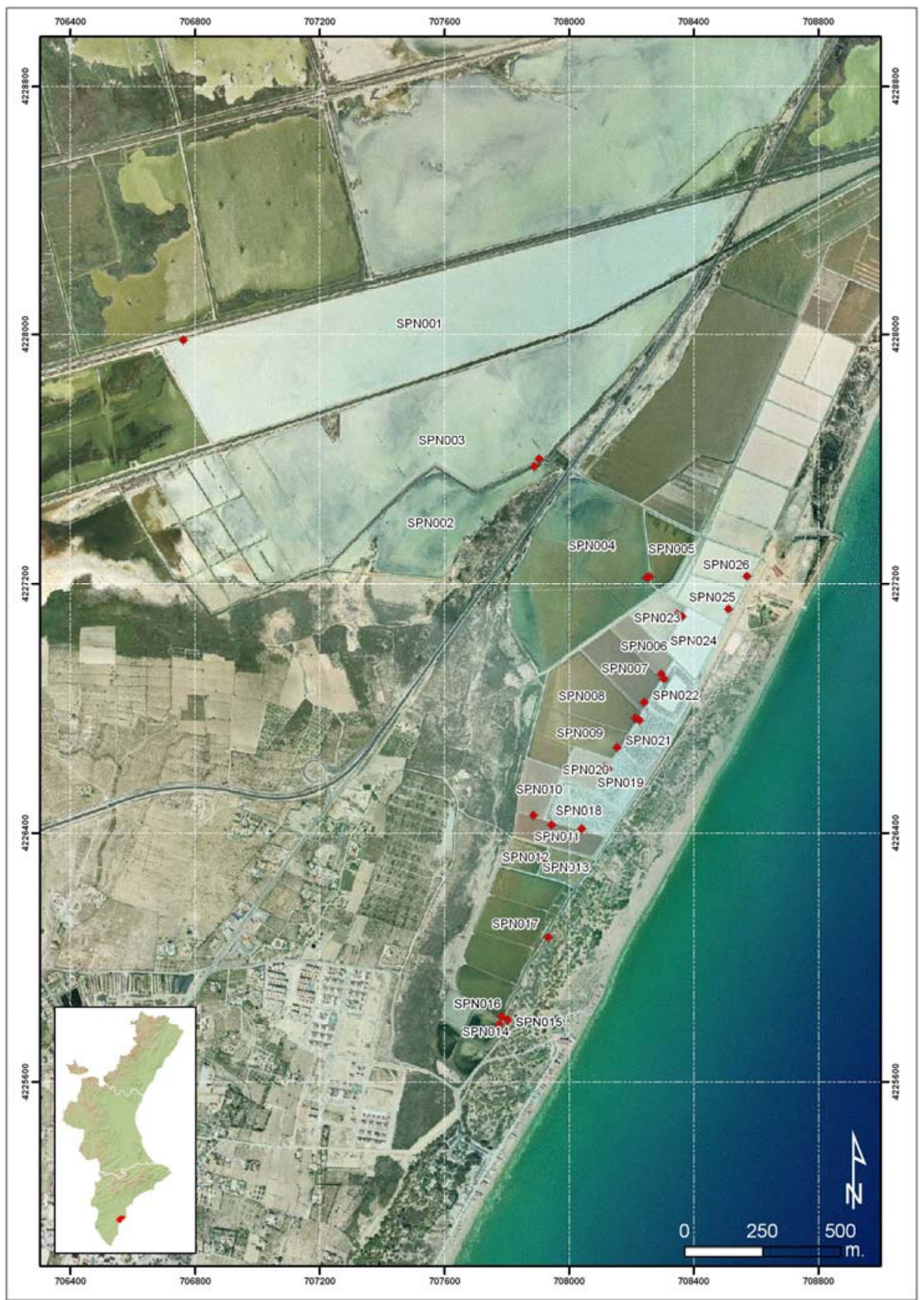

Figura 3.4: Detalle de las estaciones de muestreo estudiadas en el circuito salinero de Bonmatí 


\subsubsection{Toma de muestras de agua}

Las muestras de agua en las salinas se tomaron a unos $10 \mathrm{~cm}$ de profundidad procurando no remover la superficie del sedimento. En el caso de Santa Pola además se evitaron las esquinas de las balsas en el circuito salinero ya que tal y como mencionan algunos autores (Pedrós-Alió et al., 2000; Joint et al., 2002), es donde los detritos y organismos arrastrados por el viento tienden a acumularse. Estas muestras fueron tomadas en botes de polietileno de alta densidad de $2000 \mathrm{ml}$.

\subsection{TRATAMIENTO Y ANÁLISIS DE LAS MUESTRAS}

\subsubsection{Cadena de custodia de las muestras}

Las muestras de agua de $2000 \mathrm{ml}$ fueron refrigeradas y trasladadas al laboratorio en un tiempo no superior a 12 horas desde su recogida.

Una vez en el laboratorio, cada muestra se subdividió en alícuotas para la determinación de los diferentes parámetros, debido a que cada parámetro requiere una forma diferente de conservación de la muestra (APHA, 1998) tal y como se detalla en la figura 3.5:

- Fósforo total: Tras la homogeneización de la muestra se trasvasaron $125 \mathrm{ml}$ de muestra sin filtrar a botes de plástico que fueron conservados a $-20{ }^{\circ} \mathrm{C}$ hasta su análisis posterior.

- Clorofila $a$ : Se intentó filtrar la máxima cantidad de muestra posible (hasta un máximo de $800 \mathrm{ml}$ ) a través de filtros de membrana de acetato de celulosa de 0,45 $\mu \mathrm{m}$ (Millipore HAWP de $47 \mathrm{~mm}$ de Ø). Los filtros se conservaron a una temperatura de $-20{ }^{\circ} \mathrm{C}$ hasta su análisis.

Para el resto de parámetros se utilizó muestra filtrada. Previamente al filtrado se midió la conductividad de cada muestra con la finalidad de conocer si se trataba de una muestra con un alto contenido en sales o no, lo que era muy útil para el proceso de filtrado.

Se filtró un volumen determinado de muestra en función de la facilidad del filtrado y de la colmatación de los filtros (intentando filtrar hasta $800 \mathrm{ml}$ siempre que fuera posible). La muestra era filtrada a través de membranas de acetato de celulosa de $0,45 \mu \mathrm{m}$ (Millipore HAWP de $47 \mathrm{~mm}$ de diámetro). De este filtrado, se tomaron distintas alícuotas que se utilizaron para:

- Amonio, nitrito y fósforo soluble reactivo: que fueron determinados inmediatamente.

- Ácido ortosilícico y nitrato: $125 \mathrm{ml}$ del filtrado fueron guardados a - $20{ }^{\circ} \mathrm{C}$ hasta su análisis posterior.

- Salinidad: fue determinada a partir de la muestra filtrada. Se conservó en botes de plástico de $250 \mathrm{ml}$ a temperatura ambiente hasta su determinación. 


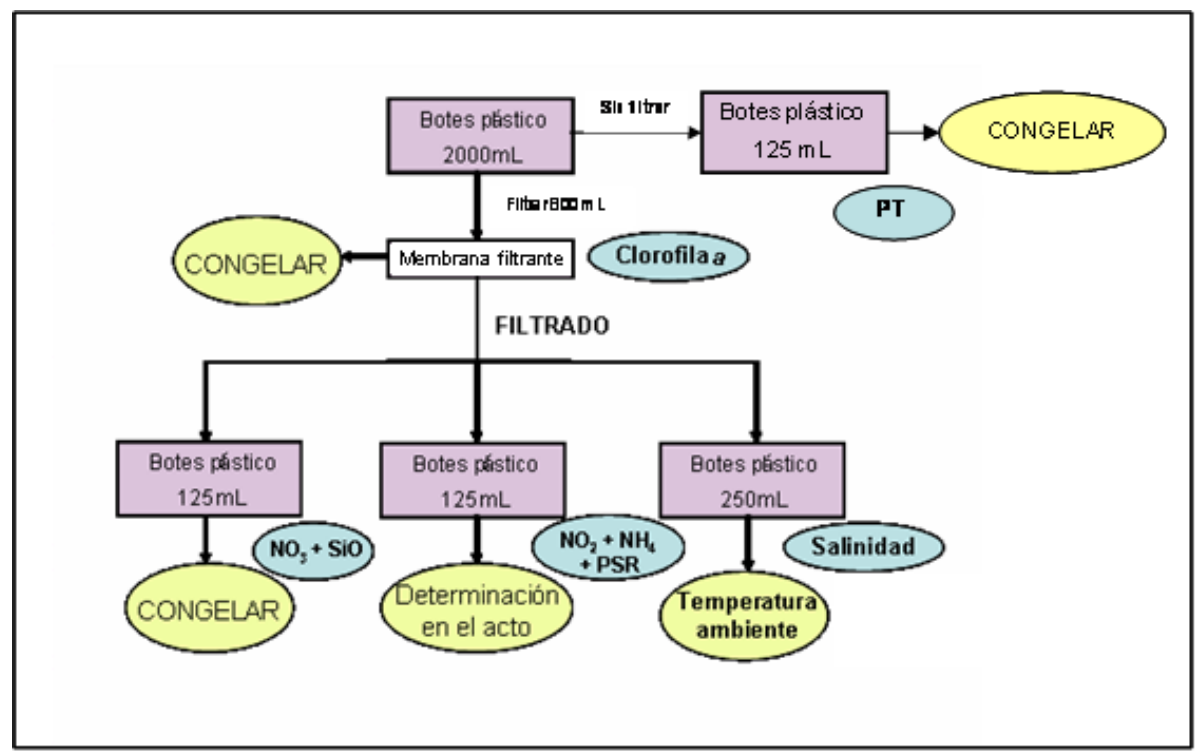

Figura 3.5: Cadena de custodia de las muestras y conservación de las distintas alícuotas

\subsubsection{Métodos analíticos}

En los métodos analíticos descritos se utilizó agua ultrapura obtenida con un equipo de purificación de agua Milli-Q 185 Plus equipado con cámara de fotooxidación ultravioleta (UV) de Millipore.

\subsubsection{Análisis de conductividad, salinidad, pH y clorofila $a$}

- Conductividad: La conductividad fue medida de forma directa mediante un conductímetro de la marca Knick Portamess 911 previamente calibrado con $\mathrm{KCl}$ y con la temperatura corregida a $25^{\circ} \mathrm{C}$ (APHA, 1998).

- Salinidad: La salinidad (Aminot, 1983) puede ser definida como el peso en gramos de materia inorgánica disuelta en $1 \mathrm{~kg}$ de agua de mar después de que todo el bromuro y yoduro ha sido reemplazado por la cantidad equivalente de cloruro, todo el carbonato convertido a óxido y toda la materia orgánica oxidada. La forma de medir la salinidad es a través de métodos indirectos que involucran la medida de parámetros físicos como conductividad, densidad, velocidad del sonido o índice de refracción. El método que proporciona mayor precisión es la medida de la conductividad (APHA, 1998).

Para aquellas muestras cuya conductividad era menor de $60 \mathrm{mS} / \mathrm{cm}$, la salinidad se midió de forma directa mediante un salinómetro (figura 3.6) de la marca Portasal modelo 8410A, previamente calibrado con estándares de agua de mar con una precisión de $\pm 0,01$ unidades de salinidad (APHA, 1998).

Sin embargo, el salinómetro no permite la medición de aquellas muestras con salinidad mayor de 38,5 g/kg. Por ello, se midió previamente la conductividad de todas las muestras y aquellas con conductividad superior a $60 \mathrm{mS} / \mathrm{cm}$ (conductividad aproximada del agua de 
mar) fueron diluidas hasta que la conductividad indicaba que la salinidad se encontraba en un rango de medida apto para el salinómetro (entre $15-38,5 \mathrm{~g} / \mathrm{kg}$ ).

Para ello se pesó una alícuota de la muestra hipersalina, que posteriormente se diluyó con agua ultrapura (Milli-Q), determinándose también el peso de la dilución final. Para determinar estos pesos se utilizó una balanza de precisión Mettler AT261 Deltarange que determina hasta la diezmilésima de gramo. Con el porcentaje en peso de la muestra y la salinidad medida en la muestra diluida, se calculó la salinidad de la muestra. Este proceso se realizó por duplicado.

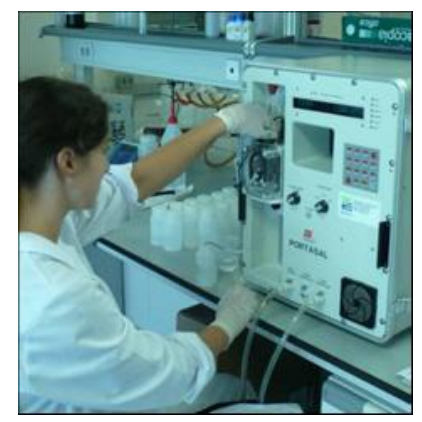

Figura 3.6: Salinómetro Portasal modelo 8410A

- pH: El pH se midió de manera directa y precisa mediante un pHmetro de la marca WTW modelo 196.

- Clorofila a: Se utilizó el método tricromático basado en espectroscopía visible para determinar la concentración de clorofila a (APHA, 1998). Para ello, las membranas de acetato de celulosa empleadas para filtrar las muestras se congelaron con la finalidad de romper las células. Posteriormente se introdujeron en $6 \mathrm{ml}$ de acetona al 90\% en agua con el $1 \%$ en carbonato cálcico y se midió la densidad óptica del extracto a distintas longitudes de onda: 630, 647 y $664 \mathrm{~nm}$, para determinar el contenido pigmentario, y a $750 \mathrm{~nm}$ para determinar la densidad óptica no debida a la clorofila $a$. Para los cálculos de la concentración se utilizaron las ecuaciones de Jeffrey y Humprey (1975).

La elevada salinidad de las muestras provocó numerosos problemas en el filtrado de las mismas, ya que por un lado era muy poca la cantidad de muestra que se podía filtrar (lo que aumentaba el error de cálculo del valor final de clorofila $a$ ) y por otro lado, esta salinidad interaccionaba con el propio filtro precipitando numerosas veces en él. Finalmente, y tras efectuar numerosas pruebas, se decidió que para aquellas muestras con una conductividad superior a $100 \mathrm{mS} / \mathrm{cm}$, se filtrara únicamente $30 \mathrm{ml}$ de muestra y se realizara el lavado del filtro de membrana con 3 alícuotas de agua Milli-Q de $5 \mathrm{ml}$ cada una de ellas, ya que esta era la única forma de asegurar la repetitividad de los resultados. A pesar de los esfuerzos realizados para conseguir resultados de clorofila $a$, éstos no se discutirán en el apartado de resultados y discusión debido a que la gran interferencia en los análisis provocada por la matriz salina no garantiza la fiabilidad de los mismos.

\subsubsection{Análisis de nutrientes}

Los análisis de nutrientes fueron realizados con un autoanalizador de flujo continuo segmentado por aire, Alliance Instruments Integral Futura (figura 3.7). Los métodos usados 
son los descritos por Treguer y Le Corre (1975), teniendo en cuenta las consideraciones hechas por Parsons et al. (1984) y Kirkwood et al. (1991). La optimización del equipo se llevó a cabo siguiendo las teorías de Coakley (1981). Se utilizaron reactivos de alta pureza Merck para análisis.

Hay que señalar que, como se detectó que los datos obtenidos con el autoanalizador de flujo segmentado no eran fiables para muestras con elevadas salinidades, se midió previamente la conductividad en todas las muestras, para detectar aquellas que pudieran tener problemas a la hora de realizar las medidas analíticas. Estas muestras fueron diluidas para alcanzar valores ligeramente inferiores a los del agua de mar. Posteriormente, se llevo a cabo el análisis. Lógicamente esto implica que los límites de detección no están determinados solamente en función de los obtenidos con el autoanalizador, sino también con los factores de dilución, por lo que los límites pueden variar según la salinidad de la muestra.
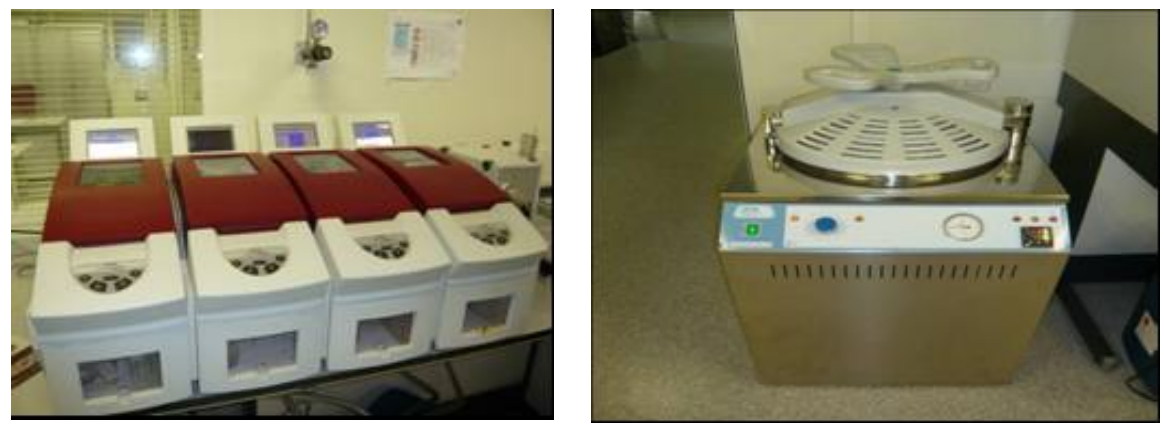

Figura 3.7: a) Autoanalizador de flujo contínuo segmentado por aire y b) Autoclave

Amonio: Su determinación se basa en la reacción de Berthelot. En medio alcalino el amonio disuelto reacciona con el hipoclorito formando una monocloramina. Este compuesto en presencia de fenol y un exceso de hipoclorito da lugar a la formación de azul de indofenol. El ión nitroprusiato cataliza la reacción. La adición de citrato trisódico elimina la interferencia de Ca y Mg (Solórzano, 1969).

Nitrito: Para la determinación de nitrito se ha utilizado el método de análisis en aguas de Shinn (1941) adaptado para el agua de mar por Bendschneider y Robinson (1952) que se basa en la reacción del ión nitrito con la sulfanilamida, en medio ácido, produciéndose un diazocompuesto que forma un complejo de color rosado con la N-naftiletilendiamina.

Nitrato: La determinación de los nitratos se basa, en la reducción de los nitratos a nitritos mediante una columna reductora de $\mathrm{Cu} / \mathrm{Cd}$ en medio básico $(\mathrm{pH}=8,5)$. El método seguido es el descrito por Grasshoff (1976). Posteriormente el ión nitrito reacciona con la sulfanilamida, en medio ácido, produciéndose un diazocompuesto que forma un complejo de color rosado con la N-naftiletilendiamina. La formación del complejo es proporcional a la concentración de nitrito.

Nitrógeno inorgánico disuelto (NID): Se obtuvo sumando las concentraciones de amonio, nitrito y nitrato. 
Fósforo soluble reactivo (PSR): Se midió siguiendo el método de Murphy y Riley (1962) que consiste en provocar la formación de un complejo fosfomolíbdico de color azul mediante la adición de molibdato amónico en medio ácido. El molibdato de amonio y el tartrato de antimonio y potasio reaccionan con el ortofosfato en un medio ácido para formar un complejo de fosfomolibdato de antimonio, el cual es reducido a azul de molibdeno por el ácido ascórbico (APHA, 1998). Pero el molibdeno cataliza también la hidrólisis de los ésteres fosfóricos presentes en el medio, como se demuestra en los estudios de Tarapchak (1983), que, al ser medidos conjuntamente con el ortofosfato, dan lugar a una sobrevaloración sistemática. Sin embargo, no es posible introducir factores de corrección porque la capacidad de hidrolización varía con el tipo de moléculas orgánicas presentes en la muestra. Por lo tanto, el fósforo que reacciona con este método es un compartimento químico heterogéneo en el que se incluyen tanto fracciones minerales como orgánicas previamente hidrolizadas en proporciones difíciles de evaluar. Por este motivo se aplica el término "fósforo soluble reactivo" (PSR), introducido por Strickland y Parsons (1965), para designar el fósforo que reacciona con el método del molibdato.

Fósforo total (PT): El análisis del PT se realiza sobre muestra sin filtrar. Para el análisis del PT se requiere de una digestión previa de la muestra, con el fin de transformar todo el fósforo presente a ortofosfato, que posteriormente se determina. Para la elección de un método adecuado de digestión se escogió el método de digestión ácida con persulfato (Valderrama, 1981), en el que la muestra es mezclada con persulfato de potasio, ácido bórico y sosa e introducida en un autoclave durante 60 minutos a $121^{\circ} \mathrm{C}$. Todo el fósforo se transforma a ortofosfato el cual es analizado por el mismo método utilizado para el PSR.

Ácido ortosilícico: Se ha utilizado el método descrito por Strickland y Parsons (1972) que sigue el método de valoración del ácido ortosilícico en agua de mar de Mullin y Riley (1955). El método recurre a la formación a pH 1 - 2 de un complejo entre el molibdato amónico y las formas monómera o dímera del ácido ortosilícico; la reducción de este último con metanol formando un complejo azul es susceptible de determinación colorimétrica.

\subsection{TRATAMIENTO ESTADÍSTICO}

A la hora de interpretar los resultados, es conveniente aplicar diversas herramientas estadísticas, con el fin de tratar de comprender la realidad que se esconde bajo la considerable cantidad de datos de los que dispone. Por ello, resulta habitual tener que trabajar con numerosas variables, una gran cantidad de valores de cada variable, y considerar las relaciones que se dan entre esas variables. No hay que olvidar que la realidad de la naturaleza es multivariante, es decir, para una mejor comprensión del fenómeno hay que tener en cuenta el comportamiento simultáneo de grupos de variables, lo cual complica seriamente la interpretación de los resultados obtenidos.

A continuación se explican las técnicas de tratamiento estadístico utilizadas en este trabajo.

\subsubsection{Análisis de componentes principales}

El método de componentes principales es una técnica de análisis multivariante y como tal, pretende reducir la dimensionalidad de los datos con una pérdida mínima de información. 
La particularidad de esta técnica es que presupone que no hay factores comunes, y por ello su objetivo no es tanto reducir el número de variables sino simplificar la estructura de los datos transformando las variables en unas pocas componentes principales que sean combinaciones lineales de dichas variables. El análisis de componentes principales es una técnica estadística que trata de transformar un conjunto de variables interrelacionadas en un conjunto de variables no correlacionadas llamadas factores, analizando la estructura de dependencia y correlación que existe entre las variables, y especificando cómo éstas explican parte de la información que contienen los factores (Díaz de Rada, 2002).

Este tipo de análisis no requiere de ninguna hipótesis particular y únicamente busca la mejor combinación lineal de variables para encontrar un conjunto de componentes que expliquen el máximo de la varianza total. En cuanto a su procedimiento de cálculo, trata de ajustar matemáticamente de la manera más óptima una nube de puntos sobre un espacio de una, dos, tres o " $n$ " dimensiones, para lo cual elige en primer lugar aquel factor que explique la mayor parte de la varianza de las variables. Este primer componente puede ser considerado como mejor resumen de las relaciones lineales existentes. Una vez obtenido este primer factor su peso se resta a las variables, y con la variabilidad restante (residual) se calcula la segunda componente principal (factor 2), de la misma forma se calcula para la tercera, la cuarta, etc.

En definitiva, en el análisis de componentes el producto final es una matriz transformada, cuyas columnas son los vectores propios de la matriz de correlaciones, y que define los componentes principales como una combinación lineal de las variables observadas.

Para el análisis de componentes principales se ha utilizado el programa estadístico Statgraphics 5.1.

\subsubsection{Análisis de conglomerados o cluster}

El análisis de conglomerados ó análisis cluster es una técnica de análisis multivariante que pretende lograr un agrupamiento de elementos (o individuos) en grupos, según el comportamiento de éstos en una serie de variables. El análisis cluster no trata de explicar estadísticamente ningún fenómeno sino que pretende describir la situación de los elementos observados en relación con determinados fenómenos, mediante su agrupación en grupos homogéneos. Las agrupaciones se realizan de tal manera que los elementos que forman parte de estos grupos deben ser muy similares (con una alta homogeneidad interna) y, a su vez, muy diferentes con respecto al resto de agrupamientos (con una alta heterogeneidad entre grupos). Así pues, se trata de clasificar una población en el menor número posible de grupos y de buscar grupos homogéneos entre sí y diferentes del resto (Díaz de Rada, 2002).

En los análisis cluster efectuados en esta tesis, se ha utilizado la distancia euclídea al cuadrado como medida del intervalo y el método de Ward como método de conglomeración. Éste es uno de los métodos de agrupación jerárquicos más potentes, generales y más utilizado por la comunidad científica. El análisis comienza con tantos conglomerados como individuos y éstos se van agrupando según diversos criterios hasta que todas las observaciones forman un único grupo o conglomerado.

Para la representación gráfica de los clusters se han utilizado los dendogramas, que son la representación gráfica que mejor ayuda a interpretar el resultado de un análisis cluster ya que refleja la formación de los conglomerados y las distancias entre ellos. El programa estadístico utilizado ha sido el SPSS 16.0. 


\section{CAPÍTULO 4}

\section{RESULTADOS Y DISCUSIÓN}

\subsection{SALINA DE CALPE}

\subsubsection{Análisis de los parámetros físico-químicos}

\subsubsection{Salinidad}

Actualmente en la salina de Calpe no se lleva a cabo, a pesar de su nombre, la explotación salinera. Como ya se ha mencionado en el apartado de área de estudio esta masa de agua está conectada con el mar a través de un conducto que sale de la playa dels Banys de la Reina y que permite la introducción de agua marina en el sistema. La finalidad de esta entrada consiste en mantener la lámina de agua y asegurar unas condiciones que garanticen la pervivencia de la laguna y su biodiversidad. Los bombeos de agua marina se llevan a cabo en verano prácticamente a diario, llegando a funcionar incluso 18 horas al día durante los meses más secos, con un caudal de unos $25 \mathrm{l} / \mathrm{s}$. El período aproximado de funcionamiento es de mayo a septiembre (varía según las precipitaciones).

Estos aportes marinos unidos a la elevada evapotranspiración existente en la zona, superan claramente los aportes de agua dulce procedentes de las escorrentías superficiales, por lo que la concentración salina, por lo general, es claramente superior a la marina. No obstante episódicamente, en los momentos de lluvias torrenciales, pueden producirse aportes esporádicos masivos de agua dulce que diluyen las aguas hiperhalinas del sistema.

Por tanto, para poder abordar el estudio de la salina en su totalidad será necesario tener en cuenta, además del funcionamiento artificial del sistema, las precipitaciones que han tenido lugar en la zona durante el período de estudio. Para ello, se han considerado las precipitaciones registradas en la estación meteorológica más cercana de la que se disponen datos completos de precipitaciones y temperaturas para el período de estudio, que es la estación denominada Benissa Convento (estación 8043 de la Agencia Estatal de Meteorología (AEMET); UTM X: 764912; UTM Y: 4289599; Altitud: 275 m), situada a unos $8 \mathrm{~km}$ de distancia de la laguna.

Las precipitaciones diarias ( $\mathrm{mm})$ se muestran en la figura 4.2. Además, en la gráfica se han marcado las fechas en que se realizaron los muestreos así como las precipitaciones correspondientes a dichas fechas.

En la figura 4.1 se muestra la ubicación de las estaciones de muestreo en el interior de la salina de Calpe para facilitar la comprensión de los resultados presentados. 


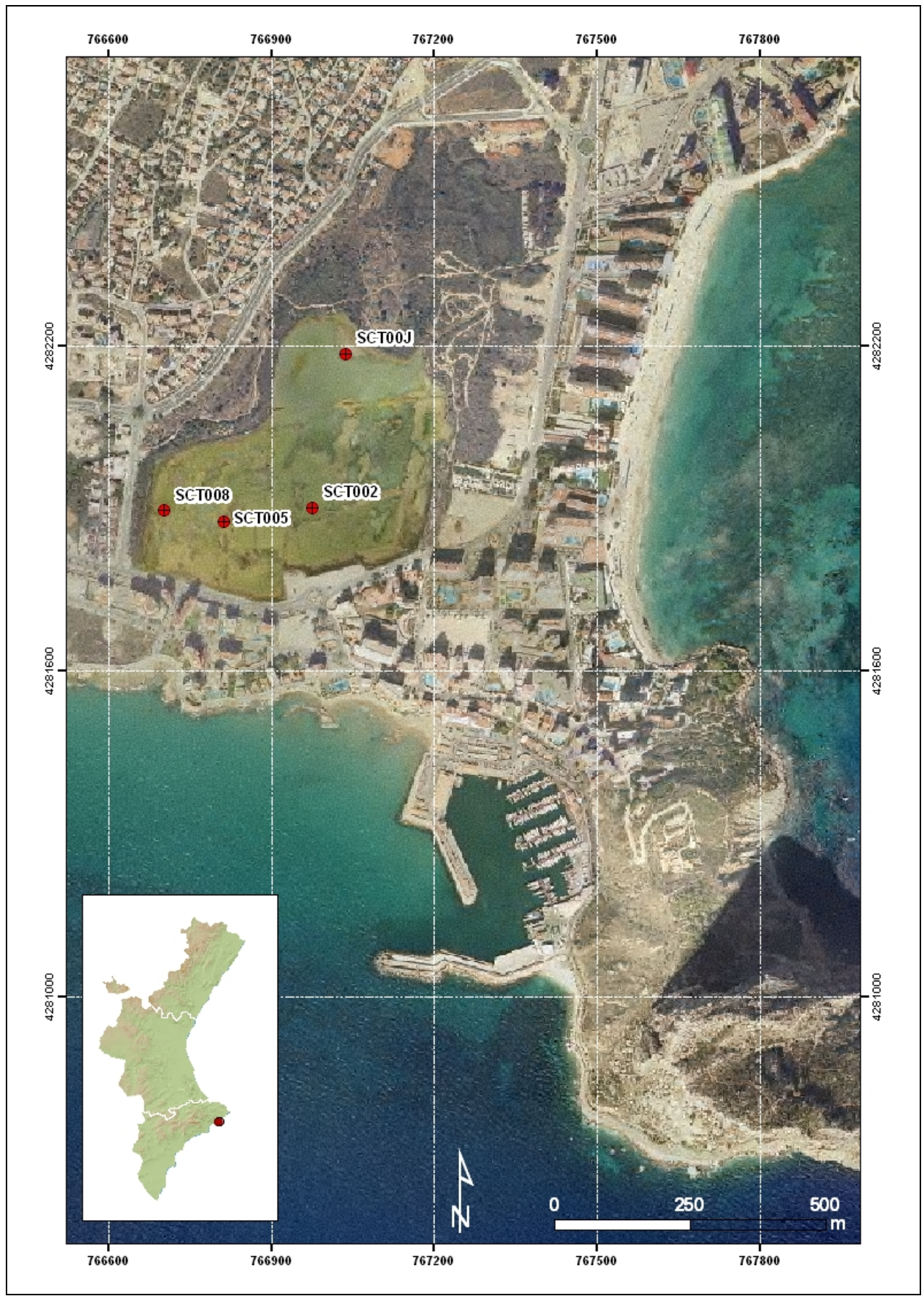

Figura 4.1: Ubicación de las estaciones de muestreo en la salina de Calpe 


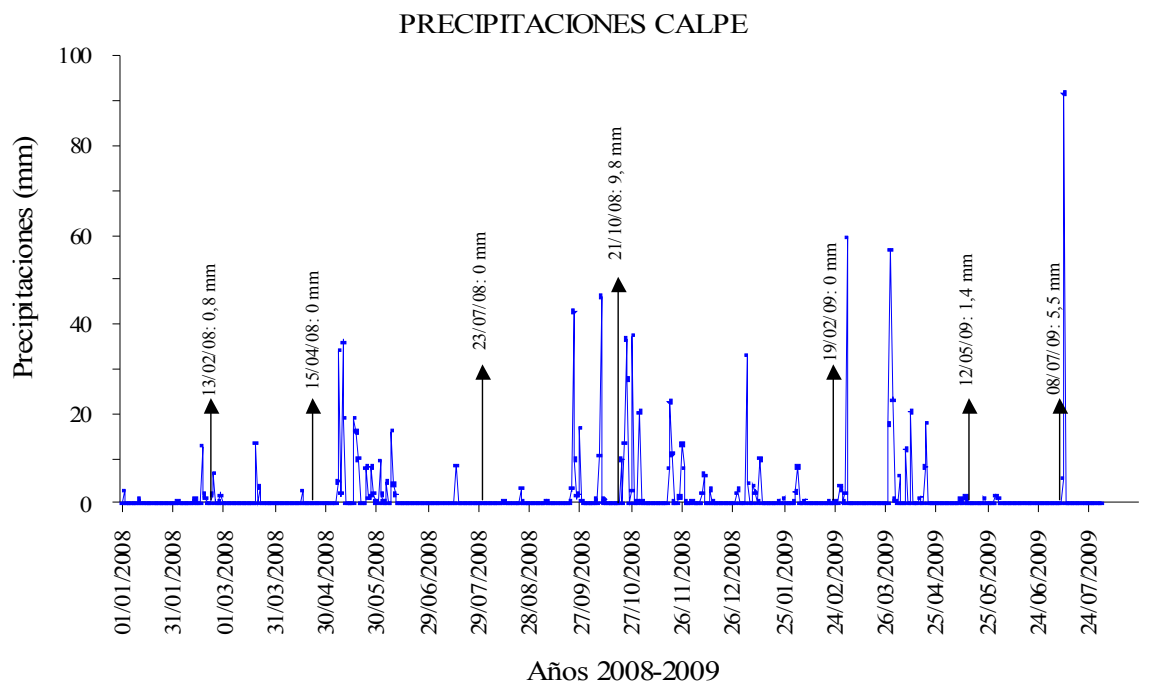

Figura 4.2: Precipitaciones diarias (mm) en la estación Benissa Convento durante el período 2008-2009. En la figura se han marcado las precipitaciones correspondientes a los días de muestreo (Fuente: AEMET)

Los valores de salinidad para cada estación de muestreo se pueden observar en la figura 4.3. Oscilan entre un mínimo de $14,91 \mathrm{~g} / \mathrm{kg}$ de la estación SCT00J en febrero de 2008 y un máximo de $61,14 \mathrm{~g} / \mathrm{kg}$ en SCT00J en julio de 2009. Como se puede apreciar, el rango de variación de las concentraciones es muy amplio ya que va desde las propias de las aguas mesohalinas a las hiperhalinas.

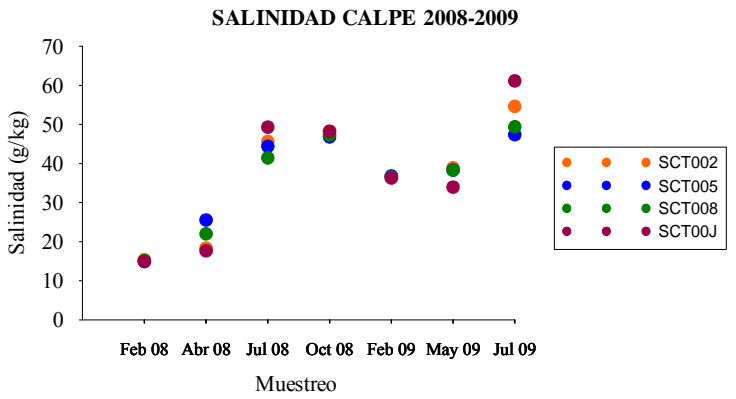

Figura 4.3: Salinidades registradas en la salina de Calpe durante las campañas de 2008-2009

En el muestreo de febrero de 2008 (13/02/08) se encuentran valores muy bajos en toda la laguna, de unos $15 \mathrm{~g} / \mathrm{kg}$ y con un mínimo de $14,91 \mathrm{~g} / \mathrm{kg}$ en SCT00J. Estas salinidades tan bajas son debidas a precipitaciones previas al muestreo que tuvieron lugar en toda la comarca de la Marina Alta. Las precipitaciones que tuvieron lugar los días previos al muestreo contribuyeron a una mayor dilución de las aguas, que posiblemente ya se encontraban muy diluídas por las anormales precipitaciones que tuvieron lugar en la comarca durante los días 10 - 12 de octubre de 2007 donde se registraron hasta 400 1/. $\mathrm{m}^{2}$. 
Estas precipitaciones no se observan en la figura 4.2 de datos meteorológicos, aunque sí que se tiene constancia de ellas por datos recogidos en los cuadernos de campo, por informaciones de los medios de comunicación y por informes de diferentes servicios de meteorología (Aemet, 2007; CEAM, 2007). Las precipitaciones fueron tan intensas en toda la cuenca vertiente que el espejo de agua era continuo hasta el mar, a pesar de los edificios. Por consiguiente, este muestreo se realizó en unas condiciones excepcionales y esto queda reflejado en los valores de salinidad, que son muy bajos debido a la dilución de las aguas.

En el muestreo de abril de 2008 (15/04/08), la salinidad aumentó ligeramente pasando a alcanzar valores entre $17,66-25,54 \mathrm{~g} / \mathrm{kg}$ por una mayor concentración de las sales de la laguna. El que se de este aumento se debe a la falta de precipitaciones importantes entre este muestreo y el anterior (ver figura 4.2), y el que sea relativamente reducida hay que achacarlo a que las bajas temperaturas de este período dieron lugar a unos niveles bajos de evapotranspiración. Los valores más bajos se encuentran en las estaciones SCT00J y SCT002 que son las situadas más hacia el interior de la laguna, mientras que los valores máximos se dan en SCT005 y SCT008 que son las estaciones más alejadas de las entradas de agua dulce y donde se produce una mayor concentración de sales.

En julio de 2008 (23/07/08), se observa un cambio apreciable en los valores de salinidad, ya que este parámetro alcanza valores hiperhalinos, entre $41,45-49,30 \mathrm{~g} / \mathrm{kg}$. A pesar de que se han producido precipitaciones importantes entre este muestreo y el de abril, parece ser que la elevada evapotranspiración junto con la entrada de agua de mar por bombeo artificial, dieron lugar a un aumento considerable de la salinidad, que prácticamente se dobla respecto al muestreo anterior.

De igual modo ocurre en el muestreo de octubre de 2008 (21/10/08). Aunque se registran precipitaciones elevadas y próximas al momento del muestreo, parece ser que el efecto que ejerce sobre la salinidad de la laguna la entrada de agua de mar unida a la elevada evapotranspiración es mucho mayor que el efecto de las precipitaciones. La salinidad presenta valores claramente superiores a los del agua de mar y mucho más uniformes que en los anteriores muestreos (entre 46,8 - 48,2 g/kg).

En febrero de 2009 (19/02/09) la salinidad es de unos 36,5 g/kg en toda la laguna, ligeramente inferior a la del agua de mar (unos 37,9 g/ $\mathrm{kg}$ en el Mediterráneo según Rodríguez, 1982; Romero, 2004). Este descenso en los valores de salinidad, es probablemente debido a la suma de un conjunto de factores: la ausencia de bombeos de agua marina, una menor evapotranspiración y la entrada de aguas dulces entre este muestreo y el anterior (ver figura 4.2).

En mayo de 2009 (12/05/09) los valores son muy similares a los del agua de mar en todas las estaciones de muestreo con unos $38,5 \mathrm{~g} / \mathrm{kg}$ en toda la laguna, excepto en SCT00J donde la concentración salina es ligeramente inferior $(33,97 \mathrm{~g} / \mathrm{kg})$. Los valores más bajos en SCT00J dejan constancia de la entrada de aguas dulces en el sistema por las importantes precipitaciones registradas durante el mes de abril de 2009.

Finalmente, en el muestreo de julio de 2009 (8/07/09), tal y como sucedía en el muestreo del mismo mes durante el año anterior, la salinidad es de nuevo muy elevada (entre 47,38 $61,14 \mathrm{~g} / \mathrm{kg}$ ) alcanzando los valores máximos de toda la campaña de muestreo. La falta de lluvias en el período comprendido entre mayo y julio de 2009, el aumento de la evapotranspiración y el bombeo intensivo de agua de mar en el interior del sistema, son los factores que dan lugar a los valores hiperhalinos de la laguna. 
En esta salina se observa una zonación espacial clara, ya que SCT005 - SCT008 presentan concentraciones más similares en todos los muestreos mientras que SCT002 - SCT00J difieren ligeramente respecto a las anteriores. Esto es debido a que SCT005 y SCT008 se encuentran muy próximas a la entrada por bombeo de agua marina, mientras que SCT002 y especialmente SCT00J se localizan más hacia el interior de la laguna.

Durante los meses en que no se efectúan bombeos, la salinidad tiende a ser ligeramente superior en SCT005 y SCT008 donde el efecto del agua dulce continental es menor. En cambio, en los meses en que se efectúan bombeos de agua marina, la salinidad de estas estaciones es menor por la dilución de las aguas hiperhalinas de la laguna con las que entran desde el mar. Por el contrario, en las estaciones SCT002 y SCT00J la salinidad es mayor durante los meses con bombeo, ya que en esta época la influencia de la evapotranspiración es mayor y el bombeo de agua marina afecta menos a estas estaciones (máximo en SCT00J en julio de 2008 y julio de 2009), y es menor en invierno por la mayor entrada de aguas dulces continentales.

\subsubsection{2. $\mathrm{pH}$}

El pH en Calpe oscila entre 7,75 (SCT008 en febrero de 2009) y 9,20 (SCT00J en julio de 2008). Los valores de $\mathrm{pH}$ en la laguna son por lo general bastante altos aunque se observa un ligero descenso en el muestreo de octubre de 2008 y un descenso importante en febrero de 2009 (ver figura 4.4).

En la salina de Calpe no se observa una correlación entre $\mathrm{pH}$ y salinidad, tal y como se aprecia en la figura 4.5a, ni tampoco entre $\mathrm{pH}$ y temperatura como muestra la figura $4.5 \mathrm{~b}$.

Aunque es un hecho conocido que la precipitación del calcio presente en la columna de agua reduce la capacidad de regular la concentración de $\mathrm{CO}_{2}$ del sistema a través de la precipitación del $\mathrm{CaCO}_{3}$ (ver introducción apartado 1.1.6), no es este el caso, porque la salinidad de Calpe no alcanza los niveles necesarios para que se de este proceso. Parece que la reducida hidrodinámica de este sistema permitiría una sobresaturación de la concentración del $\mathrm{CO}_{2}$ derivado de la descomposición de la materia orgánica (ya que la difusión del $\mathrm{CO}_{2}$ del agua a la atmósfera se ve reducida y permite que haya más $\mathrm{CO}_{2}$ en el agua) lo que da lugar a un descenso del $\mathrm{pH}$, a pesar de las altas concentraciones de calcio.

También parece que el aumento tanto del $\mathrm{CO}_{2}$ como del amonio en las aguas tiene un origen béntico y no de la columna de agua, como se explica a continuación en el apartado de amonio. Este origen béntico podría dar lugar a una mayor reducción del $\mathrm{pH}$ del que cabría esperar por la presencia de aportes de $\mathrm{CO}_{2}$ y diferentes ácidos derivados de la descomposición de la materia orgánica. 


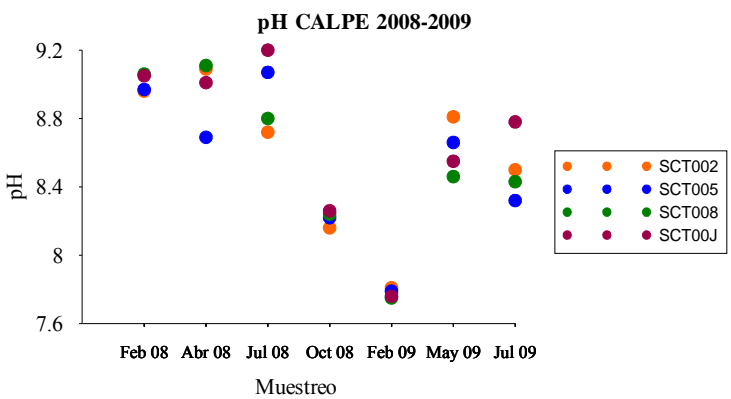

Figura 4.4: Valores de pH registrados en la salina de Calpe durante las campañas de 2008-2009
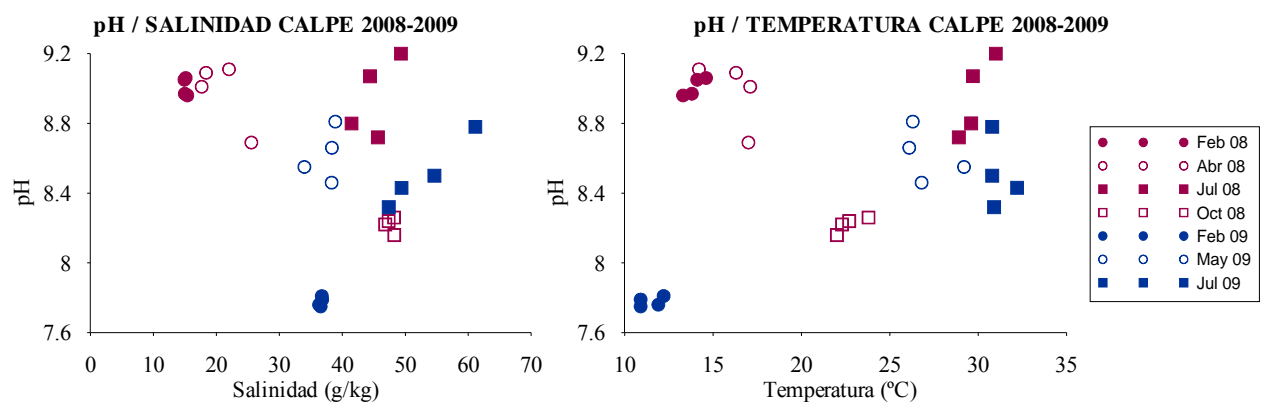

Figura 4.5: a) Comportamiento del $\mathrm{pH}$ respecto a la salinidad y b) Comportamiento del $\mathrm{pH}$ respecto a la temperatura en la salina de Calpe durante 2008-2009

\subsubsection{Amonio}

El amonio presenta un rango de concentraciones muy amplio que oscila entre valores por debajo del límite de detección $(<0,1 \mu \mathrm{M})$ en la estación SCT002 en febrero de 2008 y $133,0 \mu \mathrm{M}$ en la misma estación en el mes de febrero de 2009. Este parámetro presenta diferencias considerables a lo largo de los años 2008 - 2009 en función de la época estudiada (ver figura 4.6).

Los valores de amonio más bajos por lo general, se observan durante los meses de febrero y abril de 2008 ya que en ambos meses todas las estaciones presentan concentraciones $<1,0$ $\mu \mathrm{M}$. Estos meses son los de menores salinidades, lo que parece indicar que en estas entradas de agua dulce a la laguna no se han producido aportes significativos de amonio.

En los meses de julio de 2008 y julio de 2009 los valores son muy similares (entre 1,3 - 3,8 $\mu \mathrm{M}$ y $1,0-3,7 \mu \mathrm{M}$ respectivamente). Se observa un ligero aumento de las concentraciones de amonio que cabría achacar al proceso de concentración del nitrógeno por la evapotranspiración y a la mayor actividad biológica. También se observa un pico en mayo de 2009 donde la estación SCT00J alcanza un valor elevado que está asociado con entradas de agua dulce en el sistema $(19,1 \mu \mathrm{M})$.

En octubre de 2008, excepto en la estación SCT00J donde los valores se mantienen respecto al mes anterior $(3,3 \mu \mathrm{M})$, las concentraciones presentan valores mayores que en los muestreos anteriormente mencionados. Se alcanzan 15,5 $\mu \mathrm{M}$ en SCT008; 16,1 $\mu \mathrm{M}$ en 
SCT005 y 30,2 $\mu \mathrm{M}$ en SCT002, relacionados con el descenso que experimenta el pH en este muestreo que como ya hemos señalado parece deberse a aportes bénticos de $\mathrm{CO}_{2}$ que estarían acompañados por esta forma relativamente volátil de nitrógeno.

Finalmente, en el muestreo de febrero de 2009, se encuentran valores excepcionalmente altos, entre 111,4 y 133,0 $\mu \mathrm{M}$. Estos valores tan elevados de amonio coinciden con que se trata del muestreo donde los valores de $\mathrm{pH}$ son mucho menores. Los valores de amonio en el agua de mar difícilmente se encuentran por encima de los apreciados en las aguas dulces (Sierra et al., 2002) por lo que el aumento de la concentración de amonio en la laguna no parece ser debido a ningún aporte procedente del agua de mar sino a procesos internos.

Al observar las figuras, no se aprecia una relación entre el amonio y el contenido en sales de la laguna (figura 4.7a) aunque la gráfica de relación entre la concentración de amonio y el pH (figura 4.7b) parece indicar que estos picos de amonio, que coinciden con los valores menores de $\mathrm{pH}$, estarían asociados a procesos de degradación y mineralización de la materia orgánica (con producción de $\mathrm{CO}_{2}$ y amonio). Por otra parte, no se observa ninguna relación clara entre amonio y temperatura (figura 4.7c).

Los picos de amonio parecen proceder del sedimento ya que si procedieran de la descomposición del fitoplancton deberían ir acompañados de PSR, cosa que no sucede. Parece pues, que tanto el $\mathrm{CO}_{2}$ como el amonio, al ser volátiles, son capaces de traspasar la interfase sedimento-agua, lo que no sucede con el fosfato que queda retenido en la columna sedimentaria, probablemente en la capa superficial óxica.

En cuanto a las diferencias entre estaciones, se observa cómo en numerosas ocasiones los valores de SCT005 y SCT008 son muy similares, mientras que SCT002 y SCT00J son más variables. Por ejemplo, en el muestreo de febrero de 2009, donde se alcanzan las concentraciones máximas, se aprecia cómo los valores de SCT005 y SCT008 son similares y menores que los de SCT002 y SCT00J.

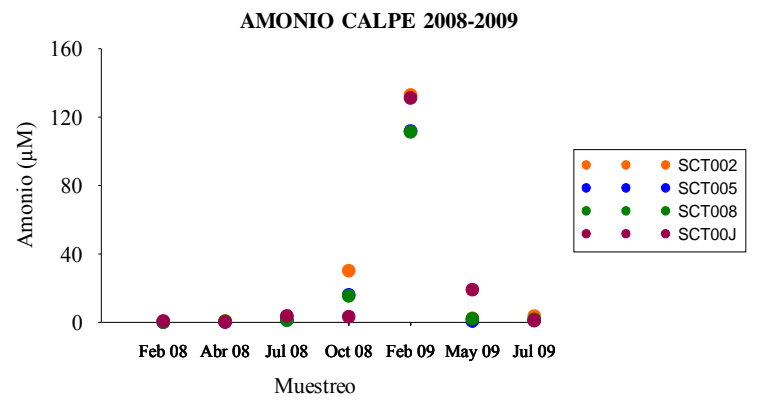

Figura 4.6: Concentraciones de amonio registradas en la salina de Calpe durante las campañas de 2008-2009 

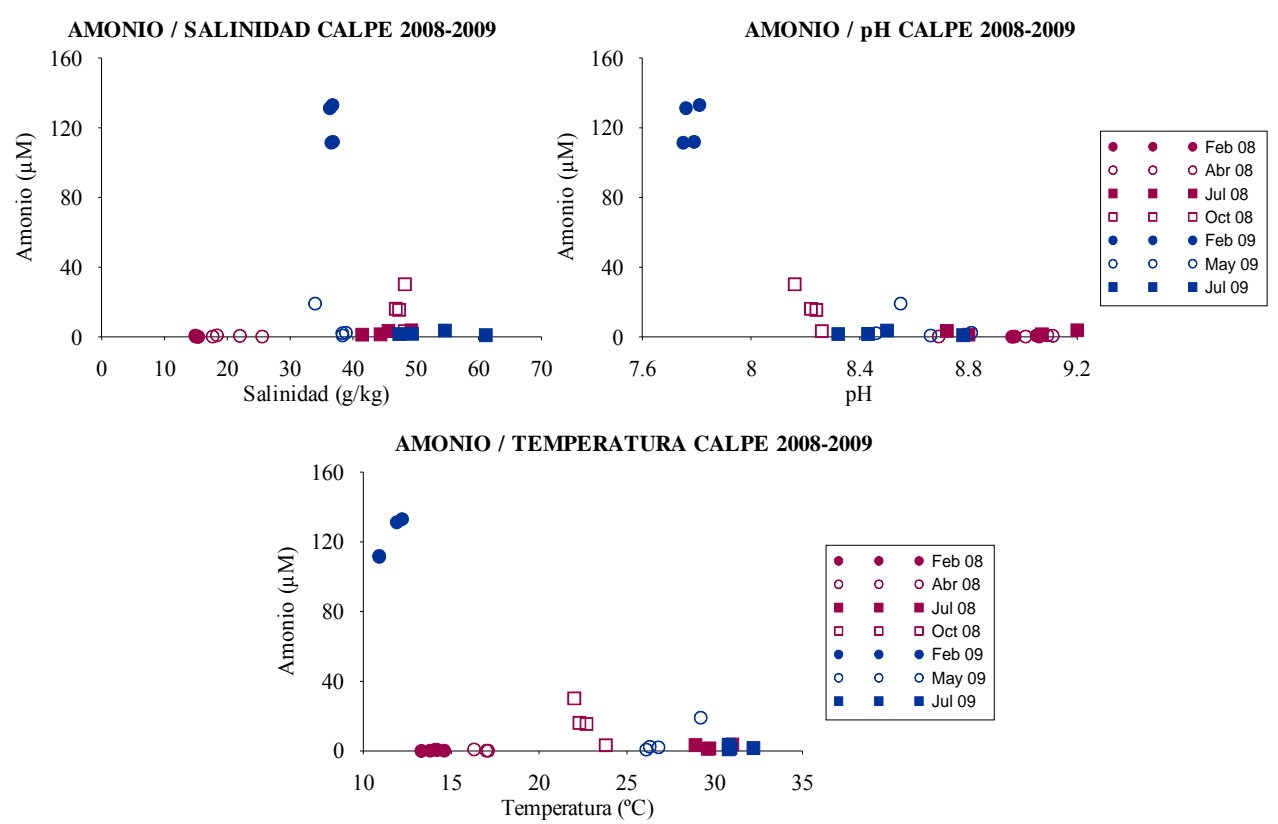

Figura 4.7: a) Comportamiento del amonio respecto a la salinidad; b) Comportamiento del amonio respecto al $\mathrm{pH}$ y c) Comportamiento del amonio respecto a la temperatura en la salina de Calpe durante 2008-2009

\subsubsection{Nitrito}

Las concentraciones de nitrito son muy bajas en toda la salina, encontrándose numerosos valores por debajo del límite de detección $(<0,01 \mu \mathrm{M})$, especialmente en febrero y abril de 2008. Todos los valores de 2008 son $<0,1 \mu \mathrm{M}$ en todas las estaciones muestreadas independientemente de la época del año (ver figura 4.8).

Sin embargo, en el muestreo de mayo de 2009 se observan valores de $1,33 \mu \mathrm{M}$ y $2,71 \mu \mathrm{M}$ en las estaciones SCT00J y SCT002 respectivamente, que si bien en SCT00J parecen tener su origen en aportes procedentes de aguas continentales, en SCT002 no está tan claro (ya que como se verá posteriormente, el contenido en ácido ortosilícico y en nitratos es elevado pero la salinidad también lo es).

El aumento más importante tiene lugar en febrero de 2009 donde se alcanzan valores de entre 1,02 y 4,05 $\mu \mathrm{M}$. Este aumento parece ser debido a procesos de nitrificación de parte de la gran cantidad de amonio existente en este momento. Hay que tener en cuenta que las tasas de nitrificación se ven potenciadas por el aumento de las concentraciones de amonio y que además existe una relación positiva entre las tasas de nitrificación y la temperatura (Helder y De Vries, 1983), con una reducción al descender la temperatura que afecta especialmente al paso de nitritos a nitratos, que queda inhibido por las bajas temperaturas invernales. Esto conduce a un ciclo estacional de la concentración de nitrito en el que durante el invierno se alcanzan los niveles más elevados (Herbert, 1999). 


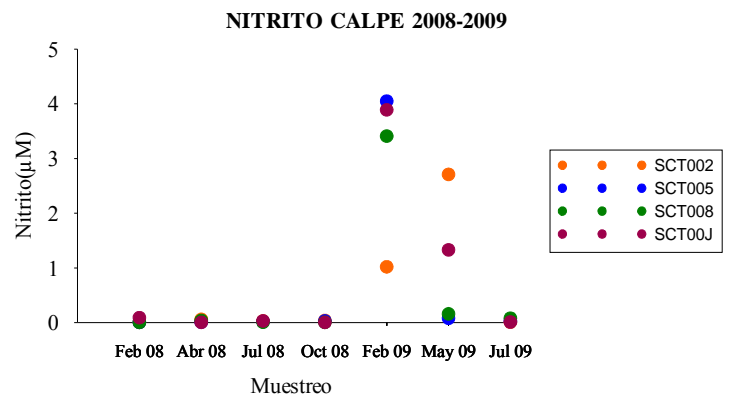

Figura 4.8: Concentraciones de nitrito registradas en la salina de Calpe durante las campañas de 2008-2009

En la figura 4.9 (a, b y c), se presenta el comportamiento del nitrito respecto a la salinidad, respecto al $\mathrm{pH}$ y respecto a la temperatura durante el período de estudio aunque no se observan pautas de comportamiento claras en ninguno de los casos.
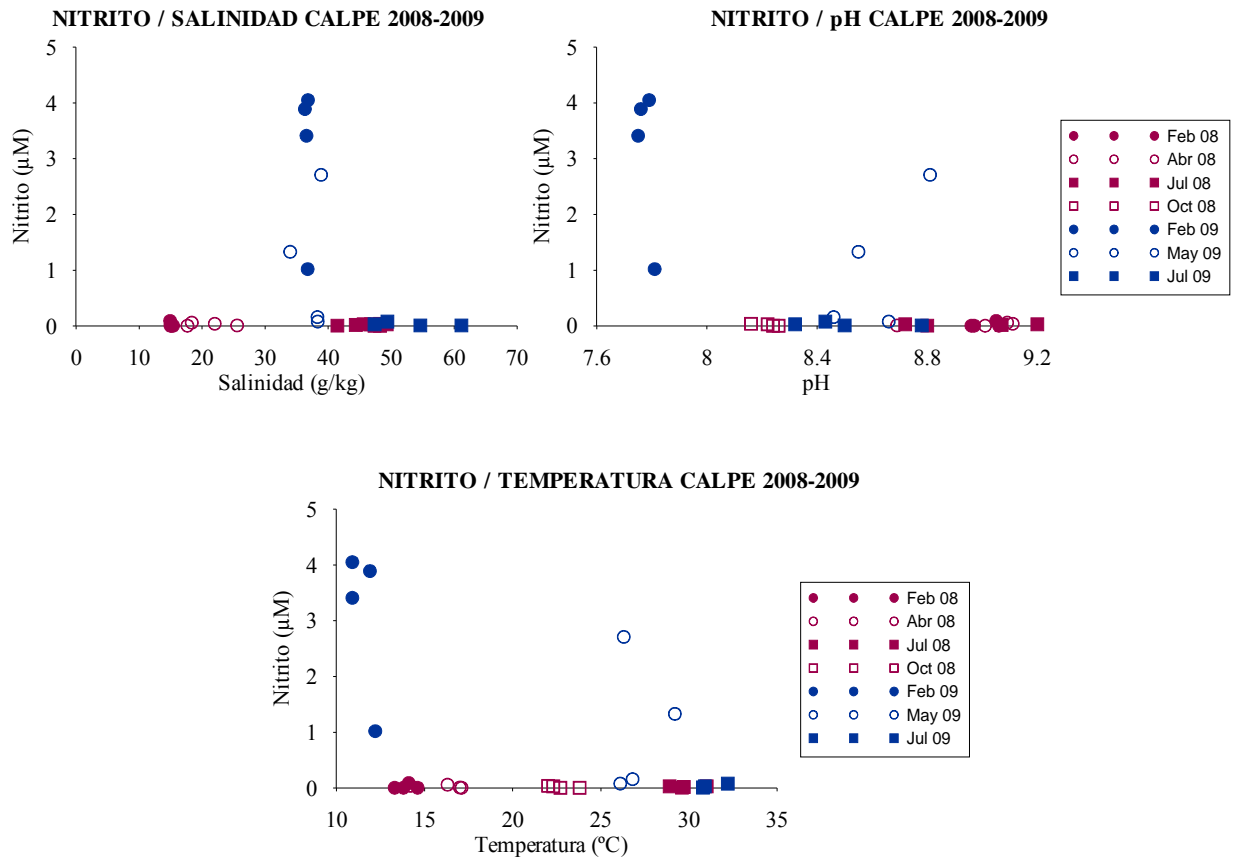

Figura 4.9: a) Comportamiento del nitrito respecto a la salinidad; b) Comportamiento del nitrito respecto al $\mathrm{pH}$ y c) Comportamiento del nitrito respecto a la temperatura en la salina de Calpe durante 2008-2009 


\subsubsection{Nitrato}

El nitrato presenta un rango de variación elevado que va desde cerca de los $20 \mu \mathrm{M}$ hasta valores por debajo del límite de detección (figura 4.10).

Los valores máximos en el año 2008 se encuentran en febrero (el valor máximo es de 5,0 $\mu \mathrm{M}$ y se da en la estación más interior de la laguna SCT00J), posiblemente debido a la carga de nitratos de origen antrópico arrastrada por las precipitaciones que fueron a parar a la salina durante dicho mes.

En el año 2009, los máximos se dan en mayo en las estaciones más interiores de la laguna $(18,3 \mu \mathrm{M}$ en SCT00J y 7,8 $\mu \mathrm{M}$ en SCT002) y, al igual que en febrero de 2008, la causa parece deberse a aportes derivados de las entradas de aguas dulces al sistema.

En febrero de 2009 también se encuentran valores elevados (entre 2,7 $\mu \mathrm{M}$ en SCT005 y 6,2 $\mu \mathrm{M}$ en SCT00J). Estos niveles parecen deberse no solo a los aportes de las aguas de escorrentía sino también al paso del amonio a nitritos y posteriormente a nitratos por el proceso de nitrificación.

En la figura 4.11 (a, b y c) se muestra el comportamiento del nitrato frente a la salinidad, donde no se observa una acumulación de este parámetro con el aumento de la concentración salina; así como el comportamiento del nitrato frente al $\mathrm{pH}$ y a la temperatura.

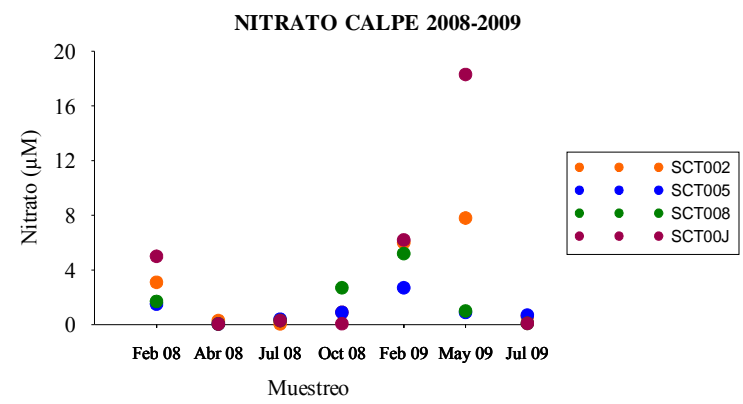

Figura 4.10: Concentraciones de nitrato registradas en la salina de Calpe durante las campañas de 2008-2009
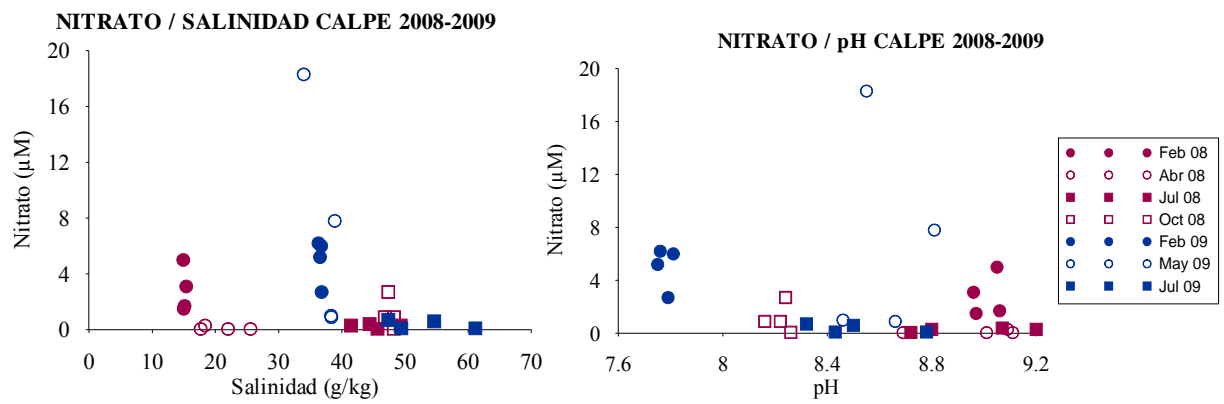


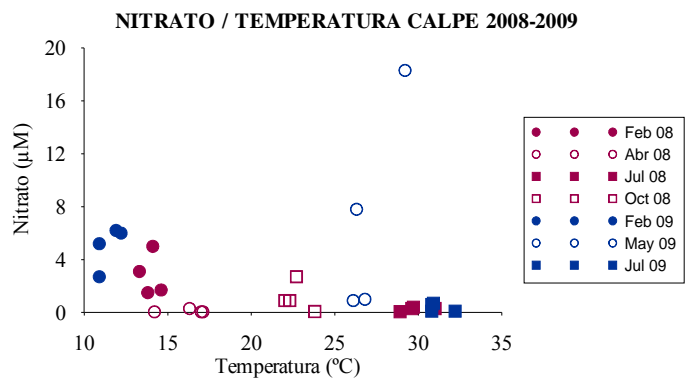

Figura 4.11: a) Comportamiento del nitrato respecto a la salinidad; b) Comportamiento del nitrato respecto al $\mathrm{pH}$ y c) Comportamiento del nitrato respecto a la temperatura en la salina de Calpe durante 2008-2009

\subsubsection{Nitrógeno Inorgánico Disuelto}

El nitrógeno inorgánico disuelto (NID) es la suma de las distintas formas de nitrógeno inorgánicas anteriormente estudiadas (amonio + nitritos + nitratos). En este caso, el contenido en NID se ve más bien condicionado por amonio y nitratos, especialmente por el amonio en aquellos muestreos en que se producen picos en este parámetro.

El rango de valores oscila entre $0,2 \mu \mathrm{M}$ en las estaciones SCT005 y SCT0J en el mes de abril de 2008 y 141,3 $\mu \mathrm{M}$ en la estación SCT00J en febrero de 2009. En las estaciones de febrero de 2009 y en octubre de 2008 los valores de NID más elevados coinciden con aquellas estaciones con valores de amonio mayores (figura 4.12).

En la figura 4.13a se representa el comportamiento del NID frente a la salinidad. En las restantes figuras se observa cómo los valores mayores de NID se dan en el muestreo con menor $\mathrm{pH}$ (figura 4.13b) y menor temperatura (figura 4.13c).

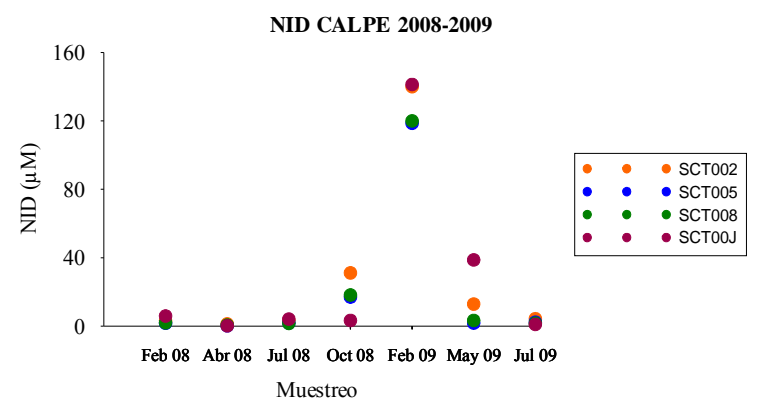

Figura 4.12: Concentraciones de NID registradas en la salina de Calpe durante las campañas de 2008-2009 

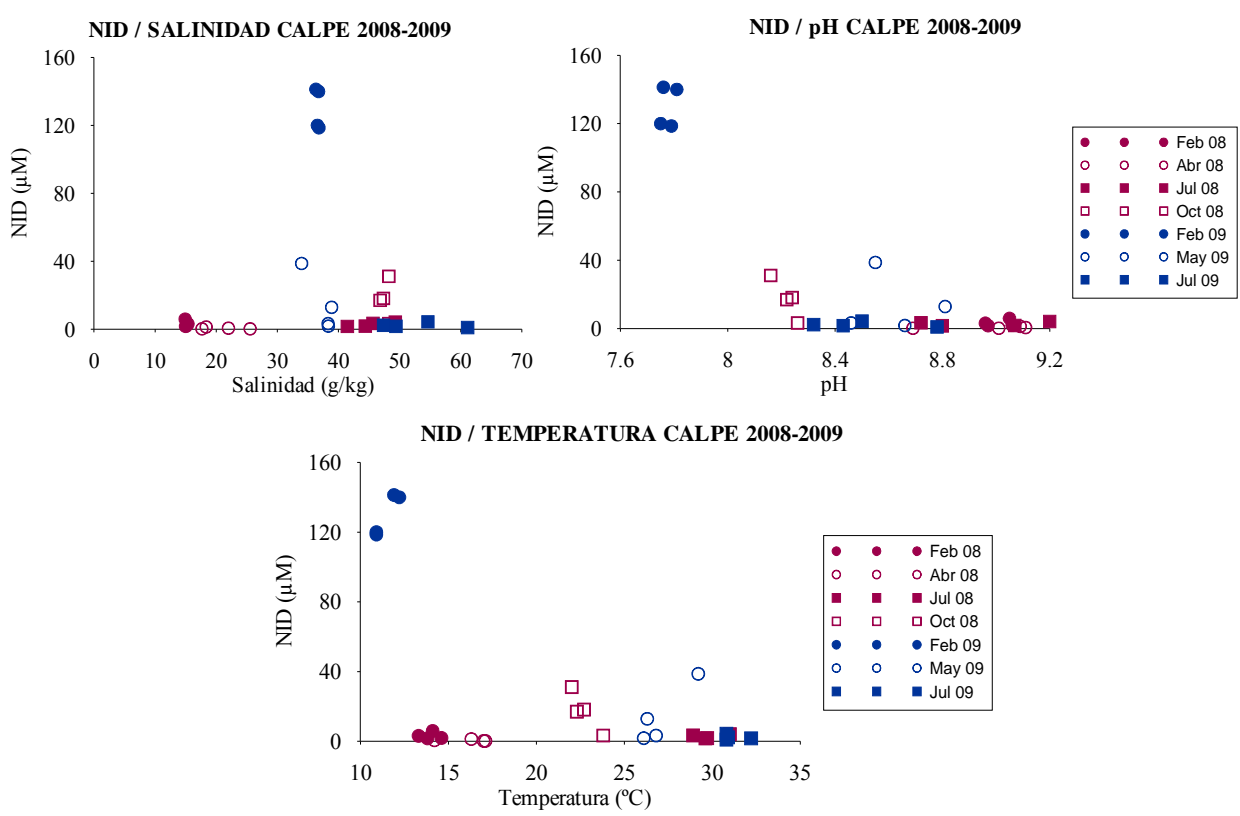

Figura 4.13: a) Comportamiento del NID respecto a la salinidad; b) Comportamiento del NID respecto al pH y c) Comportamiento del NID respecto a la temperatura en la salina de Calpe durante 2008-2009

\subsubsection{Fósforo Soluble Reactivo (PSR)}

El PSR se encuentra agotado en todo el sistema ya que todos los valores de PSR se encuentran por debajo del límite de detección, independientemente de la estación y la época del año muestreada. El límite de detección del PSR habitualmente es $<0,01 \mu \mathrm{M}$ aunque en caso de que la salinidad de la muestra sea más elevada que la del agua de mar, el límite varía según la dilución previa al análisis y puede oscilar, en este caso, entre $<0,01$ y $<0,02 \mu \mathrm{M}$.

El agotamiento del PSR se produce porque el fósforo que entra en la salina es rápidamente asimilado por el fitoplancton por lo que no se detecta en la columna de agua, siendo el nutriente limitante del sistema. Esto es debido a que el ortofosfato es la forma preferida por los seres vivos (Migon y Sandroni, 1999) y aunque muchas especies son capaces de usar fosfatos orgánicos disueltos (Riley y Chester, 1971) el fitoplancton normalmente satisface sus necesidades de fósforo por asimilación directa de ortofosfato. Además, la asimilación del fósforo que pueda entrar en la salina es rápida ya que el fitoplancton puede realizar una asimilación "en tromba" en una tasa muy elevada.

Hay que destacar que incluso en los momentos en los que se detectan aportes derivados de la mineralización de la materia orgánica con picos de amonio y descensos del $\mathrm{pH}$ por el aumento en la concentración de $\mathrm{CO}_{2}$, el PSR sigue por debajo del límite de detección. Ello nos indica que, o bien los aportes de PSR quedan retenidos en los sedimentos o si estos llegan a las aguas (indudablemente en proporciones mucho más bajas de las que cabría esperar de los niveles de amonio), son rápidamente absorbidos por la comunidad fitoplanctónica. 


\subsubsection{Relación NID/PSR}

La relación NID/PSR alcanza valores muy elevados porque el PSR se encuentra agotado en todo el sistema como hemos visto en el apartado anterior. El valor máximo es de 28260 y se alcanza en la estación SCT00J en febrero de 2009 mientras que el mínimo es de 40 y se alcanza en las estaciones SCT005 y SCT00J en abril de 2008 (figura 4.14). Destacan los valores tan elevados encontrados en el mes de febrero de 2009 por la gran cantidad de amonio existente en la laguna en ese mes. El hecho de que los valores de la relación NID/PSR estén siempre por encima de 40 muestra claramente que el sistema está controlado por el nivel de fósforo, que es evidentemente el nutriente limitante al ser la relación NID/PSR $>20$ en todo momento.

Como se puede apreciar, los gráficos de este apartado son similares a los presentados en el apartado de NID (4.1.1.6) ya que el PSR se encuentra agotado en todo el sistema. En estos no se observa ninguna relación entre este parámetro y la salinidad, ni con la temperatura (figuras $4.15 \mathrm{a} \mathrm{y} \mathrm{c)} \mathrm{aunque} \mathrm{parece} \mathrm{existir} \mathrm{una} \mathrm{relación} \mathrm{con} \mathrm{el} \mathrm{pH} \mathrm{(figura} \mathrm{4.15b)} \mathrm{al} \mathrm{observar}$ las relaciones mayores de NID/PSR con los valores de $\mathrm{pH}$ menores. Lógicamente esta relación no es casual y el aumento de la relación NID/PSR se debe a que los momentos en que el $\mathrm{pH}$ alcanza los valores más bajos están asociados a valores elevados de amonio que son los responsables del aumento de la relación. Por tanto, estos aumentos habría que relacionarlos causalmente con aportes de amonio desde el sedimento (que como ya hemos visto van unidos a los de $\mathrm{CO}_{2}$ que dan lugar al descenso del $\mathrm{pH}$ ).

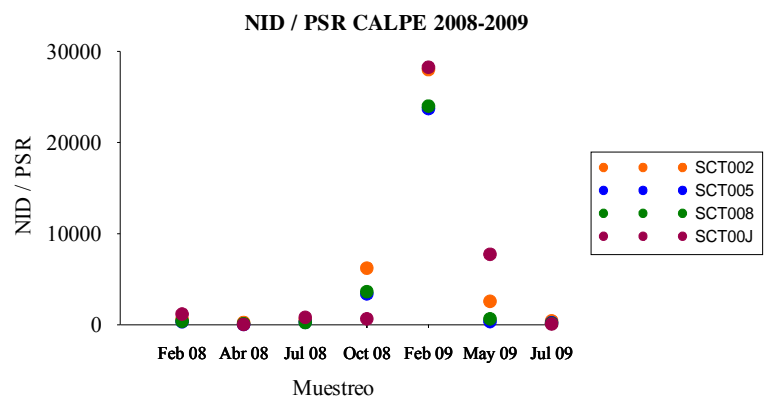

Figura 4.14: Relación NID/PSR en la salina de Calpe durante las campañas de 2008-2009
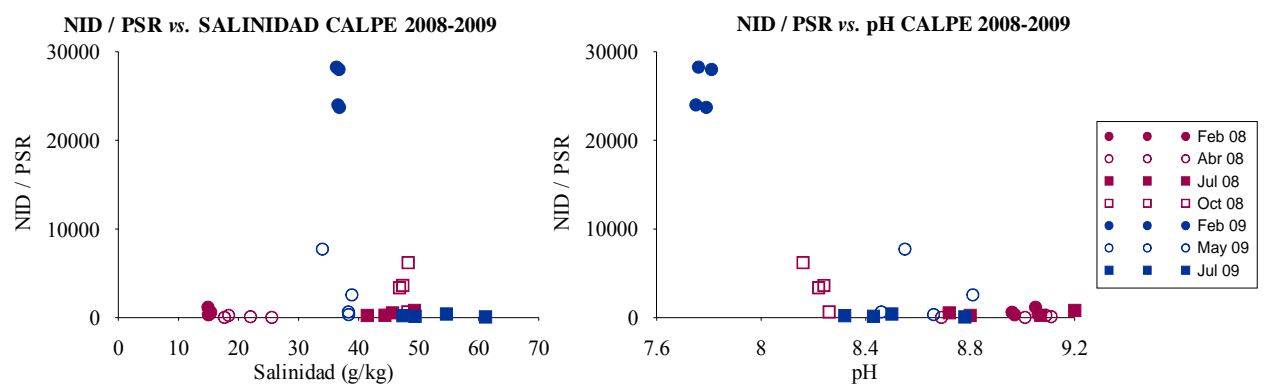


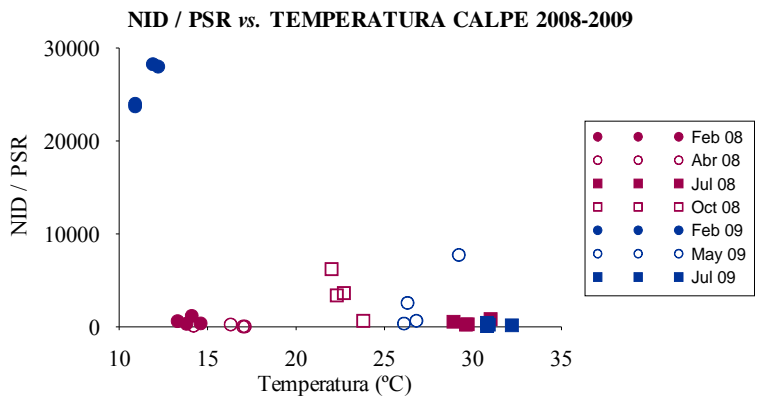

Figura 4.15: a) Comportamiento de la relación NID/PSR respecto a la salinidad; b) Comportamiento de la relación NID/PSR respecto al pH y c) Comportamiento de la relación NID/PSR respecto a la temperatura en la salina de Calpe durante 2008-2009

\subsubsection{Fósforo Total (PT)}

El PT en la salina de Calpe varía entre $0,24 \mu \mathrm{M}$ en SCT005 en febrero de 2008 y $1,98 \mu \mathrm{M}$ en SCT002 en el mes de julio de 2009. Los valores mayores de PT se encuentran en el muestreo de julio de 2009 (entre $1,07 \mu \mathrm{M}$ y 1,98 $\mu \mathrm{M}$ ), seguidos del muestreo de mayo de 2009 (entre $1,03 \mu \mathrm{M}$ y 1,54 $\mu \mathrm{M}$ ). En el año 2008 los valores más altos se encuentran en los meses de julio y octubre (ver figura 4.16).

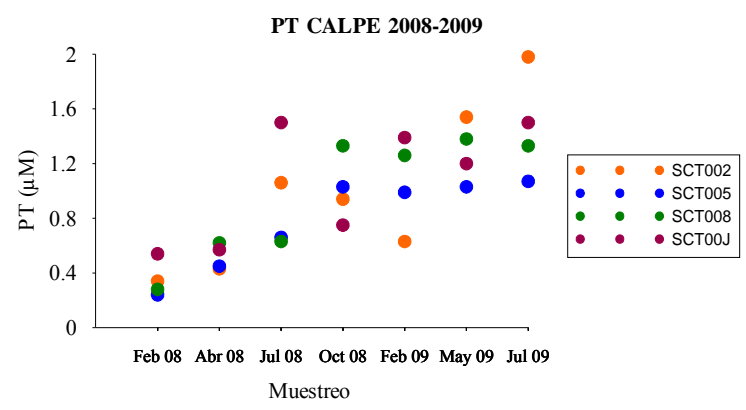

Figura 4.16: Concentraciones de PT registradas en la salina de Calpe durante las campañas de 2008-2009

En la figura 4.17a, se observa una tendencia al aumento de la concentración de PT conforme aumenta la salinidad debido al proceso de evapotranspiración, con desviaciones que son debidas indudablemente a la interferencia de los procesos de precipitación/sedimentación del PT. No se observa una relación clara entre PT y $\mathrm{pH}$ (figura 4.17b) mientras que parece que se da una relación entre PT y temperatura, ya que los valores menores se detectan en invierno y los mayores en verano. Aunque esta pauta estacional parece estar más condicionada por los procesos de aumento de la concentración salina que por un ciclo estacional asociado a la temperatura en sentido estricto (figura 4.17c). 

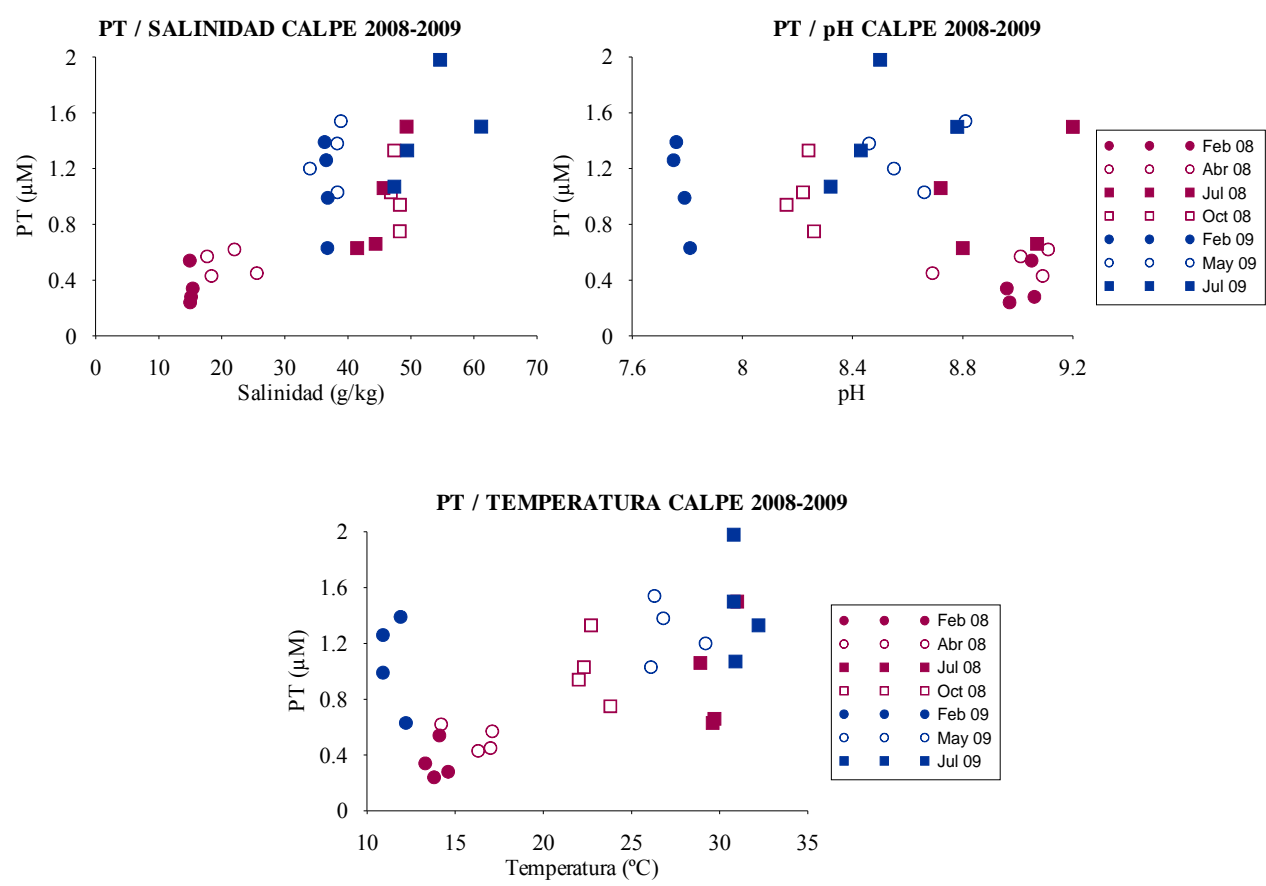

Figura 4.17: a) Comportamiento del PT respecto a la salinidad; b) Comportamiento del PT respecto al pH y c) Comportamiento del PT respecto a la temperatura en la salina de Calpe durante 2008-2009

\subsubsection{0. Ácido ortosilícico}

Los valores de ácido ortosilícico presentan oscilaciones importantes. El valor mínimo de $1,4 \mu \mathrm{M}$ se encuentra en SCT008 en el mes de febrero de 2008 mientras que el valor máximo de $152,0 \mu \mathrm{M}$ se da en SCT00J durante el mes de abril de 2008. También se observa una concentración muy alta de ácido ortosilícico en la estación SCT002 en julio de $2009(143,3 \mu \mathrm{M})$. En el 2008, los valores menores se dan en febrero de 2008 (entre 1,9 y $7,9 \mu \mathrm{M}$ ) mientras que los mayores se dan en los meses de julio y de octubre, así como en las estaciones SCT002 y SCT00J de abril. En el año 2009, los valores mayores se dan en el mes de julio (ver figura 4.18).

Al representar el ácido ortosilícico frente a la salinidad (figura 4.19a), se observa una mayor concentración de este parámetro cuanto mayor es la concentración salina alcanzando los valores mayores en julio de 2009, aunque hay algunos valores que se alejan de esta pauta y parecen deberse a aportes asociados a las entradas de agua dulce. No se observa un comportamiento claro entre este parámetro y el pH (figura 4.19b) y parece apreciarse un aumento conforme lo hace la temperatura (figura 4.19c) lo que está posiblemente relacionado con el proceso de concentración por las elevadas temperaturas.

Por lo general se aprecian concentraciones mayores en las estaciones SCT002 y SCT00J que son las estaciones más próximas a los aportes de agua dulce, mientras que en las estaciones más influenciadas por las entradas de agua de mar (SCT005 y SCT008) las concentraciones parecen ser más similares entre sí y menores. 


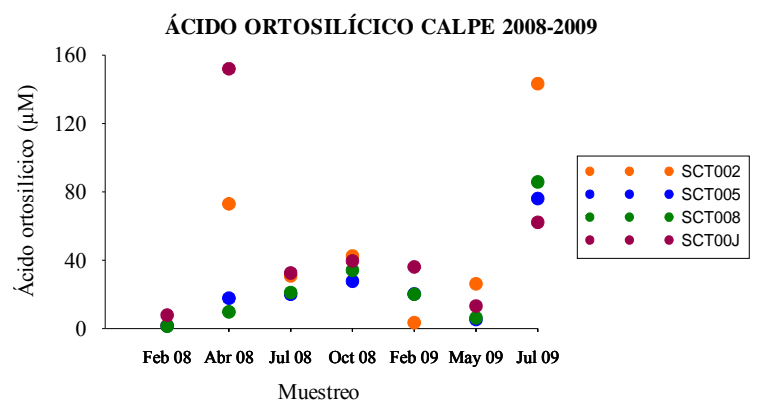

Figura 4.18: Concentraciones de ácido ortosilícico registradas en la salina de Calpe durante las campañas de 2008-2009
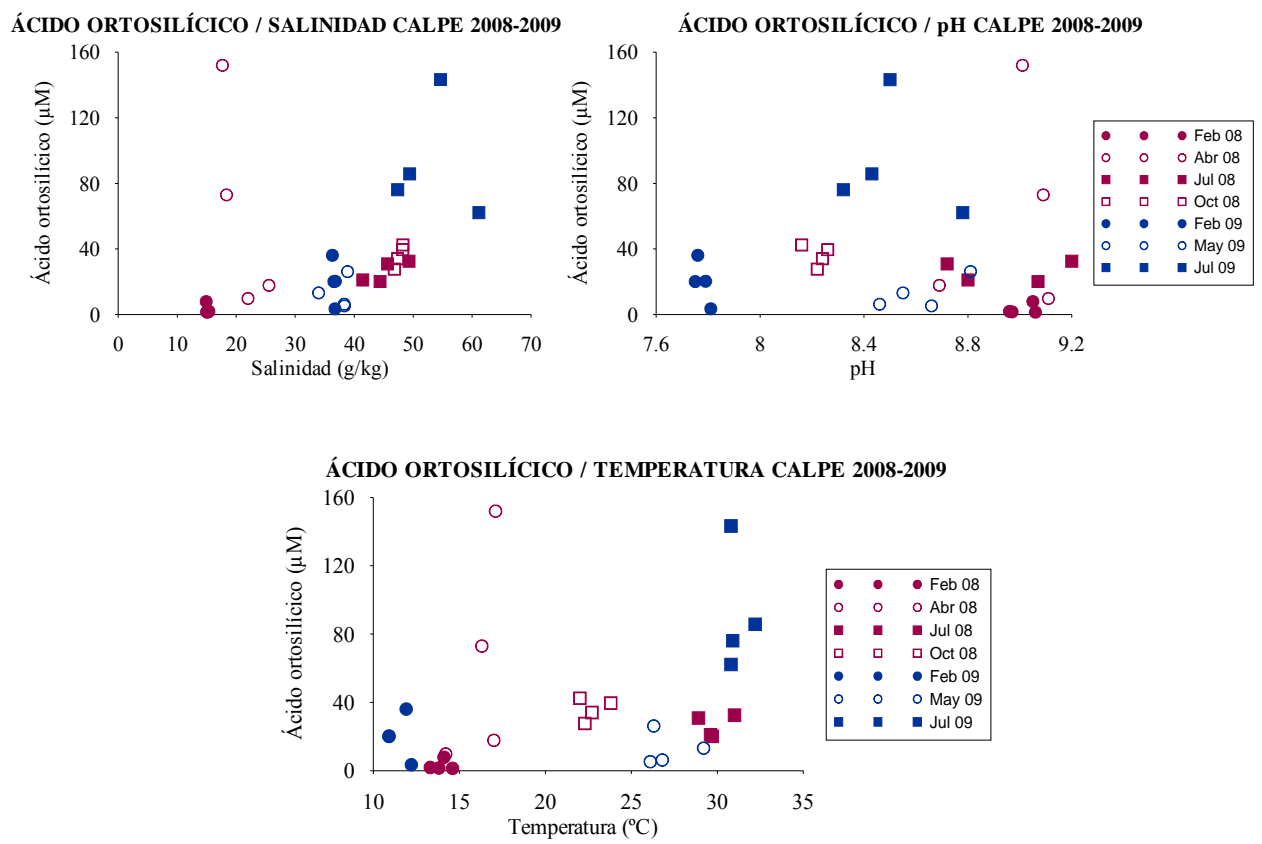

Figura 4.19: a) Comportamiento del ácido ortosilícico respecto a la salinidad; b) Comportamiento del ácido ortosilícico respecto al $\mathrm{pH}$ y c) Comportamiento del ácido ortosilícico respecto a la temperatura en la salina de Calpe durante 2008-2009 


\subsubsection{Análisis multivariable de la salina de Calpe}

Se ha realizado un análisis mediante componentes principales ó ACP (con el programa estadístico Statgraphics 5.1) de los resultados obtenidos para los diferentes parámetros físico-químicos de la salina de Calpe a excepción del PSR, que se encuentra agotado por completo en la laguna durante todos los muestreos. A los datos obtenidos se les ha efectuado una transformación logarítmica $(\log \mathrm{x}+1)$ previa al ACP (excepto al pH que ya presenta escala logarítmica) puesto que el rango de variación de los datos es muy heterogéneo.

En el análisis se han considerado los 7 muestreos llevados a cabo desde febrero de 2008 a julio de 2009 y se han incluido 7 variables: salinidad, $\mathrm{pH}$, amonio, nitrito, nitrato, PT y ácido ortosilícico. Este análisis nos ha permitido reducir las variables a dos componentes principales que en total explican un $78,712 \%$ de la varianza acumulada $(48,142 \%$ la componente 1 y $30,569 \%$ la componente 2 ).

\begin{tabular}{|rcc|}
\hline PARÁMETROS & $\begin{array}{c}\text { Componente 1 } \\
(\mathbf{4 8 , 1 4 2} \%)\end{array}$ & $\begin{array}{c}\text { Componente 2 } \\
\mathbf{( 3 0 , 5 6 9} \%)\end{array}$ \\
\hline Salinidad & 0,336225 & 0,460578 \\
\hline pH & $-0,472253$ & 0,0640458 \\
\hline Amonio & 0,491357 & $-0,160828$ \\
\hline Nitrito & 0,417703 & $-0,310551$ \\
\hline Nitrato & 0,280276 & $-0,492458$ \\
\hline PT & 0,380191 & 0,361339 \\
\hline Ác. ortosilícico & 0,157868 & 0,537008 \\
\hline
\end{tabular}

Tabla 4.1: Tabla de pesos de los componentes del ACP para los parámetros físico-químicos de Calpe

Gráfico de Pesos del Componente

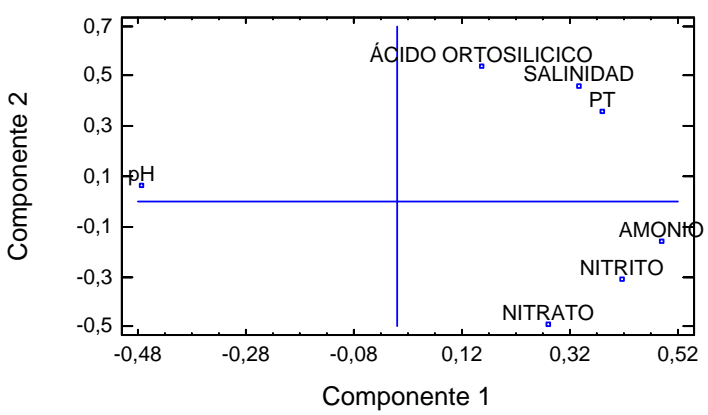

Figura 4.20: Gráfico de pesos de los componentes del ACP para los parámetros físico-químicos de Calpe

A partir de los resultados obtenidos en la tabla de pesos de los componentes (tabla 4.1) y su representación gráfica (figura 4.20) se deduce que la componente 1 representa los procesos internos asociados a la mineralización de la materia orgánica que tienen lugar en la laguna con valores bajos de $\mathrm{pH}$ y altos de amonio y nitritos (y en menor medida de nitratos y PT) donde parte del amonio es transformado en nitritos por procesos de nitrificación probablemente de origen béntico. 
La componente 2 parece estar asociada a los procesos de concentración salina a través de la evapotranspiración, lo que conlleva un aumento del PT y del ácido ortosilícico.

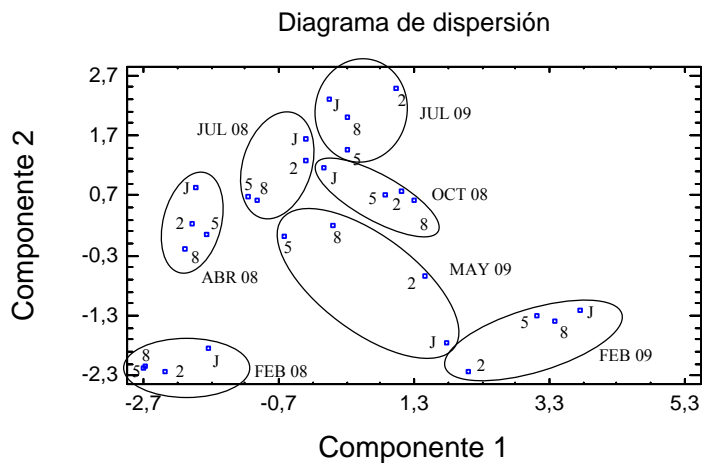

Figura 4.21: Diagrama de dispersión de los componentes 1 y 2 del ACP para los parámetros físico-químicos de la salina de Calpe

En la representación del diagrama de dispersión (figura 4.21), se puede observar cómo respecto a la componente 1 (procesos de mineralización de la materia orgánica cuyos parámetros indicadores son $\mathrm{pH}$, amonio, nitritos y en menor medida nitratos) los muestreos de febrero, abril y julio de 2008 están en consonancia ya que dichos muestreos presentan los valores más elevados de $\mathrm{pH}$, niveles de amonio y de nitritos muy bajos y valores muy bajos de nitratos (un poco superiores en febrero de 2008) aunque el peso del nitrato es menor. Los muestreos de octubre de 2008, mayo 2009 y julio de 2009 se encuentran próximos en el diagrama de dispersión porque en ellos el $\mathrm{pH}$ disminuye relativamente respecto a los muestreos anteriores. En mayo de 2009 se observa una clara división entre estaciones porque los valores de SCT002 y SCT00J se disparan en amonio, nitritos y nitratos aunque en menor medida que en febrero de 2009. Finalmente, febrero de 2009 es el que más se diferencia del resto debido a que presenta el valor menor de $\mathrm{pH}$ y tanto amonio como nitritos se disparan en dicho muestreo por los procesos de nitrificación que tienen lugar en la laguna.

Respecto a la componente 2 (procesos de concentración salina, cuyos parámetros indicadores son salinidad, PT y ácido ortosilícico) en un extremo se encuentra el muestreo de febrero de 2008 con una salinidad y un contenido en PT y ácido ortosilícico bajo. En cuanto al resto de muestreos, se diferencia julio de 2009, cuyos valores se alejan del resto debido a que este muestreo presenta los niveles de salinidad, PT y ácido ortosilícico más elevados. (Los valores de ácido ortosilícico en julio de 2009 son similares a los de abril de 2008 aunque en julio de 2009 la salinidad es mucho mayor).

En la representación del conglomerado jerárquico (realizado con el programa estadístico SPSS 16.0) (figura 4.22) se aprecia claramente que febrero de 2009 es el muestreo que más difiere del resto. Esto es debido fundamentalmente al elevado contenido en amonio aunque también destacan niveles elevados de nitritos (ambos parámetros son los más elevados de todos los muestreos), un pH relativamente bajo (el más bajo de todos) y una salinidad baja. Se observa una asociación entre algunas estaciones entre febrero y abril de 2008 que son los muestreos de menores salinidades, si bien las estaciones SCT002 y SCT00J de abril de 
2008 se asocian con julio de 2009 por los elevados contenidos de ácido ortosilícico que todas ellas presentan. Finalmente se observa una asociación entre los muestreos restantes, julio y octubre de 2008 y mayo de 2009.

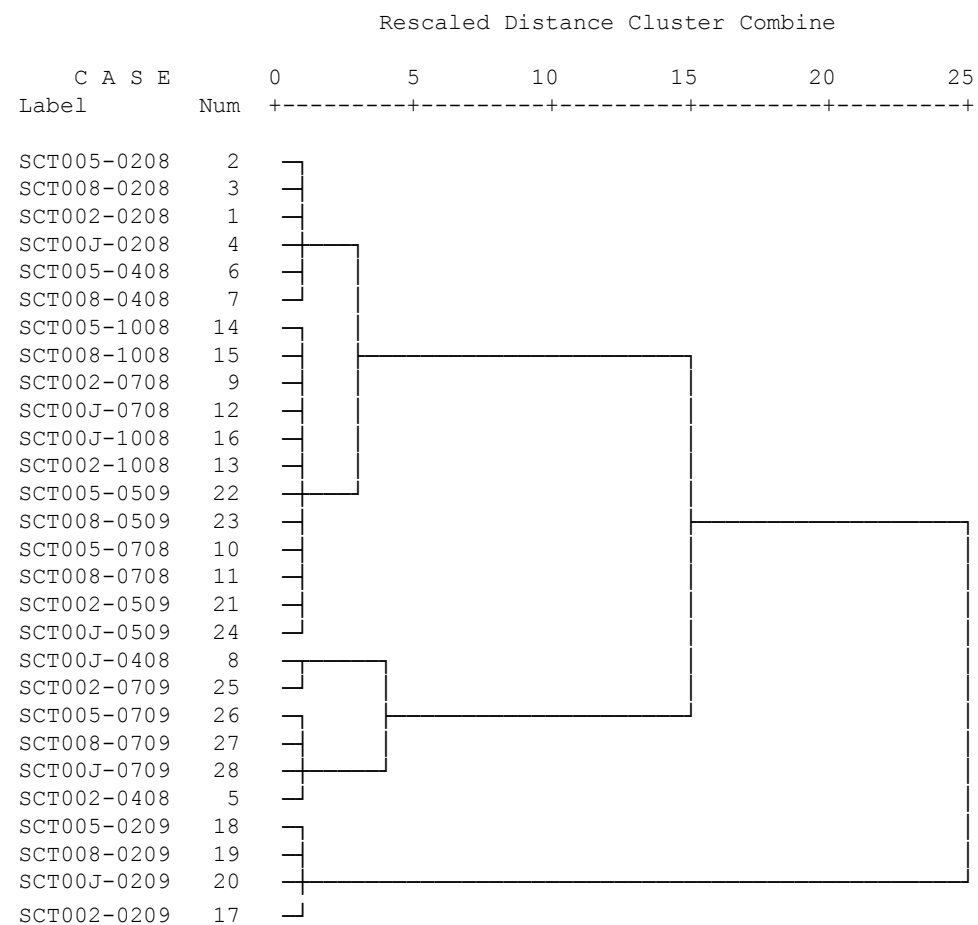

Figura 4.22: Conglomerado jerárquico con la agrupación de las estaciones para cada una de las campañas muestreadas en la salina de Calpe 


\subsection{SALINA DE LA MATA}

\subsubsection{Análisis de los parámetros físico-químicos}

\subsubsection{Salinidad}

La salinidad en La Mata alcanza valores muy elevados ya que esta laguna, aunque en parte tiene las características propias de un gran estanque "calentador" dentro del sistema La Mata - Torrevieja, dadas las características particulares del sistema de explotación sus niveles salinos son más altos de los que cabría esperar de un calentador en sentido estricto. La principal función de La Mata estriba en proporcionar agua con salinidades altas a Torrevieja para mantener la columna de agua y la salinidad que precisa el sistema de explotación.

Por tanto, la laguna de La Mata está conectada con el mar y puede recibir agua marina y aportarla a Torrevieja. Además, La Mata también puede ser utilizada como receptor de aguas de salinidades bajas provenientes de Torrevieja en momentos de lluvias torrenciales y puede recibir aportes continentales procedentes de aguas de escorrentía.

Para poder abordar el estudio de la laguna en su totalidad es necesario tener en cuenta el régimen de precipitaciones. Las precipitaciones registradas en la estación meteorológica más cercana de la que se disponen datos completos para el período de estudio es la denominada Laguna de Torrevieja (estación 7038 de la Agencia Estatal de Meteorología (AEMET); UTM X: 701067; UTM Y: 4205830; Altitud: $1 \mathrm{~m}$ ) (figura 4.23), situada a unos $7 \mathrm{~km}$ del centro de la laguna de La Mata.

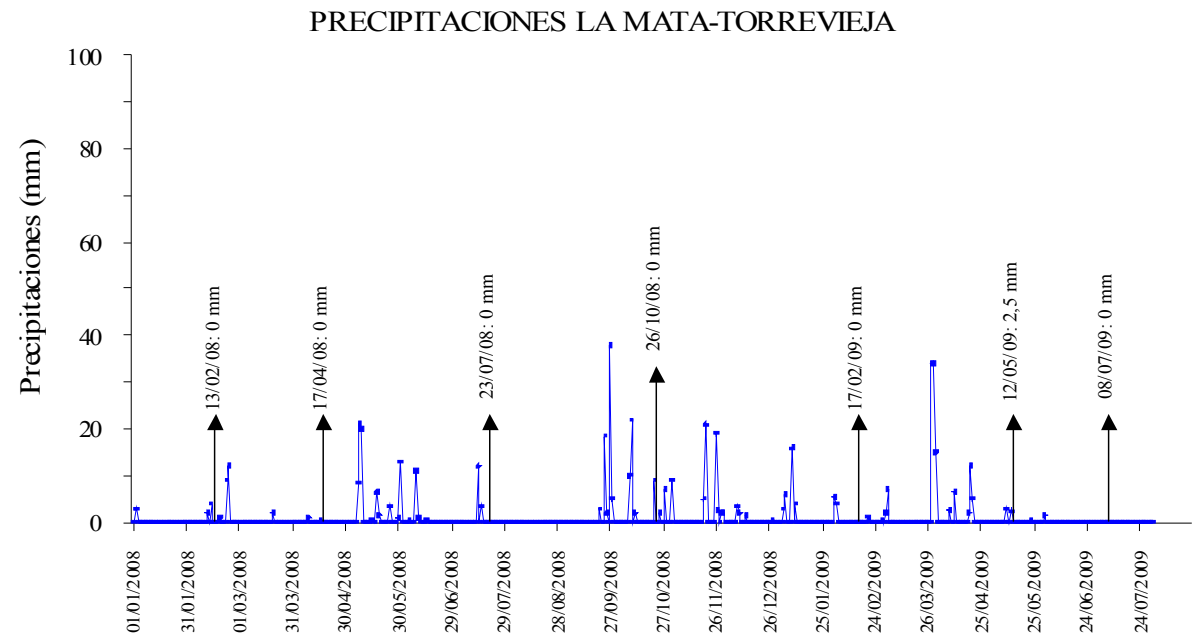

Años 2008-2009

Figura 4.23: Precipitaciones diarias (mm) en la estación Laguna de Torrevieja durante el período 2008-2009. En la figura se han marcado las precipitaciones correspondientes a los días de muestreo (Fuente: AEMET)

Además hay que considerar los trasvases de agua marina a La Mata (por su función como calentador) y especialmente de Torrevieja a La Mata (que tienen lugar en momentos puntuales con importantes precipitaciones y pueden condicionar la salinidad de esta 
última). Durante el período de estudio según la empresa gestora de las salinas de Torrevieja, no se efectuaron trasvases desde Torrevieja a La Mata. En la figura 4.24 se muestra la ubicación de las estaciones de muestreo en La Mata-Torrevieja.

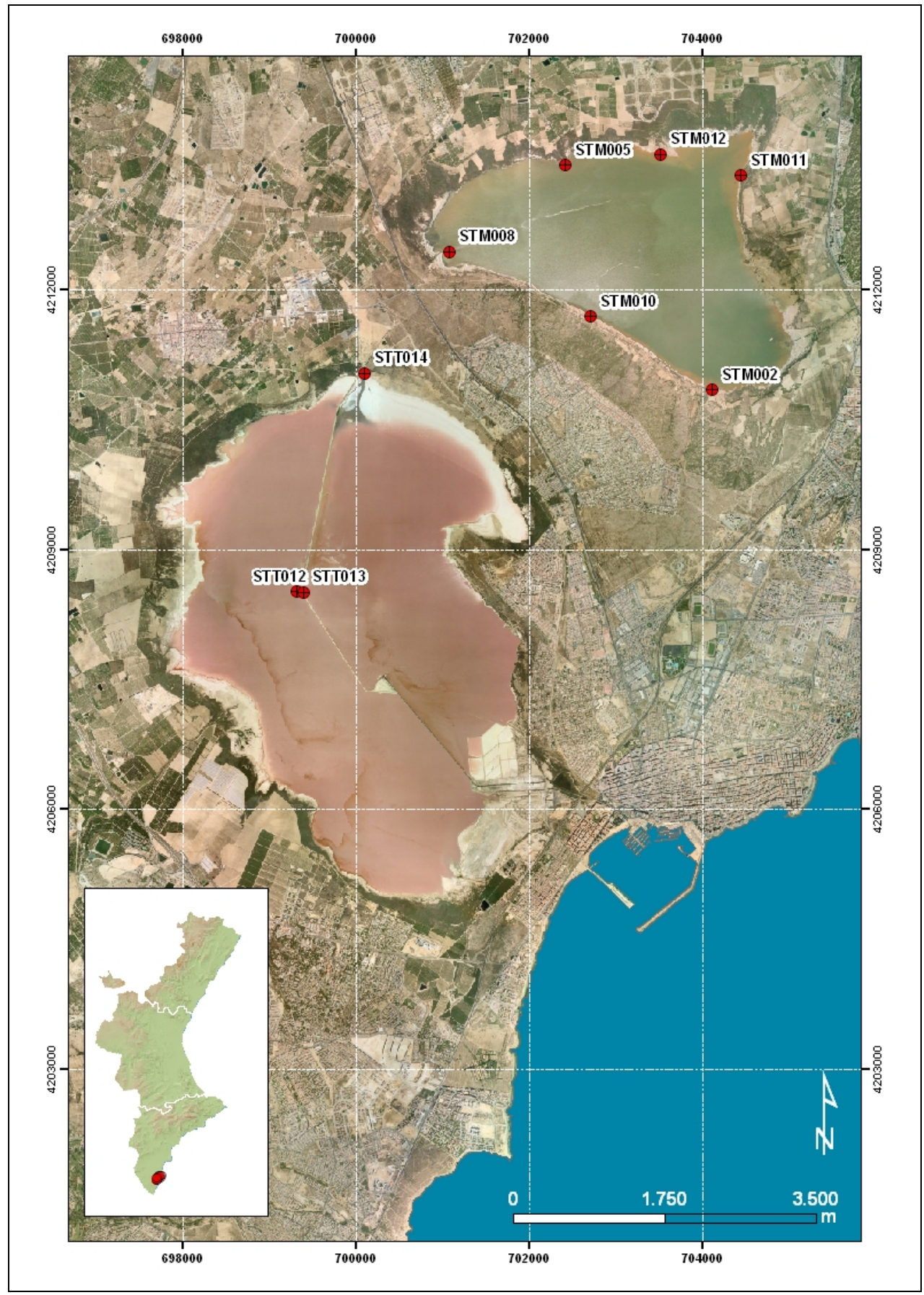


Figura 4.24: Ubicación de las estaciones de muestreo en la salina de La Mata - Torrevieja

Los valores de salinidad se muestran en la figura 4.25, donde se han representado mediante diagramas de Box-Whisker los percentiles $\mathrm{P}_{25}, \mathrm{P}_{50}, \mathrm{P}_{75}$, el máximo y el mínimo de salinidad para cada muestreo. El valor mínimo es de $97,6 \mathrm{~g} / \mathrm{kg}$ que se encuentra en la estación STM008 en el mes de febrero de 2008 y el máximo es de $136,4 \mathrm{~g} / \mathrm{kg}$ que se da en la estación STM012 en octubre del mismo año.

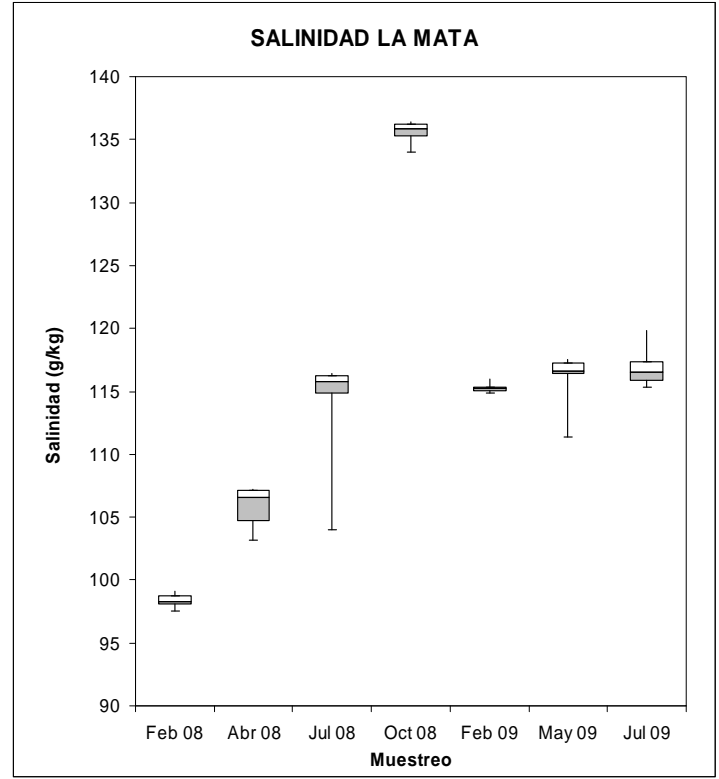

Figura 4.25: Salinidades registradas en la laguna de La Mata durante las campañas de 2008-2009

En febrero de 2008 (13/02/08) se registran valores de salinidad en torno a los $98 \mathrm{~g} / \mathrm{kg}$ en toda la laguna. Previamente al muestreo se produjeron importantes precipitaciones durante octubre de 2007 que si bien no quedan reflejadas en la figura de registros meteorológicos, tanto los cuadernos de campo de los muestreos como las informaciones de los medios de comunicación las confirman. Existe la posibilidad de que se haya producido un trasvase de aguas procedentes de escorrentías de Torrevieja a La Mata que no se puede afirmar con certeza ya que según la empresa gestora ese trasvase no ha tenido lugar aunque el estudio de algunos de los parámetros físico-químicos que veremos a continuación así parecen indicarlo.

En el muestreo de abril de 2008 (17/04/08), los valores de salinidad son un poco mayores que en el muestreo anterior (entre 103,2 - 107,2 g/ $/ \mathrm{kg}$ ). Parece ser que en el período comprendido entre febrero y este muestreo, prevalece la evapotranspiración sobre las precipitaciones (que son muy escasas como se puede observar en la figura 4.23) y sobre la entrada de agua de mar en la laguna, lo que provoca un aumento de la concentración de las sales.

En julio de 2008 (23/07/08) los valores de salinidad son ligeramente superiores, con valores entre $104-116,4 \mathrm{~g} / \mathrm{kg}$. La elevada evapotranspiración, propia de esta época del año, parece 
ser que tiene una mayor influencia respecto a otros procesos como las precipitaciones o las entradas de agua de mar, lo que tiene su reflejo en una mayor concentración de la salinidad en la laguna.

Los valores más elevados de salinidad se detectan durante el muestreo de octubre de 2008 (21/10/08) oscilando entre $134-136,4 \mathrm{~g} / \mathrm{kg}$. El considerable aumento de la salinidad de julio a octubre cabe achacarlo una vez más a la evapotranspiración que predomina sobre las precipitaciones y las entradas de agua de mar.

En el muestreo de febrero de 2009 (17/02/09), la salinidad descendió de forma considerable respecto al muestreo anterior, con valores en torno a los $115 \mathrm{~g} / \mathrm{kg}$. Este descenso es debido a que en este período la entrada de aguas dulces en la laguna fue importante (ver figura 4.23) y a que la evapotranspiración en dicho período fue menor.

En todos los muestreos del año 2009, febrero (17/02/09), mayo (12/05/09) y julio (8/07/09) se observan valores de salinidad muy similares puesto que el rango de variación oscila entre 111,4 g/kg (STM02 en mayo de 2009) y 119,8 g/kg (STM012 en julio de 2009). Estos niveles tan uniformes de salinidad de 2009 son posiblemente debidos a la gestión antrópica de la laguna mediante el canal que une La Mata con Torrevieja (que permite el vertido de aguas concentradas a Torrevieja) y al canal que une La Mata con el mar (que permite la recepción de aguas marinas de menor salinidad).

Seguramente las importantes precipitaciones que tuvieron lugar en toda la comarca previas al muestreo de febrero de 2008 afectaron a la capacidad de regulación de la salinidad a través de la gestión antrópica de los flujos de agua en el sistema Mata-Torrevieja, lo que impidió mantener unos niveles uniformes de salinidad en febrero y abril de 2008 que sí se consiguieron mantener durante el 2009.

Por otra parte, no se observan diferencias significativas de salinidad entre las diferentes estaciones de muestreo, aunque en algunos muestreos de detectan valores ligeramente inferiores en la estación STM002 (ver tabla 4.2). Esta estación es la más próxima al canal que introduce el agua de mar en la laguna de La Mata por lo que la dilución en esta estación parece ser un poco superior al resto.

\begin{tabular}{|cc|cc|}
\hline ESTACIÓN & P $_{50}$ SAL & ESTACIÓN & P $_{50}$ SAL \\
\hline STM002 & 111,4 & STM010 & 115,3 \\
\hline STM005 & 115,9 & STM011 & 116,2 \\
\hline STM008 & 116,4 & STM012 & 115,4 \\
\hline
\end{tabular}

Tabla 4.2: Valores de $\mathrm{P}_{50}$ de salinidad $(\mathrm{g} / \mathrm{kg})$ en las diferentes estaciones de La Mata para las campañas de 20082009

\subsubsection{2. $\mathrm{pH}$}

El pH oscila entre 7,65 en la estación STM002 durante el mes de abril de 2008 y 8,55 en STM011 en julio de 2009. Como se puede observar, existen diferencias importantes según el mes muestreado. Los valores menores se dan en febrero y abril de 2008 y febrero de 2009 y los mayores en julio de 2009 (ver figura 4.27). 
Aunque a partir de los datos obtenidos parecería que hay una tendencia a que aumente el $\mathrm{pH}$ cuando lo hace la salinidad (figura 4.28a), no se observa una pauta de comportamiento clara puesto que la correlación es muy baja (coeficiente de determinación $\mathrm{R}^{2}: 0,3657$ con un $\mathrm{p}$ valor $<0,001$ y un nivel de significatividad $\alpha$ de 0,01 ). Sin embargo, al representar el $\mathrm{pH}$ respecto a la temperatura (figura $4.28 \mathrm{~b}$ ) la relación es mayor (coeficiente de determinación $\mathrm{R}^{2}$ : 0,6503 con un $\mathrm{p}$ valor $<0,001$ y un nivel de significatividad $\alpha$ de 0,01 ), ya que tiende a haber un $\mathrm{pH}$ menor con temperaturas inferiores a los $20^{\circ} \mathrm{C}$ (época invernal) y un pH más elevado con temperaturas por encima de $\operatorname{los} 20^{\circ} \mathrm{C}$.

Dada la problemática del pH tanto en estas salinas como en todas las restantes, en las que se alcanzan valores claramente inferiores a los que normalmente se dan en las aguas de mar, se han realizado una serie de pruebas con el objeto de comprobar si estas diferencias en el pH se debían a cambios en el contenido de $\mathrm{CO}_{2}$ relacionados con el sistema carbónico - carbonato o a cambios en la composición iónica de las aguas a lo largo del proceso de concentración salina. Con tal fin se realizaron pruebas en aguas de $\mathrm{pH}$ relativamente bajo de Torrevieja y La Mata que consistieron en una aireación con nitrógeno $\left(\mathrm{N}_{2}\right)$ de las muestras cuyo objetivo era ver si el arrastre provocado por el $\mathrm{N}_{2}$ de los gases existentes en las muestras (fundamentalmente $\mathrm{CO}_{2}$ ) daba lugar a cambios en el $\mathrm{pH}$ o no.

En primer lugar se hicieron pruebas sobre muestras de La Mata (STM008) y Torrevieja (STT012 y STT014 (en la salida de la tubería de Pinoso)), aireando $\mathrm{N}_{2}$ (figura 4.26a) directamente en las muestras y midiendo el $\mathrm{pH}$ cada 15 minutos. Pero a fin de verificar que la falta de subida era debida a la falta de difusibilidad, se realizaron nuevas pruebas en las muestras más salinas y con mayor densidad (STT012 y STT014), manteniendo la aireación con difusor en lugar de con tubo abierto durante 22,5 horas y midiendo cada hora durante las primeras 12 horas (figura 4.26b) obteniendo los siguientes resultados:
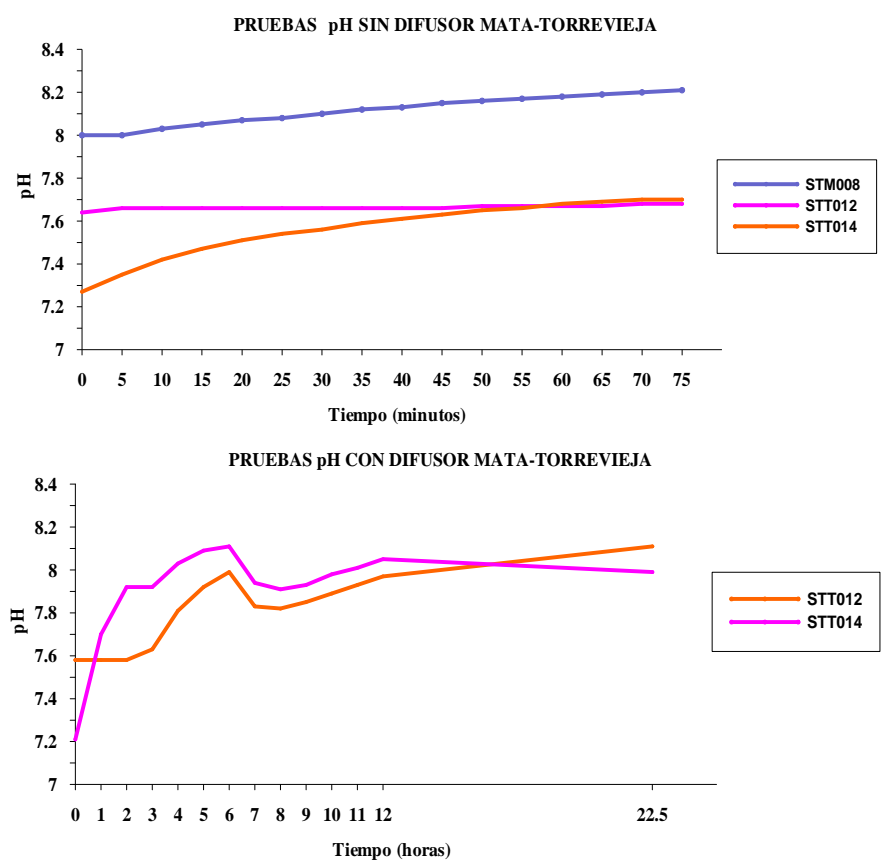

Figura 4.26: a) Pruebas $\mathrm{pH}$ sin difusor y b) Pruebas $\mathrm{pH}$ con difusor en muestras de La Mata - Torrevieja 
Como se puede observar, los ensayos muestran que tras varias horas de aireación con $\mathrm{N}_{2}$ mediante difusor, el $\mathrm{pH}$ fue aumentando progresivamente hasta alcanzar 8,1 en la muestra de la laguna de Torrevieja STT012 (figura 4.26b) y 8,2 en la de La Mata STM008 (figura 4.26a). Esto nos indica que el cambio iónico como mucho puede ser responsable de una reducción de 0,1 unidades en La Mata y de 0,2 unidades en Torrevieja, respecto a un $\mathrm{pH}$ en torno a 8,3 del agua de mar.

En La Mata, la salinidad oscila entre 97,6 - 136,4 g/kg, para estos valores posiblemente ya se ha producido la precipitación del carbonato de calcio $\left(\mathrm{CaCO}_{3}\right)$, puesto que según Lazar et al. (1983) el $\mathrm{CaCO}_{3}$ precipita cuando el agua de mar se concentra entre 2,5 - 4 veces (entre $92-148 \mathrm{~g} / \mathrm{kg}$ aproximadamente). Esto reduce la capacidad del sistema de regular la concentración de carbónico-carbonato a través de la precipitación del $\mathrm{CaCO}_{3}$, y por tanto de tamponar el efecto sobre el $\mathrm{pH}$ del aumento de las entradas de $\mathrm{CO}_{2}$ al sistema.

Además, la limitada hidrodinámica de la laguna junto con la elevada densidad de las aguas parece provocar una sobresaturación del $\mathrm{CO}_{2}$ derivado de la descomposición de la materia orgánica, lo que da lugar a los descensos de $\mathrm{pH}$ reseñados (aunque también puede darse la participación en el proceso de otros ácidos derivados de la descomposición de la materia orgánica).

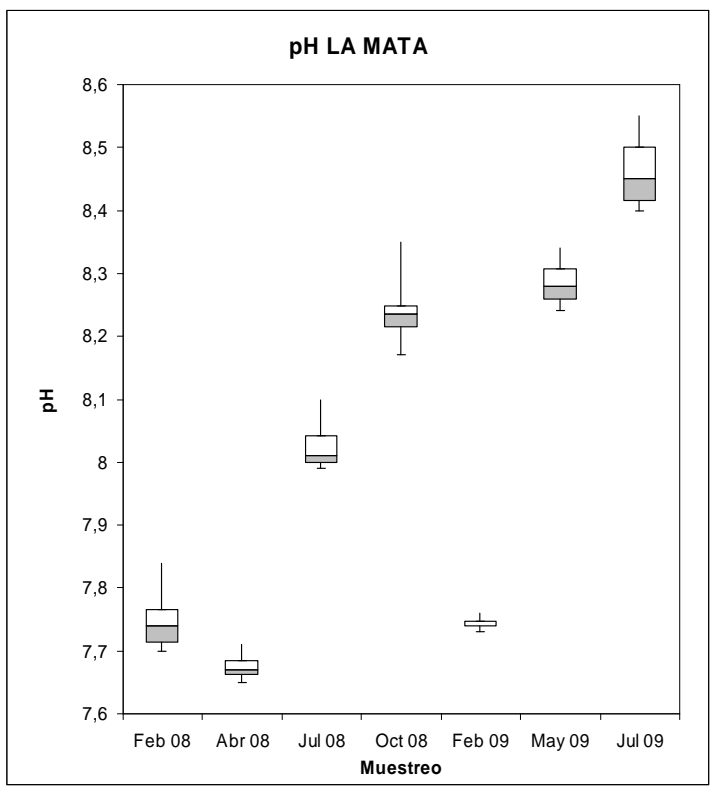

Figura 4.27: Valores de $\mathrm{pH}$ registrados en la laguna de La Mata durante las campañas de 2008-2009 

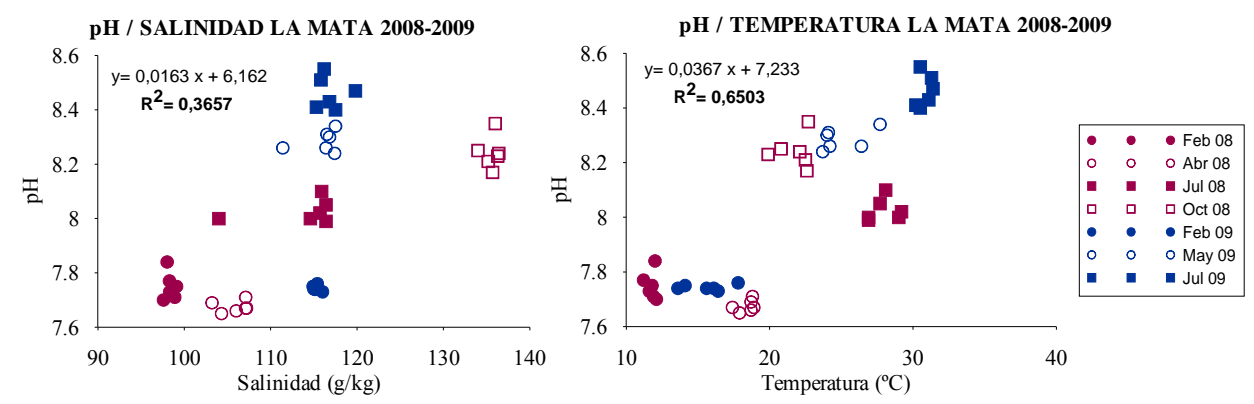

Figura 4.28: a) Comportamiento del $\mathrm{pH}$ respecto a la salinidad y b) Comportamiento del pH respecto a la temperatura en la laguna de La Mata durante 2008-2009

\subsubsection{Amonio}

El amonio presenta un rango de concentraciones muy amplio que va de 1,6 $\mu \mathrm{M}$ (STM012 en mayo de 2009) a 526,7 $\mu \mathrm{M}$ (STM002 en abril de 2008). Como se puede observar en la figura 4.29, este parámetro ha alcanzado concentraciones muy diferentes a lo largo de las campañas de muestreo. Los valores más altos se encuentran en los muestreos de febrero de 2008, abril de 2008 y julio de 2008 con concentraciones entre 258,6 y $526,7 \mu \mathrm{M}$, mientras que en los muestreos de octubre de 2008, febrero de 2009, mayo de 2009 y julio de 2009 los valores son mucho menores ya que oscilan entre 1,6 y 12,9 $\mu \mathrm{M}$ (figura 4.29).

Tal y como se muestra en la figura 4.30a, no parece observarse una relación entre las concentraciones de amonio y el contenido en sales de la laguna. Tampoco parece haber relación entre los niveles de amonio y la temperatura (figura 4.30c).

Los valores tan elevados de febrero de 2008, abril de 2008 y julio de 2008 podrían ser debidos a liberaciones de amonio procedentes de procesos de degradación de la materia orgánica, ya que estos muestreos coinciden con los de valores menores de $\mathrm{pH}$ (figura 4.30b). Aunque no se descarta que parte de esas concentraciones de amonio tan elevadas tuvieran su origen en las aguas cargadas de amonio de Torrevieja que en febrero de 2008 podrían haber sido trasvasadas a La Mata, por las intensas precipitaciones que tuvieron lugar en la comarca en esa fecha, y que se hubieran mantenido hasta julio de 2008.

En febrero de 2009 parece producirse una liberación de amonio ya que coincide con valores de $\mathrm{pH}$ relativamente bajos (achacables a procesos de remineralización de la materia orgánica); aunque parte del amonio liberado en este muestreo parece haberse transformado por nitrificación en nitritos y nitratos (ver gráfica 4.35 en que se representan las concentraciones de NID). En este caso el NID parece derivar directamente de la descomposición de la biota pelágica por los elevados niveles de PSR y la menor concentración de NID. Probablemente, la reducción de la salinidad entre octubre de 2008 y febrero de 2009, ha originado a través del shock salino la muerte y descomposición de parte de la biota pelágica que conforma el sistema planctónico de la laguna. 


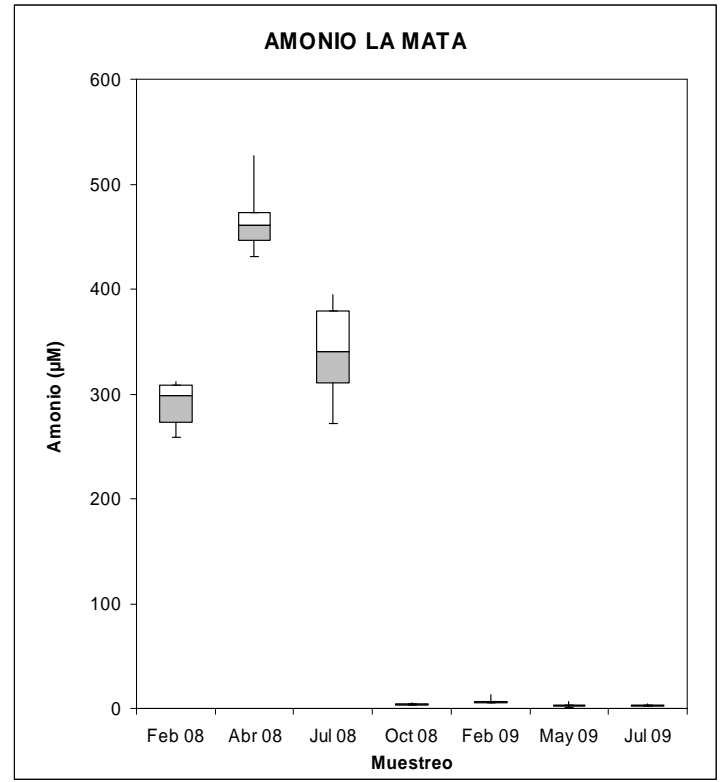

Figura 4.29: Concentraciones de amonio registradas en la laguna de La Mata durante las campañas de 2008-2009
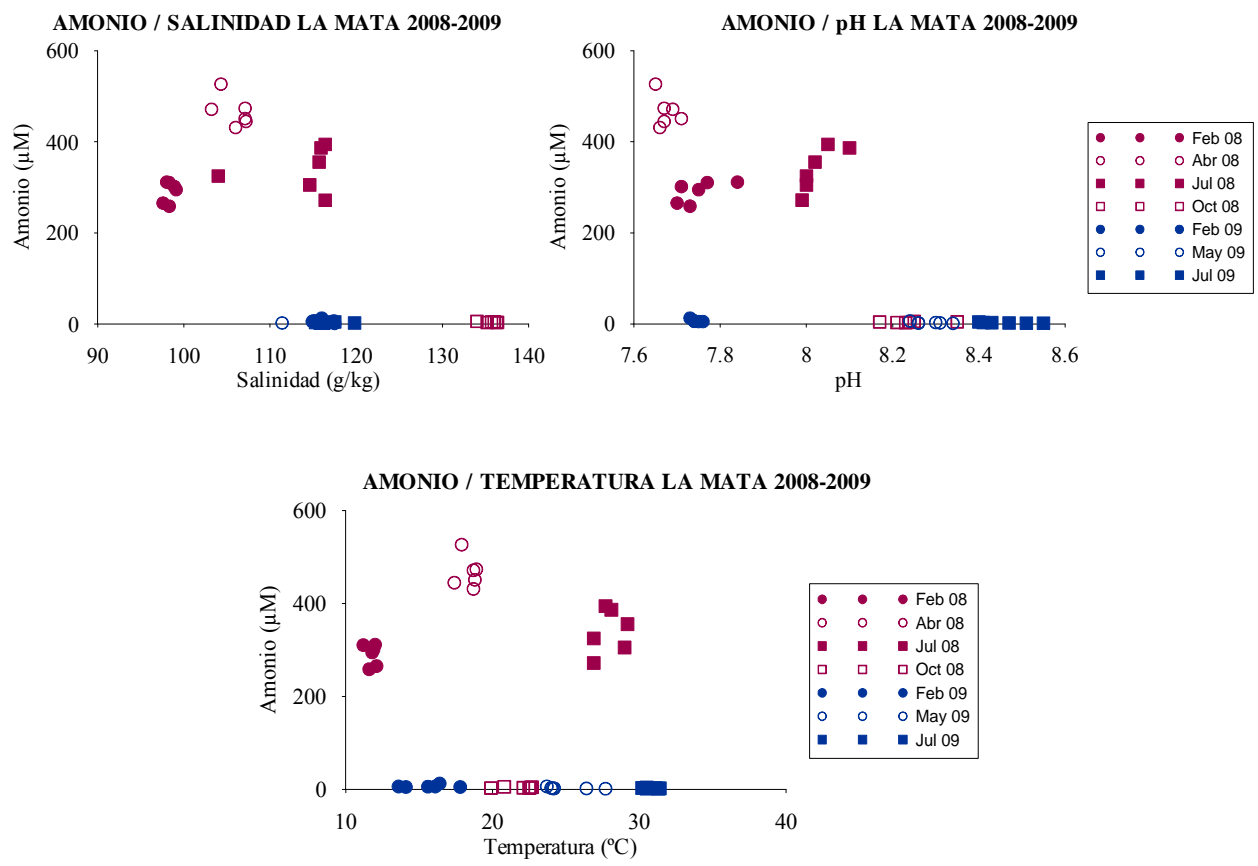

Figura 4.30: a) Comportamiento del amonio respecto a la salinidad; b) Comportamiento del amonio respecto al pH y c) Comportamiento del amonio respecto a la temperatura en la laguna de La Mata durante 2008-2009 


\subsubsection{Nitrito}

El nitrito presenta concentraciones bajas en la mayor parte de los muestreos, que oscilan entre valores por debajo del límite de detección $(<0,03 \mu \mathrm{M})$ y 2,26 $\mu \mathrm{M}$ (en STM008 durante el muestreo de febrero de 2008) (ver figura 4.31). No se observa ninguna relación entre el contenido en nitritos y la salinidad (figura 4.32a) aunque sí parece observarse una relación inversa entre nitritos y $\mathrm{pH}$ (figura 4.32b) y nitritos y temperatura (figura 4.32c).

Las concentraciones más elevadas se dan en los muestreos de febrero de 2008 y en menor medida en febrero de 2009. A partir de los resultados obtenidos, parece que la fuente de nitritos en la columna de agua es por los procesos de nitrificación que tienen lugar en la misma laguna, aunque parte de los nitritos de febrero de 2008 podría proceder de Torrevieja. Hay que recordar que la nitrificación es un proceso que está relacionado con la temperatura puesto que existe una relación positiva entre las tasas de nitrificación y la temperatura (Helder y De Vries, 1983). La nitrificación, especialmente el paso de nitritos a nitratos, puede verse inhibido en períodos de bajas temperaturas (Herbert, 1999), lo que explicaría que hubiera picos de nitritos en los meses de febrero.

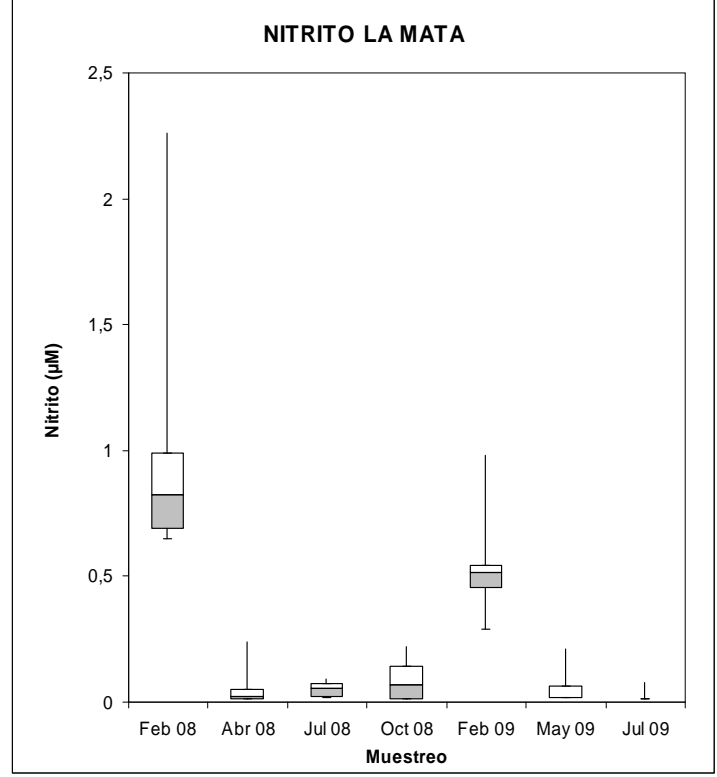

Figura 4.31: Concentraciones de nitrito registradas en la laguna de La Mata durante las campañas de 2008-2009
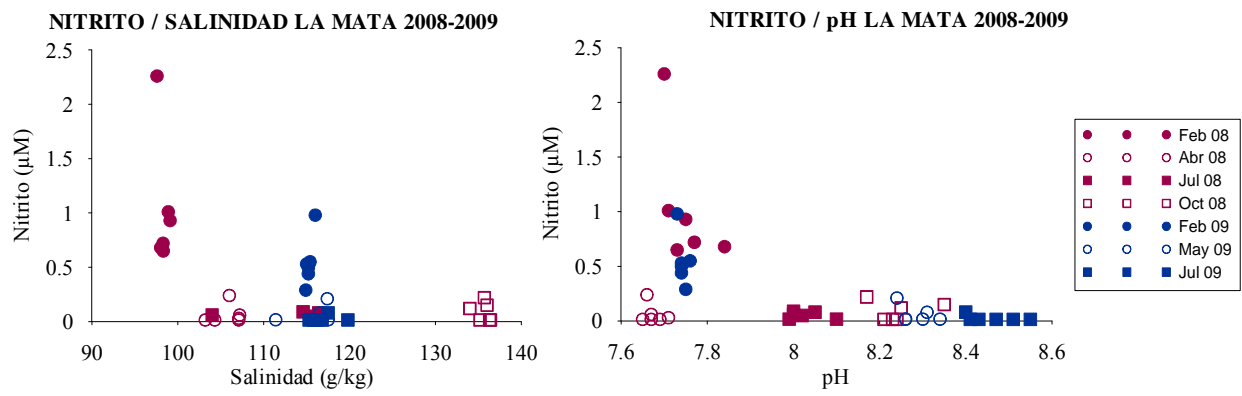


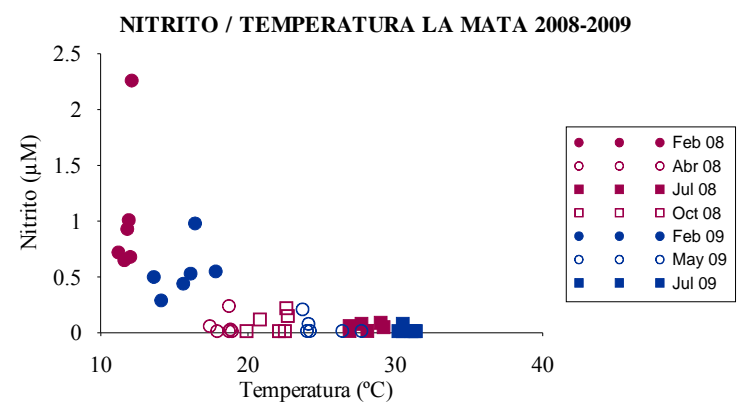

Figura 4.32: a) Comportamiento del nitrito respecto a la salinidad; b) Comportamiento del nitrito respecto al $\mathrm{pH}$ y c) Comportamiento del nitrito respecto a la temperatura en la laguna de La Mata durante 2008-2009

\subsubsection{Nitrato}

Las concentraciones de nitratos registradas en La Mata presentan una oscilación entre valores por debajo del límite de detección $(<0,3 \mu \mathrm{M})$ y $44,6 \mu \mathrm{M}$ (en STM008 durante febrero de 2008) (ver figura 4.33). No se observan grandes diferencias entre las estaciones de muestreo para este parámetro y, al igual que para el nitrito, tampoco se observa ninguna relación entre el contenido en nitratos y la salinidad (figura 4.34a) ni tampoco entre nitratos y temperatura (figura 4.34c), aunque sí parece observarse entre nitratos y $\mathrm{pH}$ (figura 4.34b), siendo el contenido en nitratos menor conforme aumenta el $\mathrm{pH}$.

Al igual que sucede con los nitritos, los niveles más altos de nitratos se detectan en los muestreos de febrero de 2008 y febrero de 2009. Parece que la principal entrada de nitratos en el sistema es a través de los procesos de nitrificación que tienen lugar en la laguna cuyo efecto es particularmente apreciable en los meses de invierno, posiblemente porque la baja actividad fitoplanctónica reduce las salidas. En febrero 2008 no se descartan entradas en la laguna procedentes de Torrevieja, cuyas aguas presentan una carga de nitratos muy elevada. Además destaca que la estación con mayor contenido en nitratos es STM008 (44,6 $\mu \mathrm{M}$ en febrero de 2008), que es la estación más próxima a la laguna de Torrevieja (ver figura 4.24). 


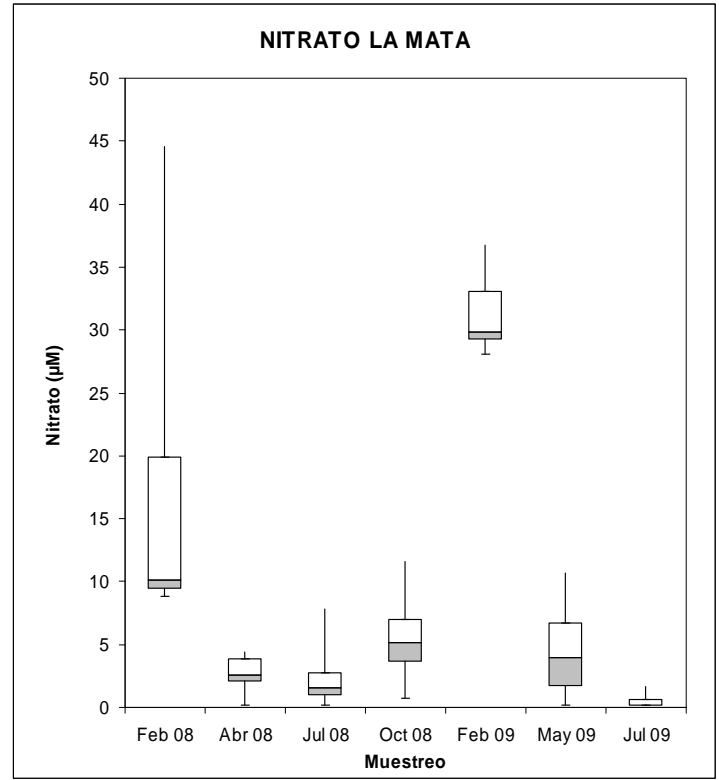

Figura 4.33: Concentraciones de nitrato registradas en la laguna de La Mata durante las campañas de 2008-2009
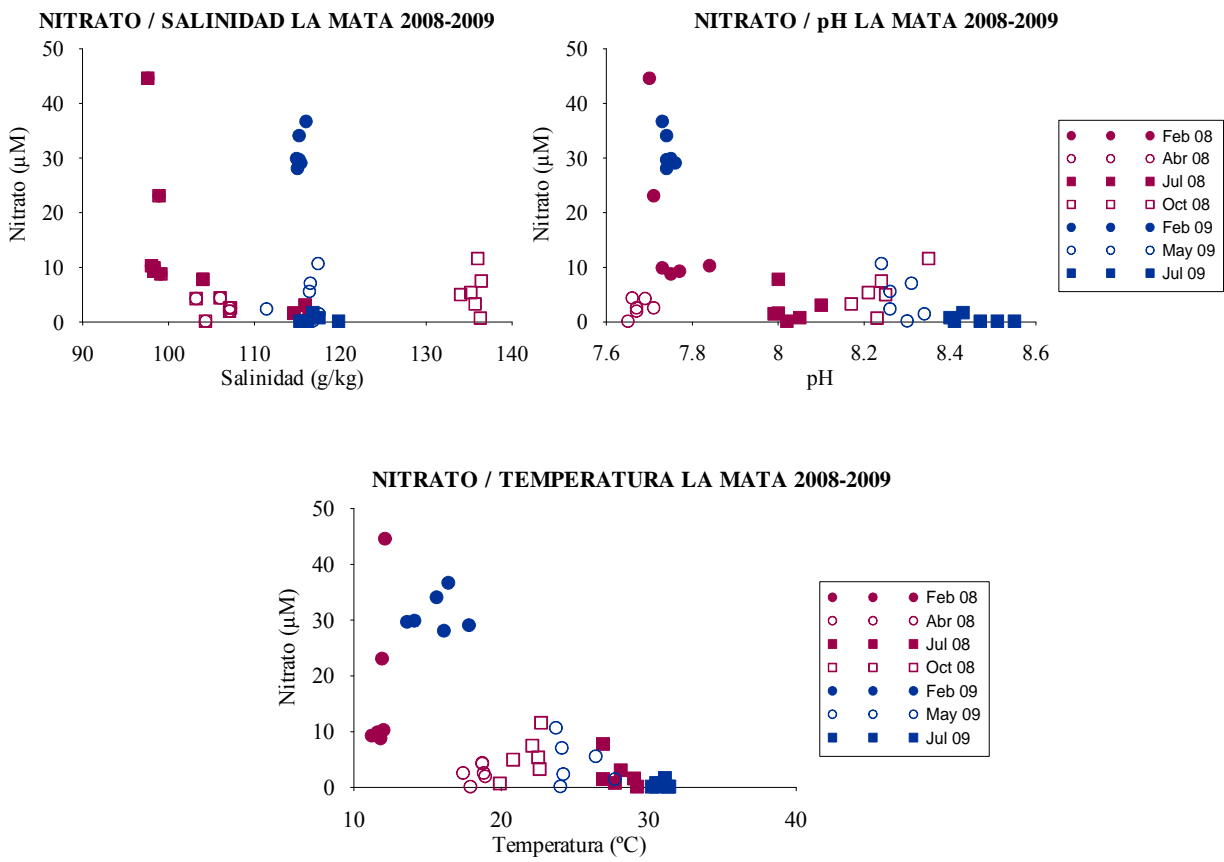

Figura 4.34: a) Comportamiento del nitrato respecto a la salinidad; b) Comportamiento del nitrato respecto al $\mathrm{pH}$ y c) Comportamiento del nitrato respecto a la temperatura en la laguna de La Mata durante 2008-2009 


\subsubsection{Nitrógeno Inorgánico Disuelto}

Este parámetro presenta una variabilidad de concentraciones muy elevada. El valor mínimo es de 1,9 $\mu \mathrm{M}$ (STM002 en julio de 2009) y el máximo es de 526,7 $\mu \mathrm{M}$ (STM002 en el mes de abril de 2008). El alto contenido en NID en los muestreos de febrero, abril y julio de 2008 parece tener su origen en las elevadas concentraciones de amonio que se alcanzan en estos meses. Los valores de NID en estos meses oscilan entre $269,1 \mu \mathrm{M}$ y $526,7 \mu \mathrm{M}$. Sin embargo, en febrero de 2009, el contenido en NID es debido fundamentalmente a la presencia de nitratos que parecen proceder de procesos de nitrificación.

En el resto de muestreos (octubre de 2008, mayo 2009 y julio de 2009) los valores de NID se encuentran en un rango de concentraciones mucho menor, entre $1,9 \mu \mathrm{M}$ y $17,5 \mu \mathrm{M}$, tal y como se puede apreciar en la figura 4.35, donde parece observarse dos grupos de valores, los $>200 \mu \mathrm{M}$ con concentraciones mucho más dispersas y los $<200 \mu \mathrm{M}$.

En la figura 4.36 ( $a, b$ y c) se representa la relación entre el NID y el contenido en sales de la laguna, así como entre el NID y el pH y el NID con la temperatura. Parece que se observa una relación inversa entre NID y salinidad y también entre NID y $\mathrm{pH}$, aunque la relación entre NID y temperatura no está tan clara.

La gran variabilidad encontrada en los resultados de NID y en cada una de las formas de nitrógeno inorgánico estudiadas, es una muestra de la complejidad de los procesos que tienen lugar en la laguna de La Mata.

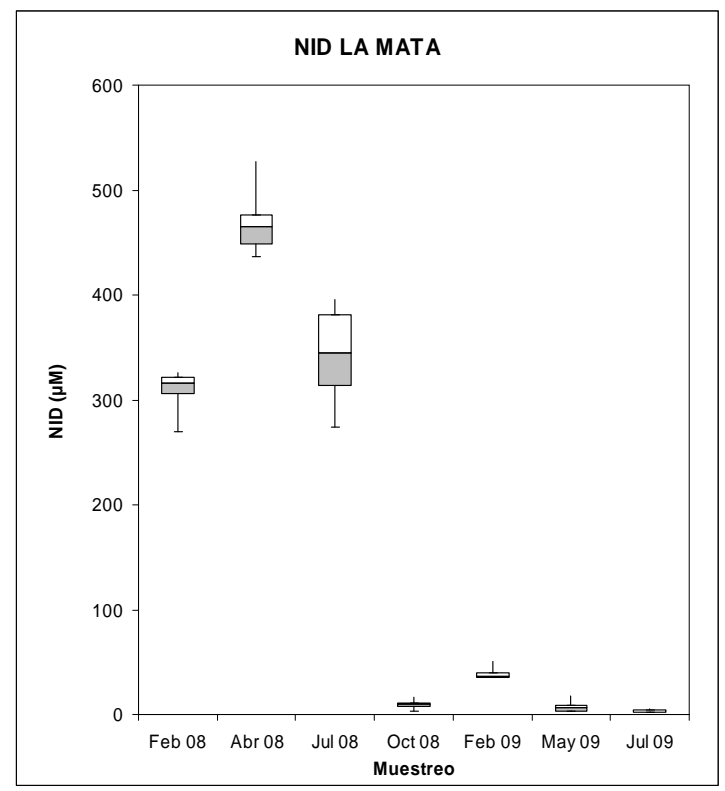

Figura 4.35: Concentraciones de NID registradas en la laguna de La Mata durante las campañas de 2008-2009 

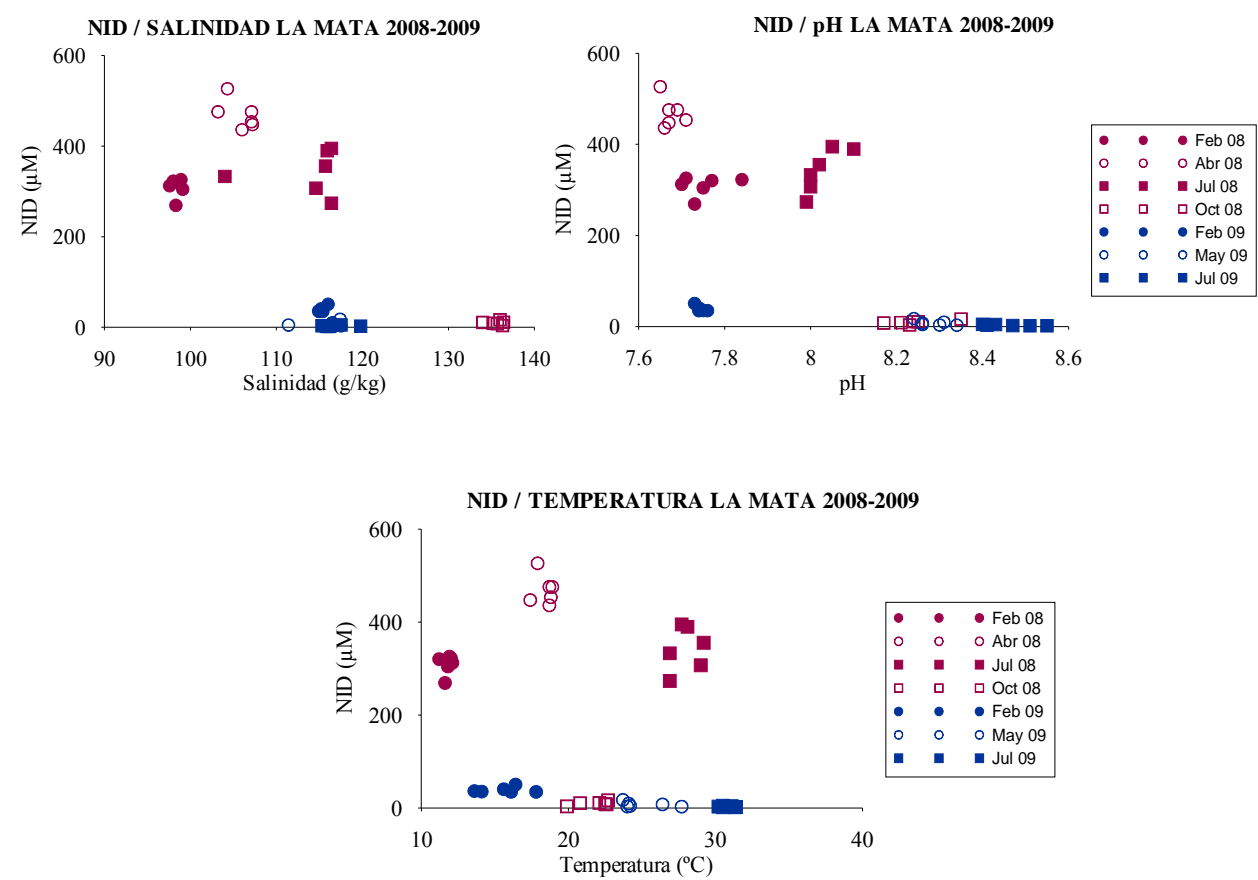

Figura 4.36: a) Comportamiento del NID respecto a la salinidad; b) Comportamiento del NID respecto al pH y c) Comportamiento del NID respecto a la temperatura en la laguna de La Mata durante 2008-2009

\subsubsection{Fósforo Soluble Reactivo (PSR)}

Los valores de PSR se encuentran por debajo de límite de detección analítico en la mayor parte de las estaciones y de los muestreos, por lo que se deduce que este parámetro se encuentra agotado en la mayor parte del sistema. Este agotamiento es debido a que el ortofosfato es la forma de fósforo preferida por el fitoplancton y puede ser rápidamente asimilado por éste.

Se detectan concentraciones significativas de PSR en febrero de 2009, con valores máximos de 1,03 $\mu \mathrm{M}$ (en STM010, STM011 y STM012) (figura 4.37), posiblemente procedentes de procesos de remineralización de la materia orgánica de la columna de agua como ya se ha señalado anteriormente, y concentraciones inferiores en algunas estaciones de febrero de 2008, mayo de 2009 y julio de 2009.

No se observa ninguna relación entre el contenido en PSR y la salinidad de la laguna (figura 4.38a) mientras que la relación entre PSR y $\mathrm{pH}$ (figura 4.38b) y entre PSR y temperatura (figura $4.38 \mathrm{c}$ ) parecen confirmar como ya hemos señalado anteriormente que las concentraciones de PSR más elevadas se deben a la mineralización de la materia orgánica de la columna de agua ya que estos coinciden con valores bajos de $\mathrm{pH}$ que indican un aumento de la concentración de $\mathrm{CO}_{2}$. 


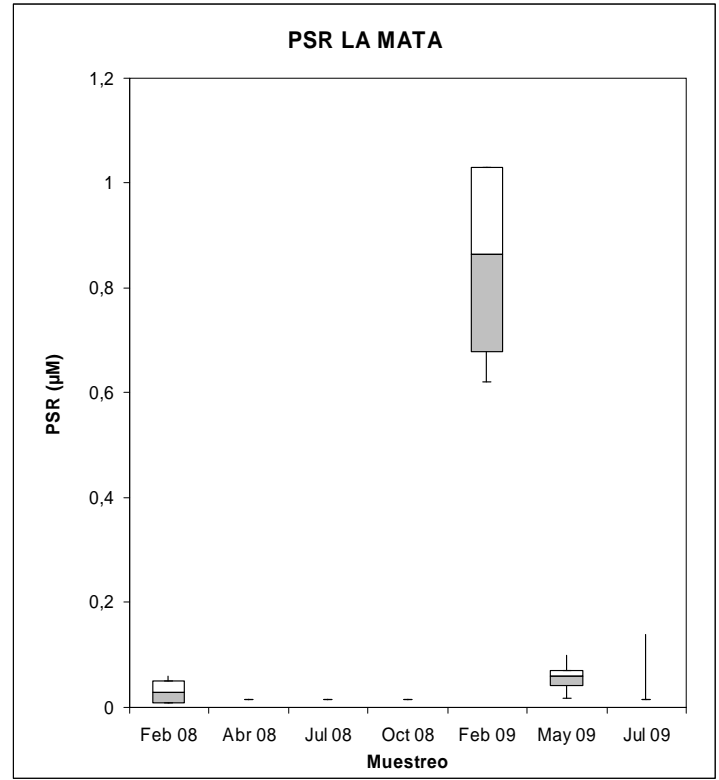

Figura 4.37: Concentraciones de PSR registradas en la laguna de La Mata durante las campañas de 2008-2009
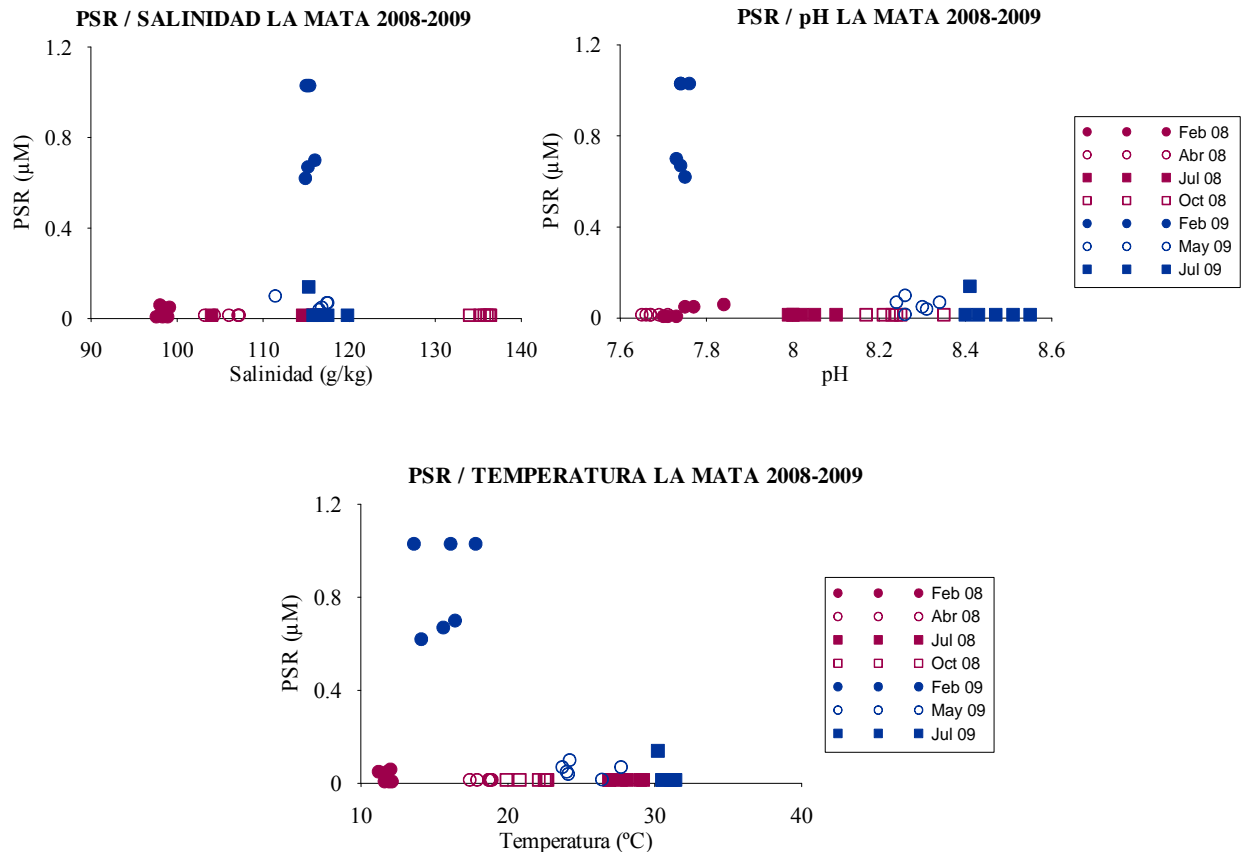

Figura 4.38: a) Comportamiento del PSR respecto a la salinidad; b) Comportamiento del PSR respecto al pH y c) Comportamiento del PSR respecto a la temperatura en la laguna de La Mata durante 2008-2009 


\subsubsection{Relación NID/PSR}

Las relaciones NID/PSR durante los meses de febrero, abril y julio de 2008 son muy elevadas debido a que en estos meses el PSR en el sistema se encuentra prácticamente agotado y el contenido en nitrógeno es elevado. La relación NID/PSR en estos meses oscila entre 5375 - 40725 mientras que para el resto de meses (de octubre de 2008 a julio de 2009) oscila entre 24 - 1100 (ver figura 4.39). Esto indica no solamente que el PSR es el factor limitante para el crecimiento del fitoplancton sino también que el amonio presente en el agua no procede de la muerte del mismo, ya que si se tratara de una liberación procedente del fitoplancton, los niveles de amonio y de PSR liberados serían proporcionales. Esta liberación parece proceder o bien del sedimento de la laguna o bien del posible trasvase de aguas desde Torrevieja en febrero de 2008.

En las figuras 4.40 ( $\mathrm{a}, \mathrm{b}$ y c) se muestran el comportamiento de la relación NID/PSR con respecto a la salinidad. Parece observarse una relación inversa entre NID/PSR y salinidad y entre NID/PSR y pH, aunque no se observa ninguna relación con la temperatura.

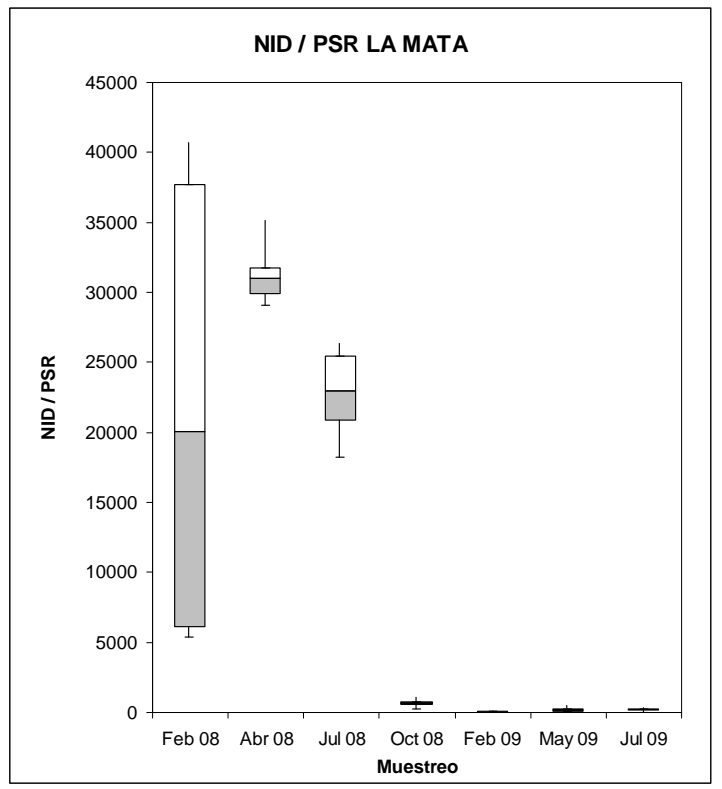

Figura 4.39: Relación NID/PSR de la laguna de La Mata durante las campañas de 2008-2009
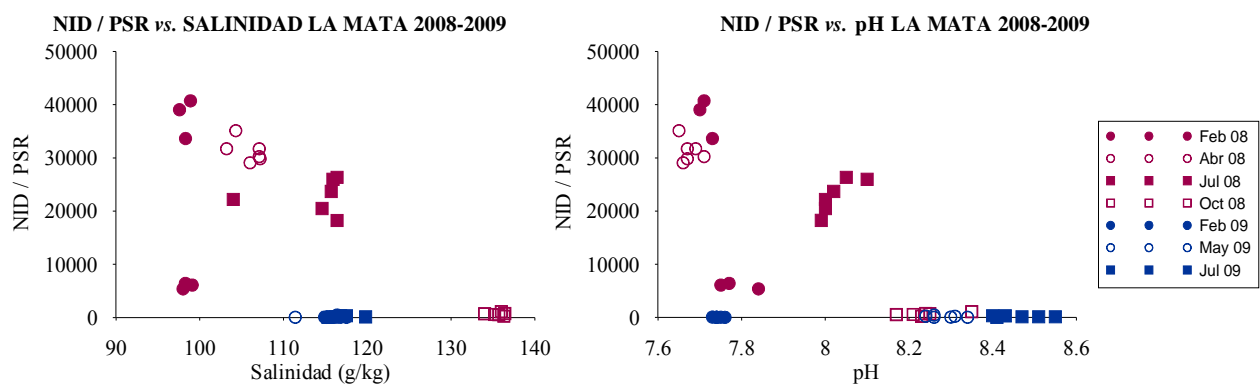


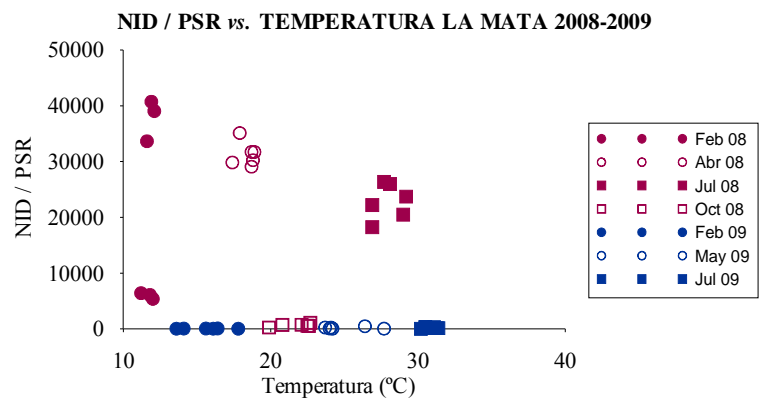

Figura 4.40: a) Comportamiento de la relación NID/PSR respecto a la salinidad; b) Comportamiento de la relación NID/PSR respecto al $\mathrm{pH}$ y c) Comportamiento de la relación NID/PSR respecto a la temperatura en la laguna de La Mata durante 2008-2009

\subsubsection{Fósforo Total (PT)}

Los valores de PT varían entre concentraciones de $0,36 \mu \mathrm{M}$ y 7,08 $\mu \mathrm{M}$ (STM008 en abril de 2008). Las concentraciones más elevadas de PT corresponden, tal y como se observa en la figura 4.41, a los muestreos de abril de 2008, julio de 2009 y algunas estaciones de febrero de 2008 (STM008 y STM010). (Hay que mencionar que no se poseen los valores para todas las estaciones en los muestreos de julio de 2008 y febrero de 2009 por lo que estos muestreos no son suficientemente representativos).

En la figura 4.42a se representa el contenido en PT respecto a la salinidad de la laguna y en las figuras $4.42 \mathrm{~b}$ y $4.42 \mathrm{c}$ el contenido en $\mathrm{PT}$ respecto al $\mathrm{pH}$ y a la temperatura aunque en ninguno de los casos se observa una pauta de comportamiento clara.

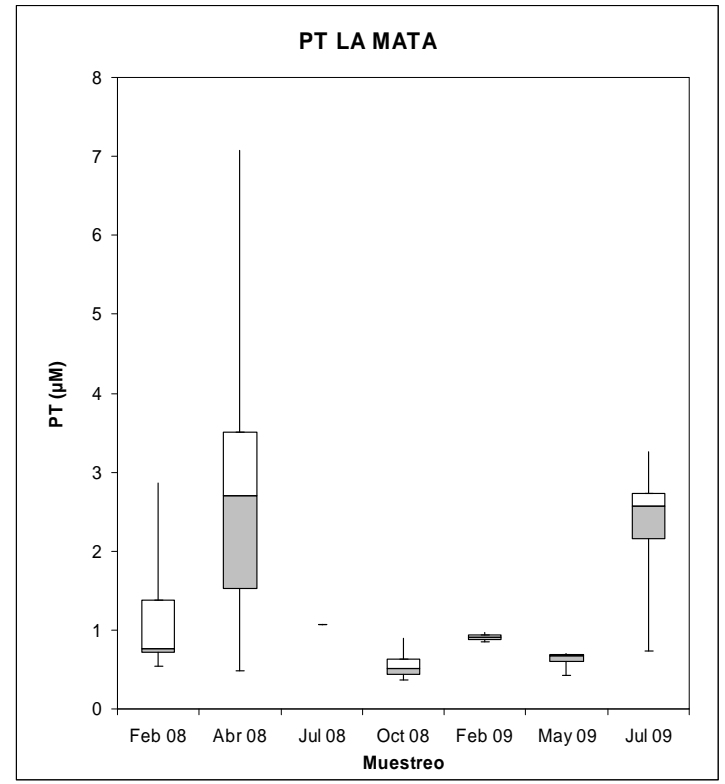

Figura 4.41: Concentraciones de PT registradas en la laguna de La Mata durante las campañas de 2008-2009 

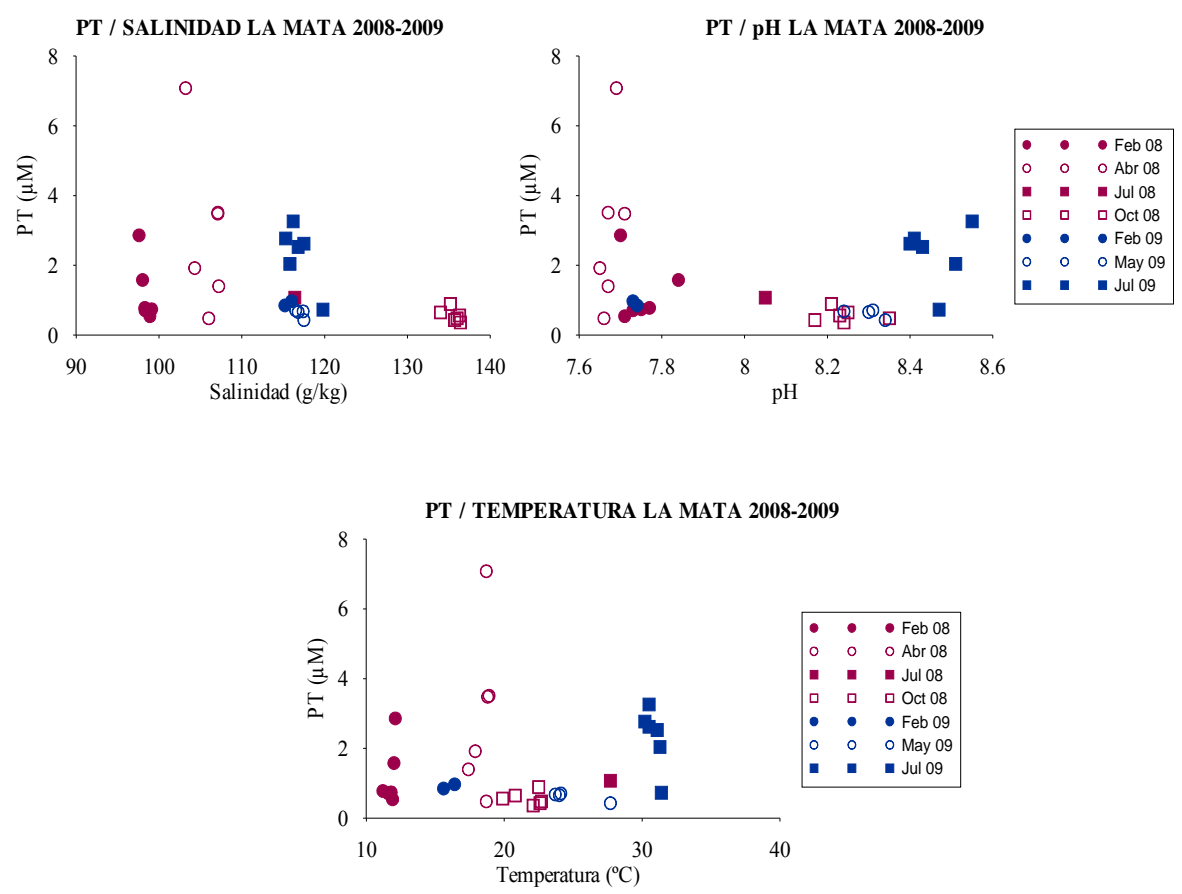

Figura 4.42: a) Comportamiento del PT respecto a la salinidad; b) Comportamiento del PT respecto al pH y c) Comportamiento del PT respecto a la temperatura en la laguna de La Mata durante 2008-2009

\subsubsection{0. Ácido ortosilícico}

El valor mínimo de ácido ortosilícico es de $18,5 \mu \mathrm{M}$ y se da en STM010 en febrero de 2009 mientras que el máximo es 75,0 $\mu \mathrm{M}$ y se da en STM008 en el mes de julio de 2008.

Durante el año 2008 las concentraciones son claramente mayores en los meses de febrero, abril y julio. Esto podría ser debido a entradas de agua procedentes de Torrevieja en febrero de 2008, con un contenido en ácido ortosilícico muy elevado (al menos a la salida de la tubería de El Pinoso) que se hubieran mantenido hasta julio. Como se puede observar en la figura 4.43, en 2009 las concentraciones son similares entre sí y más parecidas a las de octubre de 2008.

Con los resultados obtenidos y tras representar el ácido ortosilícico frente a la salinidad de la laguna (figura 4.44a), no se observa una pauta de comportamiento clara para este parámetro; aunque tampoco se observa una pauta clara entre este parámetro y el pH (figura $4.44 \mathrm{~b}$ ), ni tampoco con la temperatura (figura 4.44c).

Hay que destacar que el máximo valor de ácido ortosilícico encontrado en julio de 2008 coincide con un mínimo de diatomeas (GVA, 2008), lo que parece indicar que en esta época se ha producido una importante muerte de diatomeas cuyas frústulas podrían haber aumentado el contenido en ácido ortosilícico. Según Riley y Chester (1971), las diatomeas poseen un exoesqueleto compuesto de formas no cristalinas de sílice hidratado y pueden absorber y almacenar el silicio. 


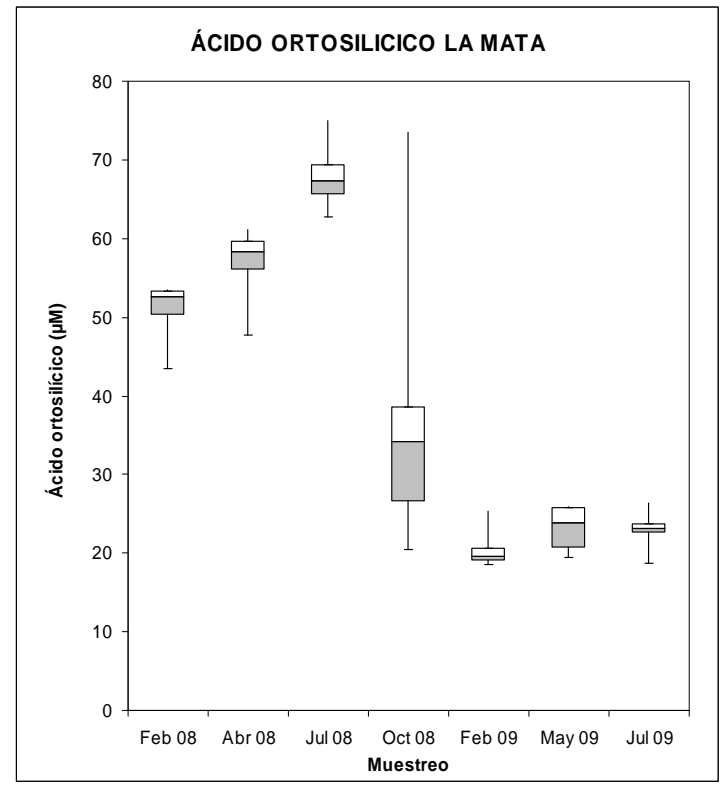

Figura 4.43: Concentraciones de ácido ortosilícico registradas en la laguna de La Mata durante las campañas de 2008-2009
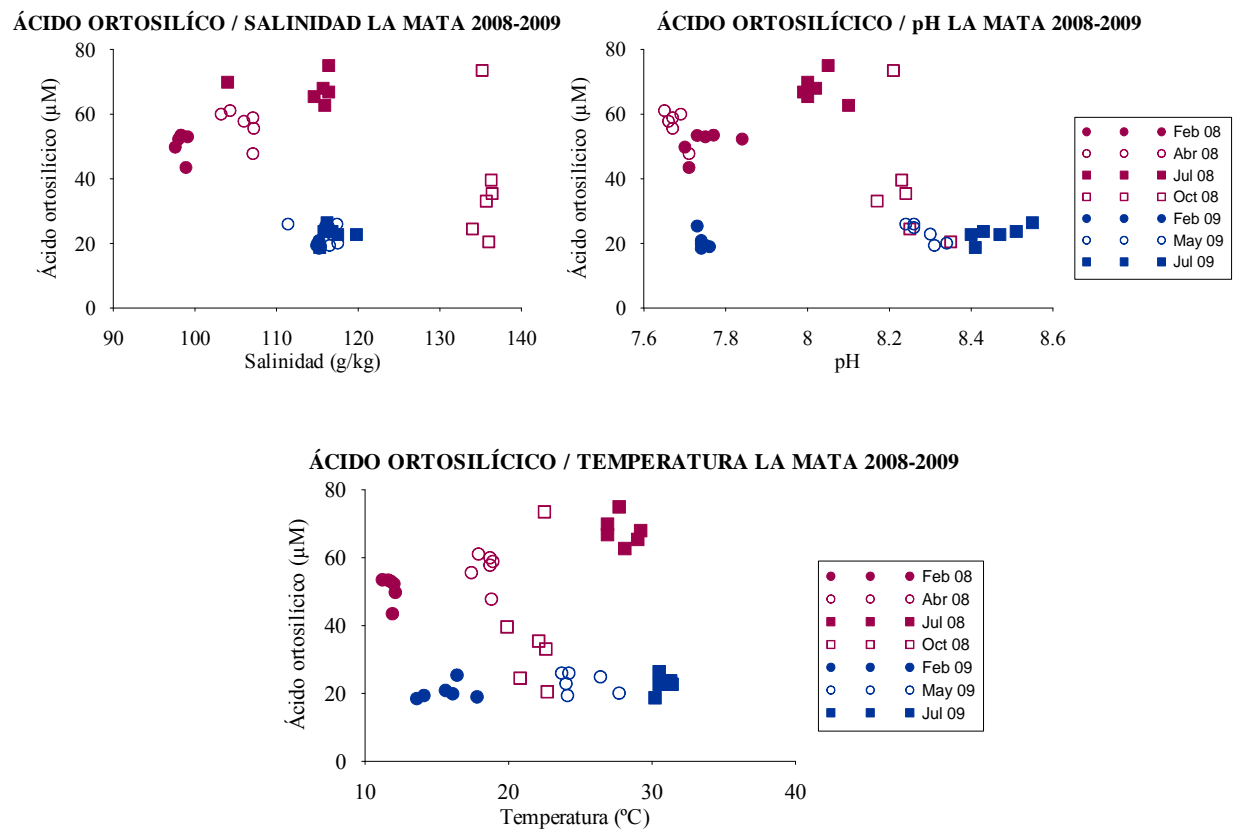

Figura 4.44: a) Comportamiento del ácido ortosilícico respecto a la salinidad; b) Comportamiento del ácido ortosilícico respecto al $\mathrm{pH}$ y c) Comportamiento del ácido ortosilícico respecto a la temperatura en la laguna de La Mata durante 2008-2009 


\subsubsection{Análisis multivariable de la laguna de La Mata}

En el análisis mediante componentes principales de los resultados obtenidos para los diferentes parámetros físico-químicos en la laguna de La Mata se han estudiado todos los parámetros excepto el PT debido a la falta de valores para este parámetro en algunos de los muestreos. A los datos obtenidos se les ha efectuado una transformación logarítmica (log $\mathrm{x}$ +1 ) previa al ACP (excepto al $\mathrm{pH}$ que ya presenta una escala logarítmica) con la finalidad de homogeneizar los datos.

El total de muestreos considerados ha sido de 7 (desde febrero de 2008 a julio de 2009) y se han incluido 7 variables: salinidad, $\mathrm{pH}$, amonio, nitrito, nitrato, PSR y ácido ortosilícico. Este análisis nos permitido reducir las variables a dos componentes principales que en total explican un 80,298 \% de la varianza acumulada (45,94\% la componente 1 y $34,358 \%$ la componente 2).

\begin{tabular}{|rcc|}
\hline PARÁMETROS & $\begin{array}{c}\text { Componente 1 } \\
(\mathbf{4 5 , 9 4} \%)\end{array}$ & $\begin{array}{c}\text { Componente 2 } \\
(\mathbf{3 4 , 3 5 8} \%)\end{array}$ \\
\hline Salinidad & 0,440185 & 0,113855 \\
\hline pH & 0,509941 & $-0,0786109$ \\
\hline Amonio & $-0,446928$ & $-0,356117$ \\
\hline Nitrito & $-0,391077$ & 0,313036 \\
\hline Nitrato & $-0,301001$ & 0,4754 \\
\hline PSR & $-0,0902282$ & 0,551997 \\
\hline Ác. ortosilícico & $-0,307845$ & $-0,4747$ \\
\hline
\end{tabular}

Tabla 4.3: Tabla de pesos de los componentes del ACP para los parámetros físico-químicos de La Mata

Gráfico de Pesos del Componente

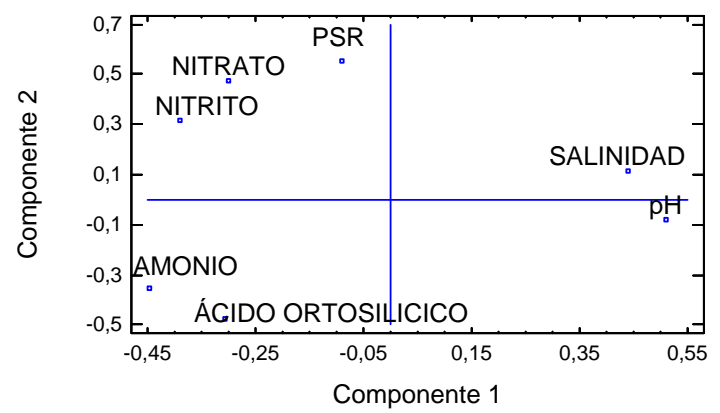

Figura 4.45: Gráfico de pesos de los componentes del ACP para los parámetros físico-químicos en la laguna de La Mata

La explicación de los componentes principales, cuyos resultados se muestran en la tabla de pesos (tabla 4.3) y su representación gráfica (figura 4.45), es similar a la de Calpe pero en La Mata es más compleja y difícil de explicar, ya que La Mata no solamente recibe aportes de agua marina con concentraciones uniformes como sucede en Calpe sino que además puede recibir aportes procedentes de Torrevieja. 
A partir de los resultados obtenidos, se deduce que la componente 1 representa procesos internos asociados a la mineralización de la materia orgánica así como el estado de la laguna cuando no se producen entradas desde Torrevieja. La componente 2 parece estar asociada a los procesos de concentración de diferentes parámetros como nitratos y PSR.

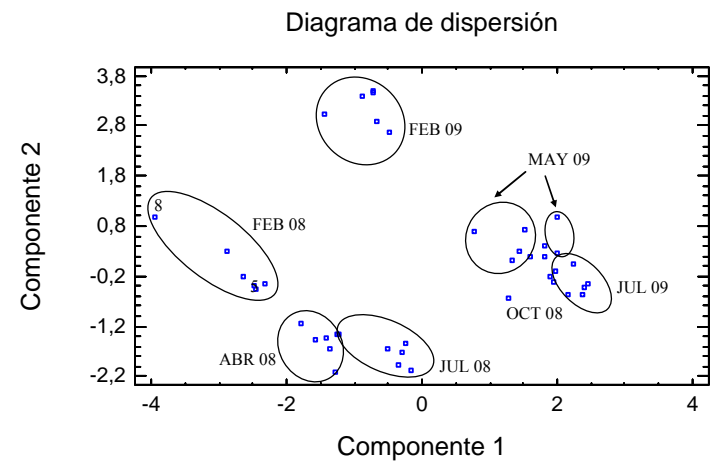

Figura 4.46: Diagrama de dispersión para los componentes 1 y 2 del ACP para los parámetros físico-químicos de la laguna de La Mata

En la representación del diagrama de dispersión (figura 4.46), se puede observar cómo respecto a la componente 1 (salinidad, $\mathrm{pH}$, amonio, nitritos y nitratos en menor medida) los muestreos de octubre 2008, mayo 2009 y julio 2009 se encuentran agrupados ya que dichos muestreos presentan valores de $\mathrm{pH}$ similares así como contenidos en amonio y nitrito bajos. Por otra parte, se encuentran los muestreos de febrero, abril y julio de 2008 que poseen valores menores de salinidad y de $\mathrm{pH}$ aunque todos ellos presentan valores muy elevados de amonio. Sin embargo, dentro de este grupo se desmarcan las estaciones STM005 y especialmente STM008 de febrero de 2008, que es la estación más próxima a la laguna de Torrevieja, porque presenta un contenido en nitritos y nitratos muy superior al resto del grupo. Febrero de 2009 es el muestreo que más se aleja de los otros muestreos porque presenta los niveles más elevados de PSR y niveles elevados de nitritos y nitratos.

Respecto a la componente 2 (nitrato, PSR y en menor medida ácido ortosilícico y amonio) en un extremo se encuentran los muestreos de abril y julio de 2008 que presentan valores muy elevados de amonio y en otro febrero de 2009 con valores bajos. Una vez más, febrero de 2009 destaca por sus valores elevados de nitritos y especialmente de nitratos así como de PSR respecto al resto de muestreos.

En la representación del conglomerado jerárquico (figura 4.47) se observa una agrupación de los muestreos de febrero, abril y julio de 2008 por un lado, y de los muestreos de 2009 y octubre de 2008 por otro lado. La principal diferencia estriba fundamentalmente en la concentración de amonio que en el primer grupo es elevadísima aunque también en el contenido en ácido ortosilícico que también es elevado. Dentro de este grupo se aprecia una asociación entre las estaciones de febrero de 2008 y las estaciones de julio de 2008 con valores de amonio < $350 \mu \mathrm{M}$ (STM002, STM011 y STM012) así como entre abril de 2008 con las estaciones de julio de 2008 con valores $>350 \mu \mathrm{M}$ (STM005, STM008 y STM010). 
Por otra parte se encuentran asociados el resto de muestreos de febrero, mayo y julio de 2009 con octubre de 2008 .

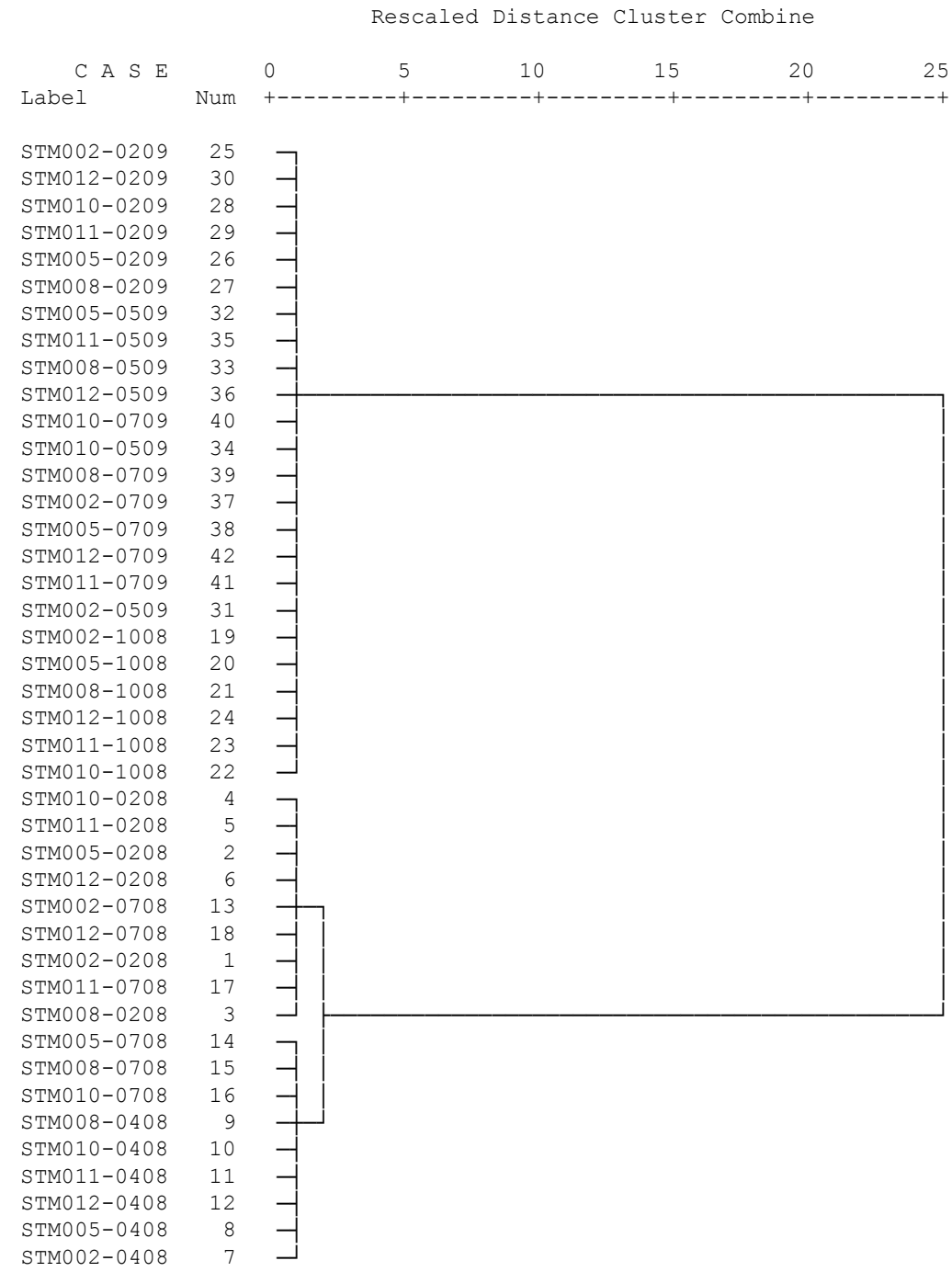

Figura 4.47: Conglomerado jerárquico con la agrupación de las estaciones para cada una de las campañas muestreadas en la laguna de La Mata 


\subsection{SALINA DE TORREVIEJA}

\subsubsection{Análisis de los parámetros físico-químicos}

\subsubsection{Salinidad}

La laguna de Torrevieja es un sistema de explotación salinera muy poco convencional ya que la sal precipita y se extrae en la totalidad de la laguna que actúa como un gran estanque "cristalizador". Por este motivo, los valores de salinidad en la laguna son muy homogéneos y muy elevados en todos los muestreos, independientemente de la época del año. Esto se aprecia en los valores extremos que oscilan entre los $252 \mathrm{~g} / \mathrm{kg}$ de STT013 en el mes de febrero de 2008 y los $276 \mathrm{~g} / \mathrm{kg}$ en STT012 durante de abril y octubre de 2008 (figura 4.48).

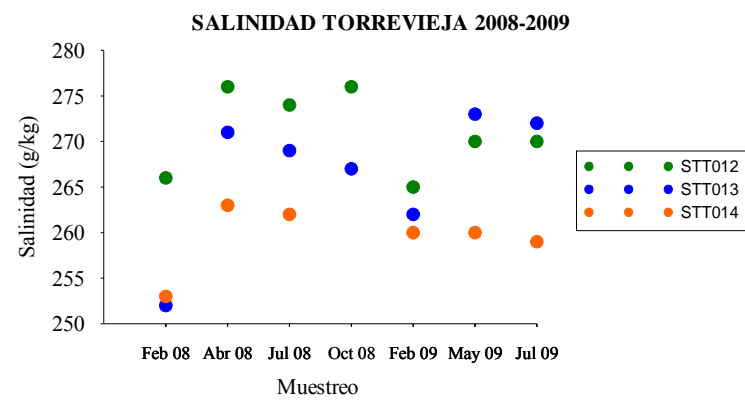

Figura 4.48: Salinidades registradas en la laguna de Torrevieja durante las campañas de 2008-2009

Los valores de salinidad en Torrevieja pueden estar condicionados por las precipitaciones (figura 4.23) pero en menor medida que las lagunas de La Mata o Calpe, ya que en caso de que se den unas lluvias que puedan afectar de forma importante la salinidad de la laguna, se efectúa un trasvase de la capa superficial sobrenadante con salinidades más bajas de Torrevieja a La Mata para que la salinidad en Torrevieja no descienda. Según la empresa gestora de las salinas durante el período de estudio no se ha producido este tipo de trasvase. Los datos de precipitaciones son los que se muestran en la figura 4.23, tomados en la estación de Laguna de Torrevieja, situada a unos $3 \mathrm{~km}$ de las estaciones de muestreo.

Hay que mencionar que el abastecimiento de agua cargada con sales de Torrevieja no se realiza únicamente a partir del agua de mar preconcentrada procedente de La Mata, sino fundamentalmente a partir de las salmueras procedentes del lavado de sal gema en el yacimiento de El Pinoso, a unos $50 \mathrm{~km}$ de distancia. La salinidad del agua tomada a la misma salida de la tubería procedente de El Pinoso (STT014) es elevada (entre 253 - 263 $\mathrm{g} / \mathrm{kg}$ ). También hay que mencionar que en el muestreo de octubre de 2008 no se pudo tomar la muestra porque no salía agua de la tubería.

Las estaciones STT012 y STT013, situadas en el centro de la laguna, presentan valores de salinidad mayores que los encontrados a la salida de la tubería de El Pinoso (STT014), ya que en estas estaciones la evapotranspiración concentra aún más el agua de la laguna y hace que su salinidad sea mayor (ver figura 4.48). Al comparar las estaciones centrales entre sí también se observan diferencias, puesto que la salinidad de STT012 es mayor que la de 
STT013 en la mayor parte de los muestreos (durante todo el 2008 y en febrero de 2009). Esto es debido a que estas estaciones, a pesar de su proximidad, se encuentran separadas por una mota quedando STT013 del lado de la laguna donde vierten las aguas de El Pinoso y quedando STT012 del lado opuesto (ver figura 4.24), siendo el efecto de la evapotranspiración en esta última mayor.

Los aumentos de salinidad en Torrevieja son debidos a la evapotranspiración y a la entrada de las salmueras procedentes de El Pinoso, mientras que los descensos son debidos a escorrentías procedentes de las precipitaciones y a entradas de agua desde La Mata.

\subsubsection{2. $\mathrm{pH}$}

Los valores de $\mathrm{pH}$ son relativamente bajos en toda la laguna durante todos los muestreos, ya que oscilan entre 7,26 y 7,52 por lo que presentan un rango de variación muy reducido (ver figura 4.49). En esta figura también se aprecia cómo el pH del agua durante el 2009 es menor en STT014 que en la laguna, mientras que durante el 2008 sucede al contrario. Hay que destacar que en Torrevieja los valores de $\mathrm{pH}$ son menores que en otras salinas.

Por otra parte, en la figura 4.50a se representa el valor del $\mathrm{pH}$ frente a la salinidad y en la figura $4.50 \mathrm{~b}$ frente a la temperatura, aunque como se puede observar estos datos no aportan una información concluyente.

Estos valores relativamente bajos de $\mathrm{pH}$ podrían ser debidos a cambios en la composición iónica durante el proceso de precipitación o a cambios en el contenido de $\mathrm{CO}_{2}$ del sistema. Según las pruebas realizadas en muestras de las salinas de La Mata - Torrevieja (descritas en los resultados de La Mata) los datos de estas pruebas, con valores de $\mathrm{pH}$ en torno a 8,2 para unos $100 \mathrm{~g} / \mathrm{kg}$ de salinidad en La Mata y de 8,1 en las aguas de cristalización de Torrevieja, podrían justificar una reducción debida al cambio iónico que como mucho implicaría un descenso de 0,1 unidades (La Mata) y de 0,2 unidades (Torrevieja) respecto al $\mathrm{pH}$ del agua de mar (en torno a 8,3).

Por otra parte, las pruebas también muestran que la mayor salinidad y por tanto, densidad de las aguas reduce la difusión de los gases en ellas. Este aspecto sería un factor importante que hace que el $\mathrm{CO}_{2}$ y otros gases formados en la descomposición de la materia orgánica, tanto en el bentos como en la columna de agua, se acumulen y puedan alcanzar concentraciones por encima de la saturación que conduzcan a estos valores tan bajos de $\mathrm{pH}$.

Además, a estas salinidades ya se ha producido la precipitación del calcio en forma de carbonato de calcio $\left(\mathrm{CaCO}_{3}\right)$ y de yeso $\left(\mathrm{CaSO}_{4} \cdot 2 \mathrm{H}_{2} \mathrm{O}\right)$, ya que según Lazar et al. (1983) el $\mathrm{CaCO}_{3}$ precipita cuando el agua de mar se concentra entre 2,5 - 4 veces (entre $92-148$ $\mathrm{g} / \mathrm{kg}$ aproximadamente) y el yeso cuando el agua de mar se concentra unas 4,5 veces (en torno a $167 \mathrm{~g} / \mathrm{kg}$ ). Esto provoca un descenso del contenido en calcio de la columna de agua y reduce la capacidad de regular la concentración de carbónico - carbonato a través de la precipitación del $\mathrm{CaCO}_{3}$, y por tanto de tamponar el efecto sobre el $\mathrm{pH}$ del aumento de las entradas de $\mathrm{CO}_{2}$ al sistema. 


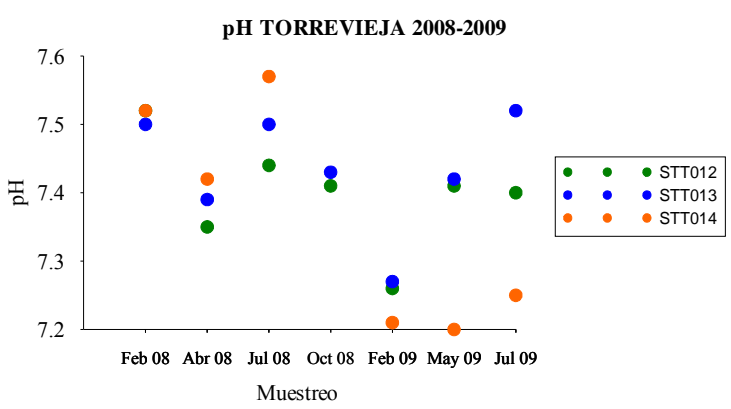

Figura 4.49: Valores de $\mathrm{pH}$ registrados en la laguna de Torrevieja durante las campañas de 2008-2009
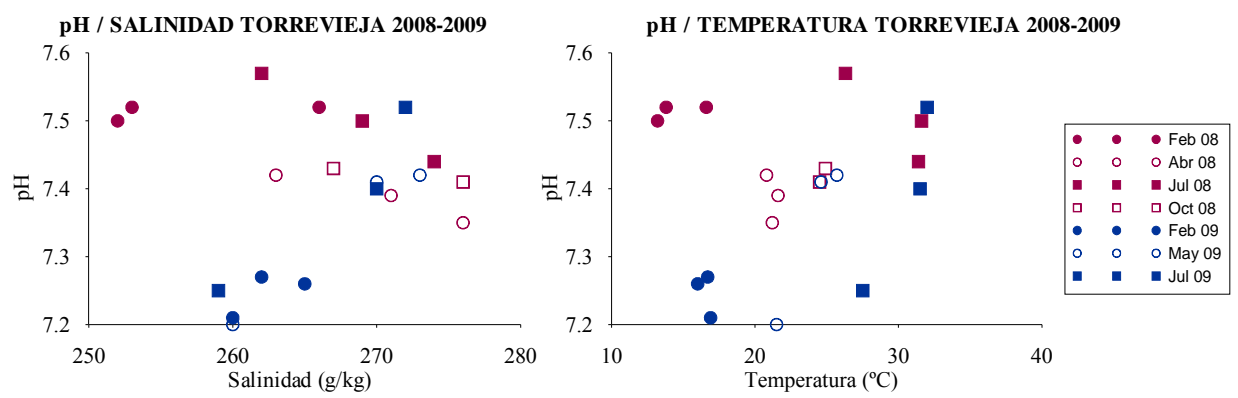

Figura 4.50: a) Comportamiento del $\mathrm{pH}$ respecto a la salinidad; b) Comportamiento del $\mathrm{pH}$ respecto a la temperatura en la laguna de Torrevieja durante 2008-2009

\subsubsection{Amonio}

El rango de concentraciones en la laguna es amplio ya que oscila entre 3,1 $\mu \mathrm{M}$ (STT012 en julio de 2008) y 94,0 $\mu \mathrm{M}$ (STT013 en mayo de 2009). Tal y como se observa en la figura 4.51 , en este parámetro se detecta una gran diferencia entre los valores obtenidos en las estaciones centrales de la laguna (STT012 y STT013) y los de la salida de agua procedente de El Pinoso (STT014) con valores muy superiores.

Los valores registrados en STT014 son muy elevados en cualquier época del año (entre $201,0 \mu \mathrm{M}$ en febrero de 2008 y $545,4 \mu \mathrm{M}$ en julio de 2008) mientras que por el contrario en las estaciones STT012 y STT013 los valores máximos son de $68,2 \mu \mathrm{M}$ y $94,0 \mu \mathrm{M}$ respectivamente, en el mes de mayo de 2009. Los valores mínimos se dan en estas estaciones durante el mes de julio de 2008.

No se observa una pauta clara de comportamiento del amonio respecto a la salinidad (figura 4.52a), ni del amonio respecto al pH (figura 4.52b), ni tampoco del amonio con la temperatura (figura $4.52 \mathrm{c}$ ).

Hay que recalcar que la concentración en STT014 (procedente de El Pinoso) es siempre significativamente mayor que la de la laguna. Esto implica que la principal entrada de amonio en la salina es a través del agua de salmuera procedente de El Pinoso. Además, parte del amonio introducido en el sistema, o bien es absorbido por el fitoplancton (el 
fitoplancton muestra preferencia de asimilación sobre el amonio respecto al nitrato, Smayda, (1983)), o bien están teniendo lugar procesos de nitrificación en las estaciones centrales que transforman parte del amonio introducido en nitritos y nitratos.

Aunque algunos autores como Oren (2009) consideran que el proceso de nitrificación autótrofa (que en condiciones normales es el responsable de la oxidación del amonio a nitratos y nitritos) no funciona a concentraciones salinas por encima de $100-150 \mathrm{~g} / \mathrm{l}$, este hecho no queda claro en este sistema, ya que cuando se analiza el comportamiento del nitrato (figura 4.55) no se observan ganancias significativas en la laguna. Todo parece indicar que la reducción de la concentración de amonio se debe a que una parte es absorbida por el fitoplancton y otra transformada en nitritos y nitratos por procesos de nitrificación.

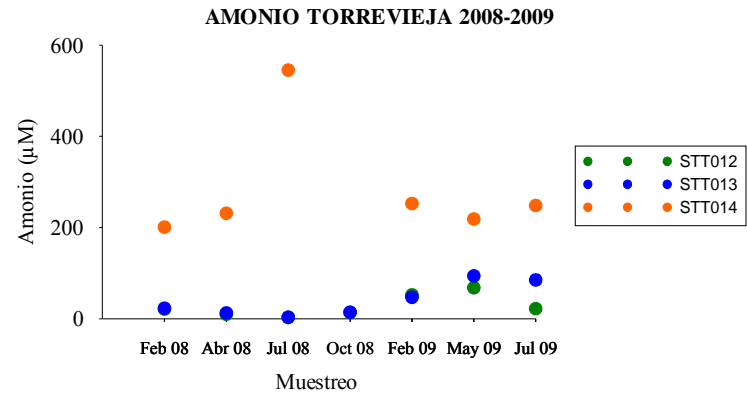

Figura 4.51: Concentraciones de amonio registradas en la laguna de Torrevieja durante las campañas de 20082009
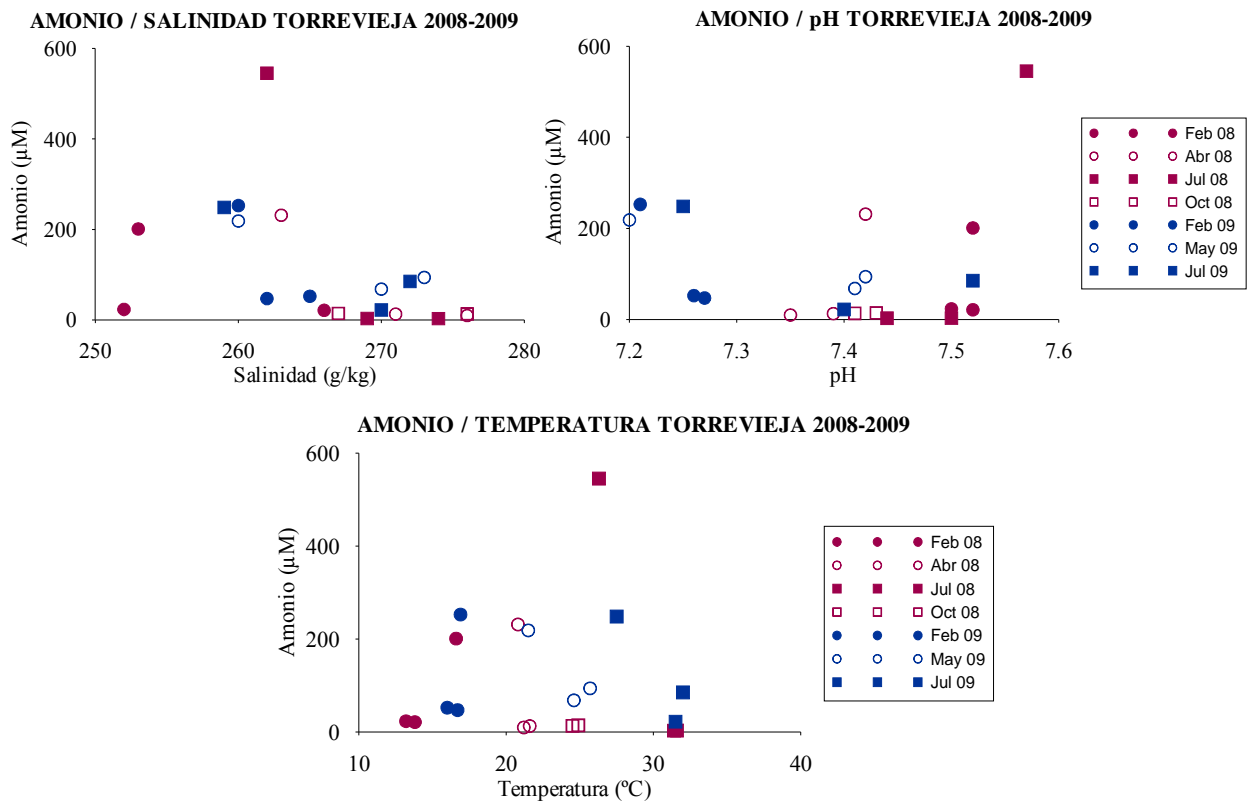

Figura 4.52: a) Comportamiento del amonio respecto a la salinidad; b) Comportamiento del amonio respecto al $\mathrm{pH}$ y c) Comportamiento del amonio respecto a la temperatura en la laguna de Torrevieja durante 2008-2009 


\subsubsection{Nitrito}

Se encuentran valores muy elevados que varían considerablemente a lo largo de la campaña de muestreo. Los valores mayores de nitritos se registran en las estaciones centrales STT012 y STT013 (entre 24,67 y 43,84 $\mu \mathrm{M}$ ) y los menores en STT014 (entre 3,04 y 3,58 $\mu \mathrm{M}$ ) como se puede observar en la figura 4.53, siendo la concentración de nitritos a la salida de la tubería de El Pinoso inferior en todos los muestreos a la del interior de la laguna.

Según se observa en la figura 4.54a parece observarse una tendencia a la acumulación de los nitritos con la concentración salina. Sin embargo, no se aprecia ninguna relación entre nitrito y $\mathrm{pH}$ (figura 4.54b) ni entre nitrito y temperatura (figura 4.54c).

Aunque algunos autores plantean que la nitrificación autótrofa no es operativa por encima de los 100-150 g/l (Oren, 2009), si comparamos los valores de nitritos en STT014 con los de la laguna observamos un claro aumento de su concentración que difícilmente podría ser achacable a la absorción del nitrato por la población fitoplanctónica y posterior exudación de una parte de ese nitrato absorbido al medio en forma de nitrito, ya que las disminuciones de la concentración de formas nitrogenadas entre STT014 y la laguna se deben fundamentalmente al amonio. De hecho el nitrato, excepto en julio de 2008, presenta concentraciones similares en la laguna a las de la salida de Pinoso e incluso en julio de 2009 valores claramente más altos en la laguna (ver figura 4.55).

Dado que la concentración de nitritos tampoco alcanza valores elevados en La Mata, no cabe atribuir su subida al proceso de acumulación por concentración de los aportes de La Mata, ya que en La Mata los valores raras veces superan son $>1 \mu \mathrm{M}$ y el factor de concentración de la salinidad sería algo superior a dos veces. Por tanto, todo indica que a través de una vía u otra hay una nitrificación de parte del amonio en la laguna.

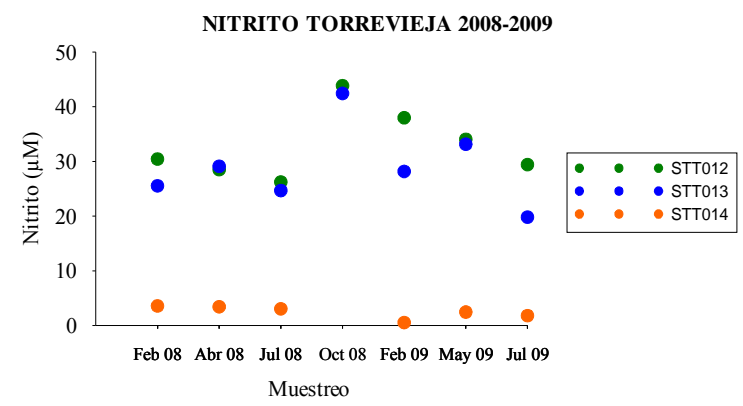

Figura 4.53: Concentraciones de nitrito registradas en la laguna de Torrevieja durante las campañas de 2008-2009
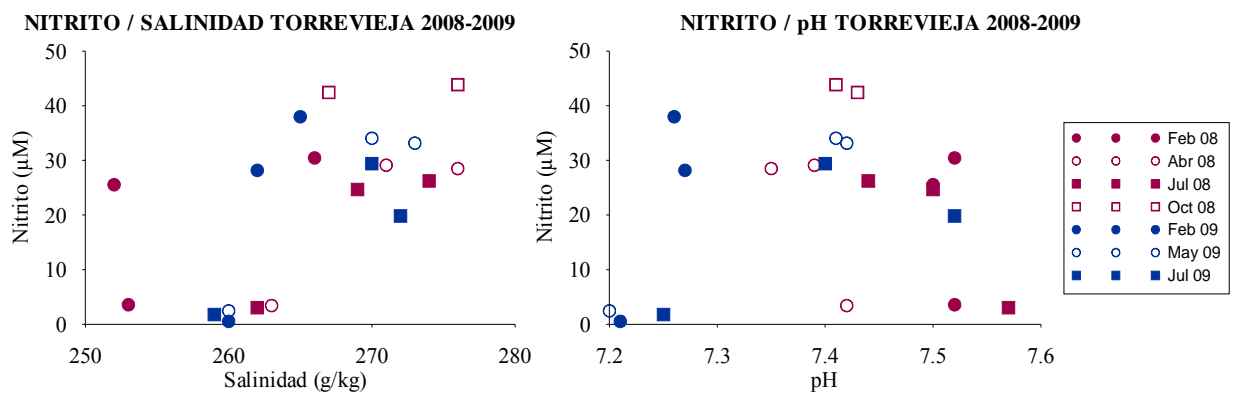


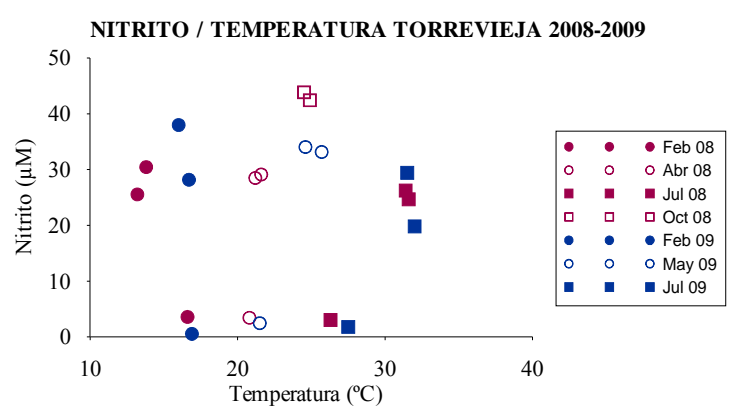

Figura 4.54: a) Comportamiento del nitrito respecto a la salinidad; b) Comportamiento del nitrito respecto al $\mathrm{pH}$ y c) Comportamiento del nitrito respecto a la temperatura en la laguna de Torrevieja durante 2008-2009

\subsubsection{Nitrato}

Los nitratos presentan concentraciones muy altas en todas las estaciones de Torrevieja independientemente de la época del año muestreada. Las concentraciones oscilan entre los $226,5 \mu \mathrm{M}$ de STT012 en el mes de abril de 2008 y los 561,7 $\mu \mathrm{M}$ de STT013 durante el mes de julio de 2008. Aunque los valores son muy elevados durante todo el período de muestreo, en la figura 4.55 se puede observar que en abril de 2008 son ligeramente inferiores al resto $(226,5-280,9 \mu \mathrm{M})$, y en julio de 2008 mayores $(421,8-561,7 \mu \mathrm{M})$.

Este contenido tan elevado de nitratos parece ser debido a que el agua que entra en la salina procedente de El Pinoso trae consigo una carga importante de este compuesto (entre 273,2 - 563,2 $\mu \mathrm{M}$ ). A pesar de ello, los valores más elevados no siempre se observan a la salida de la tubería (STT014) sino que en ocasiones se dan en el centro de la salina. De hecho el nitrato, excepto en julio de 2008, presenta concentraciones similares en la laguna a las de la salida de El Pinoso e incluso en julio de 2009 valores claramente más altos en la laguna posiblemente debidos a la acumulación de sales.

En la figura 4.56a se representa el comportamiento del nitrato respecto a la salinidad donde no se observa una tendencia clara aunque el rango de salinidad de Torrevieja es muy reducido. En la figura $4.56 \mathrm{~b}$ y $4.56 \mathrm{c}$ se representa el comportamiento del nitrato respecto al $\mathrm{pH}$ y respecto a la temperatura. La relación entre nitratos y $\mathrm{pH}$ no queda clara, aunque parece observarse una tendencia al aumento en la concentración de nitratos tal y como aumenta la temperatura.

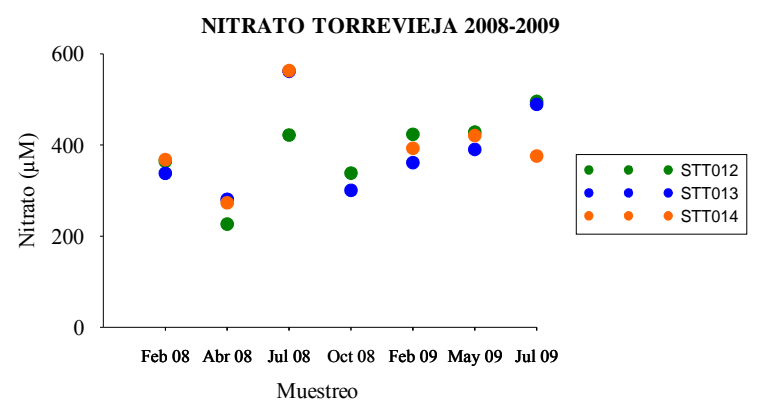

Figura 4.55: Concentraciones de nitrato registradas en la laguna de Torrevieja durante las campañas de 20082009 

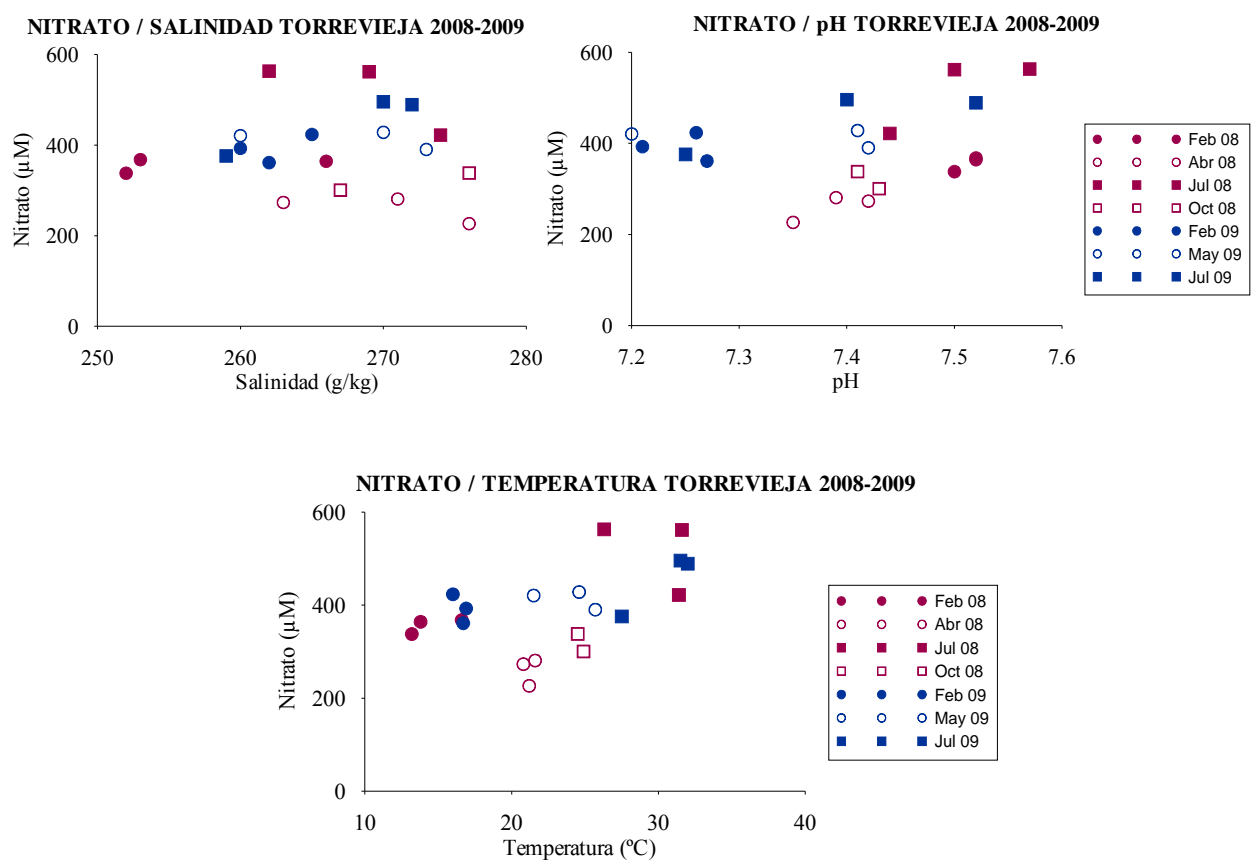

Figura 4.56: a) Comportamiento del nitrato respecto a la salinidad; b) Comportamiento del nitrato respecto al $\mathrm{pH}$ y c) Comportamiento del nitrato respecto a la temperatura en la laguna de Torrevieja durante 2008-2009

\subsubsection{Nitrógeno Inorgánico Disuelto}

El NID al ser la suma de todas las formas de nitrógeno inorgánicas ya descritas, alcanza valores muy elevados en toda la salina, debido a las grandes concentraciones tanto de amonio como de nitritos y de nitratos existentes en Torrevieja.

Los valores más elevados con diferencia se encuentran en la salida de la tubería de El Pinoso (STT014) y oscilan entre 508,1 $\mu \mathrm{M}$ en abril de 2008 hasta $1.111,6 \mu \mathrm{M}$ en julio de 2008. Aunque los valores de la laguna también son muy elevados y van desde $264,8 \mu \mathrm{M}$ en STT012 en abril de 2008 a 594,1 $\mu \mathrm{M}$ en STT013 en julio de 2009 (figura 4.57).

Estos resultados indican que la principal entrada de nitrógeno inorgánico en el sistema se produce por la tubería de El Pinoso y el hecho de que se alcancen valores menores en las estaciones centrales de la laguna muestra que parte del nitrógeno introducido es asimilado por los microorganismos planctónicos que lo coinvierten en formas orgánicas.

No se observa una pauta clara de comportamiento del NID respecto a la salinidad (figura 4.58a), ni tampoco con el pH (figura 4.58b) o la temperatura (figura 4.58c). 


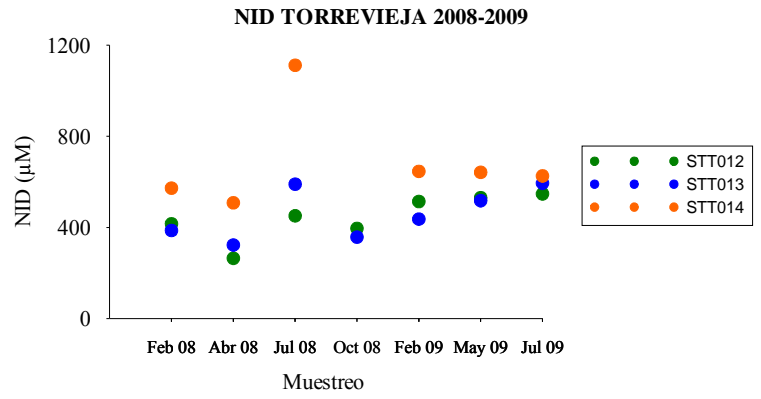

Figura 4.57: Concentraciones de NID registradas en la laguna de Torrevieja durante las campañas de 2008-2009
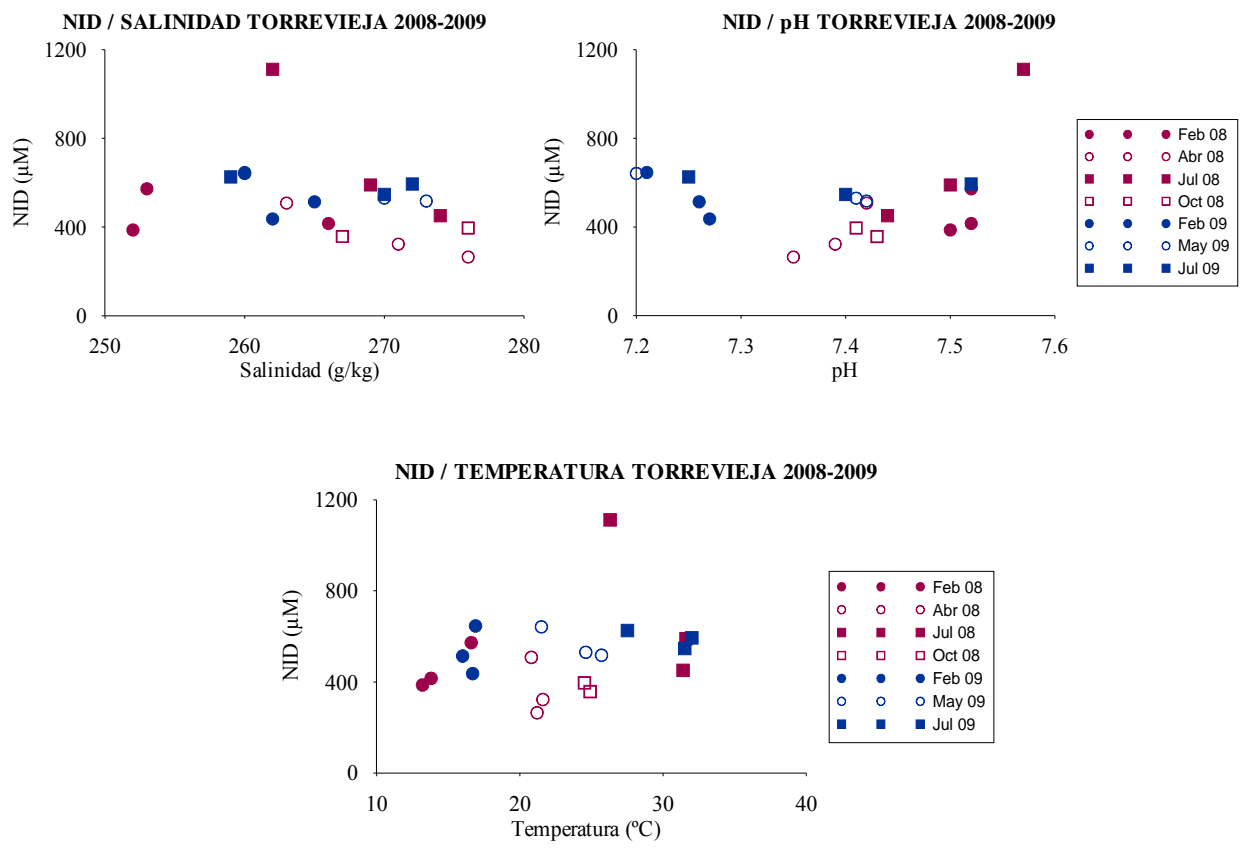

Figura 4.58: a) Comportamiento del NID respecto a la salinidad; b) Comportamiento del NID respecto al pH y c) Comportamiento del NID respecto a la temperatura en la laguna de Torrevieja durante 2008-2009

\subsubsection{Fósforo Soluble Reactivo (PSR)}

El PSR presenta valores muy bajos en toda la laguna de Torrevieja y las concentraciones son inferiores al límite de detección en buena parte de los muestreos y estaciones. Esto es debido a que el fósforo al ser el nutriente limitante en este sistema, se agota rápidamente en el agua tras ser asimilado por el fitoplancton que habita en la laguna.

Sin embargo, en la laguna se detectan concentraciones de PSR principalmente en los muestreos de octubre de 2008 (hasta $0,68 \mu \mathrm{M}$ ), febrero de 2009 (hasta $2,05 \mu \mathrm{M}$ ) y en mayo de 2009 (hasta $0,88 \mu \mathrm{M}$ ) (ver figura 4.59). En mayo de 2009 se puede observar cómo el PSR procede de las salmueras de El Pinoso aunque esto no sucede en febrero de 2009 
donde parece que el PSR procede de procesos de remineralización de la materia orgánica. En octubre de 2008 al no salir agua de la tubería en el momento del muestreo no se puede saber si procede o no de El Pinoso.

No se observa una pauta clara de comportamiento del PSR respecto a la salinidad (figura 4.60a) ni tampoco del PSR con el pH (figura 4.60b) o la temperatura (figura 4.60c).

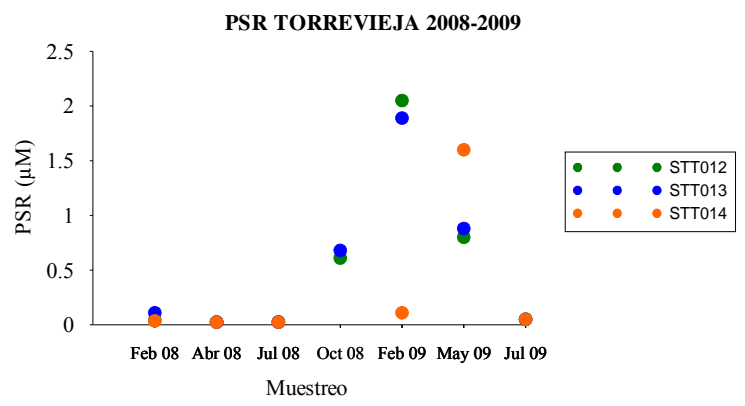

Figura 4.59: Concentraciones de PSR registradas en la laguna de Torrevieja durante las campañas de 2008-2009
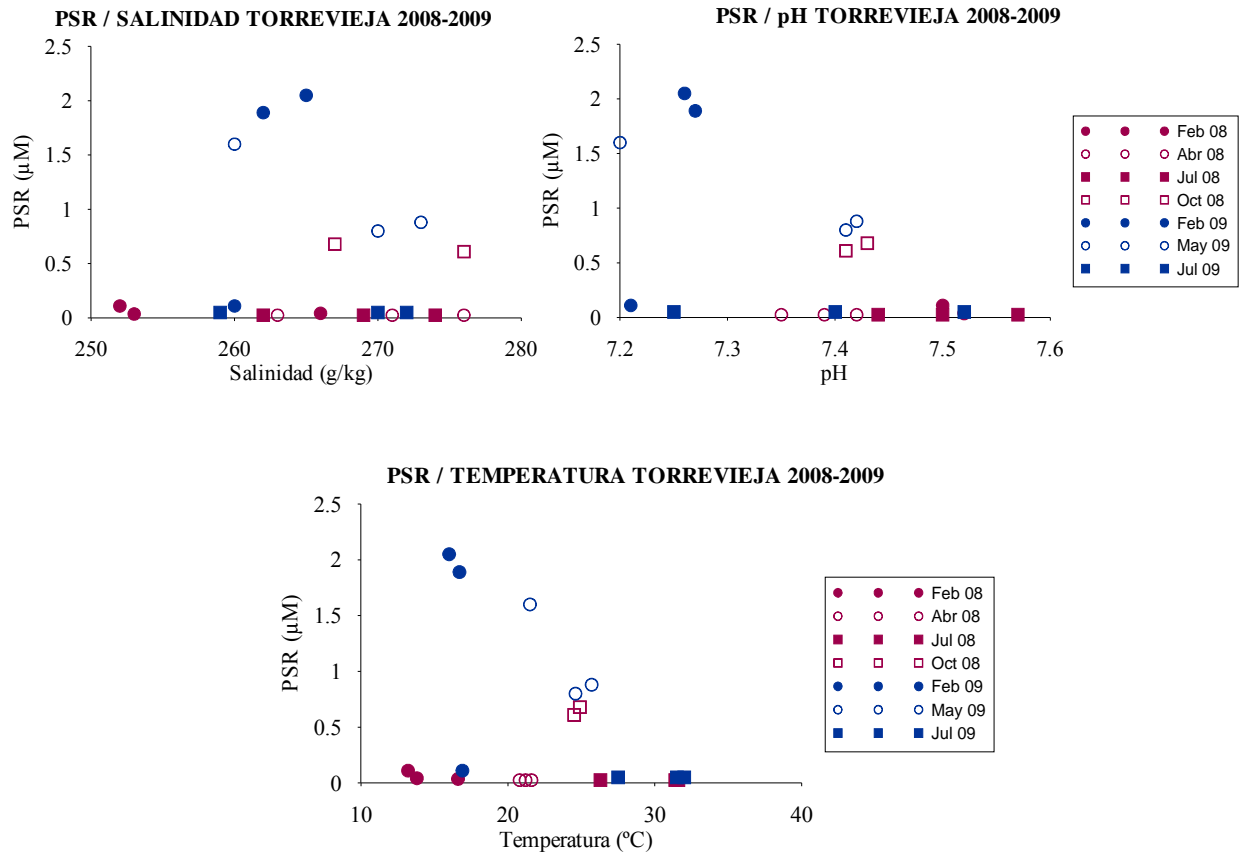

Figura 4.60: a) Comportamiento del PSR respecto a la salinidad; b) Comportamiento del PSR respecto al pH y c) Comportamiento del PSR respecto a la temperatura en la laguna de Torrevieja durante 2008-2009 


\subsubsection{Relación NID/PSR}

La relación NID/PSR presenta valores muy elevados en la laguna de Torrevieja que varían entre 231 y 23592 y son especialmente elevados durante los muestreos de febrero, abril y julio de 2008 (ver figura 4.61). Esto no es debido a que el contenido en nitrógeno de octubre de 2008 a julio de 2009 sea menor sino a que el contenido en PSR es mayor durante dichos meses. También se puede observar que la relación NID/PSR es habitualmente mayor en la salida de la tubería de Pinoso (STT014) que en la laguna. Estas relaciones nos indican claramente que el fósforo es el nutriente limitante del sistema.

En las figuras 4.62 (a, b y c) se muestra el comportamiento de la relación NID/PSR frente a la salinidad, el $\mathrm{pH}$ y la temperatura. En el primer caso no se observa ninguna relación mientras que en los restantes parece observarse una tendencia al aumento de la relación cuanto más elevados son los valores de $\mathrm{pH}$ y cuanto mayor es la temperatura.

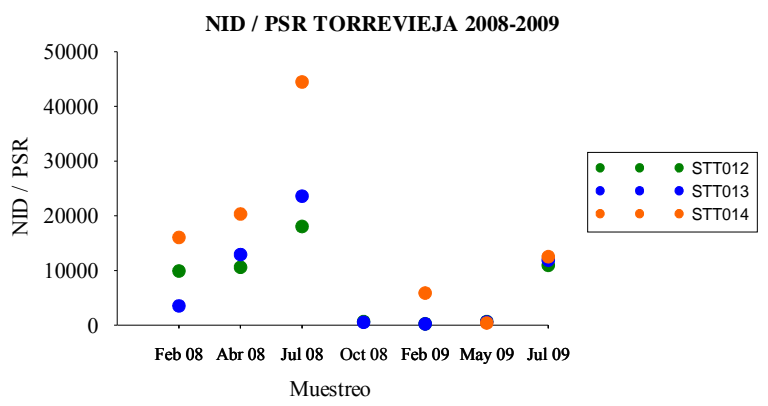

Figura 4.61: Relación NID/PSR de la laguna de Torrevieja durante las campañas de 2008-2009
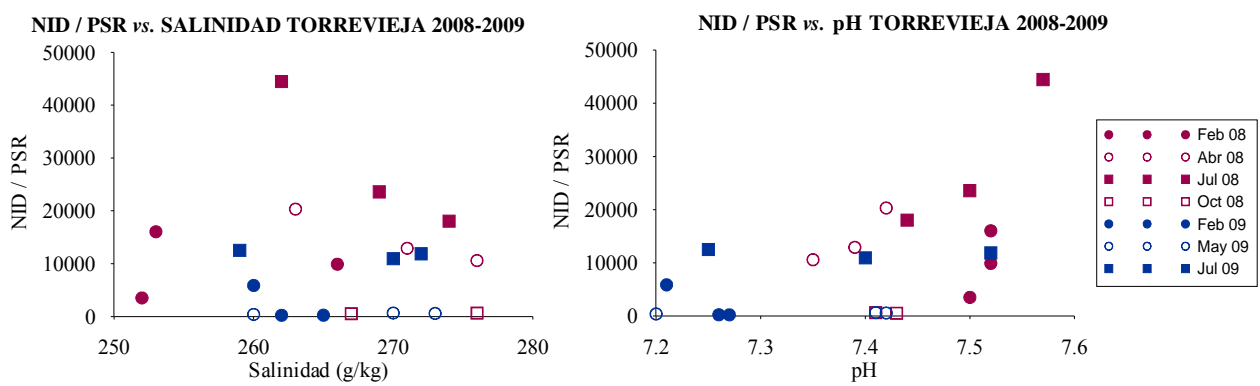


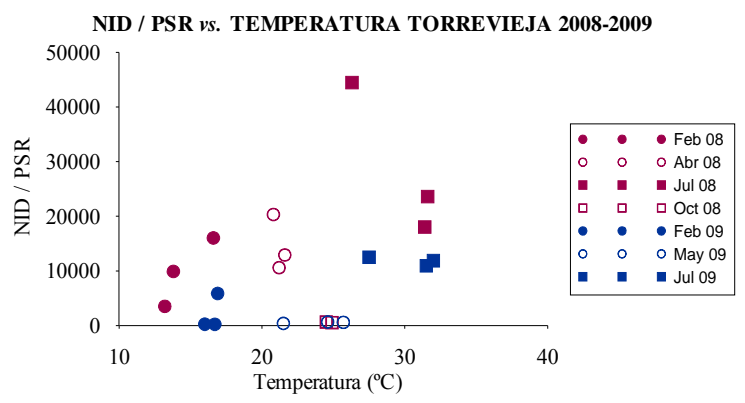

Figura 4.62: a) Comportamiento de la relación NID/PSR respecto a la salinidad; b) Comportamiento de la relación NID/PSR respecto al pH y c) Comportamiento de la relación NID/PSR respecto a la temperatura en la laguna de Torrevieja durante 2008-2009

\subsubsection{Fósforo Total (PT)}

El PT presenta un rango de concentraciones amplio, con un valor mínimo de $6,52 \mu \mathrm{M}$ (STT013 en julio de 2009) y un valor máximo de 17,74 $\mu \mathrm{M}$ (STT012 en febrero de 2009).

Las concentraciones de fósforo total a la salida de las salmueras de El Pinoso (STT014) son mucho menores que en las estaciones del interior de la laguna (STT012 y STT013), ya que en la primera oscilan entre $1,12-4,14 \mu \mathrm{M}$ y en las otras dos entre 6,52 y 17,74 $\mu \mathrm{M}$ (ver figura 4.63). El factor de concentración del PT entre las aguas de El Pinoso y las de la laguna oscila entre 3,65 en STT013 en abril de 2008 y 11,25 en STT012 en julio de 2008.

Los valores más elevados de PT en las estaciones centrales podrían ser debidos, al menos en parte, a que el proceso de concentración salina es mayor en dichas estaciones que a la salida de la tubería de El Pinoso (STT014). A estos aportes hay que añadir los procedentes de la laguna de La Mata. Además, parte de este PT podría quedar retenido en la columna de agua formando parte del ciclo de la comunidad fitoplanctónica que haría que no llegara a precipitar con la sal.

En la figura 4.64a, parece observarse un mayor contenido de PT en aquellas estaciones con mayor concentración salina, y en la figura $4.64 \mathrm{~b}$ parece haber un menor contenido en PT en las estaciones con mayor $\mathrm{pH}$. No se observa una pauta clara respecto a la temperatura (figura $4.64 \mathrm{c}$ ).

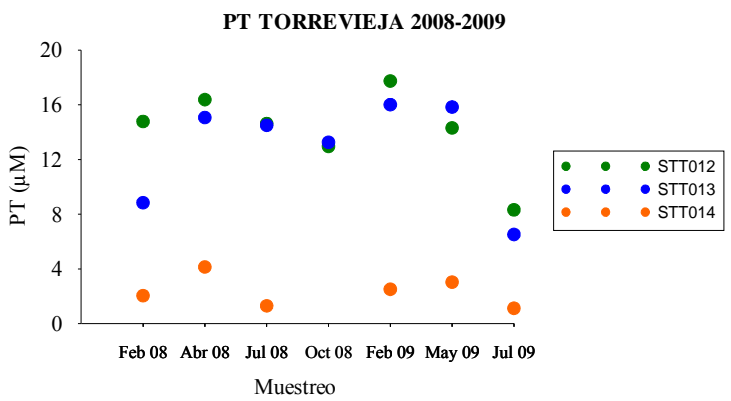

Figura 4.63: Concentraciones de PT registradas en la laguna de Torrevieja durante las campañas de 2008-2009 

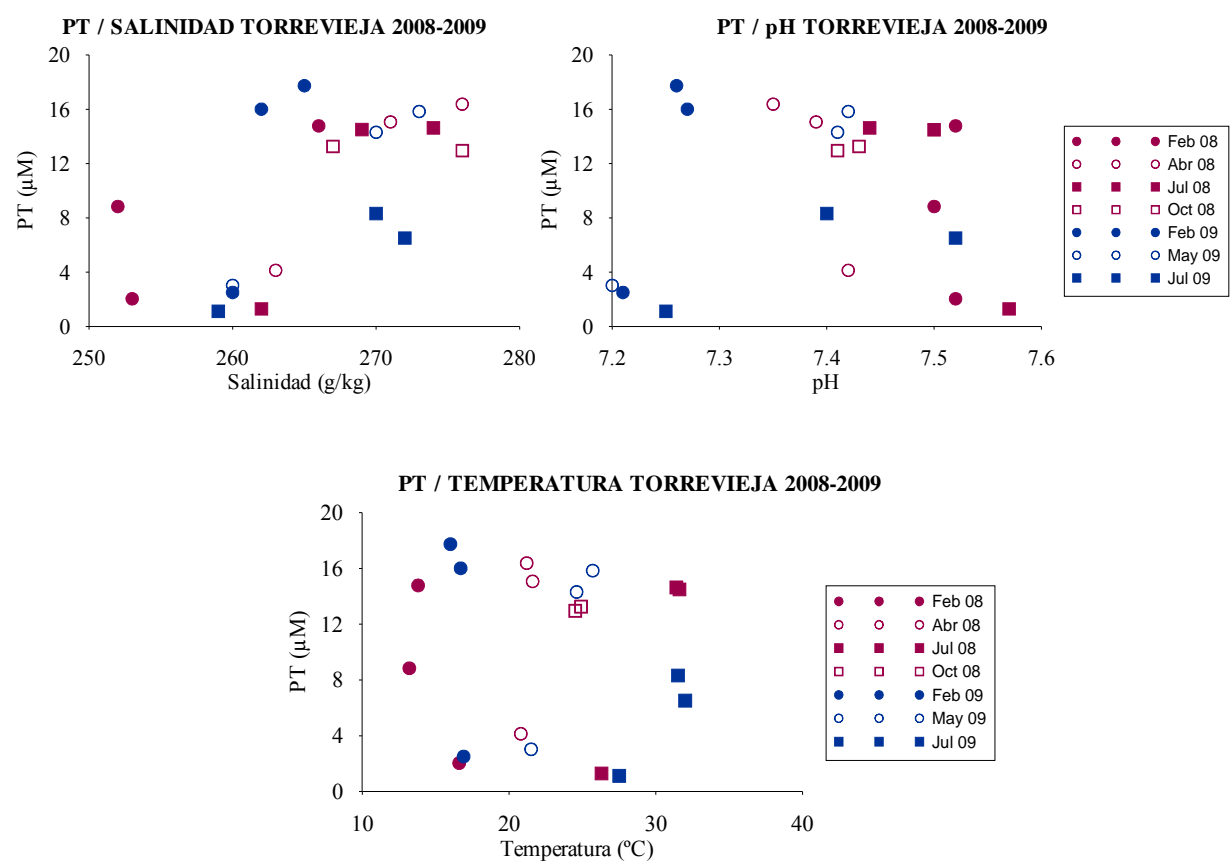

Figura 4.64: a) Comportamiento del PT respecto a la salinidad; b) Comportamiento del PT respecto al pH y c) Comportamiento del PT respecto a la temperatura en la laguna de Torrevieja durante 2008-2009

\subsubsection{0. Ácido ortosilícico}

El rango de concentraciones es muy amplio. El valor mínimo es de 2,9 $\mu \mathrm{M}$ (STT012 en febrero de 2008) mientras que el valor máximo es de 428,9 $\mu \mathrm{M}$ (STT013 en octubre de 2008). Los valores más altos se dan en octubre de 2008, aunque no se dispone del valor de STT014 para poder comparar ya que no salía agua de la tubería de El Pinoso en el momento del muestreo.

Para este parámetro se observa cómo la concentración es mucho mayor en STT014 independientemente de la época del año, mientras que en STT012 y STT013 los valores son más bajos y en ocasiones se producen grandes diferencias entre las estaciones estaciones centrales y la salida de El Pinoso. Por ejemplo en febrero de 2008 los valores de STT012 y STT013 son de 2,9 y 3,4 $\mu \mathrm{M}$ respectivamente, mientras que los de STT014 son de 106,7 $\mu \mathrm{M}$ (figura 4.65). Por lo que parece que la parece que la principal entrada de ácido ortosilícico en el sistema se produce por la entrada de las aguas de salmuera de El Pinoso. Dado que solamente en abril de 2008 se han detectado cantidades significativas de diatomeas (GVA, 2008), la reducción del ácido ortosilícico en la laguna habría que achacarla a procesos físico-químicos, probablemente a su precipitación junto con la sal.

No se observa una relación clara entre el ácido ortosilícico presente en la salina y la salinidad (figura 4.66a), el pH (figura 4.66b) y la temperatura (figura 4.66c). 


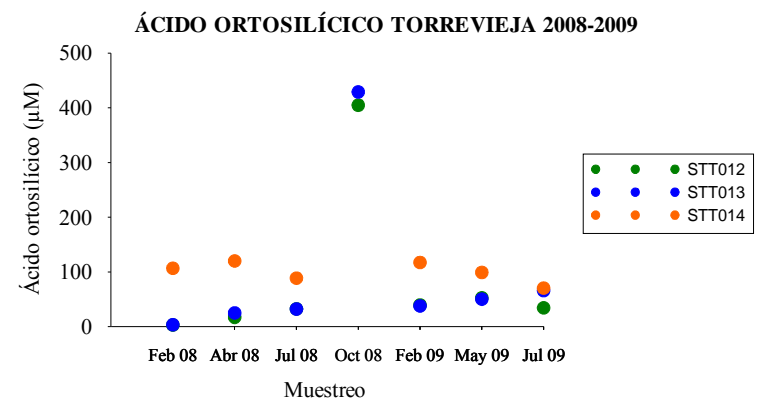

Figura 4.65: Concentraciones de ácido ortosilícico registradas en la laguna de Torrevieja durante las campañas de 2008-2009

ÁC. ORTOSILÍCICO / SALINIDAD TORREVIEJA 2008-2009
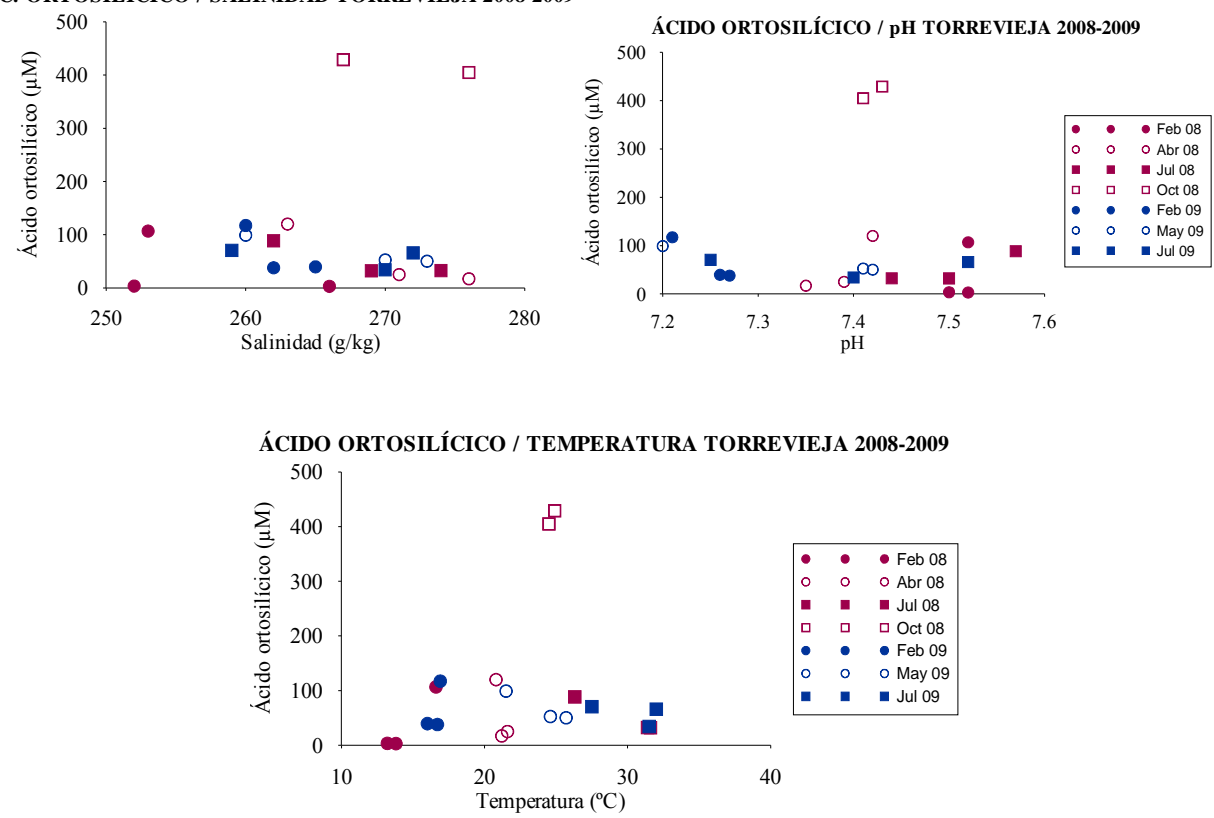

Figura 4.66: a) Comportamiento del ácido ortosilícico respecto a la salinidad; b) Comportamiento del ácido ortosilícico respecto al $\mathrm{pH}$ y c) Comportamiento del ácido ortosilícico respecto a la temperatura en la laguna de Torrevieja durante 2008-2009 


\subsubsection{Análisis multivariable de la laguna de Torrevieja}

En el análisis por componentes principales de los resultados obtenidos para los diferentes parámetros físico-químicos en la laguna de Torrevieja (estaciones STT012 y STT013) se han estudiado un total de 7 muestreos (desde febrero de 2008 a julio de 2009) y se han incluido 8 variables: salinidad, $\mathrm{pH}$, amonio, nitrito, nitrato, PSR, PT y ácido ortosilícico. A los datos obtenidos se les ha efectuado una transformación logarítmica $(\log \mathrm{x}+1)$ previa al ACP (excepto al pH que ya presenta una escala logarítmica).

Este análisis nos ha permitido reducir las variables a tres componentes principales que en total explican un $74,556 \%$ de la varianza acumulada $(36,374 \%$ la componente $1 ; 20,142 \%$ la componente 2 y $18,041 \%$ la componente 3 ).

\begin{tabular}{|rccc|}
\hline PARÁMETROS & $\begin{array}{c}\text { Componente 1 } \\
(\mathbf{3 6 , 3 7 4} \%)\end{array}$ & $\begin{array}{c}\text { Componente 2 } \\
\mathbf{( 2 0 , 1 4 2} \%)\end{array}$ & $\begin{array}{c}\text { Componente 3 } \\
\mathbf{( 1 8 , 0 4 1} \%)\end{array}$ \\
\hline Salinidad & $-0,0149038$ & 0,538204 & 0,426105 \\
\hline pH & 0,479962 & 0,121468 & 0,153827 \\
\hline Amonio & $-0,16096$ & $-0,569486$ & 0,281951 \\
\hline Nitrito & $-0,465207$ & 0,186668 & 0,0723662 \\
\hline Nitrato & 0,201818 & $-0,286379$ & 0,463614 \\
\hline PSR & $-0,502081$ & $-0,349717$ & 0,104494 \\
\hline PT & $-0,386993$ & 0,245258 & $-0,367526$ \\
\hline Ác. ortosilícico & $-0,290705$ & 0,268247 & 0,590852 \\
\hline
\end{tabular}

Tabla 4.4: Tabla de pesos de los componentes del ACP para los parámetros físico-químicos de Torrevieja

A diferencia de las dos lagunas anteriores, los resultados de este ACP no tienen una explicación tan clara debido a que en esta laguna existen factores en algunos casos contrapuestos:

- $\quad$ aportes procedentes de La Mata que no presentan un comportamiento constante en cuanto a sus concentraciones

- $\quad$ aportes procedentes de El Pinoso con entradas muy elevadas de algunos nutrientes

- $\quad$ procesos internos como el proceso de precipitación de la sal

- $\quad$ la propia actividad de explotación salinera

A partir de los resultados obtenidos en la tabla de pesos de componentes (tabla 4.4) se observa que la componente 1 está representada por los parámetros de $\mathrm{pH}$, nitrito $\mathrm{y}$ compuestos de fósforo (PSR y PT) y parece estar relacionada con el estado de la laguna cuando no hay $\mathrm{CO}_{2}$ provocado por la remoción del sedimento con la extracción de la costra salina. La componente 2 representa los parámetros de salinidad y amonio, y en menor medida PSR, y parece estar relacionada con el crecimiento de la población fitoplanctónica en la columna de agua que absorbe amonio y PSR. La componente 3 representa los parámetros de salinidad, nitratos y ácido ortosilícico, y parece estar relacionada con procesos de concentración salina.

En este análisis las componentes más representativas son la componente 1 y 2 que entre ellas explican un $56,515 \%$ de la varianza y son las que se explican a continuación con un mayor grado de detalle. 


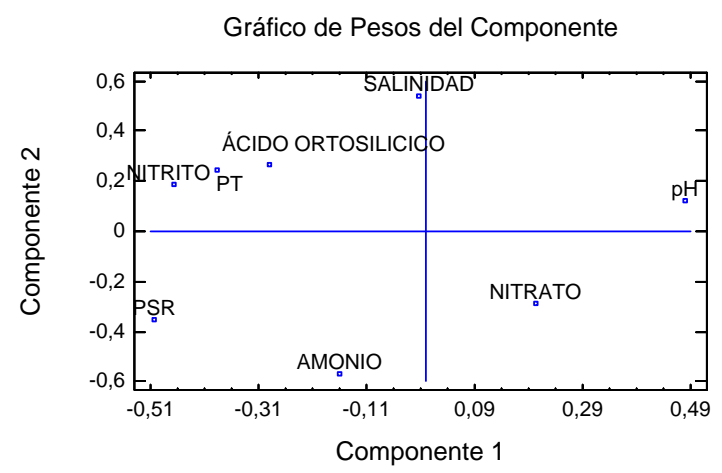

Figura 4.67: Gráfico de pesos para los componentes 1 y 2 del ACP para los parámetros físico-químicos en la laguna de Torrevieja

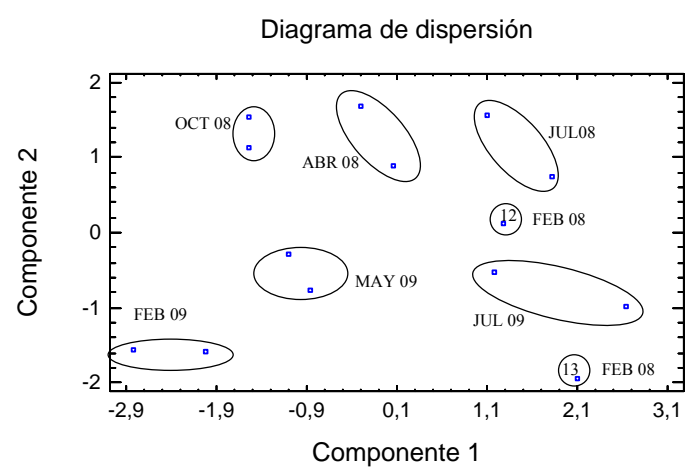

Figura 4.68: Diagrama de dispersión para los componentes 1 y 2 del ACP para los parámetros físico-químicos en la laguna de Torrevieja

A partir de las figuras 4.67 y 4.68, se puede observar cómo con respecto a la componente 1 (pH, nitrito, PSR y PT) se aprecia una agrupación entre los muestreos de febrero de 2008, julio de 2008 y julio de 2009. El pH parece ser el principal parámetro que agrupa estos muestreos ya que estos muestreos son los que presentan valores mayores de $\mathrm{pH}$. Por otra parte se encuentran abril de 2008 y mayo de 2009 con valores de $\mathrm{pH}$ inferiores a los del grupo anterior. Al comparar ambos muestreos se observa que mayo de 2009 presenta valores mayores de nitritos y PSR que abril de 2008, aunque también de pH. Finalmente se encuentran octubre de 2008 y febrero de 2009. Febrero de 2009 es el muestreo que tiene unos valores más bajos de $\mathrm{pH}$ y más altos de PSR y PT. Octubre de 2008 sería más bien un muestreo intermedio entre febrero de 2009 y el grupo anterior al presentar valores más elevados de nitritos y menores de nitratos que febrero de 2009.

En cuanto a la componente 2 (salinidad, amonio y PSR) parece que el principal parámetro que contribuye a la distribución de los muestreos es la salinidad, puesto que los muestreos de octubre 2008, abril 2008 y julio 2008 con salinidades ligeramente superiores, se encuentran en la parte superior del diagrama, mientras que los muestreos de febrero de 2009 
y la estación STT013 de febrero de 2008 con salinidades menores, se encuentran en la parte inferior.

En el conglomerado jerárquico de Torrevieja (figura 4.69) no se pueden apreciar diferencias entre las estaciones y/o entre las campañas (como sí ocurría con los sistemas ya estudiados). Esto corrobora la gran homogeneidad que existe entre ambas estaciones muestreadas y ratifica que en esta salina la actuación humana pretende (y consigue) mantener unas salinidades más o menos constantes durante la mayor parte del año, por lo que no llegar a apreciar variaciones estacionales mediante este análisis de conglomerados.

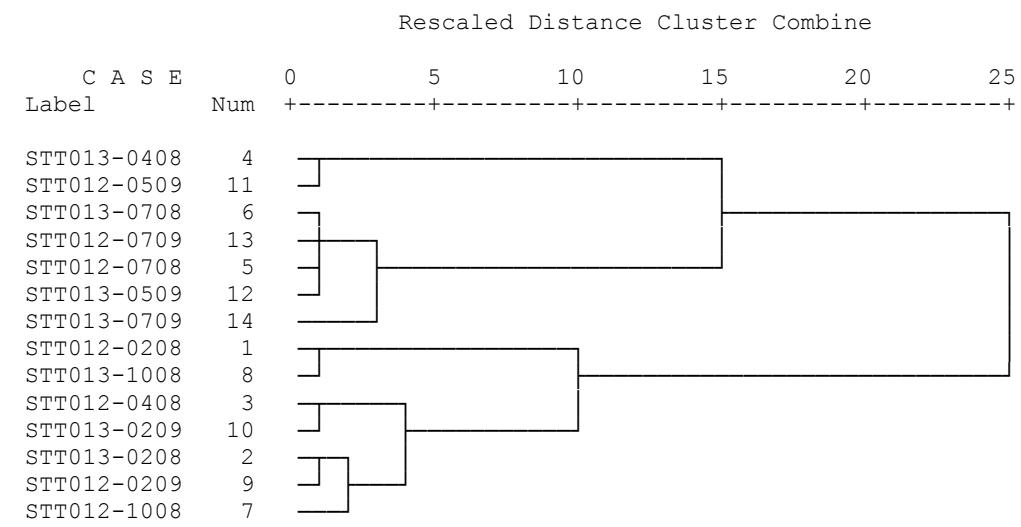

Figura 4.69: Conglomerado jerárquico con la agrupación de las estaciones para cada una de las campañas muestreadas en la laguna de Torrevieja 


\subsection{CIRCUITO SALINERO DE SANTA POLA}

\subsubsection{Análisis de los parámetros físico-químicos}

\subsubsection{Salinidad}

El circuito de Bonmatí en Santa Pola es un sistema de explotación salinera convencional, en el que se hace circular el agua de mar por una serie de balsas someras para obtener mediante evaporación una progresiva concentración de las sales. Dado que las estaciones de muestreo se encuentran distribuidas a lo largo del circuito salinero (abarcando el proceso completo desde los calentadores a los cristalizadores), la salinidad presenta un rango de concentraciones que oscila entre $38,49 \mathrm{~g} / \mathrm{kg}$ (valor muy próximo a los $37,9 \mathrm{~g} / \mathrm{kg}$ del agua de mar en el Mediterráneo) y $279 \mathrm{~g} / \mathrm{kg}$ en los cristalizadores.

En la figura 4.70 se presenta el registro de precipitaciones en la estación meteorológica más cercana de la que se disponen datos completos de precipitaciones y temperaturas para el período de estudio, que es la de Elche (estación 8018A de la Agencia Estatal de Meteorología (AEMET); UTM X: 700323; UTM Y: 4237953; Altitud: 86 m), situada a unos $13 \mathrm{~km}$ de distancia.

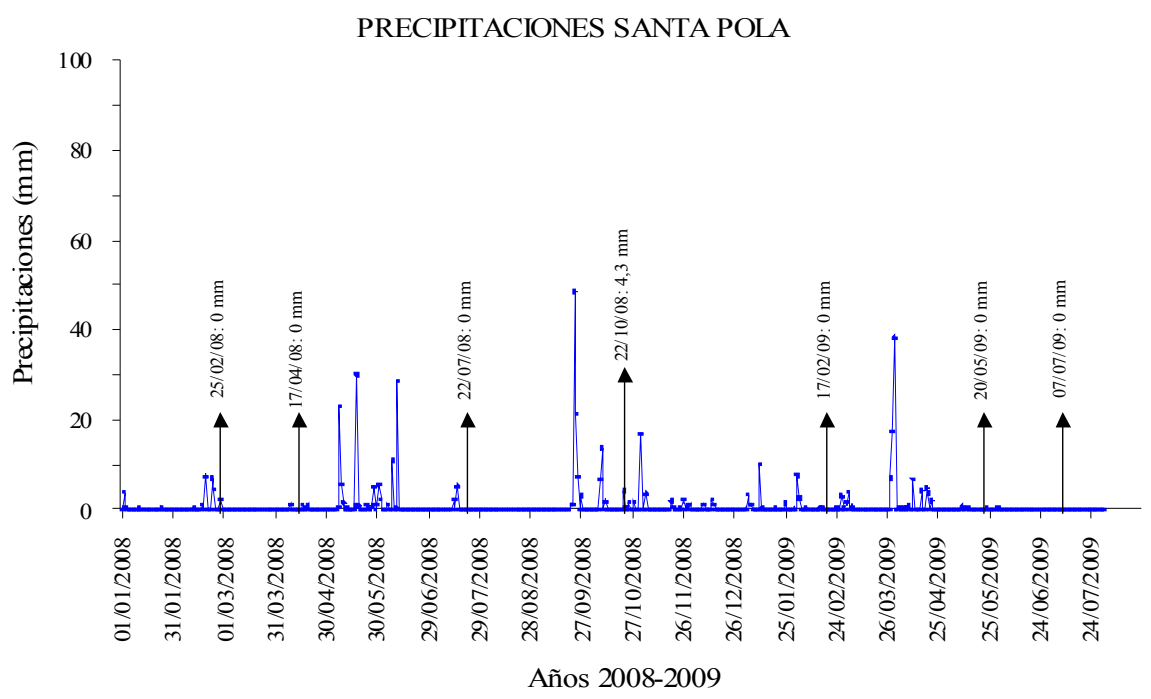

Figura 4.70: Precipitaciones diarias $(\mathrm{mm})$ en la estación Elche durante el período 2008-2009. En la figura se han marcado las precipitaciones correspondientes a los días de muestreo (Fuente: AEMET)

En primer lugar hay que mencionar que para el año 2008 se han tomado muestras en 26 estaciones (cada estación corresponde a un estanque del circuito) desde SPN001 a SPN026, si bien no se van a tener en cuenta para el análisis de los resultados las estaciones SPN015 y SPN023, ya que en dos de los cuatro muestreos realizados en el 2008 las balsas se encontraron secas, por lo que los resultados obtenidos no se consideran suficientemente representativos. 
Por otra parte, durante el año 2009, se tomaron muestras en 4 estaciones (SPN002, SPN003, SPN008 y SPN021). Está reducción en el número de estaciones se realizó porque, dentro del programa de la DMA en la que se enmarca el trabajo, se consideró que, tras un primer año de estudio en detalle del circuito se podía reducir el número de estaciones, dado que se trataba de muestras bastante uniformes. Para ello se seleccionaron cuatro balsas representativas de los procesos que tenían lugar en el circuito. Estas balsas abarcan todo el rango del circuito salinero desde la entrada de agua de mar (SPN002), calentadores (SPN003), concentradores (SPN008) a los cristalizadores finales (SPN021).

Las diferencias de salinidad entre estanques son el resultado de la gestión humana del flujo de agua en el sistema, que aprovecha diversos procesos naturales existentes, especialmente la evapotranspiración. Hay que señalar que la circulación del agua en el circuito no se detiene durante el invierno y los estanques, con alguna excepción, permanecen inundados durante todo el año.

En la figura 4.71 se puede observar cómo los máximos de $\mathrm{P}_{50}$ de salinidad se producen durante los meses previos a la cosecha de la sal, que tiene lugar, lógicamente, a finales del verano.

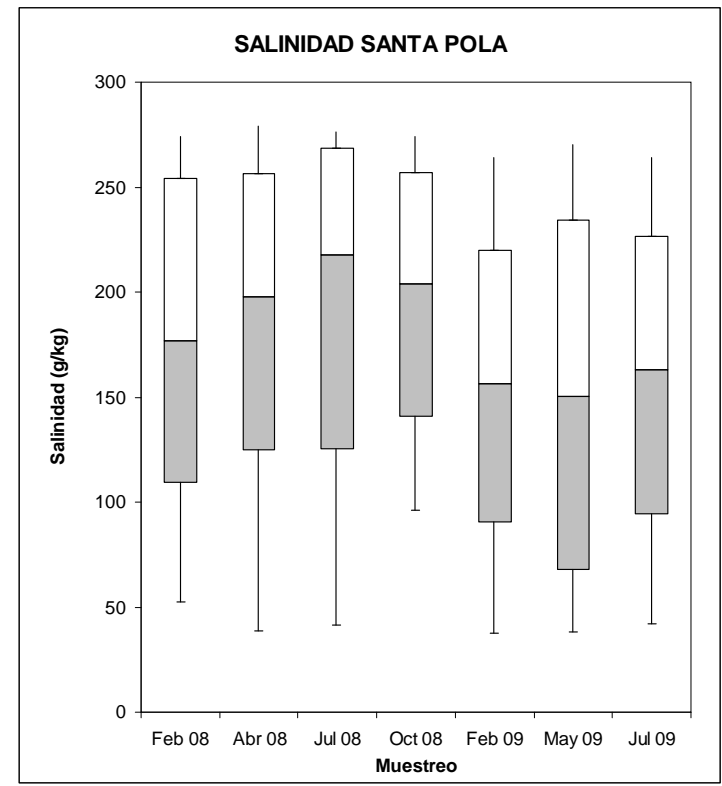

Figura 4.71: Salinidades registradas en la salina de Santa Pola durante las campañas de 2008-2009

Para estudiar los cambios espaciales dentro del circuito se ha utilizado el percentil $50\left(\mathrm{P}_{50}\right)$ de cada una de las estaciones que representan a los distintos estanques. Éstos han sido clasificados en función de este $\mathrm{P}_{50}$ en cinco rangos de salinidad, tal y como se muestra en la figura 4.72. Debemos reseñar que esta distribución de las distintas tipologías se encuentra relacionada con el flujo de circulación del agua en el circuito de Bonmatí, cuya descripción se encuentra ampliamente detallada en el apartado de área de estudio. 


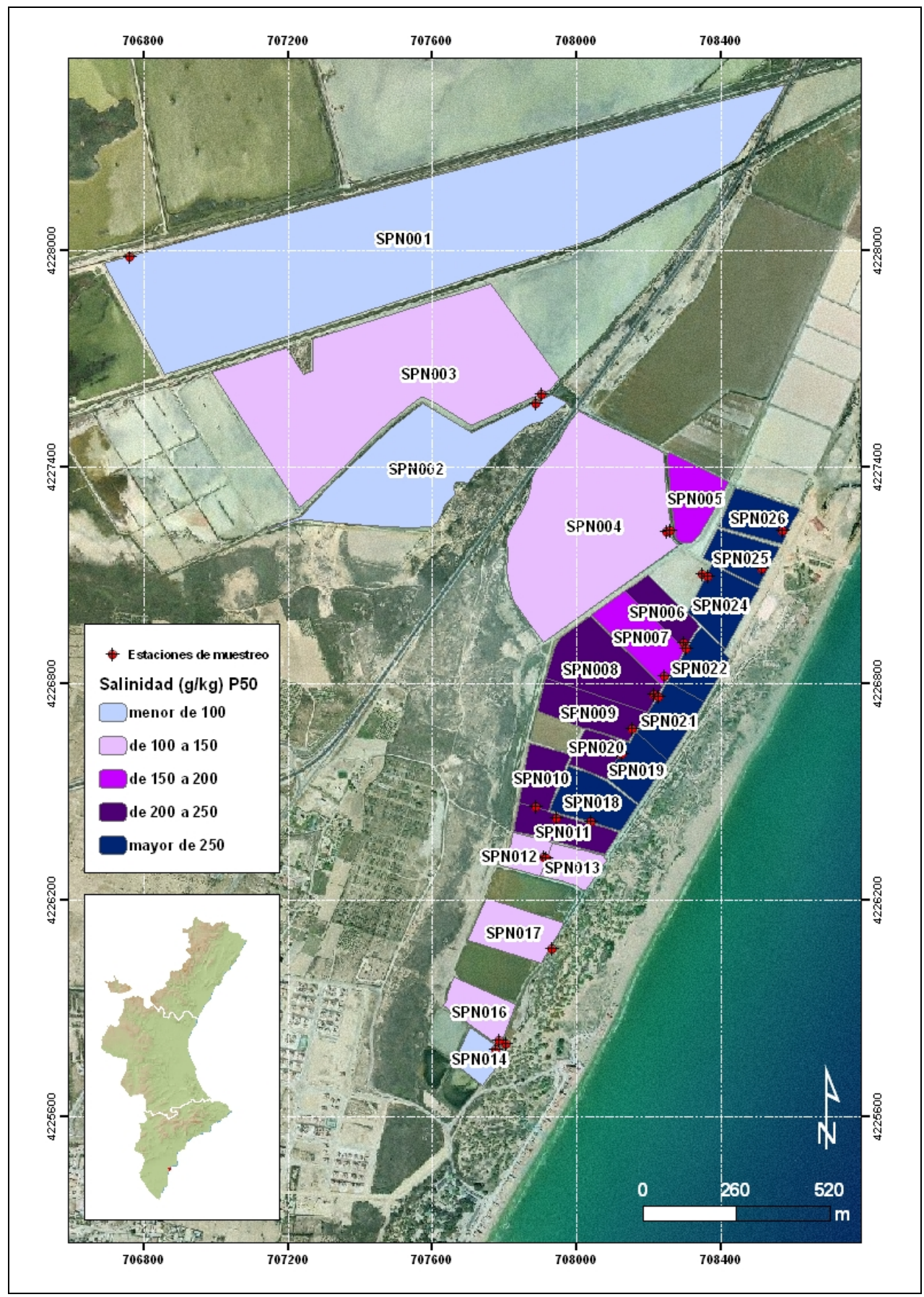

Figura 4.72: Rangos de distribución de $\operatorname{los} \mathrm{P}_{50}$ de salinidad en los distintos estanques 
Tipologías en función del $\mathrm{P}_{50}$ de salinidad:

- Tipo 1: Estanques con salinidades $<100 \mathrm{~g} / \mathrm{kg}$. Con valores inferiores a esta salinidad e incluso próximos a los del agua de mar están los estanques representados por las estaciones SPN001, SPN002 y SPN014. El valor mínimo es de 37,80 g/kg y se da en SPN002 durante febrero de 2009. Estos estanques presentan valores menores porque son aquellos hacia los que el agua de mar es dirigida cuando entra en el sistema (SPN001 y SPN002 son los más cercanos a la entrada norte y SPN014 a la entrada sur).

- Tipo 2: Estanques con salinidades entre 100 - $150 \mathrm{~g} / \mathrm{kg}$. En este rango de salinidad se encuentran una serie de estanques intermedios previos a los primeros concentradores, que actúan como calentadores y están representados por las estaciones SPN003, SPN004, SPN016, SPN017, SPN012 y SPN013. Son aquellos por los que continúa su avance el agua cada vez más concentrada dentro del circuito. En la parte norte del circuito el agua pasa de SPN003 a SPN004 (por lo que la salinidad en este segundo estanque es ligeramente superior) y en la parte sur del circuito, de SPN016 pasa a SPN017, después a SPN012 y finalmente a SPN013. Como cabría esperar del proceso de concentración, la salinidad va aumentando conforme se pasa de una balsa a otra en el circuito.

- Tipo 3: Estanques con salinidades entre 150 - $200 \mathrm{~g} / \mathrm{kg}$. En este rango se encuentran los estanques representados por SPN005 y SPN007, que ya actúan como concentradores.

- Tipo 4: Estanques con salinidades entre $200-250 \mathrm{~g} / \mathrm{kg}$. Son los estanques representados por las estaciones SPN006, SPN008, SPN009, SPN010, SPN011 y SPN020. Estos estanques actúan fundamentalmente como concentradores finales y el agua de cualquiera de ellos puede ser conducida a cualquier cristalizador según las necesidades de producción de la explotación salinera.

- Tipo 5: Estanques con salinidades $>250 \mathrm{~g} / \mathrm{kg}$. Las salinidades mayores del circuito se dan en los estanques representados por SPN018, SPN019, SPN021, SPN022, SPN024, SPN025 y SPN026, que funcionan todas ellos como cristalizadores. El valor máximo de salinidad se ha alcanzado en SPN024 con $279 \mathrm{~g} / \mathrm{kg}$.

Lógicamente a lo largo del proceso de evapotranspiración, se produce un aumento progresivo de la salinidad conforme se avanza en el circuito salinero hasta llegar a un máximo en los cristalizadores donde se produce finalmente la precipitación y extracción de la sal.

En cuanto a la variabilidad dentro de cada uno de los estanques hay que mencionar que aunque en las balsas con concentraciones más altas las variaciones son muy reducidas, éstas variaciones aumentan conforme la salinidad de las balsas se reduce. Se ha estudiado la variabilidad de los estanques (ver tabla 4.5) y para el año 2008 (en que se muestrean todos los estanques del circuito). La variabilidad en los cristalizadores es muy reducida (generalmente $<5 \%$ ), el rango de variación en los concentradores es mayor (entre 9,5 $16,7 \%$ ) y aún mayor en los calentadores (entre 7,5 - 59,5\%) especialmente en los iniciales. Destaca la gran variabilidad de los estanques representados por las estaciones SPN002, SPN003 y SPN014 (variabilidad entre 39,5-59,5\%). 


\begin{tabular}{|cc|cc|cc|}
\hline $\begin{array}{c}\text { ESTACIÓN } \\
\mathbf{2 0 0 8}\end{array}$ & $\begin{array}{c}\text { C.V. SAL } \\
(\boldsymbol{\%})\end{array}$ & ESTACIÓN & $\begin{array}{c}\text { C.V. SAL } \\
(\%)\end{array}$ & ESTACIÓN & $\begin{array}{c}\text { C.V. SAL } \\
(\%)\end{array}$ \\
\hline SPN001 & 7,48 & SPN009 & 10,25 & SPN018 & 8,23 \\
\hline SPN002 & 59,53 & SPN010 & 13,25 & SPN019 & 4,32 \\
\hline SPN003 & 39,42 & SPN011 & 16,72 & SPN020 & 9,49 \\
\hline SPN004 & 15,35 & SPN012 & 12,35 & SPN021 & 3,33 \\
\hline SPN005 & 16,03 & SPN013 & 16,15 & SPN022 & 2,63 \\
\hline SPN006 & 13,64 & SPN014 & 51,29 & SPN024 & 4,33 \\
\hline SPN007 & 14,26 & SPN016 & 12,22 & SPN025 & 2,28 \\
\hline SPN008 & 11,79 & SPN017 & 9,18 & SPN026 & 1,8 \\
\hline
\end{tabular}

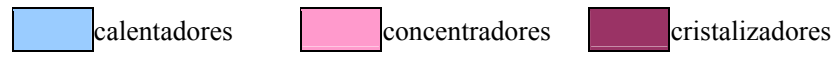

Tabla 4.5: Coeficientes de variación de la salinidad (\%) en las diferentes estaciones de Santa Pola para las campañas de 2008

\subsubsection{2. $\mathrm{pH}$}

El pH presenta un amplio rango de valores que varía entre 7,04 y 8,78 (figura 4.73). Estos resultados obtenidos se encuentran dentro del rango que cabría esperar, ya que según Javor (1989) el $\mathrm{pH}$ en las explotaciones salineras normalmente oscila entre 7,5 y 8,5 aunque en salmueras extremadamente concentradas se pueden alcanzar valores de $\mathrm{pH}$ incluso menores.

En esta salina se aprecia una relación inversa entre el pH y la salinidad $\left(\mathrm{R}^{2}: 0,6394\right)$ ya que cuanto mayor es la concentración salina de los estanques, menores son los valores detectados de $\mathrm{pH}$ (figura 4.74a) aunque no se observa ninguna relación entre $\mathrm{pH}$ y temperatura (figura 4.74b).

Dado que este descenso del pH (como lo muestran los resultados reseñados anteriormente sobre las pruebas realizadas en las muestras de La Mata - Torrevieja) no cabe achacarlo en sentido estricto a los cambios iónicos; es evidente que se debe al aumento de la concentración de $\mathrm{CO}_{2}$ y otros gases ácidos en la columna de agua.

Son muchos los investigadores que han documentado un descenso del $\mathrm{pH}$ cuanto mayor es la mayor concentración del agua de mar (Sass y Ben-Yaakov, 1977) y es ampliamente reconocido que la evaporación del agua de mar puede afectar el sistema carbónicocarbonato de diferentes formas (Lazar et al., 1983). Además, durante el proceso de evapotranspiración del agua de mar en una explotación salinera, la precipitación de $\mathrm{CaCO}_{3}$ y del $\mathrm{CaSO}_{4} \cdot 2 \mathrm{H}_{2} \mathrm{O}$ (yeso) provoca un descenso del contenido en calcio de la columna de agua, lo que reduce la capacidad del sistema de regular la concentración de $\mathrm{CO}_{2}$, haciendo que el medio sea aún más sensible a los cambios en el contenido de carbónico-carbonato (Soetaert et al., 2007).

También se pueden observar valores similares de $\mathrm{pH}$ en rangos de salinidad muy amplios, como valores de $\mathrm{pH}$ de 7,7 en salinidades de $80 \mathrm{~g} / \mathrm{kg}$ y de $270 \mathrm{~g} / \mathrm{kg}$, posiblemente debidos a variaciones tanto en la actividad biológica como en la génesis de $\mathrm{CO}_{2}$, así como por los cambios en la composición físico-química de las aguas. 
Los resultados nos indican que hay una tendencia a que el $\mathrm{pH}$ diminuya al aumentar la concentración salina (ver figura 4.74a). De hecho, los valores más bajos de $\mathrm{pH}$ (cercanos a 7) se dan a las salinidades más altas, en los cristalizadores. Esto no puede achacarse a diferencias en la capacidad de tamponización del agua ya que la precipitación del calcio se produce a salinidades inferiores a éstas. Por tanto, parece pues que hay otro factor relacionado con la salinidad, que favorece la incidencia de los gases ácidos en el $\mathrm{pH}$ del sistema. Con toda probabilidad, este factor es la disminución de la difusibilidad de los gases al aumentar la densidad del agua, que favorecería condiciones de sobresaturación que no se dan con densidades más bajas.

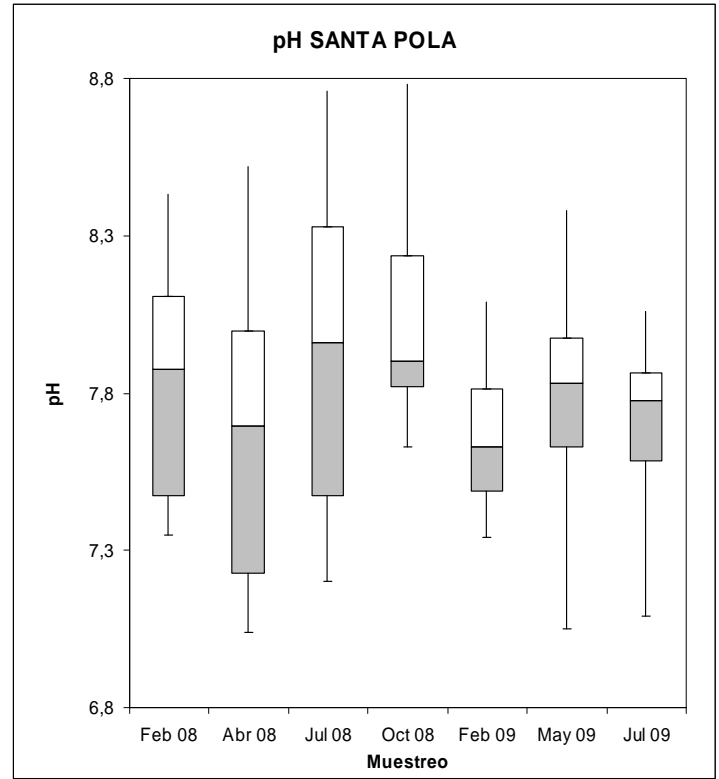

Figura 4.73: Valores de $\mathrm{pH}$ registrados en la salina de Santa Pola durante las campañas de 2008-2009
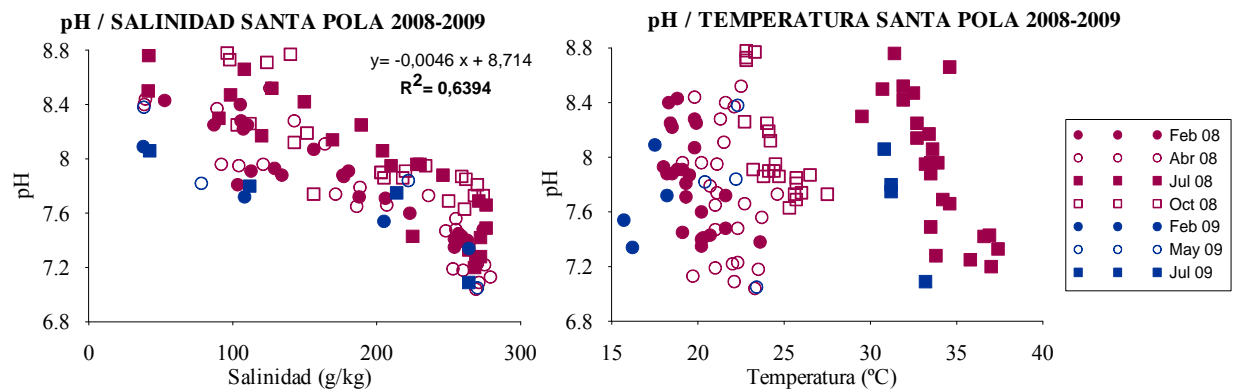

Figura 4.74: a) Comportamiento del $\mathrm{pH}$ respecto a la salinidad; b) Comportamiento del $\mathrm{pH}$ respecto a la temperatura en la salina de Santa Pola durante las campañas de 2008-2009. 


\subsubsection{Amonio}

El amonio presenta una concentración muy variable a lo largo de todo el circuito salinero puesto que oscila entre valores por debajo del límite de detección hasta un valor máximo de 214,9 $\mu \mathrm{M}$ en SPN003 durante el mes de mayo de 2009 (ver figura 4.75).

En la figura 4.76a, se puede apreciar cómo los mayores picos de amonio se dan en algunos de los estanques tipo 1 y 2 (con salinidades entre 75 y $155 \mathrm{~g} / \mathrm{kg}$ ) en febrero $(66,4 \mu \mathrm{M})$, abril $(48,9 \mu \mathrm{M})$ y octubre de $2008(150,5 \mu \mathrm{M})$, así como en mayo de $2009(214,9 \mu \mathrm{M})$, aunque fundamentalmente se dan en SPN002 y SPN003. Los más bajos se encuentran en el muestreo de julio de 2008 y julio de 2009 donde todos los valores son $<14 \mu \mathrm{M}$. Aparte de esta tendencia señalada, a lo largo del circuito salinero se observa otro pico de concentración al final del circuito, en los cristalizadores, especialmente en febrero de 2008 (figura 4.76a).

Los valores más altos corresponden a dos de las estaciones donde se da el mayor rango de variación de la salinidad (ver tabla 4.5), ya que en SPN002 va de 37,8 - $156 \mathrm{~g} / \mathrm{kg}$ y en SPN003 de 39,3 - $120 \mathrm{~g} / \mathrm{kg}$. Estas variaciones que no se dan en los otros estanques parecen tener una influencia significativa sobre los aportes de amonio, que parecen originarse en los sedimentos ya que no hay una subida de PSR simultánea como cabría esperar si este amonio procediera de la descomposición de la biota de la columna de agua. El que no haya una relación estrecha entre $\mathrm{pH} / \mathrm{CO}_{2} \mathrm{y}$ amonio, se debe probablemente a que en estas balsas aún no se ha producido la precipitación de todo el calcio por lo que podría haber una menor incidencia del aporte de $\mathrm{CO}_{2}$ en el descenso del pH (a lo que cabría añadir que las menores densidades de estas aguas favorecerían las pérdidas de $\mathrm{CO}_{2}$ a la atmósfera). Los picos secundarios que se dan al final del circuito salinero parecen deberse al proceso de concentración.

Además, se observa que todos los valores más altos de amonio coinciden con valores de $\mathrm{pH}$ $<8$, aunque no siempre se produce el mismo fenómeno a la inversa, es decir, no siempre con valores de $\mathrm{pH}<8$ se encuentran concentraciones de amonio muy grandes (figura 4.76b). No se observa relación entre el amonio y la temperatura (figura 4.76c).

Los resultados presentados muestran que el contenido en amonio es muy variable a lo largo de todo el circuito salinero, lo que coincide con los resultados de otros autores, ya que según Javor (2002) las concentraciones de amonio pueden variar ampliamente según la salina, en los distintos estanques de las explotaciones salineras, con las diferentes salinidades y a lo largo del ciclo anual.

Según Pedrós-Alió et al. (2000) en Bras del Port (Santa Pola) el amonio fue el nutriente inorgánico más abundante con valores entre $40-230 \mu \mathrm{M}$ en calentadores y concentradores y entre $150-230 \mu \mathrm{M}$ en los cristalizadores; mientras que Joint et al. (2002) presentaron valores entre 1,5 - 2,4 $\mu \mathrm{M}$ a salinidades bajas e intermedias y entre $1-3,9 \mu \mathrm{M}$ en los cristalizadores de Bras del Port. Por otra parte, Javor (2002) estableció unas concentraciones de amonio típicas para las salinas solares eutróficas, entre $1-50 \mu \mathrm{M}$ en los estanques de precipitación del yeso (precipitación que tiene lugar cuando el agua de mar se concentra unas 4,5 veces, es decir a unos $160 \mathrm{~g} / \mathrm{kg}$ de salinidad) y $5-50 \mu \mathrm{M}$ en los cristalizadores. 
En los resultados presentados aunque tres de las muestras a lo largo de las 106 muestras analizadas presentan valores $>50 \mu \mathrm{M}$, en su mayor parte se encuentran dentro de los rangos de Javor (2002) ya que se encuentran desde valores inferiores al límite de detección a 48,9 $\mu \mathrm{M}$ en los concentradores y de valores inferiores al límite de detección a 27,3 $\mu \mathrm{M}$ en los cristalizadores.

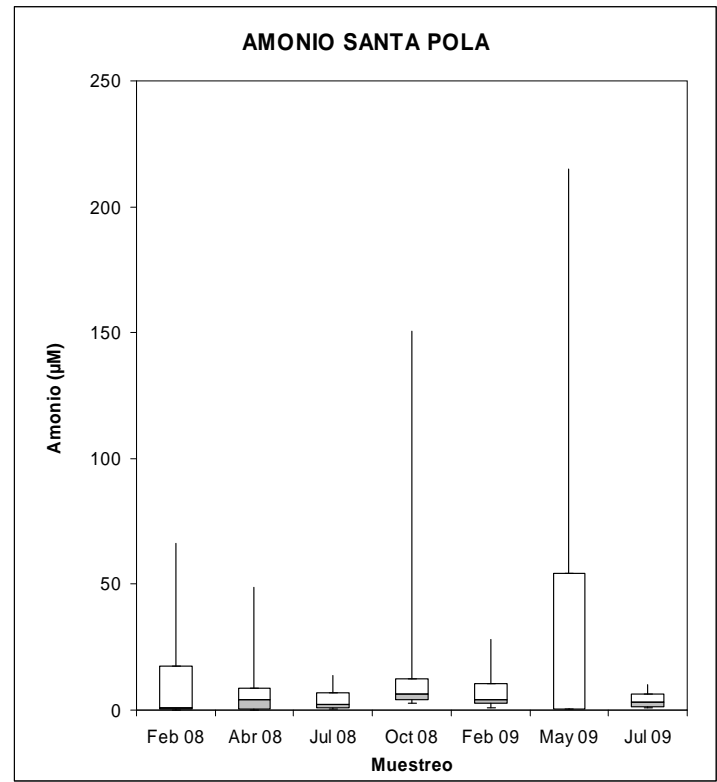

Figura 4.75: Concentraciones de amonio registradas en la salina de Santa Pola durante las campañas de 20082009
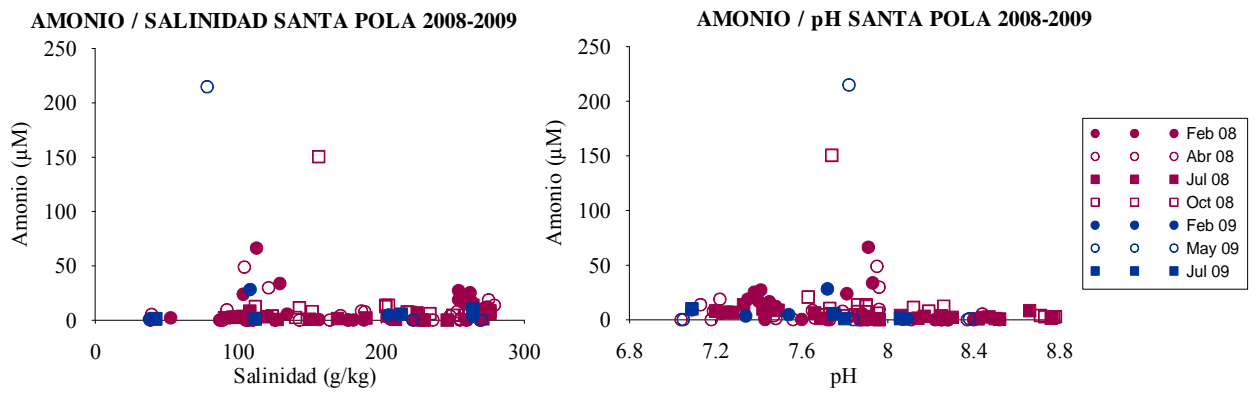


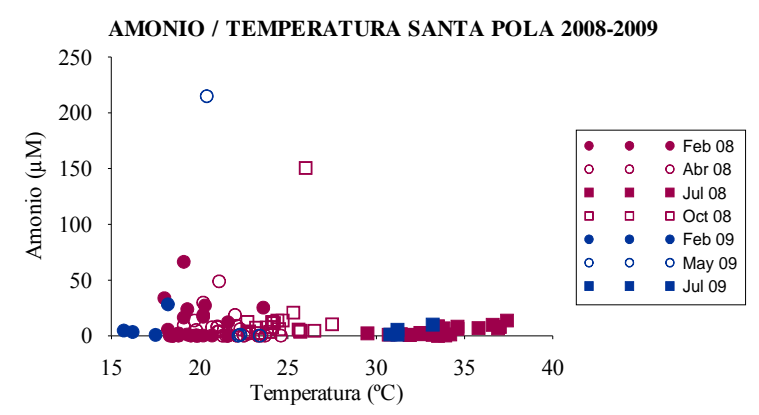

Figura 4.76: a) Comportamiento del amonio respecto a la salinidad; b) Comportamiento del amonio respecto al $\mathrm{pH}$ y c) Comportamiento del amonio respecto a la temperatura en la salina de Santa Pola durante 2008-2009

\subsubsection{Nitrito}

Gran parte de los valores de la concentración de nitritos se hallan por debajo del límite de detección analítico y cuando este compuesto se detecta las concentraciones suelen ser, por lo general, bastante bajas. La concentración mayor ha sido de $2,56 \mu \mathrm{M}$ y se ha observado en la estación que representa al estanque SPN018 en octubre de 2008 (ver figura 4.77).

Tal y como se aprecia en la figura 4.78a, los valores más altos de nitrito se encuentran en aquellas estaciones con mayor salinidad y este fenómeno se da en todos los muestreos de 2008. Con estos resultados se observa una tendencia a la acumulación del nitrito con la concentración de sales en los cristalizadores. En 2009 todos los valores de nitritos se mantienen muy bajos. Parece pues que hay una tendencia a aumentar las concentraciones al final del circuito salinero.

En las figuras $4.78 \mathrm{~b}$ y $4.78 \mathrm{c}$ no se observa una correlación significativa entre el nitrito y el $\mathrm{pH}$, ni tampoco entre el nitrito y la temperatura. Aunque los valores más altos se dan siempre con $\mathrm{pH}<8$ y temperatura $<27^{\circ} \mathrm{C}$.

El contenido en nitritos encontrado en otros circuitos salineros es prácticamente nulo (Javor (1983b), Pedrós-Alió et al. (2000) en La Trinitat - Delta del Ebro). Si bien en el mismo estudio de Pedrós-Alió dan valores de $8 \mu \mathrm{M}$ en todo el circuito salinero de Bras del Port Santa Pola. Estos resultados son similares a los primeros ya que gran parte de las concentraciones de nitritos se encuentran por debajo del límite de detección aunque se encuentran valores de hasta $1,89 \mu \mathrm{M}$ en los concentradores y de hasta $2,56 \mu \mathrm{M}$ en los cristalizadores. 


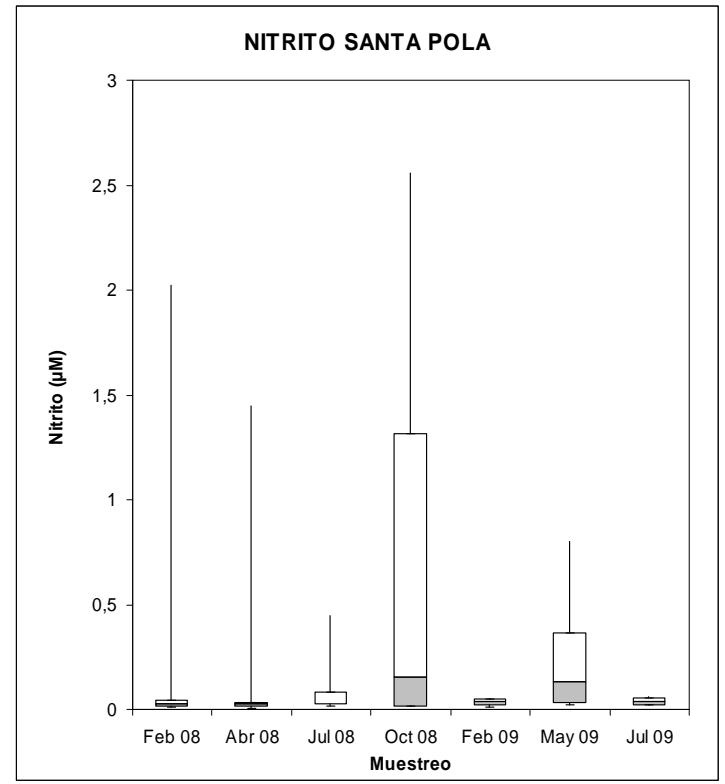

Figura 4.77: Concentraciones de nitrito registradas en la salina de Santa Pola durante las campañas de 2008-2009
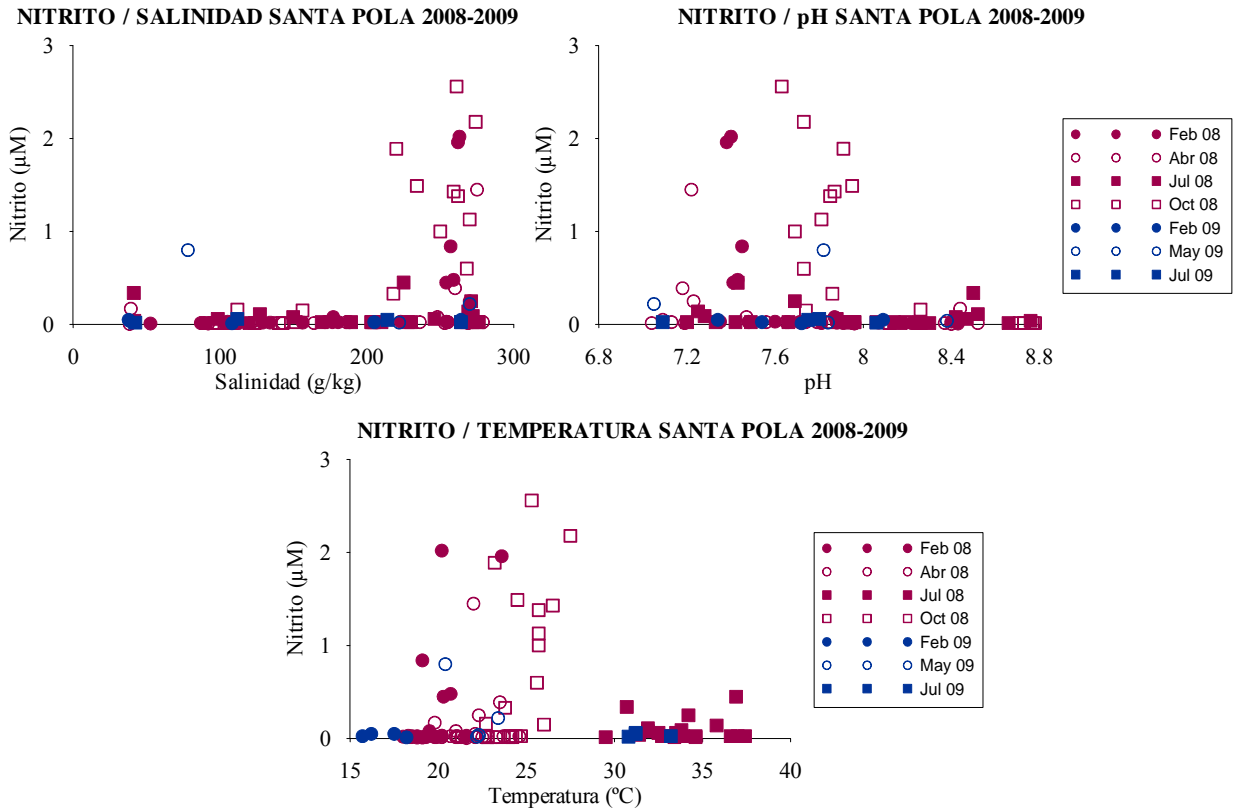

Figura 4.78: a) Comportamiento del nitrito respecto a la salinidad; b) Comportamiento del nitrito respecto al $\mathrm{pH}$ y c) Comportamiento del nitrito respecto a la temperatura en la salina de Santa Pola durante 2008-2009 


\subsubsection{Nitrato}

En el nitrato el rango de concentraciones es amplio y oscila desde valores por debajo del límite de detección a 68,6 $\mu \mathrm{M}$ (SPN018 en abril de 2008). Los valores más altos se alcanzan en abril, seguidos de julio, febrero y octubre de 2008. Sin embargo, las concentraciones de nitratos en 2009 son muy inferiores (figura 4.79). (Hay que recordar que los muestreos en 2009 son distintos ya que se muestrea un menor número de balsas).

Al igual que sucede para el nitrito, en el nitrato también se observa una tendencia a la acumulación en aquellas estaciones de muestreo con mayor salinidad que se encuentran ubicadas en los cristalizadores (figura 4.80a), y este fenómeno se repite en casi todos los muestreos. En la figura $4.80 \mathrm{~b}$ se observa una relación inversa entre nitrato y $\mathrm{pH}$, ya que este parámetro disminuye su concentración en los estanques con mayor $\mathrm{pH}$, esto podría deberse simplemente a que al aumentar la salinidad disminuye el $\mathrm{pH}$.

La mayor parte de los autores presentan concentraciones de nitratos muy bajas o no detectables en los sistemas de explotación salinera (Oren, 2009). Joint et al. (2002) encontraron valores entre $3-4 \mu \mathrm{M}$ en salinidades bajas e intermedias y de $6,2 \mu \mathrm{M}$ en salinidades altas; Pedrós-Alió et al. (2000) dieron valores de $0-4 \mu \mathrm{M}$ en calentadores y concentradores y de $4-18 \mu \mathrm{M}$ en los cristalizadores de Bras del Port.

En este caso los valores son mucho mayores, encontrando valores desde por debajo del límite de detección hasta $26,0 \mu \mathrm{M}$ en los concentradores y hasta $68,6 \mu \mathrm{M}$ en los cristalizadores. Aunque al igual que en otros estudios, también se observa un aumento del contenido en nitratos con la concentración salina, especialmente en los cristalizadores, donde puede producirse un aumento brusco de este parámetro.

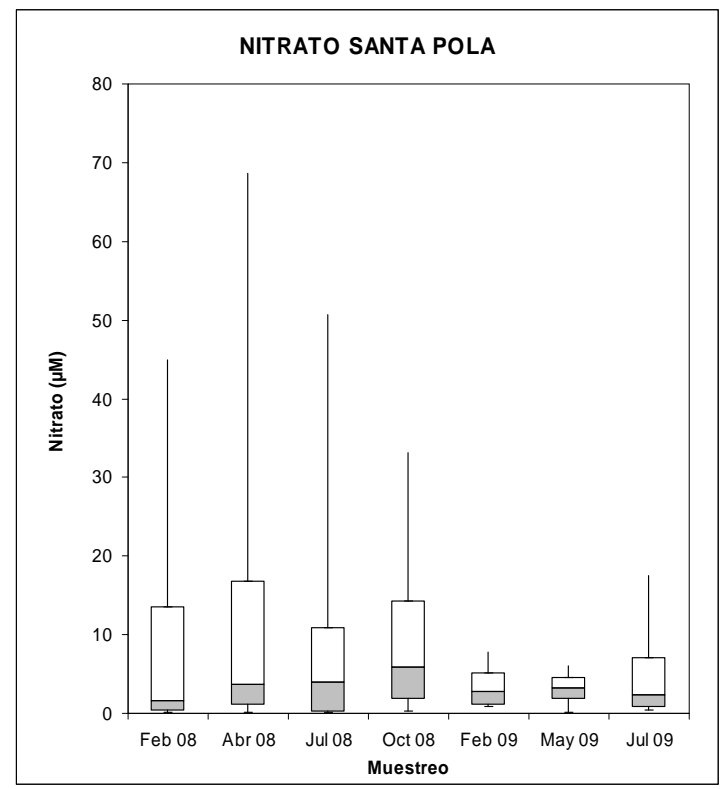

Figura 4.79: Concentraciones de nitrato registradas en la salina de Santa Pola durante las campañas de 2008-2009 

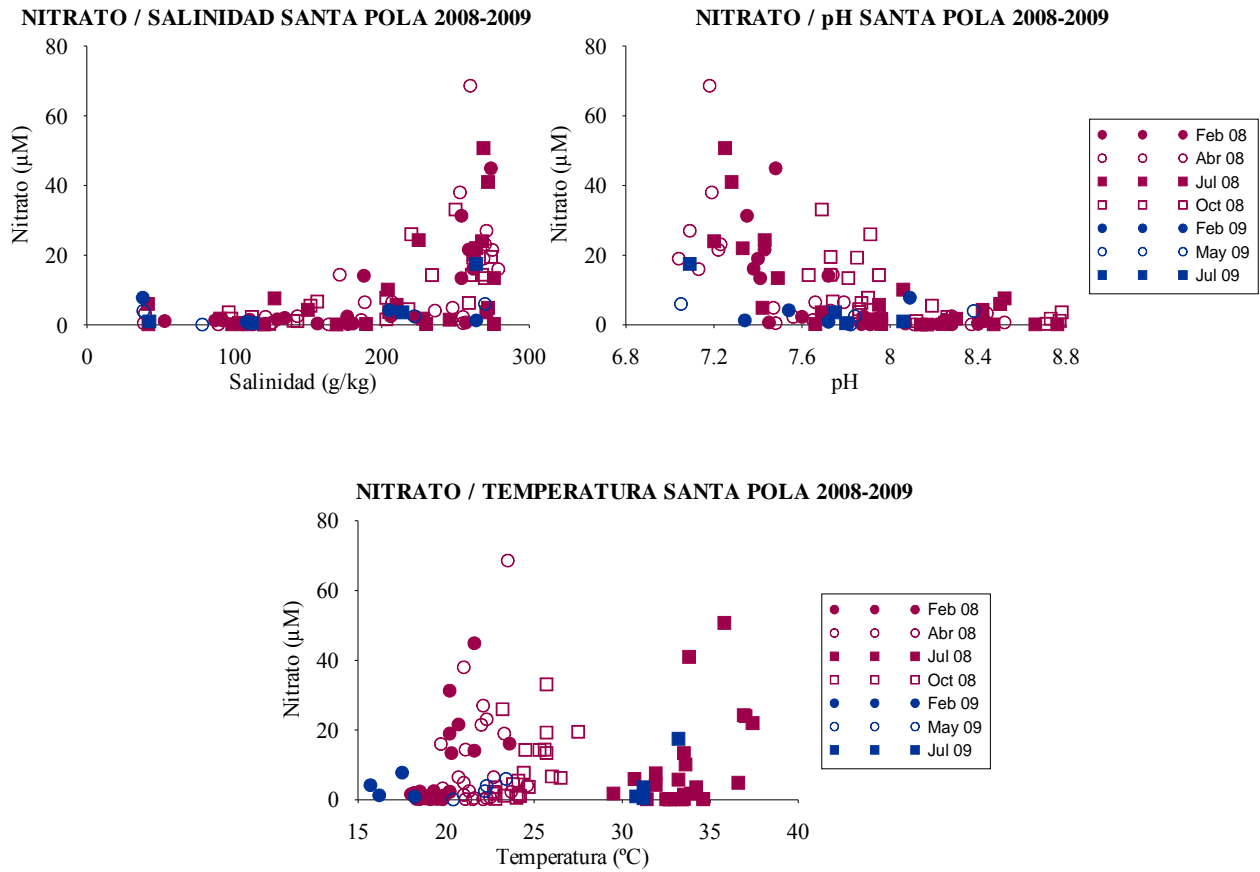

Figura 4.80: a) Comportamiento del nitrato respecto a la salinidad; b) Comportamiento del nitrato respecto al $\mathrm{pH}$ y c) Comportamiento del nitrato respecto a la temperatura en la salina de Santa Pola durante 2008-2009

\subsubsection{Nitrógeno Inorgánico Disuelto}

Las concentraciones oscilan entre valores por debajo del límite de detección y 215,8 $\mu \mathrm{M}$ (figura 4.81). Los valores más elevados se encuentran en aquellas estaciones con concentraciones más altas de amonio y secundariamente de nitratos, puesto que los nitritos son muy bajos comparativamente en todo el sistema.

Se observan por un lado, picos de NID a salinidades intermedias en los muestreos de febrero, abril y octubre de 2008 debidos a concentraciones elevadas de amonio; y picos en aquellas estaciones situadas en los cristalizadores producidos por la acumulación tanto de amonio como de nitritos y nitratos (figura 4.82a). Posteriormente se estudiará con un mayor grado de detalle el por qué de este aumento en el contenido de algunas formas de nitrógeno, especialmente nitratos y nitritos, en los cristalizadores (apartado 4.4.3).

Además se ha representado la relación NID y $\mathrm{pH}$ (figura 4.82b) y la relación NID y temperatura (figura 4.82c) aunque en ningún caso se observa una pauta de comportamiento clara. 


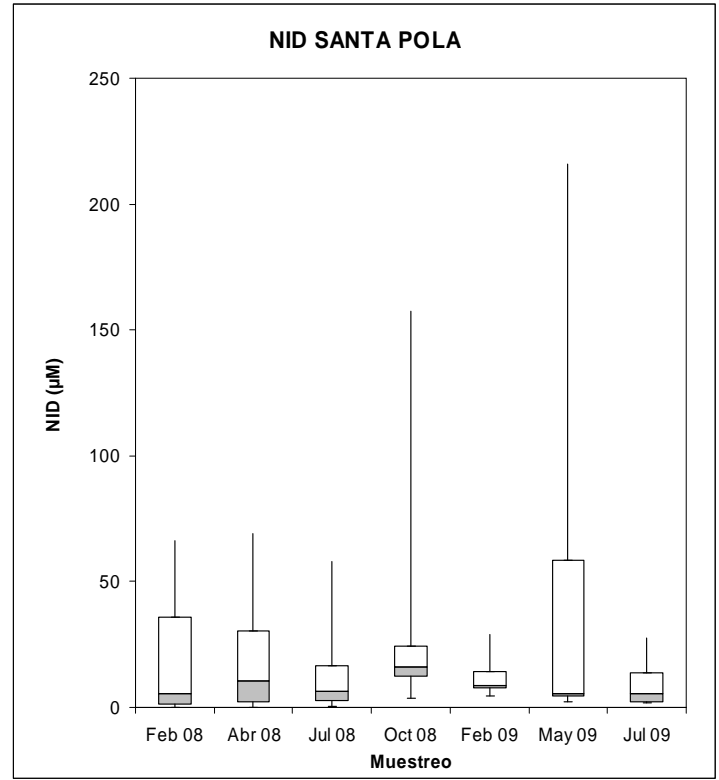

Figura 4.81: Concentraciones de NID registradas en la salina de Santa Pola durante las campañas de 2008-2009
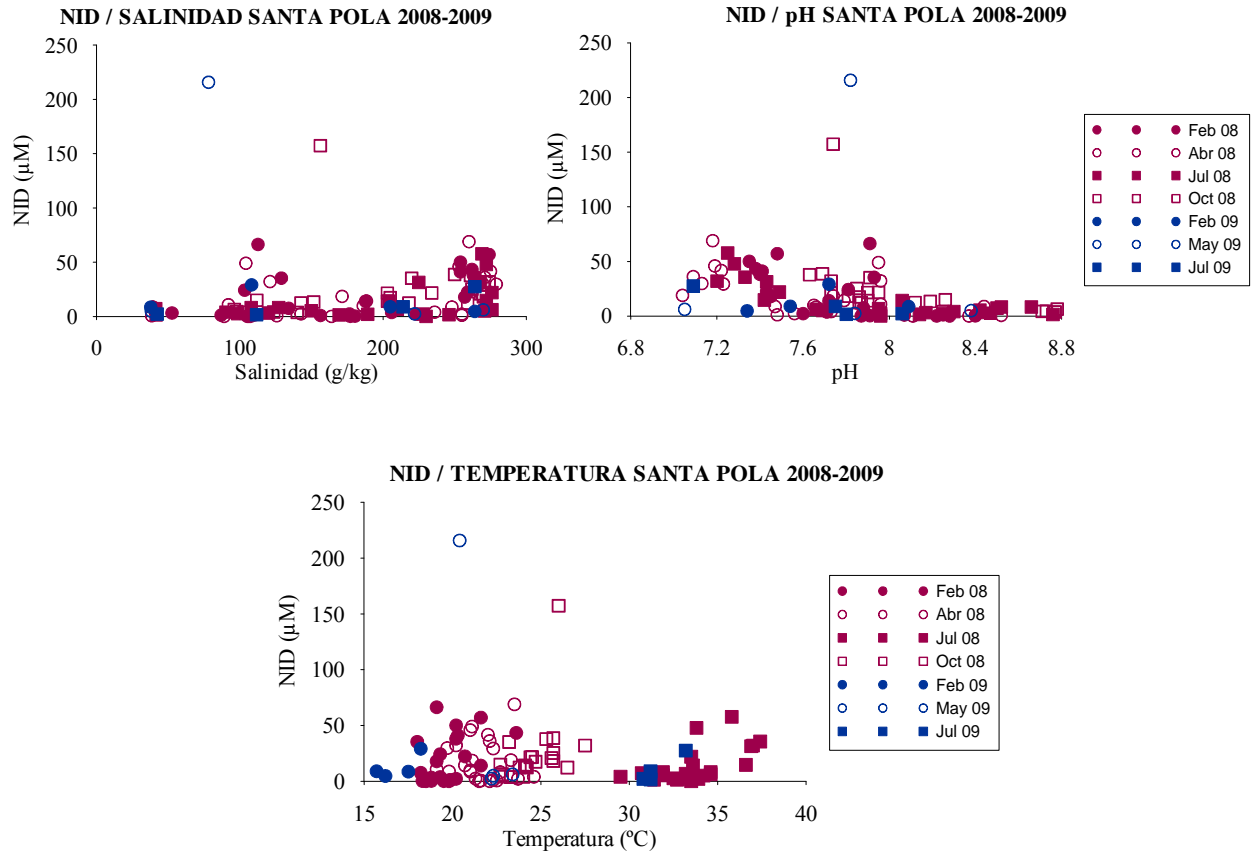

Figura 4.82: a) Comportamiento del NID respecto a la salinidad; b) Comportamiento del NID respecto al pH y c) Comportamiento del NID respecto a la temperatura en la salina de Santa Pola durante 2008-2009 


\subsubsection{Fósforo Soluble Reactivo (PSR)}

En cuanto al contenido en PSR, muchos de los valores obtenidos se encuentran por debajo del límite de detección y los que se detectan por lo general son valores bajos, la mayoría $<0,5 \mu \mathrm{M}$, siendo el fósforo en la mayor parte de los casos (hay excepciones como veremos en el próximo apartado al estudiar la relación NID/PSR), el nutriente limitante de este sistema. Esto es debido a que el ortofosfato, al ser la forma de fósforo preferida por los seres vivos (Migon y Sandroni, 1999), es rápidamente asimilado por el fitoplancton. Además, la asimilación del fósforo que pueda entrar en la salina es rápida ya que el fitoplancton puede realizar una asimilación "en tromba" en una tasa muy elevada.

Las concentraciones más altas de PSR se encuentran en los meses de julio y octubre de 2008 , con valores máximos de $2,22 \mu \mathrm{M}$ y $2,36 \mu \mathrm{M}$ respectivamente (figura 4.83). Estos valores más altos de PSR se detectan en los cristalizadores, tal y como se observa en la figura 4.84a. Por lo que en el caso del PSR, también se aprecia una pequeña acumulación de este parámetro con la concentración de sales. No se aprecia una relación clara entre el PSR y el pH (figura 4.84b), ni tampoco entre el PSR y la temperatura (figura 4.84c).

Los resultados de fosfato presentados por Pedrós-Alió et al. (2000) en Bras del Port oscilaron entre $4-8 \mu \mathrm{M}$ en los calentadores y concentradores, y $5-7 \mu \mathrm{M}$ en los cristalizadores; mientras que en La Trinitat oscilaron entre 2 - $3 \mu \mathrm{M}$ en los concentradores y concentradores, y $1-2 \mu \mathrm{M}$ en los cristalizadores. En cambio, en los estudios de Javor (1983 a y b) el fosfato se mantuvo en niveles no detectables durante todo el circuito salinero aumentando en los cristalizadores $(2-5 \mu \mathrm{M})$.

En este caso, los valores fueron menores y oscilaron entre valores por debajo del límite de detección hasta $0,95 \mu \mathrm{M}$ en los concentradores y hasta $2,36 \mu \mathrm{M}$ en los cristalizadores aunque al igual que para otros autores, también se observó un aumento en el contenido de fosfatos por concentración en los cristalizadores. 


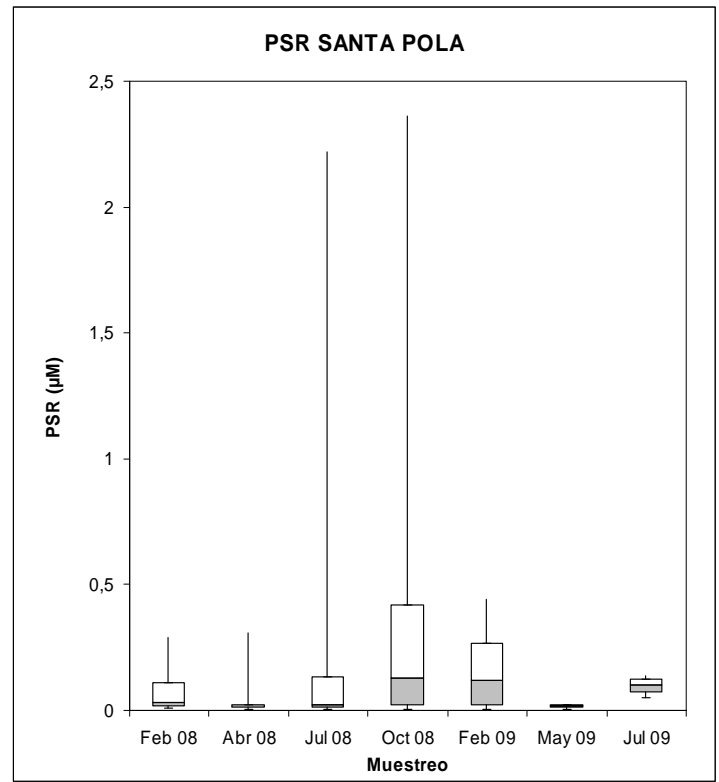

Figura 4.83: Concentraciones de PSR registradas en la salina de Santa Pola durante las campañas de 2008-2009
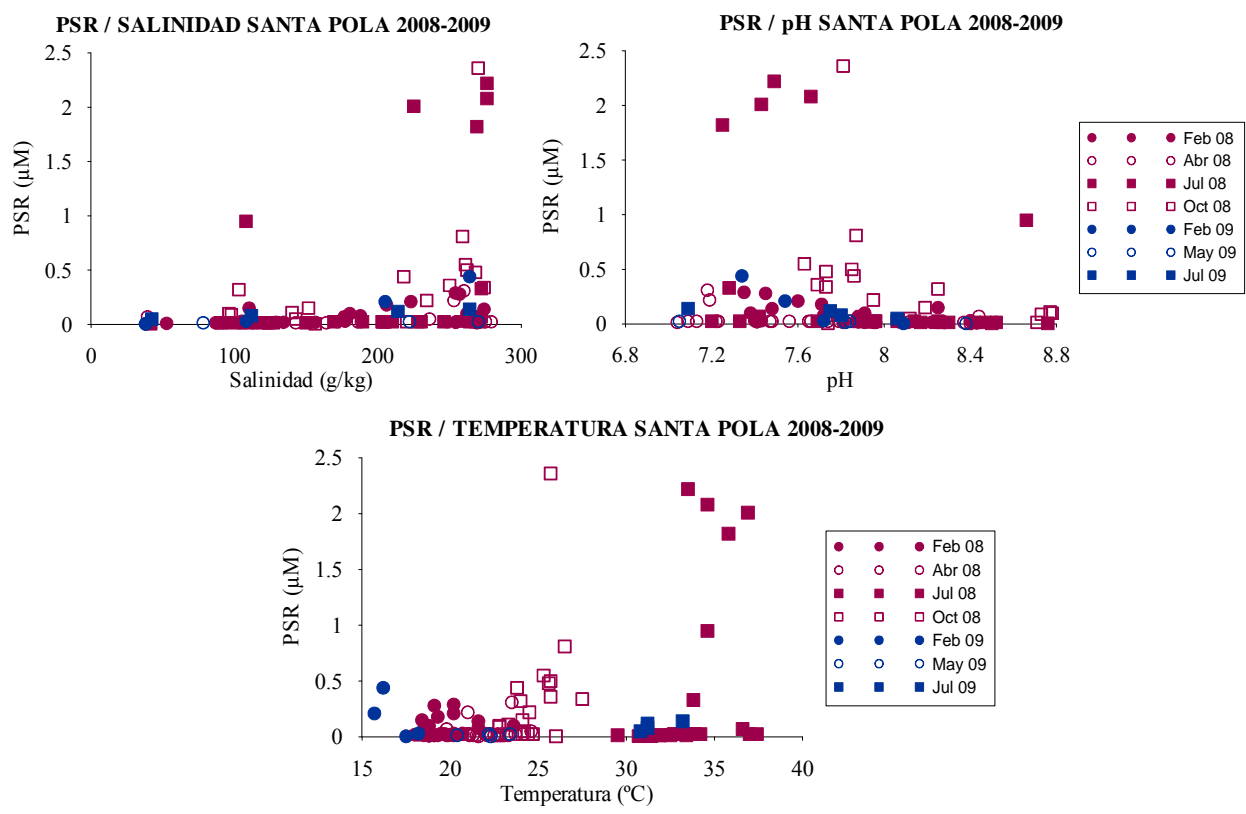

Figura 4.84: a) Comportamiento del PSR respecto a la salinidad; b) Comportamiento del PSR respecto al pH y c) Comportamiento del PSR respecto a la temperatura en la salina de Santa Pola durante 2008-2009 


\subsubsection{Relación NID/PSR}

La relación NID/PSR en el circuito salinero es muy variable y oscila entre 3 y 31460 . Aunque en general los valores de la relación NID/PSR están por encima de 20 a lo largo de la mayor parte del circuito (lo que indica que según la relación de Redfield el nutriente limitante es el $\mathrm{P}$ ), se dan esporádicamente valores inferiores a 10 o próximos a éste. Desgraciadamente ninguna conclusión podemos sacar en lo que se refiere a cuál es el factor determinante de estos cambios en la relación NID/PSR ya que si bien en julio de 2008 a $276 \mathrm{~g} / \mathrm{kg}$ de salinidad en SPN020 la relación NID/PSR es en torno a 3, en abril del mismo año en SPN024 con $279 \mathrm{~g} / \mathrm{kg}$ la relación es de 1192 (figuras 4.85 y 4.86 a, b y c).

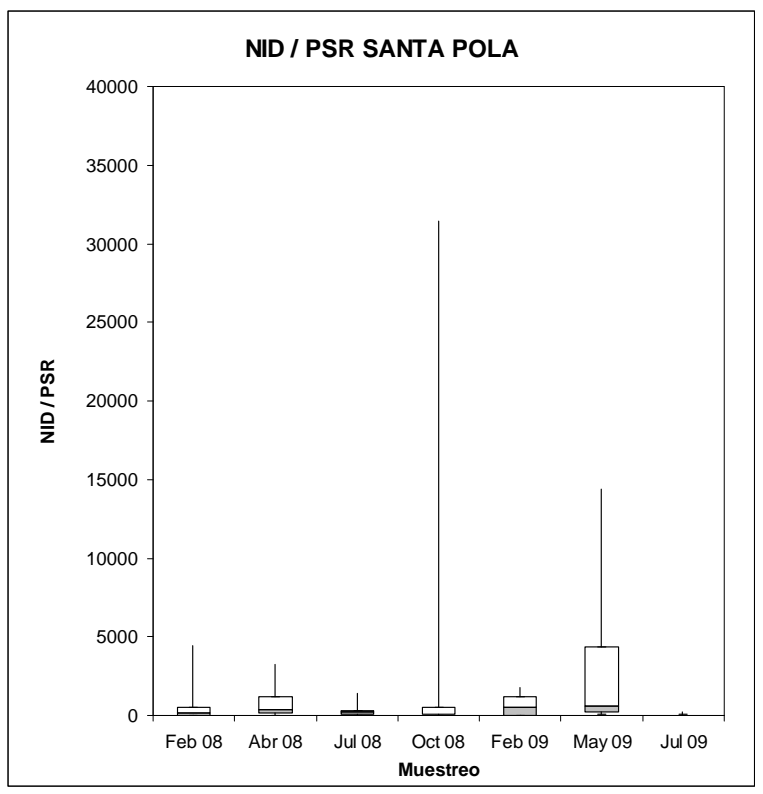

Figura 4.85: Relación NID/PSR de la salina de Santa Pola durante las campañas de 2008-2009
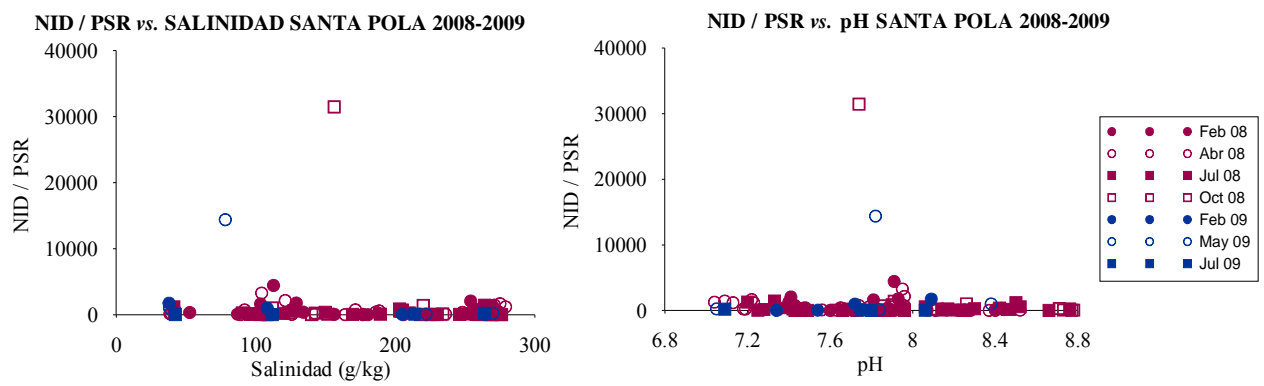


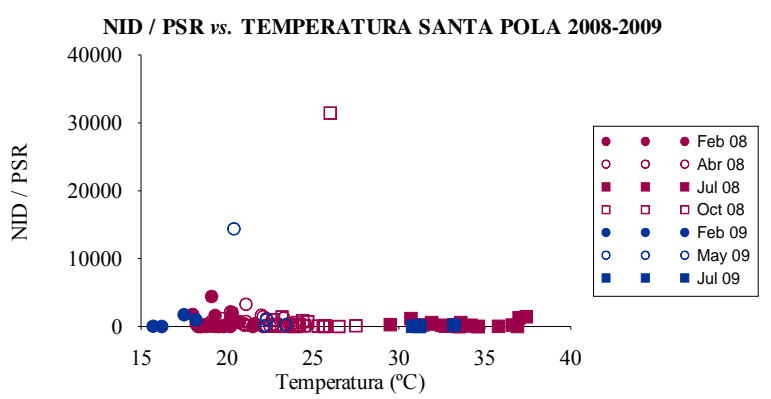

Figura 4.86: a) Comportamiento de la relación NID/PSR respecto a la salinidad; b) Comportamiento de la relación NID/PSR respecto al pH y c) Comportamiento de la relación NID/PSR respecto a la temperatura en la salina de Santa Pola durante 2008-2009

\subsubsection{Fósforo Total (PT)}

El rango de concentraciones oscila, tal y como se puede observar en la figura 4.87, entre 0,25 y $13,34 \mu \mathrm{M}$. Aunque existen valores elevados de PT en diferentes estaciones y épocas de muestreo, parece que el rango de concentraciones esté condicionado más bien por la concentración salina y no por la estación del año. Hay que mencionar que el descenso observado entre el muestreo de octubre de 2008 y febrero de 2009 , es en parte debido a que en 2009 solamente se muestrearon dos de los estanques con salinidades elevadas y en ellos no se detectaron picos de PT. (Los picos de PT no se dan en todos los estanques y si en 2009 se hubieran muestreado todos los estanques cabría la posibilidad de que se hubieran encontrado variaciones en estos resultados).

En la figura 4.88a, se puede apreciar la relación existente entre PT y concentración salina, ya que se observa una mayor concentración de PT en el agua conforme aumenta la salinidad. En la figura 4.88b se observa una relación inversa entre el PT y el contenido en $\mathrm{pH}$ (ya que éste es inverso a la salinidad tal y como se ha visto en la figura 4.74a). En la figura 4.88c se representa la relación entre PT y temperatura, donde se observan dos grupos de muestras, los correspondientes a los muestreos de julio y el resto de muestreos. En cada grupo parece detectarse una cierta tendencia al aumento en el contenido de PT con el aumento de la temperatura. 


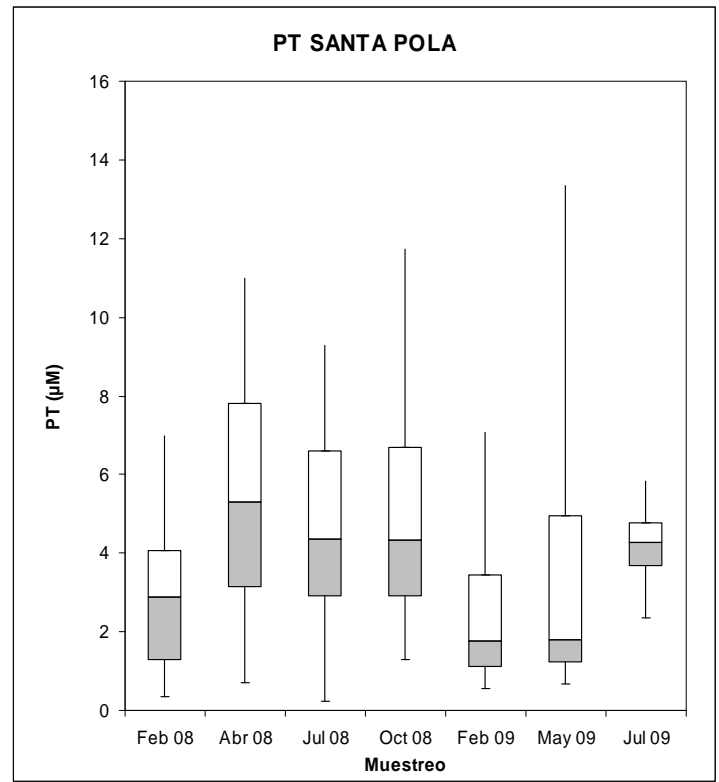

Figura 4.87: Concentraciones de PT registradas en la salina de Santa Pola durante las campañas de 2008-2009
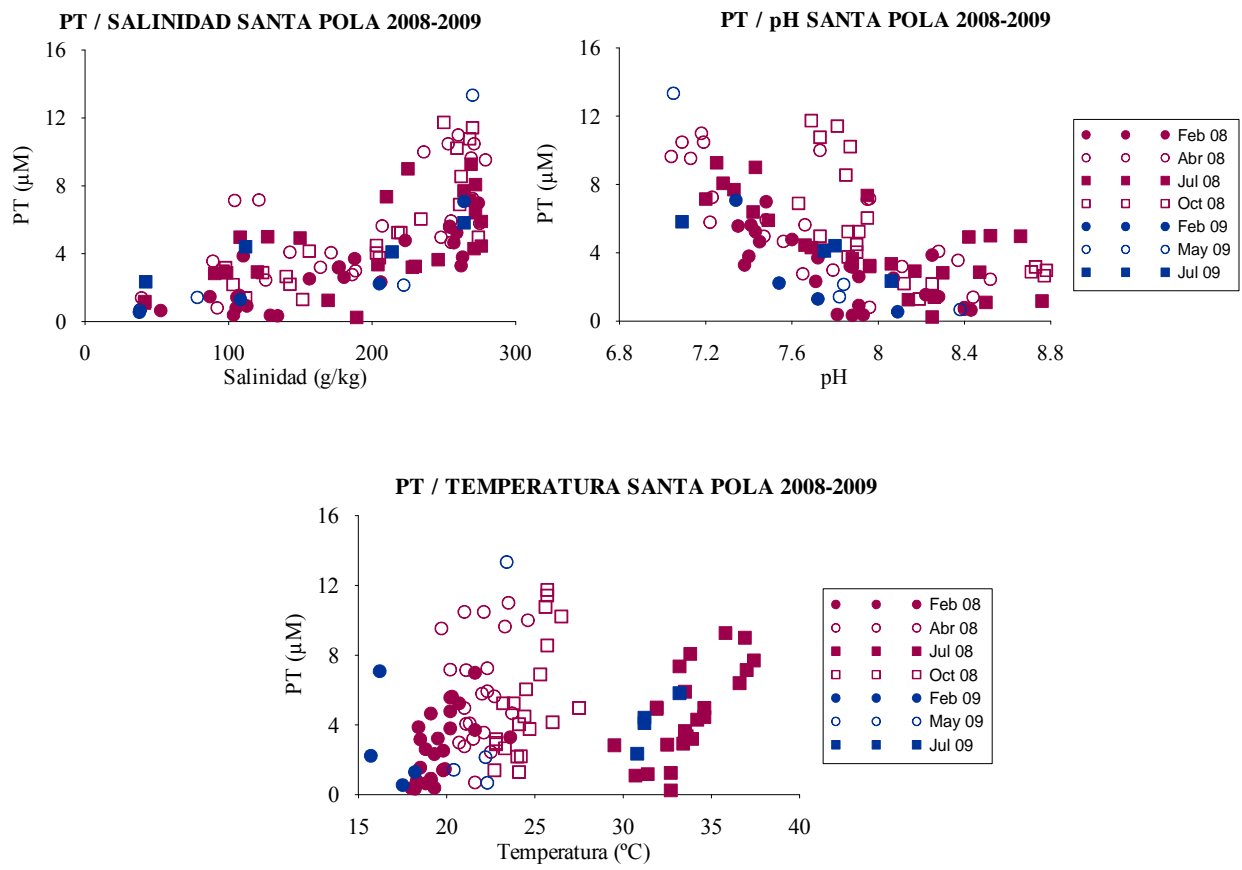

Figura 4.88: a) Comportamiento del PT respecto a la salinidad; b) Comportamiento del PT respecto al pH y c) Comportamiento del PT respecto a la temperatura en la salina de Santa Pola durante 2008-2009 


\subsubsection{0. Ácido ortosilícico}

El ácido ortosilícico presenta valores que oscilan entre 0,2 y $74,1 \mu \mathrm{M}$. Los valores más altos se dan durante los meses de julio y octubre de 2008 , mientras que los más bajos con diferencia se producen en el muestreo de febrero de 2008 (figura 4.89).

En las figuras $4.90 \mathrm{a}, \mathrm{b}$ y c, se representa el comportamiento del ácido ortosilícico respecto de la salinidad, al $\mathrm{pH}$ y a la temperatura, aunque no se aprecian tendencias claras entre estos parámetros. Parece ser que, al tratarse de un circuito salinero, no se produce una entrada importante de aguas de escorrentía en el sistema, lo que limita la entrada de ácido ortosilícico en la salina, aunque sí que se observa una acumulación de éste en los estanques durante aquellos meses en que la evapotranspiración es mayor.

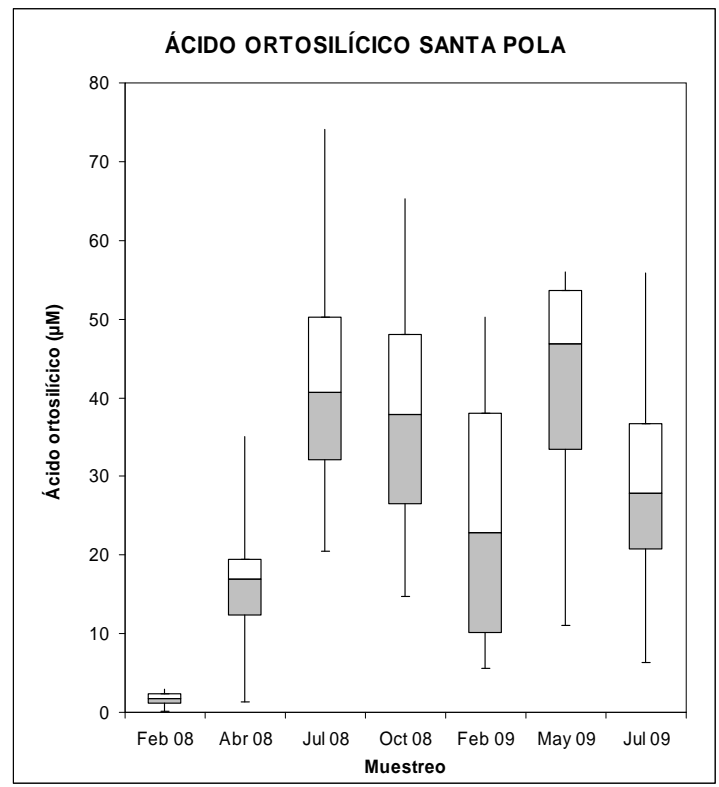

Figura 4.89: Concentraciones de ácido ortosilícico registradas en la salina de Santa Pola durante las campañas de 2008-2009
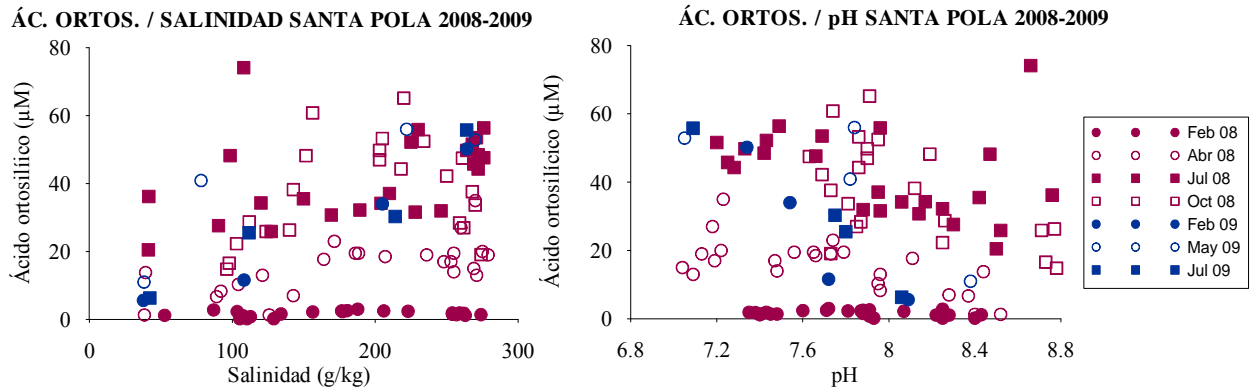
ÁC. ORTOS. / TEMPERATURA SANTA POLA 2008-2009

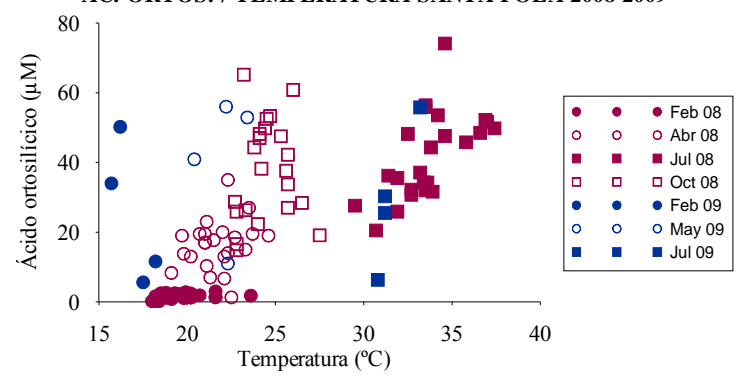

Figura 4.90: a) Comportamiento del ácido ortosilícico respecto a la salinidad; b) Comportamiento del ácido ortosilícico respecto al $\mathrm{pH}$ y c) Comportamiento del ácido ortosilícico respecto a la temperatura en la salina de Santa Pola durante 2008-2009 


\subsubsection{Análisis multivariable de la salina de Santa Pola}

En el análisis mediante componentes principales de los resultados obtenidos para los diferentes parámetros físico-químicos del circuito salinero de Bonmatí en la salina de Santa Pola se han analizado un total de 4 muestreos (aquellos en los que se estudia un mayor número de estanques, desde febrero de 2008 a octubre de 2008) y se han incluido 8 variables: salinidad, $\mathrm{pH}$, amonio, nitrito, nitrato, PSR, PT y ácido ortosilícico. A los datos obtenidos se les ha efectuado una transformación logarítmica $(\log x+1)$ previa al ACP (excepto al $\mathrm{pH}$ que ya presenta una escala logarítmica).

Este análisis nos permitido reducir las variables a tres componentes principales que en total explican un $71,964 \%$ de la varianza acumulada $(45,378 \%$ la componente $1 ; 13,967 \%$ la componente 2 y $12,619 \%$ la componente 3 ).

\begin{tabular}{|rc|cc|}
\hline PARÁMETROS & $\begin{array}{c}\text { Componente 1 } \\
(\mathbf{4 5 , 3 7 8} \%)\end{array}$ & $\begin{array}{c}\text { Componente 2 } \\
(\mathbf{1 3 , 9 6 7 \% )}\end{array}$ & $\begin{array}{c}\text { Componente 3 } \\
\mathbf{( 1 2 , 6 1 9} \%)\end{array}$ \\
\hline Salinidad & 0,442938 & $-0,13406$ & $-0,271723$ \\
\hline pH & $-0,420554$ & 0,405234 & 0,180286 \\
\hline Amonio & 0,204762 & $-0,159938$ & 0,763169 \\
\hline Nitrito & 0,290285 & $-0,0727722$ & 0,460645 \\
\hline Nitrato & 0,437226 & $-0,145409$ & $-0,0153681$ \\
\hline PSR & 0,261583 & 0,491186 & 0,120034 \\
\hline PT & 0,441427 & 0,150247 & $-0,287786$ \\
\hline Ác. ortosilícico & 0,215169 & 0,708489 & 0,0397214 \\
\hline
\end{tabular}

Tabla 4.6: Tabla de pesos de los componentes del ACP para los parámetros físico-químicos de Santa Pola

Gráfico de Pesos del Componente

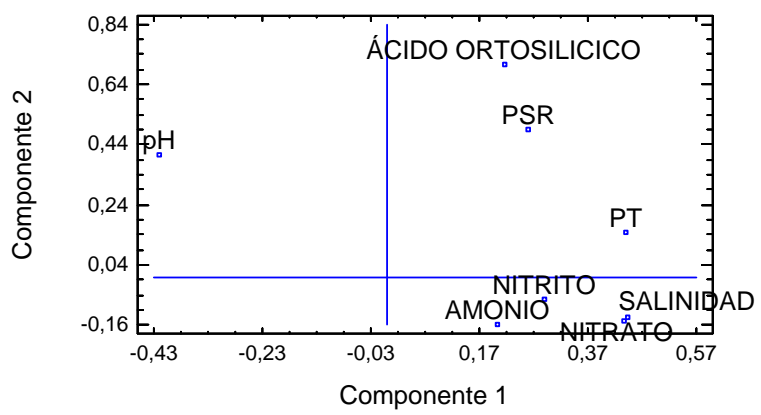

Figura 4.91: Gráfico de pesos de los componentes del ACP para los parámetros físico-químicos en la laguna de Santa Pola

A partir de los resultados obtenidos en la tabla de pesos de los componentes (tabla 4.6) y su representación gráfica (figura 4.91), se observa que la componente 1 representa los procesos de concentración salina $(\mathrm{pH}$ negativo y salinidad, nitratos, PT y en menor medida el resto de parámetros positivos). La componente 2 parece estar relacionada con el crecimiento de la comunidad fitoplanctónica en la columna de agua, con PSR y al ácido ortosilícico positivos, 
aunque en ese caso también el amonio debería estar asociado con esta componente de manera positiva. Sin embargo, el amonio se encuentra en la componente 3 representada fundamentalmente por este parámetro, y esto parece deberse a las considerables variaciones que ya han sido comentadas en los resultados (apartado 4.4.1.3).

Por tanto, en este caso la componente más relevante es la componente 1 que representa el gradiente salino ya que existe una relación entre salinidad y $\mathrm{pH}$, que tiende a disminuir conforme aumenta la salinidad, mientras que nitratos y PT tienden a concentrarse tal y como aumenta la concentración salina.

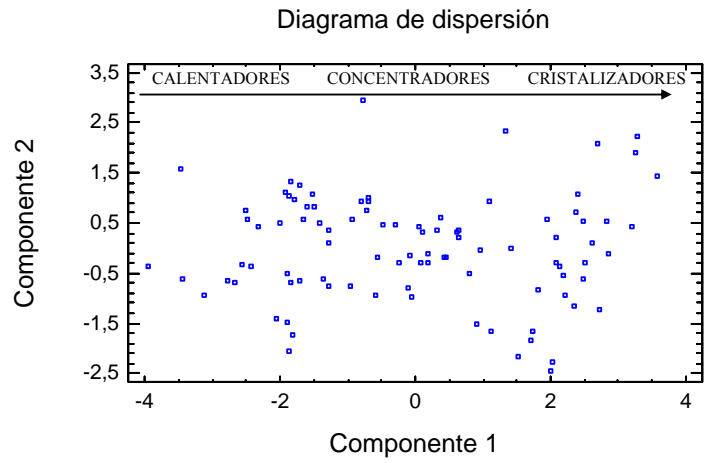

Figura 4.92: Diagrama de dispersión para los componentes 1 y 2 del ACP para los parámetros físico-químicos de la laguna de Santa Pola

A partir del conglomerado jerárquico elaborado con los valores de $\mathrm{P}_{50}$ de cada uno de los parámetros físico-químicos estudiados en cada estanque para el año 2008 (ver figura 4.93), se han obtenido unos rangos que permiten una diferenciación entre estanques en función de la salinidad (los valores de $\mathrm{P}_{50}$ de cada estanque se muestran en la tabla 4.7):

- Estanques con $\mathrm{P}_{50}$ de salinidad $<175 \mathrm{~g} / \mathrm{kg}$. Dentro de este grupo se pueden observar dos subgrupos:

- $\mathrm{P}_{50}$ de salinidad $<140 \mathrm{~g} / \mathrm{kg}$, que se encuentran representado por las estaciones SPN016, SPN017, SPN001, SPN003, SPN012, SPN002, y SPN014.

- $\mathrm{P}_{50}$ de salinidad entre 140 - $175 \mathrm{~g} / \mathrm{kg}$, representado por las estaciones SPN005, SPN013 y SPN004.

- Estanques con $\mathrm{P}_{50}$ de salinidad $>175 \mathrm{~g} / \mathrm{kg}$. Dentro de este grupo también se pueden observar dos subgrupos:

- $\mathrm{P}_{50}$ de salinidad entre 175 - $250 \mathrm{~g} / \mathrm{kg}$ formado por las estaciones SPN006, SPN020, SPN010, SPN011, SPN007, SPN009 y SPN008.

- $\mathrm{P}_{50}$ de salinidad $>250 \mathrm{~g} / \mathrm{kg}$ formado por las estaciones SPN018, SPN021, SPN022, SPN026, SPN025, SPN019 y SPN024. 


\begin{tabular}{|cc|cc|cc|}
\hline ESTACIÓN & P $_{50}$ SAL & ESTACIÓN & P $_{50}$ SAL & ESTACIÓN & P $_{50}$ SAL \\
\hline SPN001 & 92,0 & SPN009 & 205,0 & SPN018 & 260,5 \\
\hline SPN002 & 78,4 & SPN010 & 212,0 & SPN019 & 264,0 \\
\hline SPN003 & 107,9 & SPN011 & 214,0 & SPN020 & 244,5 \\
\hline SPN004 & 140,3 & SPN012 & 125,5 & SPN021 & 261,0 \\
\hline SPN005 & 157,1 & SPN013 & 145,0 & SPN022 & 270,5 \\
\hline SPN006 & 248,0 & SPN014 & 64,3 & SPN024 & 265,5 \\
\hline SPN007 & 196,7 & SPN016 & 102,1 & SPN025 & 263,5 \\
\hline SPN008 & 194,6 & SPN017 & 101,7 & SPN026 & 269,0 \\
\hline
\end{tabular}

Tabla 4.7: Valores de $\mathrm{P}_{50}$ de salinidad (g/kg) en las diferentes estaciones de Santa Pola en las campañas de 2008

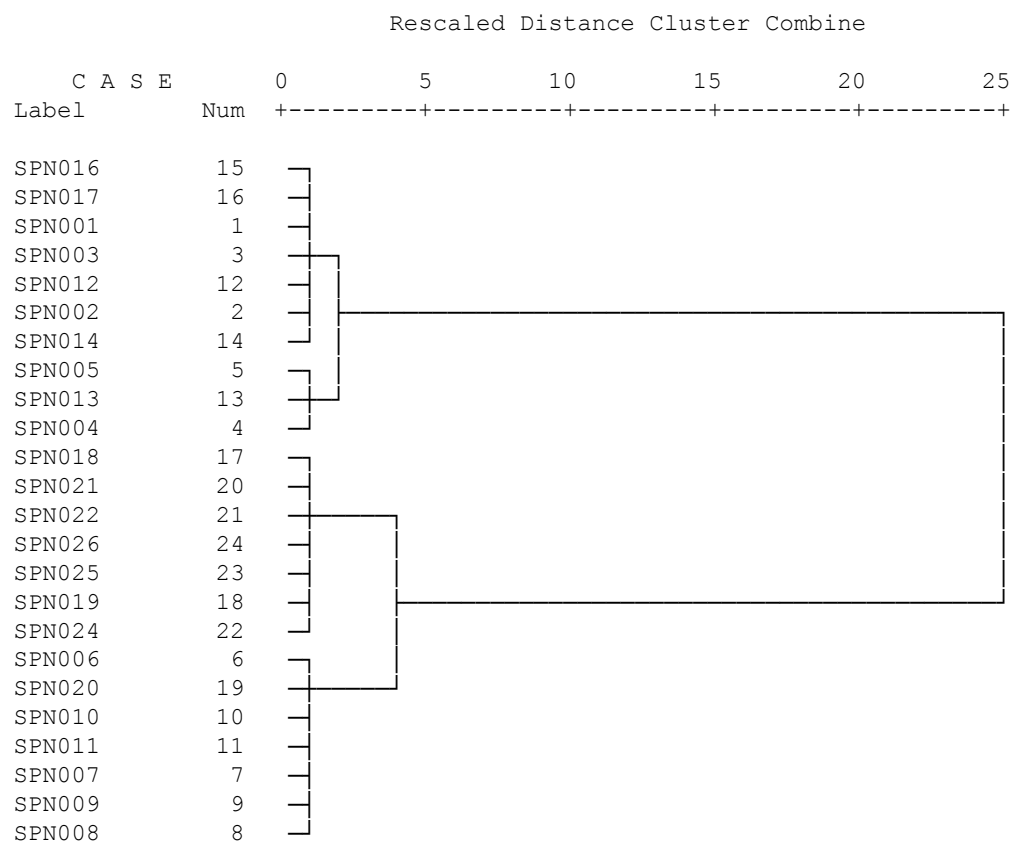

Figura 4.93: Conglomerado jerárquico con la agrupación de las estaciones para cada una de las campañas muestreadas en la salina de Santa Pola durante el 2008 
Sin embargo, como el rango inferior aún queda demasiado amplio, se realizó otro conglomerado jerárquico de los estanques con $\mathrm{P}_{50}$ de salinidad $<140 \mathrm{~g} / \mathrm{kg}$, con el fin de ver si se podían encontrar diferencias (figura 4.94):

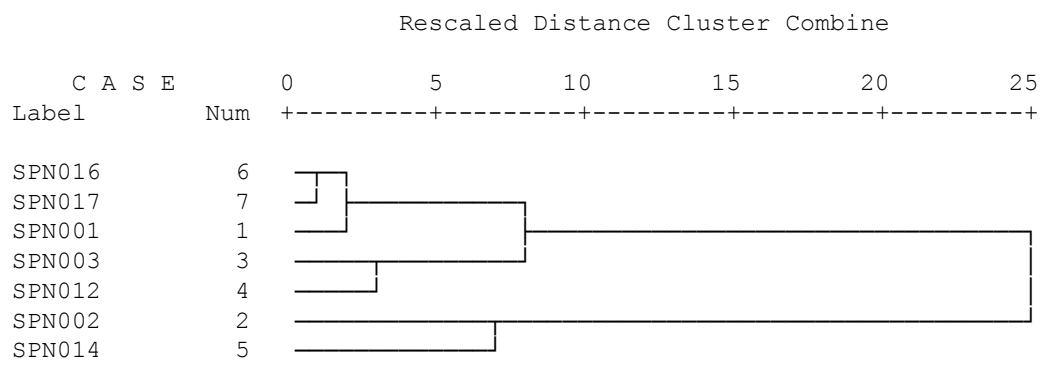

Figura 4.94: Conglomerado jerárquico con la agrupación de las estaciones con $\mathrm{P}_{50}$ de salinidad $<140 \mathrm{~g} / \mathrm{kg}$ en la salina de Santa Pola durante el 2008

A partir de este conglomerado surge un nuevo rango de clasificación entre estanques en función de la salinidad de 2008 que sería el siguiente:

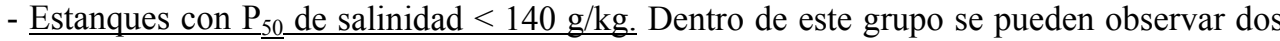
subgrupos:

- $\mathrm{P}_{50}$ de salinidad $<85 \mathrm{~g} / \mathrm{kg}$, que se encuentran representado por las estaciones SPN002, y SPN014.

- $\mathrm{P}_{50}$ de salinidad entre 85 - $140 \mathrm{~g} / \mathrm{kg}$, representado por las estaciones SPN016, SPN017, SPN001, SPN003 y SPN012.

Los resultados obtenidos en el tratamiento estadístico indican que hay que modificar los rangos de salinidades con lo que se obtiene una nueva clasificación en tipologías en función del $\mathrm{P}_{50}$ para los estanques de Santa Pola distinta a la planteada inicialmente en el apartado de salinidad y que sería la siguiente (ver figura 4.95):

- Tipo 1: salinidades $<85 \mathrm{~g} / \mathrm{kg}$

- Tipo 2: salinidades entre $85-140 \mathrm{~g} / \mathrm{kg}$

- Tipo 3: salinidades entre 140 - $175 \mathrm{~g} / \mathrm{kg}$

- Tipo 4: salinidades entre 175 - $250 \mathrm{~g} / \mathrm{kg}$

- Tipo 5: salinidades $>250 \mathrm{~g} / \mathrm{kg}$

Estas tipologías serán utilizadas posteriormente para analizar las tendencias de los diferentes parámetros físico-químicos y establecer el potencial ecológico a partir de los $\mathrm{P}_{50}$ de cada uno de los tipos. 


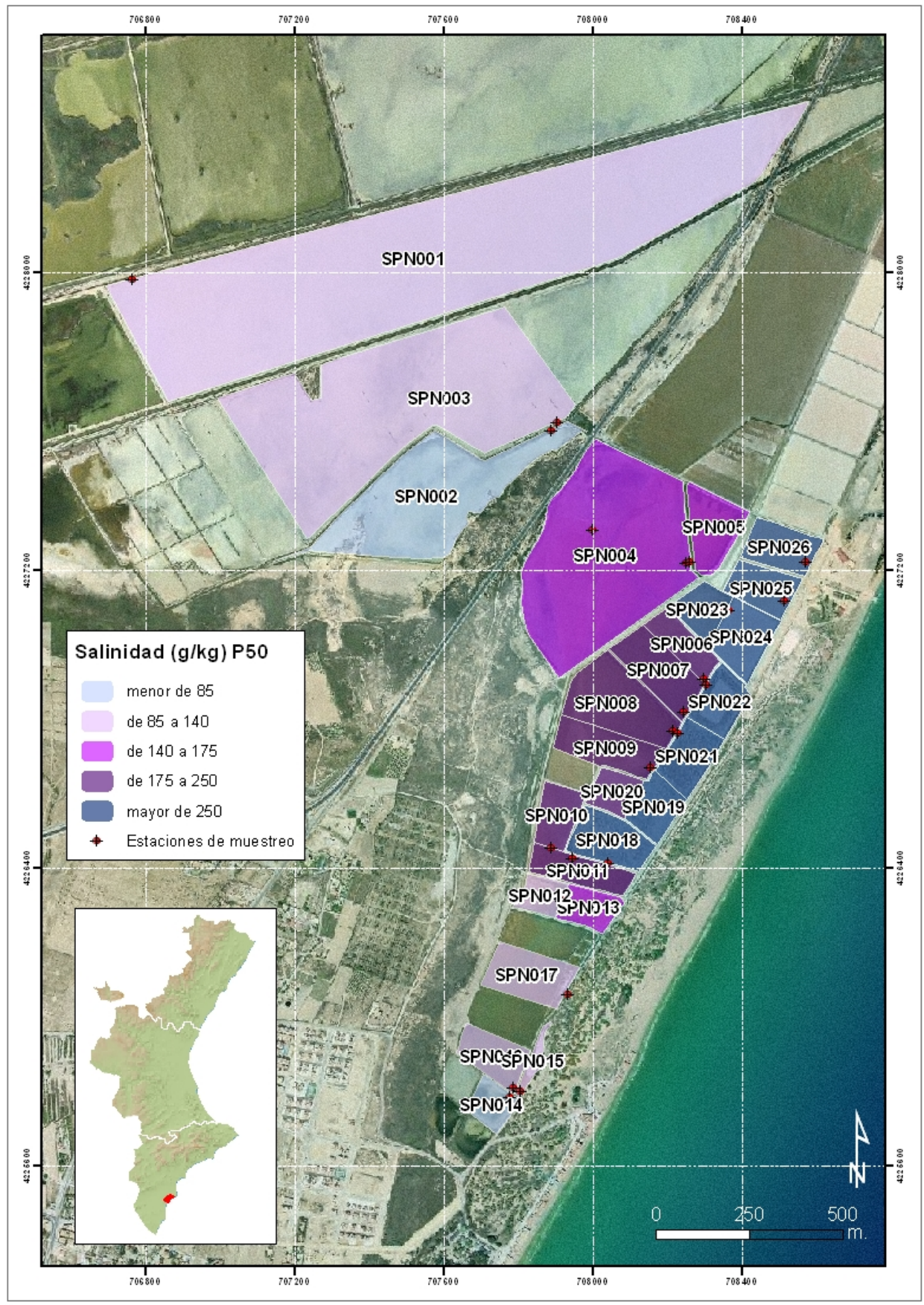

Figura 4.95: Nuevos rangos de distribución de los $\mathrm{P}_{50}$ de salinidad en los distintos estanques 


\subsubsection{Problemática del NID y de sus variaciones de concentración a lo largo del circuito salinero}

Como ya se ha estudiado anteriormente, se han detectado picos de nitritos, nitratos (y de PSR en menor medida) en los cristalizadores del circuito salinero. El aumento en la concentración de estos parámetros no es progresiva, tal y como sucede en el caso del PT que presenta una relación lineal con el contenido en sales (ver figura 4.88a), sino que tras presentar valores relativamente bajos en los concentradores se detectan altas concentraciones en los cristalizadores.

Para poder saber si estos picos de nitratos, nitritos (y en menor medida fosfatos) que se dan en los cristalizadores de Santa Pola son debidos a los procesos propios de la concentración salina o está interviniendo algún otro proceso, es necesario estudiar las solubilidades de éstos parámetros y compararlos con la solubilidad de la sal.

\subsubsection{Estudio de las solubilidades}

La solubilidad es la máxima cantidad de soluto que puede disolverse en una cantidad fija de disolvente y a una temperatura dada (la solubilidad de los sólidos aumenta cuando lo hace la temperatura).

La comparación entre solubilidades se va a realizar estudiando los siguientes compuestos: $\mathrm{NaCl}, \mathrm{NaNO}_{3}$ y $\mathrm{NaNO}_{2}$ y $\mathrm{Na}_{3} \mathrm{PO}_{4}$ en el punto de cristalización.

A continuación se muestra la solubilidad de dichos compuestos a $20^{\circ} \mathrm{C}$ y 1 atmósfera de presión, teniendo en cuenta que la elevada salinidad de las muestras en los cristalizadores incrementa la densidad de las mismas, siendo aproximadamente de 1,2 kg/L (densidad obtenida pesando volúmenes conocidos de muestra).

- $\mathrm{NaCl} \leftrightarrow \mathrm{Na}^{+}+\mathrm{Cl}^{-}$;

$\mathrm{S}: 35,9 \mathrm{~g} / 100 \mathrm{~g}$ agua $\rightarrow 359 \mathrm{~g} / \mathrm{L}$ de agua

considerando que la densidad de la muestra es $1,2 \mathrm{~kg} / \mathrm{L} \rightarrow 430,80 \mathrm{~g} / \mathrm{L}$

- $\mathrm{NaNO}_{3} \leftrightarrow \mathrm{Na}^{+}+\mathrm{NO}_{3}^{-}$;

$\mathrm{S}: 87,6 \mathrm{~g} / 100 \mathrm{~g}$ agua $\rightarrow 876 \mathrm{~g} / \mathrm{L}$

considerando que la densidad de la muestra es $1,2 \mathrm{~kg} / \mathrm{L} \rightarrow 1051,2 \mathrm{~g} / \mathrm{L}$

- $\mathrm{NaNO}_{2} \leftrightarrow \mathrm{Na}^{+}+\mathrm{NO}_{2}^{-}$;

S: $80,8 \mathrm{~g} / 100 \mathrm{~g}$ agua $\rightarrow 808 \mathrm{~g} / \mathrm{L}$

considerando que la densidad de la muestra es $1,2 \mathrm{~kg} / \mathrm{L} \rightarrow 969,6 \mathrm{~g} / \mathrm{L}$

- $\mathrm{Na}_{3} \mathrm{PO}_{4} \leftrightarrow 3 \mathrm{Na}^{+}+\mathrm{PO}_{4}{ }^{-3}$;

$\mathrm{S}: 12,1 \mathrm{~g} / 100 \mathrm{~g}$ agua $\rightarrow 121 \mathrm{~g} / \mathrm{L}$

considerando que la densidad de la muestra es $1,2 \mathrm{~kg} / \mathrm{L} \rightarrow 145,2 \mathrm{~g} / \mathrm{L}$

Estos datos nos indican que sería posible que en el punto de cristalización del $\mathrm{NaCl}$ la concentración de esta sal (que es determinante de la salinidad) no siguiera aumentando mientras que sí lo podría hacer la de los compuestos de nitratos y nitritos, al poseer una 
mayor solubilidad. Es decir, cuando se utiliza la salinidad para establecer los procesos de concentración, no se está teniendo en cuenta que puede haber un aumento de la concentración de nitratos y nitritos derivado simplemente de la evapotranspiración.

\subsubsection{Factores de concentración de los nitratos en los cristalizadores}

Como se acaba de ver, en las aguas de los cristalizadores del circuito salinero, el contenido en nitritos y nitratos puede ser mucho mayor que el contenido en cloruros. Esto permite una concentración muy elevada de estos parámetros. Debido a que la principal diferencia se produce en el paso de los concentradores a los cristalizadores, a continuación se va a calcular el aumento de la concentración en el caso del nitrato en este paso, con el fin de comprobar si las altas concentraciones en los cristalizadores derivan de simples procesos de concentración salina o no.

Los concentradores finales (con salinidades entre 175 - $250 \mathrm{~g} / \mathrm{kg}$ ), son los estanques representados por las estaciones SPN006, SPN007, SPN008, SPN009, SPN010, SPN011 y SPN020, y el agua de cualquiera de ellos puede ser conducida a cualquier cristalizador según las necesidades de producción de la explotación salinera. Por otra parte, los cristalizadores (con salinidades $>250 \mathrm{~g} / \mathrm{kg}$ ) son los estanques representados por SPN018, SPN019, SPN021, SPN022, SPN024, SPN025 y SPN026.

Con los valores de $\mathrm{P}_{50}$ de nitratos en el año 2008, se ha realizado una estimación del contenido en nitratos teórico que podría haber en los cristalizadores partiendo de los valores existentes en los concentradores, teniendo en cuenta el factor de concentración que ha podido experimentar el agua según el aumento de la concentración salina. La estimación se ha realizado considerando la concentración mínima de nitratos $(1,4 \mu \mathrm{M}$ para $244,5 \mathrm{~g} / \mathrm{kg}$ de salinidad en SPN020) para establecer el rango inferior, y la concentración máxima de nitratos $(12,1 \mu \mathrm{M}$ para $212 \mathrm{~g} / \mathrm{kg}$ en SPN010) para establecer el rango superior.

Los valores de los concentradores se representan en la tabla 4.8a y las estimaciones para los cristalizadores se representan en la tabla $4.8 \mathrm{~b}$, donde además se han incluido las concentraciones reales de nitratos.

\begin{tabular}{|c|c|c|}
\hline $\begin{array}{c}\text { P }_{50} \text { SANTA } \\
\text { POLA 2008 }\end{array}$ & $\begin{array}{c}\text { SALINIDAD } \\
(\mathrm{g} / \mathrm{Kg})\end{array}$ & $\begin{array}{c}\text { NITRATO } \\
(\mu \mathrm{M})\end{array}$ \\
\hline SPN006 & 248,0 & 3,6 \\
\hline SPN007 & 196,7 & 2,6 \\
\hline SPN008 & 194,6 & 1,9 \\
\hline SPN009 & 205,0 & 1,7 \\
\hline SPN010 & 212,0 & 12,1 \\
\hline SPN011 & 214,0 & 4,3 \\
\hline SPN020 & 244,5 & 1,4 \\
\hline
\end{tabular}

$\Rightarrow$\begin{tabular}{|c|c|c|c|c|}
\hline $\begin{array}{c}\text { P }_{50} \text { SANTA } \\
\text { POLA 2008 }\end{array}$ & $\begin{array}{c}\text { SALINIDAD } \\
(\mathrm{g} / \mathrm{Kg})\end{array}$ & $\begin{array}{c}\text { NITRATO } \\
(\mu \mathrm{M})\end{array}$ & $\begin{array}{c}\text { Estimación } \\
\text { conc. } \mathrm{NO}_{3} \\
\text { inferior }(\mu \mathrm{M})\end{array}$ & $\begin{array}{c}\text { Estimación } \\
\text { conc. } \mathrm{NO}_{3} \\
\text { superior }(\mu \mathrm{M})\end{array}$ \\
\hline SPN018 & 260,5 & 34,6 & 1,49 & 14,9 \\
\hline SPN019 & 264,0 & 20,3 & 1,51 & 15,1 \\
\hline SPN021 & 261,0 & 34,7 & 1,49 & 14,9 \\
\hline SPN022 & 270,5 & 20,2 & 1,55 & 15,4 \\
\hline SPN024 & 265,5 & 9,9 & 1,52 & 15,2 \\
\hline SPN025 & 263,5 & 20,4 & 1,51 & 15,0 \\
\hline SPN026 & 269,0 & 21,3 & 1,54 & 15,4 \\
\hline
\end{tabular}

Tabla 4.8: a) $\mathrm{P}_{50}$ de los nitratos en los concentradores y b) $\mathrm{P}_{50}$ de los nitratos en los cristalizadores de Santa Pola junto con estimaciones teóricas del rango inferior y superior de nitratos calculados a partir del aumento en la concentración salina

A partir de estos resultados se puede observar que aunque en algunos casos las concentraciones se encuentran dentro del rango de nitratos que cabría esperar, en la mayor parte de los casos las concentraciones reales de nitratos son muy superiores a las estimadas por un simple proceso de concentración salina. 
Por este motivo, aunque las concentraciones de nitratos (y nitritos) que se pueden encontrar en las aguas de los cristalizadores pueden ser mucho mayores que las del $\mathrm{NaCl}$ (puesto que la solubilidad es mayor, tal y como se ha estudiado en el apartado anterior), los elevados picos de nitratos (y nitritos) existentes no se pueden explicar por un simple proceso de concentración salina. Esto parece indicar que existen otros procesos internos como la nitrificación que podrían estar generando nitritos y nitratos. 


\subsection{DIFERENCIAS Y SEMEJANZAS ENTRE LAS TRES SALINAS}

\subsubsection{Análisis de los parámetros físico-químicos en todas las salinas}

\subsubsection{Salinidad}

Las salinas estudiadas presentan grandes diferencias con respecto a la salinidad debido a que la gestión humana que de ellas se hace presenta también diferencias significativas, y esto condiciona en gran medida los niveles y variaciones de la salinidad de los distintos sistemas.

\section{- Salina de Santa Pola}

Puesto que las estaciones de muestreo se encuentran distribuidas a lo largo de todo el circuito salinero (abarcando el proceso completo desde los calentadores a los cristalizadores), el rango de concentraciones es muy amplio y oscila entre $38,49 \mathrm{~g} / \mathrm{kg}$ (valor muy próximo a los $37,9 \mathrm{~g} / \mathrm{kg}$ del agua de mar en el Mediterráneo) y $279 \mathrm{~g} / \mathrm{kg}$ en los cristalizadores. Este rango es tan amplio que permite el establecimiento de una tipología para la clasificación de las aguas de Santa Pola.

Los valores menores de salinidad se dan en los estanques donde se produce la entrada de agua de mar en el circuito, representados por las estaciones: SPN001, SPN002 y SPN014; mientras que los valores mayores se dan en los cristalizadores que están representados por las estaciones: SPN018, SPN019, SPN021, SPN022, SPN024, SPN025 y SPN026.

La variabilidad en los cristalizadores es muy reducida (generalmente $<5 \%$ ), aunque esta variabilidad aumenta en los estanques de menor salinidad, siendo en los concentradores mayor (entre 9,5-16,7\%) y aún mayor en los calentadores (entre 7,5-59,5\%). Destaca la gran variabilidad de los estanques representados por las estaciones SPN002, SPN003 y SPN014 (variabilidad entre 39,5-59,5\%).

\section{- Salina de Calpe}

En la actualidad no se viene realizando una explotación salinera en Calpe, por lo que la laguna presenta valores mucho más bajos que el resto de sistemas, ya que la gestión humana no fuerza el proceso de evapotranspiración para alcanzar los niveles próximos a la cristalización que precisaría el sistema si estuviera en explotación. La salinidad aunque normalmente es mayor que la del agua de mar no supera los niveles de un calentador.

Existen varios factores que condicionan la salinidad de la laguna:

- El funcionamiento artificial del sistema con bombeos intensivos de agua marina, especialmente en verano, para mantener la lámina de agua y unas condiciones que garanticen la pervivencia de la laguna y su biodiversidad.

- Las precipitaciones, que tienen una influencia considerable en esta salina, por tratarse de una zona donde esporádicamente se dan lluvias torrenciales acumuladas en espacios temporales muy cortos.

- Finalmente la evapotranspiración, que es la responsable básicamente del aumento de la concentración de la sal dentro de la laguna a partir de las aguas marinas que entran. 
En el período de muestreo el rango de salinidades ha variado entre $14,91 \mathrm{~g} / \mathrm{kg}$ en febrero de 2008 y $61,14 \mathrm{~g} / \mathrm{kg}$ en julio de 2009 . Aunque hay que decir que probablemente niveles tan bajos como los alcanzados en febrero eran valores esporádicos, al igual que la intensidad y la magnitud de las lluvias responsables de estas condiciones.

En esta salina se aprecia una zonación espacial clara. En SCT00J y SCT002, situadas más hacia el interior de la laguna, la salinidad es menor en invierno por la entrada de aguas dulces continentales, mientras que en verano, la mayor evapotranspiración y los bombeos de agua marina hacen que la salinidad sea más elevada en los extremos de la laguna. En cambio en SCT005 y SCT008, más próximas a las entradas por bombeo de agua marina, la salinidad es mayor en invierno por una menor influencia de las aguas continentales, y menor en verano por la dilución de las aguas hiperhalinas de la laguna con las que entran desde el mar.

\section{-Salina de La Mata - Torrevieja}

Esta salina está constituida por dos lagunas, la laguna de La Mata y la laguna de Torrevieja, que funcionan como dos estanques de grandes dimensiones.

La salinidad en cada una de ellas es muy diferente, ya que durante el período de muestreo la de La Mata ha oscilado entre 97,6 g/ $\mathrm{kg}$ en febrero de 2008 y 136,4 g/ $\mathrm{kg}$ en octubre de 2008, mientras que la de Torrevieja ha oscilado entre $252 \mathrm{~g} / \mathrm{kg}-276 \mathrm{~g} / \mathrm{kg}$. Las grandes diferencias de salinidad entre ambas lagunas dependen de la función que dentro del proceso de explotación salinera tiene cada una de ellas, ya que La Mata funciona como un gran estanque "calentador", mientras que Torrevieja funciona como un gran estanque "cristalizador".

La función de La Mata estriba en proporcionar agua con salinidades altas a Torrevieja para mantener la columna de agua y la salinidad que precisa el sistema de explotación de Torrevieja. Para ello, la laguna de la Mata está conectada con el mar y puede recibir agua marina y aportarla a Torrevieja tras concentrarla o recibir agua de Torrevieja en momentos de lluvias torrenciales cuando entran en ésta aguas dulces procedentes de escorrentías. Los valores de salinidad en el interior de la laguna de La Mata son bastante homogéneos aunque en ocasiones se detectan valores menores en la estación más próxima a la entrada de agua de mar por bombeo al sistema (STM002).

El calentador de La Mata se aleja de los calentadores convencionales por las necesidades de explotación y por la manipulación que se hace de este sistema y alcanza concentraciones muy superiores a las de los calentadores de Santa Pola $(<100 \mathrm{~g} / \mathrm{kg})$. La Mata es, por tanto, un gran estanque calentador - concentrador, ya que el sistema es forzado con el propósito de alcanzar salinidades elevadas que reduzcan lo menos posible la salinidad del gran cristalizador de Torrevieja.

En Torrevieja los valores de salinidad son muy elevados y homogéneos en toda la laguna debido a su sistema de explotación anual que mantiene la salinidad de las aguas en el punto de cristalización ya que se cosecha durante todo el año. La evapotranspiración hace que las concentraciones salinas sean mayores en el centro de la laguna que a la salida de la tubería con salmueras procedentes de El Pinoso. Entre las estaciones centrales de la laguna también se observan diferencias de salinidad. Esto es debido a que STT013 queda del lado de la laguna donde vierten las aguas de El Pinoso mientras que STT012 queda del lado opuesto, siendo el efecto de la evapotranspiración en esta última mayor. 
Los aumentos de salinidad en el estanque son debidos a la evapotranspiración y a las entradas de las salmueras de El Pinoso, mientras que los descensos son debidos a escorrentías procedentes de las precipitaciones y a entradas de agua desde La Mata.

\subsubsection{2. $\mathrm{pH}$}

\section{- Salina de Santa Pola}

En el circuito salinero de Santa Pola el pH presenta un amplio rango de valores que varía entre 7,04 y 8,78. En esta salina se observa una relación inversa entre el $\mathrm{pH}$ y la salinidad (ver figura 4.74a).

Los valores menores de $\mathrm{pH}$ no son debidos a cambios en la composición iónica en sentido estricto, sino a la disminución de la difusibilidad de los gases (fundamentalmente $\mathrm{CO}_{2} \mathrm{y}$ otros gases ácidos procedentes de la descomposición de la materia orgánica) al aumentar la densidad del agua, lo que favorecería unas condiciones de sobresaturación que no se dan a densidades más bajas.

Además, durante el proceso de evapotranspiración del agua de mar en una explotación salinera, la precipitación de $\mathrm{CaCO}_{3}$ y del $\mathrm{CaSO}_{4} \cdot 2 \mathrm{H}_{2} \mathrm{O}$ (yeso) provoca un descenso del contenido en calcio de la columna de agua, lo que reduce la capacidad del sistema de regular la concentración de $\mathrm{CO}_{2}$, haciendo que el medio sea aún más sensible a los cambios en el contenido de carbónico-carbonato.

\section{-Salina de Calpe}

Los valores de $\mathrm{pH}$ en Calpe oscilan entre 7,75 y 9,20. Por lo general se encuentran valores bastante altos aunque se observa un ligero descenso de este parámetro en octubre de $2008 \mathrm{y}$ un descenso importante en febrero de 2009 (ver figura 4.4).

Aunque la salinidad en Calpe no alcanza valores tan elevados como para que se de la precipitación del carbonato de calcio, parece ser que la reducida hidrodinámica del sistema junto a la elevada densidad de las aguas permite una sobresaturación de $\mathrm{CO}_{2} \mathrm{y}$ otros gases ácidos procedentes de la descomposición de la materia orgánica (posiblemente de origen béntico) que provocan un descenso del $\mathrm{pH}$.

\section{-Salina de La Mata - Torrevieja}

El pH en La Mata oscila entre 7,65 y 8,55. Existen diferencias importantes según el mes muestreado, dándose los valores menores en los meses de febrero y abril de 2008 y en febrero de 2009. En este caso no parece observarse una relación clara entre la salinidad y el $\mathrm{pH}$ (figura 4.28a) y los valores menores parecen deberse una vez más a sobresaturaciones con $\mathrm{CO}_{2}$ procedente de la descomposición de la materia orgánica.

Los valores de $\mathrm{pH}$ en Torrevieja son relativamente bajos en toda la laguna durante todos los muestreos, ya que oscilan entre 7,26 y 7,52. Estos valores son menores que en otras salinas. Las pruebas realizadas con muestras de La Mata y de Torrevieja muestran que la mayor salinidad y por tanto, densidad de las aguas reduce la difusibilidad de los gases en ellas. Esto hace que el $\mathrm{CO}_{2}$ y otros gases formados en la descomposición de la materia orgánica, tanto en el bentos como en la columna de agua, puedan alcanzar concentraciones por encima de la saturación que conduzcan a estos valores tan bajos de $\mathrm{pH}$. Además, a las elevadas salinidades de Torrevieja ya se ha producido la precipitación del calcio, por lo que 
se reduce la capacidad de regular el contenido de carbónico - carbonato y de tamponar el efecto sobre el $\mathrm{pH}$ de las elevadas entradas de $\mathrm{CO}_{2}$ al sistema.

Si se representa el conjunto de valores de $\mathrm{pH}$ de todas las salinas, se observa una relación inversa entre el $\mathrm{pH}$ y la salinidad (coeficiente de determinación $\mathrm{R}^{2}$ : 0,6245, con un p valor $<0,001$ y un nivel de significatividad $\alpha$ de 0,01) (figura 4.96a) que no se da entre el pH y los valores de temperatura (figura 4.96b). Por otra parte se aprecia una variación importante del $\mathrm{pH}$ en rangos de salinidad amplios, como valores de $\mathrm{pH}$ de 7,7 en salinidades tanto de $40 \mathrm{~g} / \mathrm{kg}$ como de $270 \mathrm{~g} / \mathrm{kg}$. Esto puede ser debido tanto a variaciones por la actividad biológica como por la génesis de $\mathrm{CO}_{2}$.

Numerosos investigadores que han documentado un descenso del $\mathrm{pH}$ conforme se produce una mayor concentración del agua de mar (Sass y Ben-Yaakov, 1977) siendo ampliamente reconocido que la evaporación del agua de mar podría afectar el sistema carbónicocarbonato de diferentes formas (Lazar et al., 1983).

Además, como ya se ha comentado, la precipitación del calcio reduce la capacidad de regular la concentración de carbónico - carbonato y de tamponar el efecto sobre el $\mathrm{pH}$ de las elevadas entradas de $\mathrm{CO}_{2}$ al sistema.

Por tanto, cualquier actividad de descomposición de la materia orgánica podrá dar lugar a una disminución significativa del $\mathrm{pH}$. Incluso en aquellas salinas con salinidades inferiores, como son Calpe o la laguna de La Mata, se observan descensos esporádicos del $\mathrm{pH}$ en determinados muestreos, ya que la reducida hidrodinámica de estos sistemas provoca una sobresaturación de $\mathrm{CO}_{2}$ durante el proceso de descomposición de la materia orgánica.

En las pruebas realizadas en muestras de La Mata - Torrevieja (ver figuras 4.26 a y b) quedó confirmado que la reducción de los valores de $\mathrm{pH}$ no es debida a cambios en la composición iónica de las aguas en sentido estricto sino a cambios en el sistema carbónicocarbonato. Además, se observó que la mayor salinidad y por tanto, densidad de las aguas reduce la difusibilidad de los gases en ellas, lo que haría que el $\mathrm{CO}_{2}$ y otros gases formados en la descomposición de la materia orgánica tanto en el bentos como en la columna de agua, pudieran alcanzar concentraciones por encima de la saturación que darían lugar a estos valores tan bajos de $\mathrm{pH}$.
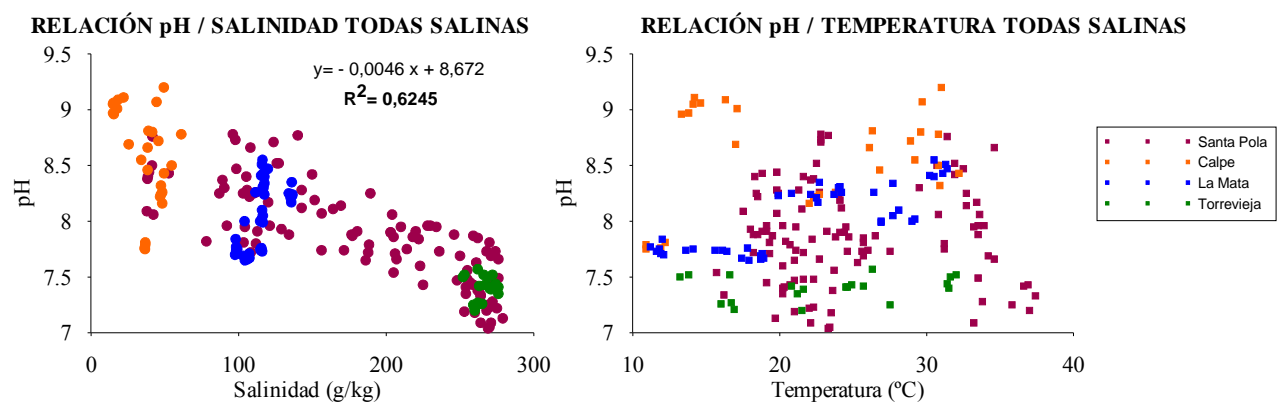

Figura 4.96: a) Comportamiento del $\mathrm{pH}$ respecto a la salinidad y b) Comportamiento del pH respecto a la temperatura en todas las salinas durante 2008-2009 


\subsubsection{Amonio}

\section{- Salina de Santa Pola}

El amonio presenta una concentración muy variable a lo largo de todo el circuito salinero ya que oscila entre valores por debajo del límite de detección y un máximo de 214,9 $\mu \mathrm{M}$. Los mayores picos se dan en algunos de los estanques de entrada al circuito, fundamentalmente en SPN002 y SPN003, que corresponden con dos estaciones donde la variación de la salinidad presenta un rango elevado. También se observan picos en los cristalizadores, que son especialmente elevados en febrero de 2008.

Todos los valores más altos de amonio coinciden con valores de $\mathrm{pH}<8$, aunque no siempre se produce el mismo fenómeno a la inversa, es decir, no siempre con valores de $\mathrm{pH}$ $<8$ se encuentran concentraciones de amonio muy grandes. Los picos en las salinidades intermedias probablemente se deban a procesos de remineralización de la materia orgánica (de origen sedimentario ya que no se corresponde con una subida simultánea de PSR), mientras que el aumento en los cristalizadores posiblemente se deba a una acumulación de amonio al final del circuito resultado del proceso de concentración de materiales de la actividad salinera (figuras $4.76 \mathrm{a}$ y $4.76 \mathrm{~b}$ ).

\section{-Salina de Calpe}

En esta salina los valores de amonio son variables y oscilan entre valores por debajo del límite de detección y 133,0 $\mu \mathrm{M}$. Los valores mayores se alcanzan en febrero de 2009 . No parece que la concentración de amonio esté gobernada por los aportes de aguas dulces o marinas sino por procesos internos.

Las gráficas de relación de la concentración de amonio con $\mathrm{pH}$ (figura 4.7b) parecen indicar que los picos de amonio estarían asociados a procesos de mineralización de la materia orgánica, aunque la falta de picos de PSR parece indicar que la fuente de $\mathrm{CO}_{2} \mathrm{y}$ amonio es béntica y no de la columna de agua.

\section{- Salina de La Mata - Torrevieja}

En la laguna de La Mata se llegan a encontrar valores muy elevados de amonio, de hasta $526,7 \mu \mathrm{M}$ en abril de 2008. Las concentraciones más altas se registran durante los meses de febrero, abril y julio de 2008 (ver figura 4.29) y podrían ser debidas a liberaciones procedentes de procesos de degradación de la materia orgánica aunque no se descarta un posible trasvase de aguas cargadas de amonio procedente de Torrevieja. En febrero de 2009 también parece producirse una liberación de amonio que parece haberse transformado por nitrificación en nitritos y nitratos. Todos estos muestreos coinciden con valores menores de $\mathrm{pH}$.

El rango de concentraciones de amonio en la laguna de Torrevieja es muy amplio ya que oscila entre $3,1 \mu \mathrm{M}$ y $94,9 \mu \mathrm{M}$. Tal y como se observa en la figura 4.51 , en este parámetro se detecta una gran diferencia entre los valores obtenidos en las estaciones centrales de la salina (STT012 y STT013) y los de la salida de El Pinoso (STT014) con valores muy superiores (entre 201,0 $\mu \mathrm{M}$ y 545,4 $\mu \mathrm{M}$ ). Parece ser que la principal entrada de amonio en el sistema es a través las salmueras procedentes de El Pinoso, siendo una parte absorbida por el fitoplancton y otra parte transformada en nitritos y nitratos por procesos de nitrificación. 
Al representar el contenido en amonio de todas las salinas frente a la salinidad y frente al $\mathrm{pH}$ (figuras 4.97a y 4.97b), no se observa una pauta de comportamiento generalizada para todas ellas. Esto es debido a que el amonio es un nutriente que experimenta una gran variabilidad de concentraciones entre las diferentes salinas, e incluso en las mismas salinas a lo largo del tiempo (Javor, 2002).

Se observan procesos de remineralización de la materia orgánica y acumulación por concentración de sales en Santa Pola; entradas desde el conducto de El Pinoso a la laguna de Torrevieja y liberaciones por procesos de degradación de la materia orgánica durante ciertos meses del año (especialmente en invierno) en Calpe y La Mata.
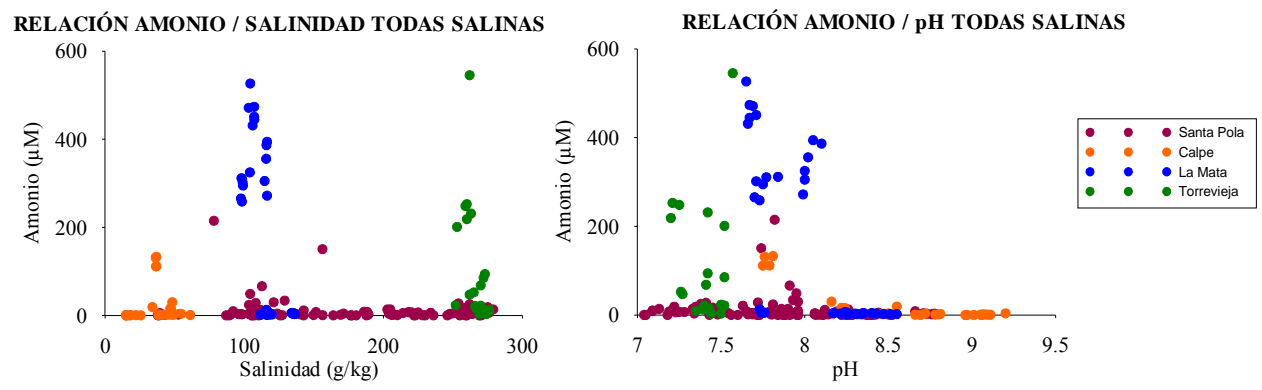

Figura 4.97: a) Comportamiento del amonio respecto a la salinidad y b) Comportamiento del amonio respecto al $\mathrm{pH}$ en todas las salinas durante 2008-2009

\subsubsection{Nitrito}

Las pautas de comportamiento de este parámetro varían según la salina estudiada aunque excepto en la laguna de Torrevieja, por lo general se observan valores muy bajos.

- Salina de Santa Pola

El contenido en nitritos es menor que en otros sistemas, aunque se observa una tendencia a la acumulación del nitrito (valor máximo de 2,56 $\mu \mathrm{M}$ ) con la concentración de las sales en los cristalizadores (ver figura 4.78a).

\section{- Salina de Calpe}

Los valores para este parámetro son muy bajos en toda la laguna excepto en las estaciones más interiores de la laguna (SCT002 y SCT00J) en mayo de 2009 por aportes procedentes de aguas continentales y en febrero de 2009 (hasta 4,05 $\mu \mathrm{M}$ ), donde procesos de nitrificación parecen ser los causantes del elevado contenido de nitritos.

\section{- Salina de La Mata - Torrevieja}

El comportamiento de este parámetro en La Mata es muy similar al de Calpe encontrando valores muy bajos en toda la laguna excepto en febrero de 2008 y en febrero de 2009 por procesos de nitrificación, aunque en febrero de 2008 no se descarta un trasvase desde Torrevieja. Hay que recordar que la nitrificación es un proceso relacionado con la temperatura, ya que existe una relación positiva entre las tasas de nitrificación y la temperatura (Helder y De Vries, 1983) especialmente en el paso de nitritos a nitratos que puede verse inhibido en períodos de bajas temperaturas (Herbert,1999), este es el motivo de que los mayores picos de nitritos se detecten en los meses más fríos. 
En la salina de Torrevieja las concentraciones detectadas, al contrario de lo que sucede en el resto de salinas, son muy elevadas puesto que se llegan a alcanzar $43,84 \mu \mathrm{M}$ en octubre de 2008. Las concentraciones son mucho mayores en STT012 y STT013 situadas en el centro de la laguna que en la salida de la tubería procedente de El Pinoso (STT014) (ver figura 4.53). Aunque algunos autores plantean que la nitrificación autótrofa no es operativa en las salinidades más altas (a partir de 100-150 g/l) todo parece indicar que de una forma $\mathrm{u}$ otra se está produciendo una nitrificación de parte del amonio que hay en la laguna.

\subsubsection{Nitrato}

\section{- Salina de Santa Pola}

El rango de concentraciones es amplio y oscila desde valores por debajo del límite de detección a $68,6 \mu \mathrm{M}$. Al igual que sucede para el nitrito, en el nitrato también se observa una tendencia a la acumulación en los cristalizadores (figura 4.80a) y este fenómeno se repite en casi todos los muestreos.

\section{- Salina de Calpe}

El nitrato presenta valores en muchos casos por debajo del límite de detección analítico. Los valores máximos en el año 2008 se dan en febrero y en 2009 en mayo (hasta 18,3 $\mu \mathrm{M}$ en la estación más interior SCT00J) posiblemente debidos a la entrada de aguas dulces cargadas con nitratos en el sistema. En febrero de 2009 también se encuentran valores altos aunque en este caso el aumento del nitrato parece deberse no solo a los aportes de las aguas de escorrentía sino también al paso del amonio a nitritos y posteriormente a nitratos por el proceso de nitrificación (ver figura 4.10).

\section{- Salina de La Mata - Torrevieja}

En La Mata se pueden encontrar desde concentraciones de nitratos inferiores al límite de detección hasta 44,6 $\mu \mathrm{M}$. Los niveles más altos se encuentran en los muestreos de febrero de 2008 y febrero de 2009 (ver figura 4.33). Parece que la principal entrada de nitratos en el sistema es a través de los procesos de nitrificación que tienen lugar en la laguna y que son particularmente visibles en los meses de invierno cuando la actividad biológica es menor aunque una parte de los nitratos de febrero de 2008 podría tener su origen en las aguas de Torrevieja.

En la laguna de Torrevieja, los nitratos oscilan entre $226,5 \mu \mathrm{M}$ y $561,7 \mu \mathrm{M}$, por lo que se encuentran concentraciones muy altas en toda la laguna independientemente de la época del año muestreada (ver figura 4.55). Este contenido tan elevado es debido a que el agua que entra en el sistema procedente de El Pinoso lleva consigo una carga importante de nitratos. Los valores más elevados no siempre se observan en la salida de la tubería (STT014) sino que en ocasiones se dan en el centro de la laguna como sucede en julio de 2009 donde los nitratos parecen concentrarse con la acumulación de sales.

\subsubsection{Nitrógeno Inorgánico Disuelto}

Dado que el NID es la suma de las diferentes formas de nitrógeno inorgánico y debido a que la mayor parte de las salinas alcanzan valores superiores de amonio respecto a nitritos y nitratos, el comportamiento del NID viene marcado por el descrito para el amonio. Si bien hay excepciones como los cristalizadores de Santa Pola que también se encuentran determinados por la acumulación de nitritos y nitratos y en Torrevieja donde alcanza 
valores muy elevados no solamente debido al amonio, sino también a los nitritos y nitratos (hasta $1.111,6 \mu \mathrm{M}$ ).

En el caso de Torrevieja (ver figura 4.57) la principal entrada de nitrógeno inorgánico en el sistema se produce por la tubería de El Pinoso y el hecho de que se alcancen valores menores en las estaciones centrales de la laguna muestra que parte del nitrógeno introducido es asimilado por los microorganismos planctónicos que lo coinvierten en formas orgánicas.

\subsubsection{PSR}

Este parámetro está prácticamente agotado en todas las salinas, por lo que se puede afirmar que el fósforo es el nutriente limitante en los sistemas salinos estudiados. Esto es debido a que el PSR es rápidamente asimilado por el fitoplancton ya que el ortofosfato es la forma preferida por los seres vivos (Migon y Sandroni, 1999) y además puede ser asimilado "en tromba", por lo que en muchos casos no se detecta en la columna de agua.

- Salina de Santa Pola

Muchos de los valores obtenidos se encuentran por debajo del límite de detección, la mayoría $<0,5 \mu \mathrm{M}$. Aunque se detectan concentraciones de hasta $2,36 \mu \mathrm{M}$ en algunos cristalizadores, especialmente durante los meses de julio y octubre de 2008, por acumulación con la concentración de sales (ver figura 4.84a).

- Salina de Calpe

En la salina de Calpe se encuentra totalmente agotado.

- Salina de La Mata - Torrevieja

En La Mata los valores de PSR están por debajo del límite de detección en buena parte de las estaciones y muestreos, por lo que se deduce que el PSR se encuentra prácticamente agotado en la mayor parte del sistema. Únicamente se encuentran valores en febrero de 2009 , con un valor máximo de $1,03 \mu \mathrm{M}$ posiblemente procesos de remineralización de la materia orgánica de la columna de agua.

El PSR presenta valores en general muy bajos en toda la laguna de Torrevieja aunque se detectan concentraciones principalmente en febrero y mayo de 2009 (ver figura 4.59), con un valor máximo de 2,05 $\mu \mathrm{M}$. En mayo de 2009 se puede observar cómo el PSR procede de las salmueras de El Pinoso aunque esto no sucede en febrero de 2009 donde parece que el PSR procede de procesos de remineralización de la materia orgánica.

\subsubsection{NID/PSR}

Por lo general la relación NID/PSR presenta valores muy elevados en todas las salinas lo que nos indica claramente que el fósforo es el nutriente limitante de los diferentes sistemas.

\section{- Salina de Santa Pola}

La relación NID/PSR en el circuito salinero es muy variable y oscila entre 3 y 31460 . Aunque en general los valores de la relación NID/PSR están por encima de 20 a lo largo de la mayor parte del circuito se dan esporádicamente valores inferiores a 10 o próximos a éste, aunque estos valores no siguen ninguna pauta determinada. 


\section{- Salina de Calpe}

La relación NID/PSR alcanza valores muy elevados porque el PSR se encuentra agotado en todo el sistema. Destacan los valores tan elevados encontrados en el mes de febrero de 2009 por la gran cantidad de amonio existente en la laguna en ese mes.

\section{- Salina de La Mata - Torrevieja}

En la laguna de La Mata la relación NID/PSR en los meses de febrero, abril y julio de 2008 es muy elevada debido a que el PSR en el sistema se encuentra prácticamente agotado y el contenido en nitrógeno es elevado. Esto indica no solamente que el PSR es el factor limitante para el crecimiento del fitoplancton sino también que el amonio presente en el agua no procede del fitoplancton sino del sedimento.

La relación NID/PSR presenta valores muy elevados en la laguna de Torrevieja que son especialmente elevados durante los muestreos de febrero, abril y julio de 2008 , aunque esto no es debido a que el contenido en nitrógeno de octubre de 2008 a julio de 2009 sea menor sino a que el contenido en PSR es mayor durante dichos meses.

\subsubsection{PT}

\section{- Salina de Santa Pola}

El rango de concentraciones oscila entre $0,25 \mu \mathrm{M}$ y $13,34 \mu \mathrm{M}$. Se observa una relación entre PT y salinidad (figura 4.88a), con una acumulación de este parámetro a lo largo de todo el proceso de concentración salino y no solamente en la parte final del circuito.

\section{- Salina de Calpe}

El PT en la salina de Calpe varía entre $0,24 \mu \mathrm{M}$ y $1,98 \mu \mathrm{M}$. Parece observarse una tendencia a que el contenido en este parámetro aumente tal y como aumenta la salinidad de la laguna (ver figura 4.17a) con desviaciones que son debidas a la interferencia de los procesos de precipitación/sedimentación del PT.

\section{- Salina de La Mata - Torrevieja}

En La Mata el PT varía entre 0,36 $\mu \mathrm{M}$ y 7,08 $\mu \mathrm{M}$ (ver figura 4.41). En este parámetro no se poseen los valores de todas las estaciones en los muestreos de julio de 2008 y febrero de 2009, por lo que estos muestreos no se consideran suficientemente representativos.

En Torrevieja el rango de concentraciones es amplio, entre $6,52 \mu \mathrm{M}$ y $17,74 \mu \mathrm{M}$ (febrero de 2009). Las concentraciones de PT son mayores en las estaciones centrales (STT012 y STT013) que a la salida de la tubería (STT014) (ver figura 4.63). Con un factor de concentración entre las aguas de El Pinoso y las de la laguna que oscila entre 3,65 en STT013 en abril de 2008 y 11,25 en STT012 en julio de 2008.

Los valores más elevados de PT en las estaciones centrales podrían ser debidos, al menos en parte, a que el proceso de concentración salina es mayor en dichas estaciones que a la salida de la tubería. A estos aportes hay que añadir los procedentes de La Mata. Además, parte de este PT podría quedar retenido en la columna de agua formando parte del ciclo de la comunidad fitoplanctónica que haría que no llegara a precipitar con la sal. 
En la figura 4.98 se observa claramente una tendencia al aumento en la concentración de PT cuanto mayor es la concentración salina en el conjunto de las salinas. (Coeficiente de determinación $\mathrm{R}^{2}$ : 0,5175 con un $\mathrm{p}$ valor $<0,001$ y un nivel de significatividad $\alpha$ de 0,01 ).

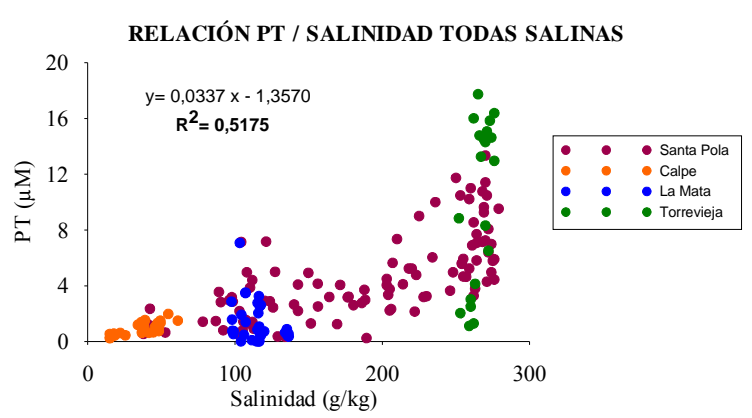

Figura 4.98: Comportamiento del PT respecto a la salinidad en todas las salinas durante 2008-2009

\subsubsection{0. Ácido ortosilícico}

En este parámetro el comportamiento es diferente según la salina estudiada.

\section{- Salina de Santa Pola}

Presenta valores que oscilan entre $0,2 \mu \mathrm{M}$ y $74,1 \mu \mathrm{M}$. No se aprecian tendencias claras en este parámetro. Parece ser que, al tratarse de un circuito salinero, no se produce una entrada importante de aguas de escorrentía en el sistema, lo que limita la entrada de ácido ortosilícico en la salina, aunque sí que se observa una acumulación de éste en los estanques durante aquellos meses en que la evapotranspiración es mayor (ver figura 4.89).

\section{- Salina de Calpe}

Las concentraciones varían entre $1,4 \mu \mathrm{M}$ y $152,0 \mu \mathrm{M}$. Se observa una mayor concentración de este parámetro cuanto mayor es la concentración salina aunque hay algunos valores que se alejan de esta pauta y parecen deberse a aportes asociados a las entradas de agua dulce (figura 4.19a).

\section{- Salina de La Mata - Torrevieja}

En La Mata, con valores entre $18,5 \mu \mathrm{M}$ y $75,0 \mu \mathrm{M}$, no se observa una pauta de comportamiento clara para este parámetro (ver figura 4.44a). Mientras que en Torrevieja, con valores entre 2,9 $\mu \mathrm{M}$ y 428,9 $\mu \mathrm{M}$. Parece que la principal entrada de ácido ortosilícico en el sistema se produce por la entrada de las aguas de salmuera de El Pinoso ya que las concentraciones a la salida de la tubería son mucho mayores que las encontradas en el centro de la laguna, tal y como se puede observar en la figura 4.65. 


\subsubsection{Análisis multivariable de los parámetros físico-químicos}

Se han analizado mediante componentes principales los resultados obtenidos para el conjunto de parámetros físico-químicos estudiados en las salinas de Calpe, La Mata, Torrevieja (excepto la estación STT04 de la tubería de Pinoso) y el circuito salinero de Bonmatí en Santa Pola durante las 4 campañas llevadas a cabo desde febrero de 2008 a octubre de 2008. Los datos de 2009 no han sido incluidos porque se poseen datos de pocas estaciones en el circuito salinero de Bonmatí, por lo que es más representativo considerar solamente el año 2008. Se han incluido un total de 8 variables: salinidad, $\mathrm{pH}$, amonio, nitrito, nitrato, PSR, PT y ácido ortosilícico.

El análisis se ha realizado a partir de los $\mathrm{P}_{50}$ obtenidos para cada parámetro en cada una de las estaciones de las diferentes salinas. A dichos resultados se les ha efectuado una transformación logarítmica $(\log \mathrm{x}+1)$ previa al ACP (excepto al $\mathrm{pH}$ que ya presenta una escala logarítmica). El análisis nos permitido reducir las variables a tres componentes principales que explican un $87,083 \%$ de la varianza acumulada $(50,209 \%$ la componente 1 ; $23,201 \%$ la componente 2 y 13,672\% la componente 3 ).

\begin{tabular}{|rcc|c|}
\hline & $\begin{array}{c}\text { Componente 1 } \\
(\mathbf{5 0 , 2 0 9 \% )}\end{array}$ & $\begin{array}{c}\text { Componente 2 } \\
\mathbf{( 2 3 , 2 0 1 \% )}\end{array}$ & $\begin{array}{c}\text { Componente 3 } \\
\mathbf{( 1 3 , 6 7 2 \% )}\end{array}$ \\
\hline Salinidad & 0,44013 & $-0,0698391$ & $-0,204951$ \\
\hline pH & $-0,453626$ & $-0,125402$ & 0,187738 \\
\hline Amonio & 0,0694572 & 0,680399 & 0,00745459 \\
\hline Nitrito & 0,320697 & $-0,0011787$ & 0,698317 \\
\hline Nitrato & 0,451486 & 0,0884686 & 0,291717 \\
\hline PSR & 0,297175 & $-0,142613$ & $-0,570085$ \\
\hline PT & 0,436755 & $-0,305065$ & 0,009895 \\
\hline Ác. ortosilícico & 0,0996544 & 0,628667 & $-0,157652$ \\
\hline
\end{tabular}

Tabla 4.9: Tabla de pesos de los componentes del ACP para los parámetros físico-químicos

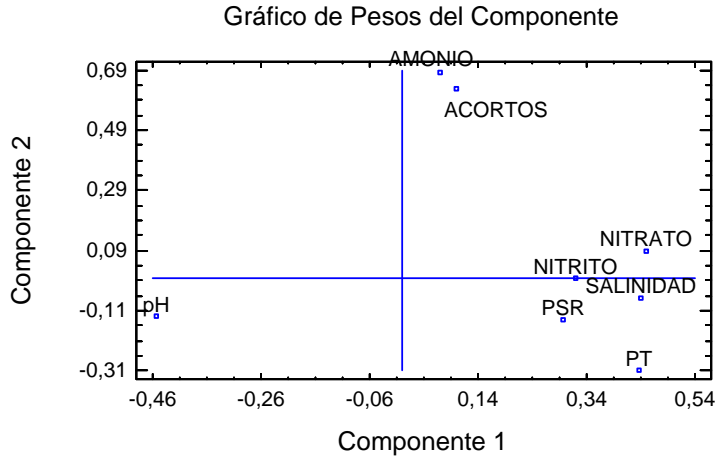

Figura 4.99: Gráfico de pesos de los componentes 1 y 2 del ACP para los parámetros físico-químicos de todas las salinas durante 2008 
Gráfico de Pesos del Componente

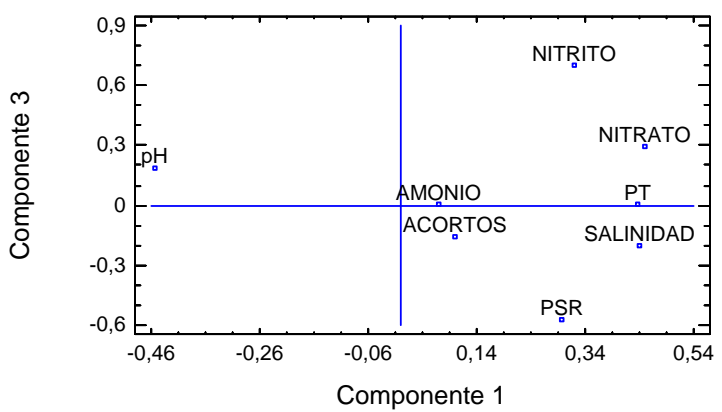

Figura 4.100: Gráfico de pesos de los componentes 1 y 3 del ACP para los parámetros físico-químicos de todas las salinas durante 2008

Los resultados obtenidos en la tabla de pesos (tabla 4.9) y sus representaciones gráficas (figuras 4.99 y 4.100) muestran que la componente 1 parece estar asociada a procesos de concentración salina (salinidad, $\mathrm{pH}$ y $\mathrm{PT}$ fundamentalmente y con un peso bastante menor nitritos, nitratos y PSR, formando estos tres últimos la componente 3). La componente 2 representa fundamentalmente las entradas de amonio y de ácido ortosilícico, probablemente debido a los altos valores de estos parámetros encontrados en la laguna de La Mata.

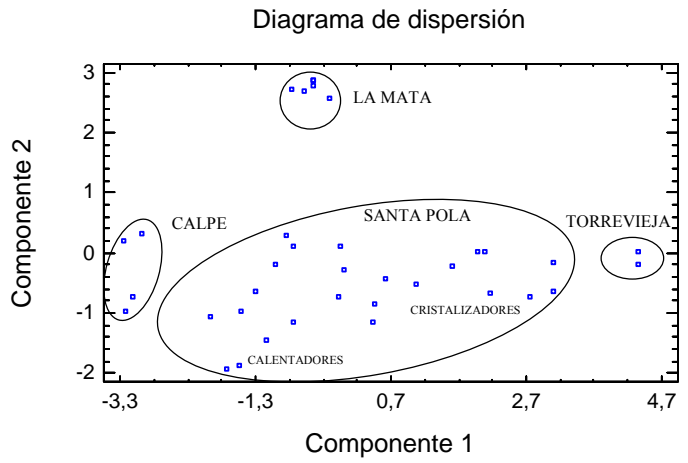

Figura 4.101: Diagrama de dispersión para los componentes 1 y 2 del ACP para los parámetros físico-químicos de todas las salinas durante 2008

En el diagrama de dispersión (figura 4.101) se puede observar cómo existe una diferenciación clara entre las distintas salinas. En cuanto a la componente 1 se observa un gradiente en función de la salinidad, puesto que Calpe es la salina que se encuentra en la parte inferior de esta componente, seguida de la parte baja del circuito salinero, La Mata, los cristalizadores de Santa Pola y finalmente Torrevieja. Destaca la clara diferenciación de 
la salina de Torrevieja respecto al resto de salinas al presentar unos valores excepcionalmente elevados tanto de salinidad, como de nitritos, nitratos y PT.

En cuanto a la componente 2, en este caso es la salina de La Mata la que se aleja más del resto de salinas debido a que presenta valores muy elevados de amonio y ácido ortosilícico, seguida a una distancia considerable de Torrevieja y de los cristalizadores y en último lugar de Calpe y la parte baja del circuito.

Respecto a la componente 3 es la salina de Torrevieja la que más se aleja del resto de salinas al presentar los valores más elevados de nitritos y nitratos procedentes de las aguas de salmuera de El Pinoso.

Diagrama de dispersión

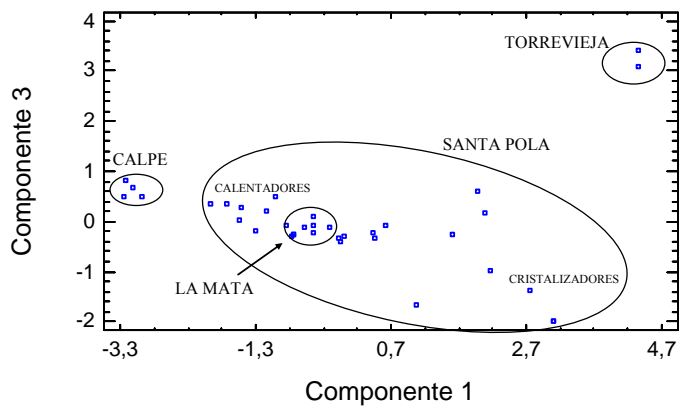

Figura 4.102: Diagrama de dispersión para los componentes 1 y 3 del ACP para los parámetros físico-químicos de todas las salinas durante 2008

En este tratamiento estadístico se ha podido comprobar la diferencia existente entre los sistemas salineros estudiados teniendo en cuenta todos los parámetros medidos. Son fundamentalmente los procesos de concentración salina los que dan lugar a la diferenciación entre ellos. En estos procesos de concentración salina se produce un aumento de la salinidad, nitratos y PT y un descenso del pH. Esto da lugar a que Calpe y Torrevieja tengan un comportamiento muy diferente. Calpe se podría definir como un sistema similar a una laguna costera con una cierta influencia humana. Torrevieja es una salina en explotación, con unas salinidades próximas a la cristalización durante todo el año. Santa Pola, en cambio sería un sistema salinero con una sucesión de estanques desde calentadores (similares a Calpe) hasta cristalizadores (similares a Torrevieja). Finalmente La Mata sería similar a los concentradores de Santa Pola. Este gradiente observado en el simple funcionamiento de estos sistemas se ve reflejado en este tratamiento estadístico.

Si se realiza un análisis por conglomerados jerárquicos (figura 4.103) se aprecia claramente no solamente que existe una agrupación por salinidad sino también por el tipo de compuestos físico-químicos que contiene cada salina. La salina de Calpe forma un subgrupo junto con aquellas estaciones del circuito salinero en las que se produce la entrada de agua de mar en el circuito y aquellos estanques intermedios previos a los primeros concentradores. A este subgrupo, se une el formado por las estaciones del circuito salinero que actúan como concentradores y los cristalizadores. Por otra parte se encuentran las estaciones de Torrevieja que forman un grupo en sí mismas y que se terminan uniendo 
al grupo anterior y finalmente se encuentra la laguna de La Mata cuyo contenido en algunos parámetros físico-químicos (amonio y ácido ortosilícico fundamentalmente) la hace diferenciarse del resto de salinas.

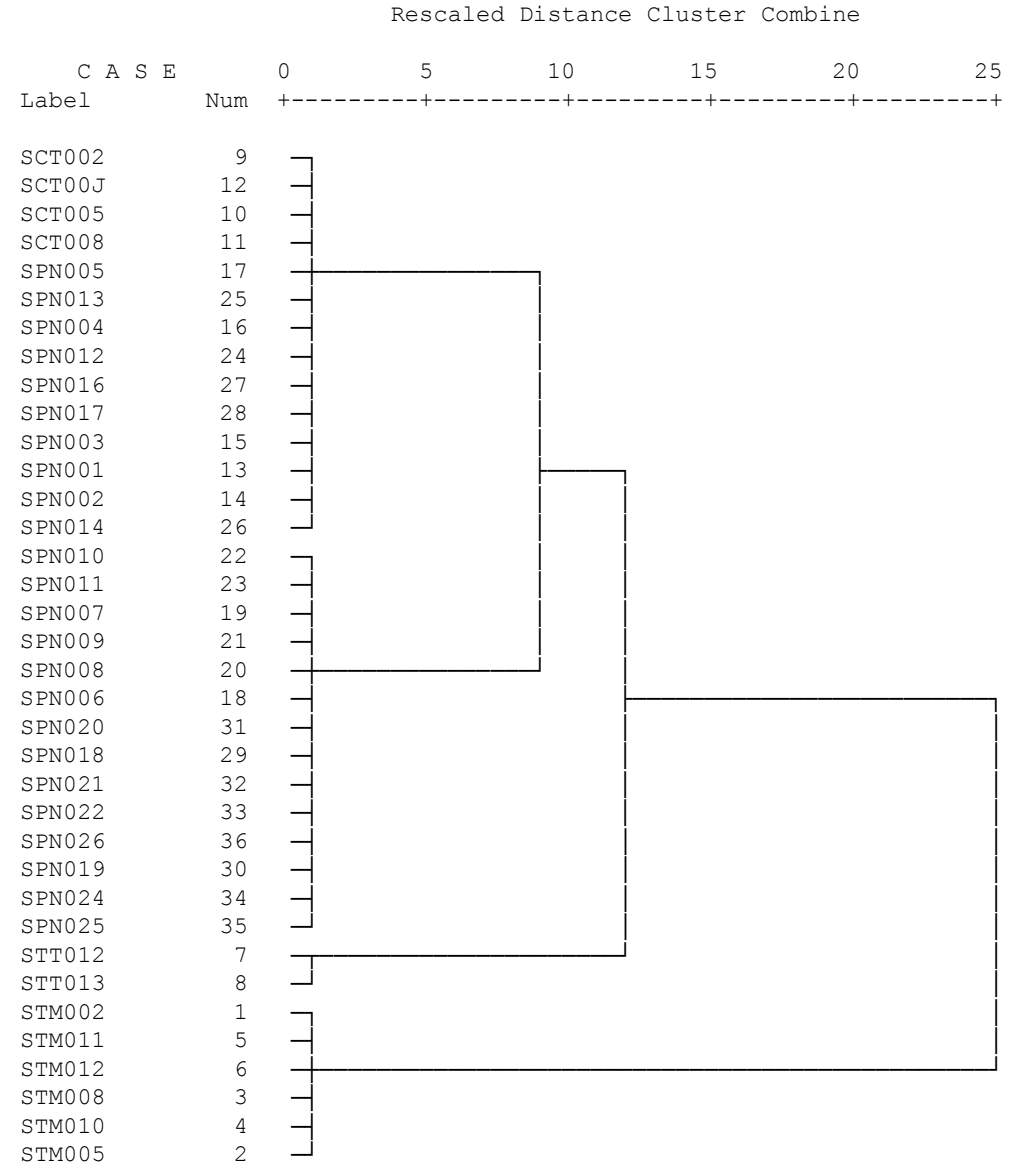

Figura 4.103: Conglomerado jerárquico con la agrupación de las estaciones de todas las salinas (excepto STT014) a partir de los $\mathrm{P}_{50}$ de los parámetros físico-químicos estudiados durante el 2008 


\subsection{ESTABLECIMIENTO DE LOS CRITERIOS PARA DETERMINAR EL POTENCIAL ECOLÓGICO EN LAS SALINAS DE LA COMUNIDAD VALENCIANA}

\subsubsection{Indicadores de calidad en las salinas}

El primer paso para establecer el estado o el potencial ecológico de una masa de agua es definir los elementos de calidad o indicadores que van a ser utilizados. En las MAMM, pueden ser aplicables los indicadores de cualquiera de las categorías de masas de agua superficial a las que más se parezca la masa de agua en cuestión (Anexo V apartado 1.1.5. de la DMA), en este caso, las masas de agua de transición.

Sin embargo, para el caso de las salinas no parecen válidos la mayor parte de los indicadores de calidad propuestos para las aguas de transición (Anexo V apartado 1.1.3. de la DMA) dadas las condiciones ambientales tan particulares y extremas de estos sistemas. Seguidamente se realiza un análisis de cada uno de ellos:

\section{- Indicadores biológicos.}

Los ecosistemas salinos presentan unas salinidades tan elevadas que son muy pocos los organismos que han podido adaptarse a estas condiciones tan extremas y por lo general, no existen organismos superiores que habiten en ellas. De ahí que estos ambientes sean básicamente microbianos (Grant, 2004). Por ello, es muy difícil encontrar bioindicadores para estas masas de agua, ya que solamente las especies halófilas o halotolerantes son capaces de prosperar en estos ambientes tan extremos.

- Fitoplancton: Las salinas estudiadas presentan una biomasa fitoplanctónica abundante a pesar del alto contenido en sales de algunos de los sistemas, como sucede en Torrevieja o en los cristalizadores del circuito de Santa Pola (GVA, 2008). Sin embargo, no es fácil encontrar un indicador fitoplanctónico adecuado para todas ellas debido a los amplios rangos de salinidades, ya que por ejemplo Dunaliella salina que podría ser un buen indicador por ser una especie halófila, solamente se encuentra en salinidades en torno a $120 \mathrm{~g} / \mathrm{kg}$ o mayores.

- Flora acuática (macroalgas y macrófitos): Se pueden encontrar macrófitos o macroalgas en las lagunas de Calpe y de La Mata, pero no en la laguna de Torrevieja o en el circuito salinero de Santa Pola por la elevada salinidad y el alto grado de antropización de estos sistemas.

- Invertebrados bénticos: La elevada salinidad de estos sistemas condiciona la presencia de estos organismos. En las salinidades más bajas se pueden encontrar macroinvertebrados bénticos como sucede en la salina de Calpe, aunque este indicador no es aplicable a todos los rangos de salinidad.

- Peces: Habitualmente no se encuentran peces en estos sistemas dada su elevada salinidad (según Litchfield y Gillevet (2002) no se observan peces por encima de $40-50 \mathrm{~g} / \mathrm{kg}$ de salinidad), aunque existen excepciones como el fartet (Aphanius iberus) especie en peligro de extinción localizada en las salinas de Santa Pola.

A primera vista, con los resultados obtenidos en nuestro grupo de investigación con algunos indicadores biológicos (fitoplancton, macroinvertebrados) parece complejo 
encontrar una especie o género que pueda ser buen indicador de la calidad, puesto que no todos se localizan a todas las salinidades. Además, el elevado contenido en sales, el amplio rango de salinidad entre las distintas salinas, e incluso la variación existente dentro de una misma salina son tan determinantes, que es muy difícil encontrar un bioindicador adecuado para todas ellas que no esté condicionado fundamentalmente por los niveles y las variaciones de la salinidad. Por este motivo, en estas condiciones tan extremas se pueden encontrar organismos buenos indicadores de la tipología pero no de la calidad de las aguas.

\section{- Indicadores hidromorfológicos}

- Condiciones morfológicas (variación de la profundidad; cantidad, estructura y sustrato del lecho; estructura de la zona intermareal).

- Régimen de mareas (flujo de agua dulce y exposición a las olas).

Ninguno de estos indicadores es adecuado para el caso de las salinas, ya que no se producen variaciones en ninguno de estos parámetros por las condiciones de las explotaciones salineras, y cualquier cambio hidromorfológico daría lugar a cambios o impactos significativos en el uso al que sirven.

\section{- Indicadores químicos y físico-químicos}

- Contaminantes específicos: no se producen aportes de sustancias prioritarias u otras sustancias contaminantes en las salinas (al menos en aquellas donde se realiza explotación salinera) ya que los fines alimenticios de la sal hace que este tipo de parámetros sea muy controlado por las propias empresas gestoras.

- Generales: transparencia, condiciones térmicas, oxigenación, salinidad y condiciones de los nutrientes

Los indicadores físico-químicos (generales) pueden ser aplicados en todas las salinas y finalmente se convierten en el tipo de indicadores más adecuado para el estudio del potencial ecológico en estos sistemas. La salinidad es el parámetro que evidentemente más va a condicionar las características ambientales y se trata de un buen indicador de la tipología de las masas de agua aunque no del estado, por lo que será necesario el análisis de los diferentes nutrientes con el fin de ver cuáles son los más adecuados para determinar el potencial ecológico.

\subsubsection{Masas de agua de referencia}

Ninguna de las salinas estudiadas puede ser utilizada como salina de referencia. Santa Pola y La Mata-Torrevieja fundamentalmente porque las aguas de entrada a ambos sistemas no lo son, y Calpe porque se trata más bien una laguna hiperhalina y solo recogería las condiciones de un calentador.

Como en este caso no hay condiciones de referencia y a la espera de que se puedan obtener del proceso de intercalibración de las MAMM entre los Estados Miembros, se ha abordado esta problemática mediante una modelación teórica a partir de las condiciones de referencia en las aguas de entrada del sistema, es decir de las masas de agua costeras.

Hay que considerar que el proceso de intercalibración para las masas de aguas costeras se encuentra en un estado mucho más avanzado y las masas de agua de la Comunidad Valenciana ya se encuentran caracterizadas. En este caso se ha utilizado la caracterización 
mediante el sistema de indicadores fitoplanctónicos Phymed que presenta una alta correlación con el PT (Pachés, 2010).

\subsubsection{El proceso de establecimiento del potencial ecológico}

Esta propuesta de metodología para el establecimiento del potencial ecológico se ha aplicado en la salina de Santa Pola, porque tanto por sus características como por el tipo de rango salino, es la salina más representativa de las estudiadas. Para elaborar una metodología que permitiera establecer el potencial ecológico en las salinas de la Comunidad Valenciana el proceso seguido ha sido el siguiente:

- Según los criterios del Workshop para MAMM (WFD CIS, 2009) debe verse cómo cambian las condiciones de calidad con la implementación de todas las medidas de mitigación posibles, lo que nos daría el potencial ecológico. En este caso, y para la problemática que se aborda, las medidas de mitigación que cabe establecer se centran en la reducción de los aportes de nutrientes (especialmente de P) a partir de las aguas costeras que abastecen la salina.

- Por tanto, en primer lugar se va a establecer cuáles son las condiciones ecológicas de estas aguas costeras y después se verá cómo pueden influir los cambios en la calidad de éstas sobre las distintas tipologías establecidas para la salina de Santa Pola. Para ello, y dado que, como posteriormente se verá, existe una relación entre PT y salinidad en la salina, una vez establecidos los diferentes niveles de calidad de las aguas de entrada se obtendrán los valores en la salina que corresponden a estos niveles.

A continuación se explica el procedimento utilizado con mayor detalle:

\section{Aguas de entrada /Calidad en las aguas de entrada}

Para determinar la calidad de las aguas que entran en la salina de Santa Pola, se han seleccionado las estaciones pertenecientes a la red de muestreo de la DMA: DP118 (Playa de Bras del Port, Santa Pola) y DP119 (Playa del Pinet, Elche), por ser las más próximas a las entradas de agua de mar en el circuito salinero, tal y como se puede observar en la figura 4.104. Se ha considerado que ambas son igualmente importantes ya que la principal entrada de agua en el circuito se encuentra situada entre ambas, ya que en la entrada norte (más próxima a la estación DP118) solamente se toma agua una vez al año (ver apartado 2.4.3.2 del área de estudio, circulación de las aguas en el circuito de Bonmatí). 


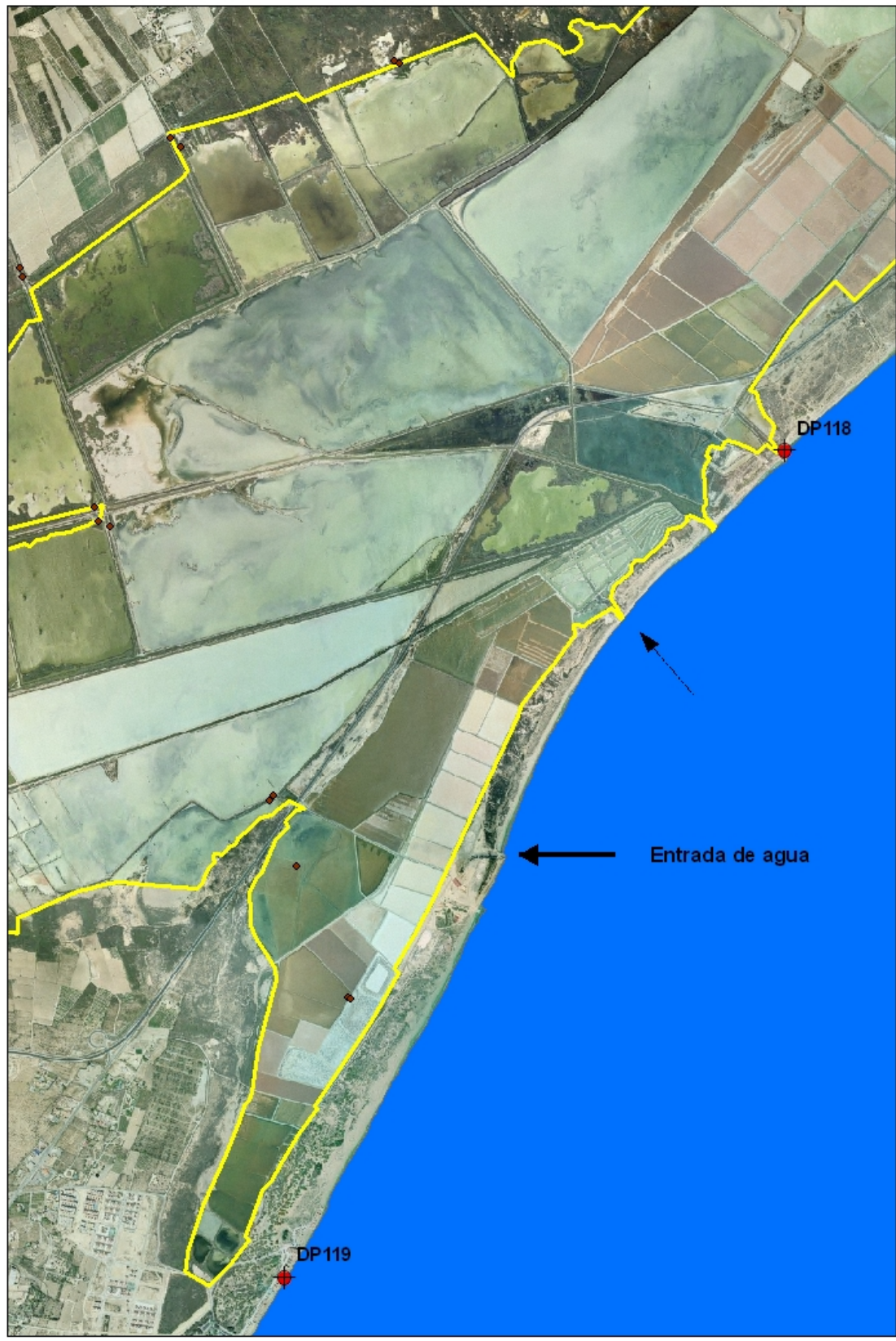

Figura 4.104: Localización de las estaciones DP118 y DP119, así como de las entradas de agua de mar en el circuito salinero 
Para establecer la calidad de las aguas en dichas estaciones se ha utilizado el índice Phymed que es un sistema de indicadores ecológicos desarrollado para la aplicación de la DMA basado en la composición y biomasa de la comunidad fitoplanctónica y que está elaborado a partir de los datos de fitoplancton mensuales obtenidos durante tres años (de agosto de 2005 a julio de 2008) (Pachés, 2010). En este caso se ha aplicado el índice Phymed a las estaciones DP118 y DP119 durante el año estudiado 2008. Según estos resultados obtenidos, la estación DP118 presenta un EQR de 0,27 (Malo) y la estación DP119 de 0,6 (Moderado-Bueno) y al considerar ambas estaciones, el EQR es de 0,47 (Moderado).

Como ya se estableció en el apartado 4.4.2 de resultados del análisis estadístico de Santa Pola, el circuito salinero de Santa Pola presenta cinco tipologías que están determinadas por el rango de salinidad. Por tanto, se ha calculado el valor de los $\mathrm{P}_{50}$ de los diferentes parámetros para estas tipologías, así como para las estaciones DP118 y DP119, cuyos resultados se muestran en la tabla 4.10

\begin{tabular}{|l|c|c|c|c|c|c|c|c|c|}
\hline P50 $_{\mathbf{5 0}} 2008$ & $\begin{array}{c}\text { P50 } \\
\text { SALINIDAD } \\
(\mathrm{g} / \mathrm{Kg})\end{array}$ & P50 $\mathrm{pH}$ & $\begin{array}{c}\text { P50 } \\
\text { AMONIO } \\
(\mu \mathrm{M})\end{array}$ & $\begin{array}{c}\text { PITRITO } \\
(\mu \mathrm{M})\end{array}$ & $\begin{array}{c}\text { NITRATO } \\
(\mu \mathrm{M})\end{array}$ & $\begin{array}{c}\text { P50 NID } \\
(\mu \mathrm{M})\end{array}$ & $\begin{array}{c}\text { P50 PSR } \\
(\mu \mathrm{M})\end{array}$ & $\begin{array}{c}\text { P50 PT } \\
(\mu \mathrm{M})\end{array}$ & $\begin{array}{c}\text { P50 AC } \\
\text { ORTOS. } \\
(\mu \mathrm{M})\end{array}$ \\
\hline S.POLA < 85 G/KG & 69,8 & 8,33 & 1,9 & 0,028 & 1,2 & 5,4 & 0,008 & 1,29 & 15,4 \\
\hline S. POLA 85 - 140 G/KG & 105,2 & 8,37 & 2,8 & 0,015 & 0,4 & 4,2 & 0,015 & 2,83 & 13,8 \\
\hline S. POLA 140 - 175 G/KG & 146,3 & 8,13 & 3,4 & 0,020 & 1,6 & 6,5 & 0,025 & 2,43 & 24,7 \\
\hline S. POLA 175 - 250 G/KG & 210 & 7,86 & 1,3 & 0,025 & 2,5 & 6,3 & 0,025 & 4,04 & 19,5 \\
\hline S. POLA > 250 G/KG & 266 & 7,41 & 8,4 & 0,42 & 20,5 & 33,9 & 0,250 & 7,48 & 27,0 \\
\hline DP118 - DP119 & 37,2 & 8,22 & 0,7 & 0,11 & 1,0 & 1,9 & 0,005 & 0,31 & 2,5 \\
\hline
\end{tabular}

Tabla 4.10: $\mathrm{P}_{50}$ de la salinidad y de los parámetros físico-químicos para las diferentes tipologías de Santa Pola así como para las playas más próximas a las entradas de agua durante el año 2008

Utilizando los valores de los $\mathrm{P}_{50}$ de los distintos parámetros de los tipos de la salina junto a los de las aguas de entrada, se ha establecido el comportamiento de los parámetros físicoquímicos a lo largo de todo el proceso de concentración que se da en el circuito salinero, tal y como se muestran en la figura 4.105. 

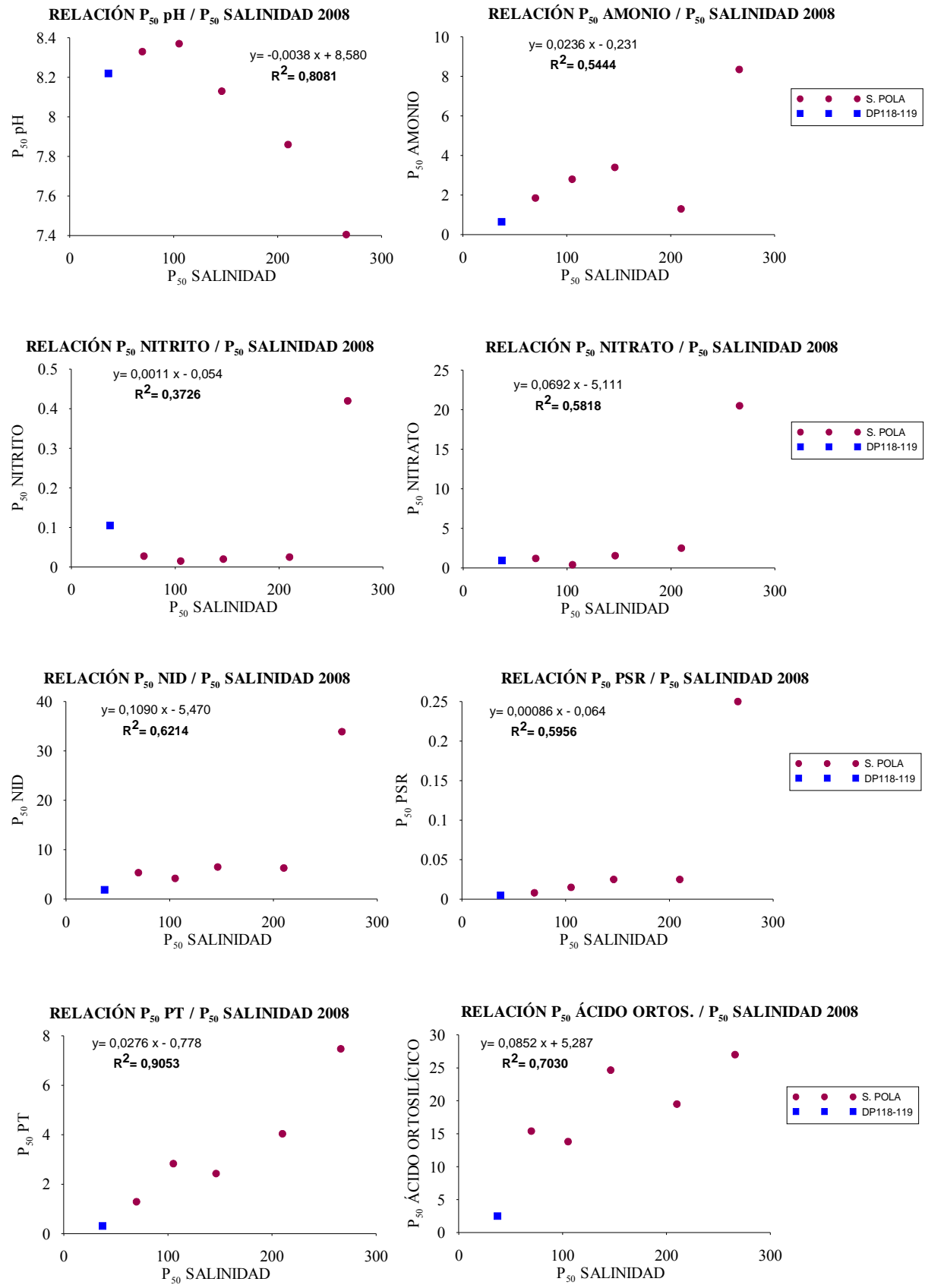

Figura 4.105: Relación entre el $\mathrm{P}_{50}$ de cada parámetro físico-químico y el $\mathrm{P}_{50}$ de la salinidad en el circuito salinero de Santa Pola y en las estaciones DP118 y DP119 para el año 2008 
En las gráficas de la figura 4.105, se representa el ajuste lineal de cada parámetro con la salinidad. Como se puede observar, el parámetro que presenta un mejor ajuste con la salinidad es el PT (Coeficiente de determinación $\mathrm{R}^{2}$ : 0,9053 con un $\mathrm{p}$ valor $<0,001$ y un nivel de significatividad $\alpha$ de 0,01$)$, seguido del $\mathrm{pH}\left(\mathrm{R}^{2}: 0,8081\right)$. En el caso del $\mathrm{pH}$, éste presenta un ajuste muy elevado con la salinidad si solamente se consideran los valores por encima de $100 \mathrm{~g} / \mathrm{kg}$, ( $\left.\mathrm{R}^{2}: 0,9813\right)$.

Dados estos resultados, se confirma que el parámetro más adecuado para la determinación del potencial ecológico es el PT. Respecto al resto de parámetros físico-químicos, aunque hay un repunte en la fase final de amonio, nitrito, nitrato y PSR en el circuito, los datos son tan variables que no parece factible su selección.

\section{A fin de determinar los efectos de la reducción de los niveles de PT en la aguas de entrada, lo primero es determinar los posibles valores de PT en estas aguas para los diferentes niveles de $\operatorname{EQR}(1 ; 0,75 ; 0,50 ; 0,25$ y 0$)$ utilizando la correlación existente entre Phymed y PT.}

El PT presenta una correlación estadística muy alta con el índice Phymed puesto que el contenido en fitoplancton está muy relacionado con los niveles de presión eutrófica (Pachés, 2010). Dado que esta relación lineal presenta un $\mathrm{R}^{2}: 0,8497$, se han podido calcular estos valores con una fiabilidad aceptable. La relación lineal obtenida sigue la relación siguiente:

$$
\text { Índice Phymed }=-2,8586 \cdot \mathrm{PT}+1,2929
$$

Esta relación permite conocer los valores de PT para cada EQR ( $1 ; 0,75 ; 0,50 ; 0,25$ y 0$)$ según el índice Phymed. En este caso se ha dividido en 4 grupos para establecer las 4 clases de potencial ecológico posibles (en el caso del establecimiento del estado ecológico en las masas de agua costeras se divide en 5 clases). Los valores de PT que marcarán los límites de clases en las aguas de entrada se muestran en la tabla 4.11:

\begin{tabular}{|c|c|l}
\hline PHYMED & PT $(\boldsymbol{\mu M})$ & \\
\cline { 1 - 1 } $0,75-1,00$ & $0,19-0,10$ & \multirow{2}{*}{ BUENO Y MÁXIMO } \\
\cline { 1 - 1 } $0,50-0,75$ & $0,28-0,19$ & MODERADO \\
\cline { 2 - 2 } $0,25-0,50$ & $0,36-0,28$ & DEFICIENTE \\
\hline $0-0,25$ & $0,45-0,36$ & MALO \\
\hline
\end{tabular}

Tabla 4.11: Contenido en PT ( $\mu \mathrm{M})$ para cada EQR establecido con el índice Phymed

Puesto que existe una relación lineal entre la concentración de PT y la salinidad, se ha estudiado cómo cambiarían las condiciones en el circuito salinero de Santa Pola con el cambio del nivel de eutrofia en las aguas de entrada, para de esta manera establecer los niveles que corresponderían a un EQR de $1 ; 0,75 ; 0,50 ; 0,25$ y 0 para cada tipología del circuito salinero, considerando el valor de $\mathrm{P}_{50}$ de PT para las aguas de entrada (DP118DP119) que es de $0,31 \mu \mathrm{M}$ a $37,21 \mathrm{~g} / \mathrm{kg}$ de salinidad y teniendo en cuenta los valores de PT 
que marcan los límites entre clases obtenidos en la tabla 4.11. Los resultados se muestran en la tabla 4.12.

\begin{tabular}{|l|c|c|c|c|c|c|c|}
\hline \multicolumn{1}{|c|}{$\mathbf{P}_{\mathbf{5 0}} \mathbf{2 0 0 8}$} & $\begin{array}{c}\text { SALINIDAD } \\
(\mathbf{g} / \mathbf{K g})\end{array}$ & $\mathbf{P T}(\boldsymbol{\mu M})$ & $\begin{array}{c}\text { PT EQR } \\
\mathbf{1}\end{array}$ & $\begin{array}{c}\text { PT EQR } \\
\mathbf{0 , 7 5}\end{array}$ & $\begin{array}{c}\text { PT EQR } \\
\mathbf{0 , 5 0}\end{array}$ & $\begin{array}{c}\text { PT EQR } \\
\mathbf{0 , 2 5}\end{array}$ & $\begin{array}{c}\text { PT EQR } \\
\mathbf{0}\end{array}$ \\
\hline DP118-DP119 & $\mathbf{3 7 , 2 1}$ & $\mathbf{0 , 3 1}$ & $\mathbf{0 , 1 0}$ & $\mathbf{0 , 1 9}$ & $\mathbf{0 , 2 8}$ & $\mathbf{0 , 3 6}$ & $\mathbf{0 , 4 5}$ \\
\hline SP $<85 \mathrm{~g} / \mathrm{kg}$ & 69,8 & 1,29 & 0,42 & 0,79 & 1,17 & 1,50 & 1,87 \\
\hline SP $85-140 \mathrm{~g} / \mathrm{kg}$ & 105,2 & 2,83 & 0,91 & 1,73 & 2,56 & 3,29 & 4,11 \\
\hline SP $140-175 \mathrm{~g} / \mathrm{kg}$ & 146,3 & 2,43 & 0,78 & 1,49 & 2,19 & 2,82 & 3,53 \\
\hline SP $175-250 \mathrm{~g} / \mathrm{kg}$ & 210 & 4,04 & 1,30 & 2,48 & 3,65 & 4,69 & 5,86 \\
\hline SP $>250 \mathrm{~g} / \mathrm{kg}$ & 266 & 7,48 & 2,41 & 4,58 & 6,75 & 8,68 & 10,85 \\
\hline
\end{tabular}

Tabla 4.12: Concentraciones de PT del circuito salinero según diferentes niveles de eutrofia en las aguas de entrada

\section{3) Establecimiento de las rectas que marcan los límites de los diferentes estados de potencial ecológico en función dela salinidad}

Se pasa a utilizar la correlación lineal entre salinidad y PT para establecer las rectas que corresponderían a los diferentes valores de salinidad y fósforo, para cada uno de estos valores de entrada.

Una vez se ha determinado que existe una relación lineal entre el PT y la salinidad, se ha utilizado ésta para determinar las rectas que corresponderían a los distintos EQRs que limitan las cuatro clases del potencial ecológico (figura 4.106). En esta figura se han representado también las concentraciones de PT de La Mata, Torrevieja y Calpe con el fin de que se pueda apreciar el potencial ecológico en que se encontrarían:

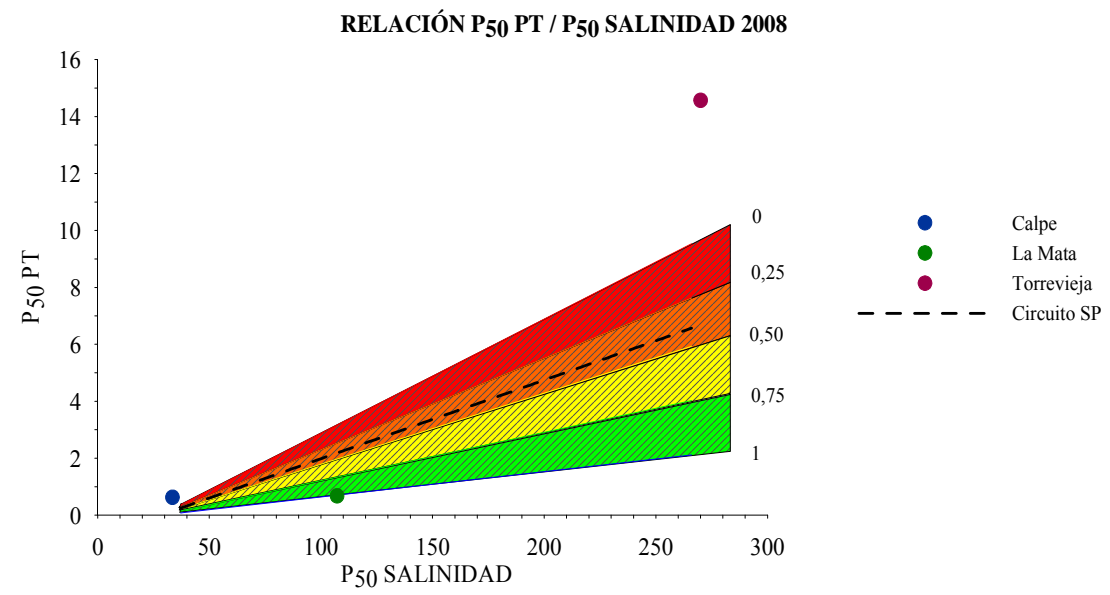

Figura 4.106: Valores de PT estimados a partir de distintos niveles de eutrofia en las aguas de entrada que corresponderían a un EQR de $1 ; 0,75 ; 0,50 ; 0,25$ y 0 en el circuito de Santa Pola y concentraciones de PT en La Mata, Torrevieja y Calpe

Estas son las rectas que establecen los límites entre las distintas clases de salinidad: 


\begin{tabular}{|c|}
\hline POTENCIAL ECOLÓGICO \\
\hline PT $=0,0089 \cdot$ SAL $-0,251$ \\
\hline PT $=0,0169 \cdot$ SAL $-0,477$ \\
\hline PT $=\mathbf{0 , 0 2 4 9} \cdot$ SAL $-\mathbf{0 , 7 0 3}$ \\
\hline PT $=\mathbf{0 , 0 3 2 1} \cdot$ SAL $-\mathbf{0 , 9 0 3}$ \\
\hline PT $=0,0401 \cdot$ SAL $-1,129$ \\
\hline
\end{tabular}

EQR 1

EQR 0,75

EQR 0,5

EQR 0,25

EQR 0

Tabla 4.13: Rectas que establecen las clases de potencial ecológico para los diferentes niveles de salinidad

Como se puede apreciar en la figura 4.106:

- $\quad$ El circuito salinero de Santa Pola presenta un potencial ecológico deficiente.

- La laguna de Calpe se encuentra ligeramente por debajo del rango salino de Santa Pola y al no ser correcta una extrapolación y menos por la parte inferior de las rectas, no debería ser considerada en esta clasificación para los sistemas salineros, ya que se trata de una laguna hiperhalina que recoge unas condiciones salinas propias de un calentador o más bajas.

- La laguna de La Mata presenta un potencial ecológico clasificado como bueno y máximo.

- La laguna de Torrevieja presenta un potencial ecológico especialmente malo, al presentar un contenido de PT muy superior incluso al establecido por la recta que determina el potencial ecológico de malo.

\subsubsection{Medidas de mitigación propuestas}

A continuación se proponen una serie de medidas de mitigación para aquellos sistemas en los que la calidad de las aguas podría ser mejorada. Se ha de considerar que, al tratarse de MAMM, estas medidas no deben presentar impactos negativos significativos sobre su uso específico ni sobre el medio ambiente en general.

\section{- Circuito salinero de Santa Pola}

En el circuito de Santa Pola, con un potencial ecológico deficiente, se plantea la reducción del contenido en PT en la masa de agua costera a través de la reducción de los aportes de PT a estas aguas, que son introducidas para la evaporación del agua de mar. Ésta es la principal vía de entrada de agua en la salina y el contenido en nutrientes del circuito vendrá determinado por la calidad de las aguas de entrada.

\section{- Laguna de Calpe}

En la laguna de Calpe, que no ha podido ser incluída en la clasificación propuesta para los sistemas salineros, las principales entradas de agua son las procedentes de las precipitaciones y de los bombeos de agua marina. Se ha considerado el estado de la masa de agua costera de la que se toma el agua que se introduce por bombeo en la laguna y que presenta un estado ecológico "bueno" según el índice Phymed. Por ello en esta laguna no se plantean medidas de mitigación. 


\section{- Laguna de La Mata}

En la laguna de La Mata al presentar un potencial ecológico calificado como bueno no se plantean medidas de mitigación.

\section{- Laguna de Torrevieja}

Las principales entradas de agua en la laguna son las procedentes de La Mata con un potencial ecológico bueno, y las procedentes de El Pinoso con un contenido en nutrientes muy elevado no solamente en cuanto al PT sino también en el resto de parámetros, por lo que las medidas de mitigación propuestas van dirigidas a mejorar la calidad de las aguas procedentes de El Pinoso a través del estudio de medidas que reduzcan el nivel de nitrógeno y fósforo en las aguas utilizadas en el lavado de la sal gema de El Pinoso.

En primer lugar se ha estudiado la composición físico-química de la muestra para el lavado de sal gema de El Pinoso (con la que se disuelven las sales para la generación de salmueras), que son aguas procedentes de un acuífero próximo y que según la muestra facilitada por la empresa gestora de las salinas en fecha 13 de octubre de 2009 presenta los siguientes resultados:

\begin{tabular}{|c|c|c|c|c|c|c|c|c|}
\hline $\begin{array}{c}\text { SALINIDAD } \\
(\mathbf{g} / \mathbf{K g})\end{array}$ & $\mathbf{p H}$ & $\begin{array}{c}\text { AMONIO } \\
(\boldsymbol{\mu M})\end{array}$ & $\begin{array}{c}\text { NITRITO } \\
(\boldsymbol{\mu M})\end{array}$ & $\begin{array}{c}\text { NITRATO } \\
(\boldsymbol{\mu M})\end{array}$ & NID $(\boldsymbol{\mu M})$ & $\begin{array}{c}\text { PSR } \\
(\boldsymbol{\mu M})\end{array}$ & PT $(\boldsymbol{\mu M})$ & $\begin{array}{c}\text { AC. } \\
\text { ORTOS. } \\
(\boldsymbol{\mu M})\end{array}$ \\
\hline 7,8 & 7,67 & 0,2 & $<0,01$ & 483,3 & 483,5 & $<0,01$ & 0,17 & 27,8 \\
\hline
\end{tabular}

Tabla 4.14: Composición físico-química de la muestra para el lavado de sal gema en El Pinoso

Según estos resultados (a la espera de comprobarlos con más datos) todo hace pensar que el PT existente en la laguna procede en su mayor parte del existente en las salmueras del yacimiento de sal de El Pinoso (la concentración de PT a la salida de la tubería de El Pinoso varía entre $1,1-4,4 \mu \mathrm{M})$, y no del agua de lavado, con un contenido muy bajo en PT $(0,17 \mu \mathrm{M})$.

En cuanto a otros parámetros como el nitrato, con elevadas concentraciones en el agua de la laguna, aunque no sea un parámetro determinante del potencial ecológico propuesto en esta tesis doctoral, se habrían de plantear medidas para reducir las entradas en el sistema, como por ejemplo cambiando el agua con la que se lavan las sales y seleccionando otra fuente para el lavado de la sal, en el caso de que los resultados de otros indicadores que se apliquen en el futuro así lo indiquen.

Posteriormente el potencial ecológico debería ser recalculado tras llevar a cabo el proceso de intercalibración entre los distintos Estados Miembros y tras plantear las medidas de mitigación propuestas para cada salina. 


\section{CAPÍTULO 5}

\section{CONCLUSIONES}

\subsection{CONCLUSIONES GENERALES DEL CONJUNTO DE LAS SALINAS}

\section{- Salinidad}

La salinidad de los distintos sistemas está condicionada fundamentalmente por las condiciones de gestión que el ser humano hace de ellas. Como en los tres sistemas esta gestión presenta diferencias significativas, también las hay con respecto a su salinidad.

Santa Pola es una salina convencional, donde las salinidades van desde niveles algo mayores a los del mar en los calentadores $(38,49 \mathrm{~g} / \mathrm{kg})$ hasta las del punto de cristalización en los cristalizadores $(279 \mathrm{~g} / \mathrm{kg})$. El tratamiento estadístico en función del $\mathrm{P}_{50}$ de la salinidad nos permite proponer una tipología de clasificación para las aguas de Santa Pola: Tipo 1: < 85 g/kg; tipo 2: entre 85 - 140 g/kg; tipo 3: entre 140 - 175 g/kg; tipo 4: entre 175 - 250 g/kg y tipo 5: $>250 \mathrm{~g} / \mathrm{kg}$.

La Mata-Torrevieja consta de dos estanques comunicados y los resultados obtenidos no descartan la posible existencia de un trasvase bidireccional de aguas entre ambos estanques, con el objetivo de mantener una salinidad de las aguas en el punto de cristalización en Torrevieja que permita una cosecha durante todo el año. Así, La Mata funciona como un gran calentador (aunque alcanza concentraciones superiores a las de otros calentadores), con concentraciones más variables y salinidades en torno a los $100 \mathrm{~g} / \mathrm{kg}$. Esta laguna se vio afectada por las precipitaciones que tuvieron lugar en febrero de 2008 y que condicionaron su salinidad al menos en los muestreos de febrero y abril de 2008.

En Calpe, el manejo humano no pretende forzar el sistema para aumentar la salinidad y buscar la precipitación de la sal sino simplemente mantener la lámina de agua y la biodiversidad de la laguna. Así, al no estar en explotación, la salinidad aunque normalmente es mayor que la del agua de mar no supera los niveles de un calentador. Ésta se encuentra condicionada fundamentalmente por las precipitaciones, la evapotranspiración y especialmente por los bombeos de agua de marina que tienen lugar en el sistema.

\section{- $\mathbf{p H}$}

En los tres sistemas se han detectado descensos claros del pH que en algunos casos se acercan al punto de la neutralidad.

Aunque en Santa Pola se aprecia una relación inversa entre $\mathrm{pH}$ y salinidad, las pruebas realizadas indican que este descenso no se debe a los cambios de la composición iónica en sentido estricto. Parece que al respecto hay algunos factores determinantes: 
- La disminución de la concentración de calcio al precipitar en forma de carbonato y sulfato de calcio que disminuye la capacidad de regular la concentración de $\mathrm{CO}_{2}$ del sistema.

- El aumento de la densidad que disminuye la difusión del $\mathrm{CO}_{2}$ y posibilita su acumulación en el agua.

- En gran parte de los casos, los gases que dan lugar al descenso del pH parecen provenir de los sedimentos y no de la columna de agua, ya que solo hay amonio asociado y no PSR.

En Calpe se encuentran valores relativamente bajos de $\mathrm{pH}$ a pesar de que la concentración salina no es lo suficientemente alta como para que se dé la precipitación del calcio. La reducida hidrodinámica de la laguna permite una sobresaturación del $\mathrm{CO}_{2}$ derivado de la descomposición de la materia orgánica que reduce el $\mathrm{pH}$.

\section{- Amonio}

El amonio es un nutriente que experimenta una gran variabilidad entre las distintas salinas, a diferentes salinidades y a lo largo del ciclo anual. En los tres sistemas se han observado picos de amonio derivados de procesos de remineralización de la materia orgánica que parecen proceder la mayor parte de las veces del sedimento, aunque es de destacar que:

- En Torrevieja se detecta una importante entrada de amonio en la laguna a través de las aguas de salmueras procedentes de El Pinoso, siendo una gran parte de este amonio absorbido por el fitoplancton de la laguna mientras que otra parte parece que es nitrificado (en forma de nitritos fundamentalmente).

- Los valores mayores de La Mata parecen proceder de procesos de remineralización de la materia orgánica, si bien no se descarta una posible entrada de aguas cargadas de amonio procedentes de Torrevieja en febrero de 2008, que parecen afectar a los niveles de los diferentes compuestos inorgánicos de nitrógeno hasta julio de 2008.

- En Santa Pola se observa una tendencia a la concentración de este parámetro en los cristalizadores. Se dan picos intermedios de amonio especialmente elevados en dos estanques (SPN002 y SPN003) que parecen proceder del sedimento, puesto que no van acompañados de aumentos en el contenido de PSR.

\section{- $\quad$ Nitritos y nitratos}

Los niveles más altos de las concentraciones de nitratos y nitritos derivan de aportes externos (especialmente en Calpe y La Mata-Torrevieja para el nitrato) y de posibles procesos de nitrificación (o al proceso de concentración salina) en los cristalizadores de Santa Pola (para el nitrito y el nitrato) y Torrevieja (para el nitrito y en menor medida el nitrato).

\section{- NID}

Las concentraciones más elevadas de NID son debidas en su mayor parte a los altos niveles de amonio que se llegan a alcanzar en las diferentes salinas.

El hecho de que los valores de NID en Torrevieja sean mayores a la salida de la tubería de El Pinoso que en la laguna, indican que parte de ese nitrógeno es asimilado por el fitoplancton. 
Las concentraciones en Santa Pola se encuentran especialmente condicionadas por el amonio en los muestreos en los que se detectan picos, así como por las altas concentraciones tanto de amonio como de nitritos y nitratos en los cristalizadores.

\section{- $\quad$ PSR}

Se encuentra totalmente agotado en Calpe y prácticamente agotado en el resto de salinas, excepto en algunos estanques del circuito salinero de Santa Pola, donde se observa una concentración de PSR con el aumento de sales en los cristalizadores. Estos valores más altos parecen deberse a dos factores:

- La presión que introducen las condiciones salinas de los cristalizadores es tan grande que la biomasa fitoplanctónica está limitada por ésta y no absorbe todo el PSR disponible.

- En algunos estanques de salinidades intermedias el "shock salino” provocado por el manejo humano puede dar lugar a la muerte y remineralización de la biota planctónica y a la existencia de concentraciones significativas de PSR en las aguas.

- $\quad$ PT

Se observa una acumulación de este parámetro conforme aumenta la concentración salina. Los rangos de variación suelen ser amplios.

En Torrevieja se observan valores de PT mayores en la laguna que a la salida de la tubería de El Pinoso, con un factor de concentración en la laguna que puede oscilar entre 3,64 - 11,25 veces la concentración procedente de El Pinoso según la época del año y que lógicamente es menor en la estación más afectada por los aportes de El Pinoso.

\section{- Ácido ortosilícico}

Los rangos de variación de este nutriente son elevados y se observa una acumulación con la concentración salina y aumentos significativos por entradas procedentes de aportes de aguas de escorrentía. En el caso de Torrevieja se detecta una entrada importante a través de las aguas de salmuera de El Pinoso. En Santa Pola, al tratarse de un circuito salinero no se detectan entradas externas importantes aunque sí una mayor concentración en los cristalizadores, especialmente en aquellos meses en que la evapotranspiración es mayor.

\subsection{CONCLUSIONES RESPECTO A LOS CRITERIOS PARA DETERMINAR EL POTENCIAL ECOLÓGICO DE LAS SALINAS}

La salina de Santa Pola es la más representativa a la hora de comparar el estado de los diferentes parámetros físico-químicos de las salinas objeto de estudio. El análisis estadístico de los datos de Santa Pola muestra que la clasificación de los estanques se realiza básicamente en función de la salinidad y no de otros parámetros físico-químicos. Por ello la salinidad es un buen indicador de la tipología aunque no de la caracterización del estado/potencial ecológico de una salina.

El índice de calidad ecológico propuesto está basado en parámetros físico-químicos y no es un índice biológico como cabría esperar, ya que dadas las condiciones tan extremas y singulares de las salinas no existe un elemento biológico que pueda ser tomado como índice de calidad. 
Sin embargo, se pueden tomar los parámetros físico-químicos puesto que también son parte de la ecología del sistema.

La DMA propone que las condiciones de referencia pueden tomarse a partir de datos existentes, juicios de expertos o modelos teóricos. En este caso se ha creado un modelo teórico a partir de los valores de $\mathrm{P}_{50} \mathrm{PT}$ respecto a los valores de $\mathrm{P}_{50}$ de salinidad, según el cual la salina de Santa Pola presenta un estado/potencial ecológico deficiente, La Mata bueno y Torrevieja malo, por lo que es necesario la aplicación de medidas de mitigación en Santa Pola y Torrevieja. 


\section{CAPÍTULO 6}

\section{LÍNEAS FUTURAS DE INVESTIGACIÓN}

- Analizar en profundidad el pH midiendo el contenido en $\mathrm{CO}_{2}$ y en $\mathrm{H}_{2} \mathrm{~S}$ en las aguas.

- $\quad$ Estudiar en profundidad el ciclo del nitrógeno en los sistemas salineros.

- Analizar las posibilidades de reducción del nitrógeno en La Mata - Torrevieja y las consecuencias que esto tendría en el sistema a través de un análisis de la calidad de la aguas utilizadas en el lavado del yacimiento de El Pinoso, buscando alternativas a estas aguas y/o medidas para corregir el estado de éstas.

- Analizar el potencial ecológico en Calpe viendo cómo pueden variar las concentraciones de nutrientes y el fitoplancton si cambiaran las condiciones de las aguas de entrada.

- Comparar los resultados obtenidos en otros sistemas salineros del Mediterráneo a fin de ver si es posible utilizar al menos algún parámetro, estadístico o de relación de las comunidades fitoplanctónicas como indicador de la calidad de las aguas.

- Verificar el modelo desarrollado para el PT con datos de otros sistemas salineros con el fin de optimizar su desarrollo.

- Poner a punto la determinación analítica de la clorofila $a$ en estos sistemas con elevadas salinidades.

- Poner a punto la metodología para la determinación del estado/potencial de los sistemas salineros teniendo en cuenta no solamente los parámetros fisicoquímicos (nutrientes) sino también los parámetros biológicos (fitoplancton, peces, vegetación) y químicos (sustancias prioritarias) que son objeto de otras tesis doctorales y trabajos de investigación. 



\section{CAPÍTULO 7}

\section{BIBLIOGRAFÍA}

Aemet, 2007. Las lluvias torrenciales del 11 y 12 de octubre de 2007 en la Comunidad

Valenciana. Instituto Nacional de Meteorología. Informe publicado en http://www.aemet.es/documentos/es/divulgacion/estudios/lluviascomval1.pdf. [Consulta 27 de septiembre de 2010].

Agencia de Medio Ambiente. 1990. Vol. 3: Parques y Parajes Naturales. Apéndice a la guía de la naturaleza de la Comunidad Valenciana. Ed. Levante-El Mercantil Valenciano.

Alcocer, J. y Escobar, E. 1993. Athalassohalinity (on the concept of salinity in inlands waters). Hidrobiológica 3: 1 - 2.

Amat, F. 1983. Diferenciación y distribución de las poblaciones de Artemia de España. VI Biogeografía. Investigación Pesquera 47: 231 - 240.

Aminot, A. 1983. Mesure de la salinité. En Aminot, A. y Chaussepied, M. (Eds.). Manuel des analyses chimiques en milieu marin. Centre National pour l'Explotation des Océans, Brest: 45 - 62.

Amit, O. y Bentor, Y.K. 1971. PH dilution curves of saline waters. Chemical Geology 7: $307-313$.

Antón, J., Rosselló-Mora, R., Rodríguez-Valera, F. y Amann R.I. 2000. Extremely halophilic Bacteria in crystallizer ponds from solar salterns. Applied Environmental Microbiology 66: 3052 - 3057.

APHA, 1998. Standard methods of the examination of water and wastewater, $20^{\text {th }}$ edition. American Public Health Association, American Water Works Association, Water Environment Federation, Washington.

Armengot, R. y Pérez-Cuevas, A. 1989. Cap 10: El clima. Guía de la naturaleza de la Comunidad Valenciana. Ed. Levante-El Mercantil Valenciano.

Baha Al-Deen, B. y Baha Al-Deen, A.H. 1972. Posible efecto de microalgas en la forma de cristalización de cloruro de sodio en la Salina de Araya. Boletín Instituto Oceanográfico Universidad Oriente 11: 35 - 38.

Baird, C. 2001. Química ambiental. Ed. Reverté. Barcelona. 
Barata, C., Hontoria, F., Amat F. y Browneb, R. 1996. Competition between sexual and parthenogenetic Artemia: temperature and strain effects. Journal of Experimental Marine Biology and Ecology 196: 313 - 328.

Benlloch, S., Martínez-Murcia A.J. y Rodríguez-Valera, F. 1995. Sequencing of bacterial and archaeal 16S rRNA genes directly amplified from a hypersaline environment. Systematic and Applied Microbiology 18: 574 - 581.

Bendschneider, K. y Robinson, R.J. 1952. A new spectrophotometric determination of nitrite in sea water. Journal of Marine Research 2: 87 - 96.

Bethoux, J.P., Morin, P. Madec C. y Gentili, B. 1992. Phosphorus and nitrogen behaviour in the Mediterranean Sea. Deep-Sea Research 39: 1641 - 1654.

Box, M. 1987. Humedales y áreas lacustres de la provincia de Alicante. Instituto de Estudios Juan Gil-Albert y Diputación de Alicante. Alicante.

Britton, R.H. y Johnson, A.R. 1987. An ecological account of a Mediterranean salina: the Salin de Giraud, Camargue (S. France). Biological Conservation 42: 185 - 230.

Casamayor, E.O., Calderón-Paz J.I. y Pedrós-Alió, C. 2000. 5s rRNA fingerprints of marine bacteria, halophilic archaea and natural prokaryotic assemblages along a salinity gradient. FEMS Microbiology Ecology 34: 113 - 119.

Casillas-Martínez, L., González, M.L., Fuentes-Figueroa, Z., Castro, C.M., NievesMendez, D., Hernández, C., Ramírez, W., Sytsma, R.E., Pérez-Jiménez, J. y Visscher, P.T. 2005. Community structure, geochemical characteristics and mineralogy of a hypersaline microbial mat, Cabo Rojo, PR, Geomicrobiology Journal 22: 269 - 281.

CEAM, 2007. Informe sobre las lluvias torrenciales del 11 - 12 de octubre de 2007 en la Comunidad Valenciana. Centro de Estudios Ambientales del Mediterráneo. Programa de Meteorología-Climatología. Fundación CEAM. 26 de octubre de 2007. http://www.uv.es/ femenia/oratge/GOTAFREDA2007/informe_lluvias_11_12_octubre.pdf [Consulta 27 de septiembre de 2010].

Clavero, E., Hernández-Mariné, M. Grimalt, J.O., García-Pichel, F. 2000. Salinity tolerance of diatoms from thalassic hypersaline environments. Journal of Phycology 36: 1021 - 1034.

Coakley, W.A. 1981. Handbook of automated analysis. Continuous flow techniques. Marcel Dekker, New York.

Coleman, M.U. y White, M.A. 1993. The role of biological disturbances in the production of solar salt. $7^{\text {th }}$ Symposium of Salt 1: $623-631$.

Correll, D.L. 1998. The role of phosphorus in the eutrophication of receiving waters: a review. Journal of Environmental Quality 27: 261 - 266. 
Chen, H. y Jiang, J-G. 2009. Osmotic responses of Dunaliella to the changes of salinity. Journal of Cellular Physiology 219: 251 - 258.

Davis, J.S. 1978. Biological communities of a nutrient enriched salina. Aquatic Botany 4: $23-42$.

Davis, J.S. 1993. Biological management for problem solving and biological concepts for a new generation of solar saltworks. $7^{\text {th }}$ Symposium on Salt 1: $611-616$.

Davis, J.S. 2000. Structure, function and management of the biological system for seasonal solar saltworks. Global Nest: The International Journal 2: 217 - 226.

Davis, J.S. y Giordano, M. 1996. Biological and physical events involved in the origin, effects, and control of organic matter in solar saltworks. International Journal of Salt Lake Research 4: 335 - 347.

Dean, W.E. 1978. Theoretical versus observed successions from evaporation of seawater, pp. 74 - 85. En Dean, W.E. y Schreiber, B.C. (Eds.). Marine Evaporites, Society of Economic Paleontologists and Mineralogists Short Course, $n^{\circ} 4$, Tulsa.

Declaración de Ramsar. 1971. Convención relativa a los humedales de importancia internacional especialmente como hábitat de aves acuáticas. Ramsar, Irán. 2/2/1971. http://www.cma.gva.es/comunes_asp/documentos/legislacion/cas/006000216_1.htm [Consulta 04 de junio de 2010].

Díaz de Rada, V. 2002. Técnicas de análisis multivariante para investigación social y comercial. Ed. Ra-Ma. Madrid.

Directiva 79/409/CEE del Consejo, de 2 de abril de 1979, relativa a la conservación de las aves silvestres. Diario Oficial n L 103 de 25/04/1979:0001-0018.

Directiva 92/43/CEE del Consejo, de 21 de mayo de 1992, relativa a la conservación de los hábitats naturales y de la fauna y flora silvestres. Diario Oficial $n^{\circ}$ L 206 de 22/07/1992:0007-0050.

Directiva 2000/60/CE del Parlamento Europeo y del Consejo. 23 octubre de 2000, por la que se establece un marco comunitario de actuación en el ámbito de la política de aguas. Unión Europea (DO L 327 de 22/12/2000, p. 1).

Dolapsakis, N.P., Tafas, T., Abatzopoulos, T.J., Ziller, S. y Economou-Amilli, A. 2005. Abundance and growth of microalgae at Megalon Embolon solar saltworks in northern Greece: an aquaculture prospect. Journal of Applied Phycology 17: 39 - 49.

Dundas, I. E. y Halvorson, H.O. 1966. Arginine metabolism in Halobacterium salinarium, an obligately halophilic bacterium. Journal of Bacteriology 91: 113 - 119. 
Elloumi, J., Carrias, J.-F., Ayadi, H., Sime-Ngando, T., Boukhris, M. y Bouaïn, A. 2006. Composition and distribution of planktonic ciliates from ponds of different salinity in the solarwork of Sfax, Tunisia. Estuarine, Coastal and Shelf Science 67: 21 - 29.

Folch, R. 1992. Història natural dels Països Catalans. Vol. 16: Espais naturals. Enciclopèdia Catalana. Barcelona.

Fourçans, A., García de Oteyza, T., Wieland, A., Solé, A., Diestra, E., Van Bleijswijk, J., Grimalt, J.O., Kühl, M., Esteve, E., Muyzer, G., Caumette, P. y Duran, R. 2004. Characterization of functional bacterial groups in a hypersaline microbial mat community (Salins-de-Giraud, Camargue, France). FEMS Microbiology Ecology 51: 55 - 70.

Fraser, P.D. y Bramley, P.M. 2004. The biosynthesis and nutritional uses of carotenoids. Progress in Lipid Research 43: 228 - 265.

Grant, W.D. 2004. Life at low water activity. Philosophical Transactions of the Royal Society. Biological Sciences 359: 1249 - 1267.

Grasshoff, K. 1976. Methods of Seawater Analysis. Verlag Chemie: Weinheim, New York.

Gunde-Cimerman, N., Zalar, P., de Hoog S. y Plemenitas, A. 2000. Hypersaline waters in salterns-natural niches for halophilic black yeasts. FEMS Microbiology Ecology 32: 235 240.

GVA. 2002. Catálogo de Zonas Húmedas de la Comunidad Valenciana. http://www.cma.gva.es/areas/espacios/zonas_humedas/zon/memoria2002.pdf. [Consulta: 26 de octubre de 2009].

GVA. 2008. Análisis de las características de las aguas costeras de la Comunitat Valenciana así como el estudio de las repercusiones de la actividad humana en éstas, en aplicación de la directiva marco del agua. Consellería de Medio Ambiente, Agua, Urbanismo y Vivienda. Valencia. España.

Hardie, L.A. 1984. Evaporites: marine or non-marine. American Journal of Science 284: $193-240$.

Harvie, C.E., Weare, J.H., Hardi L.A. y Eugster, H.P. 1980. Evaporation of seawater: calculated mineral sequences. Science 208: 498 - 500.

Heiskanen, A.S., Van de Bund, W., Cardoso, A.C. y Nõges, P. 2004. Towards good ecological estatus of surface waters in Europe - interpretation and harmonisation of the concept. Water Science and Technology 49: 169 - 177.

Helder, W. y De Vries, R.T.P. 1983. Estuarine nitrite maxima and nitrifying bacteria (EMS-Dollard Estuary). NETH. Journal of Sea Research 17: 1 - 18.

Herbert, R.A. 1999. Nitrogen cycling in coastal marine ecosystems. FEMS Microbiology Reviews 23: 563 - 590. 
Herrmann, A.G., Knake, D., Schneider, J. y Peters, H. 1973. Geochemistry of modern seawater and brines from salt pans: main components and bromine distribution. Contributions to Mineralogy and Petrology 40: 1 - 24.

Holser, W.T. 1979. Mineralogy of evaporites, pp. 211 - 294 in Burns, R.G. (Ed.), Marine Minerals, Mineralogical Society of America Short Course Notes. Vol. 6. Washinton D.C.

Ibrekk, A.S y Pedersen, T.S. 2005. Characterisation methodology and future challenges of heavily modified water bodies in Norway: Case study of the Suldal pilot river basin. Environmental Science and Policy 8: 227 - 231.

Javor, B.J. 1983a. Nutrients and ecology of the Western Salt and Exportadora de Sal saltern brines pp. 195 - 205. En: Schreiber B.C. y Harner H.L. (Eds.). $6^{\text {th }}$ Symposium on Salt. Vol.1. The Salt Institute, Toronto.

Javor, B.J. 1983b. Planktonic standing crop and nutrients in a saltern ecosystem. Limnology and Oceanography 28: 153 - 159.

Javor, B.J. 1989. Hypersaline environments. Microbiology and Biogeochemistry. SpringerVerlag. New York.

Javor, B.J. 2002. Industrial microbiology of solar salt production. Journal of Industrial Microbiology and Biotechnology 28: 42 - 47.

Jeffrey, S.W. y Humphrey, G.F. 1975. New spectrophotometric equations for determining chlorophylls a, b and c in higher plants, algae and natural phytoplankton. Biochemie und Physiologie der Pflanzen 167: 191 - 194.

Joint, I., Henriksen, P., Garde, K. y Riemann, B. 2002. Primary production, nutrient assimilation and microzooplancton grazing along a hypersaline gradient. FEMS Microbiology Ecology 39: 245 - 257.

Justic, D., Rabalais, N.N., Turner R.E. y Dortch, Q. 1995. Changes in nutrient structure of river-dominated coastal waters: Stoichiometric nutrient balance and its consequences. Estuarine Coastal and Shelf Science 40: 339-356.

Kennedy, I.R. 1986. Acid soil and acid rain. The impact on the environment of nitrogen and sulphur cycling. Research Studies Press Ltd., England.

Kinsman, D.J.J., Boardman, M. y Borcsik, M. 1974. An experimental determination of the solubility of oxygen in marine brines pp. 325-327. En Coogan, A.H. (Ed.). $4^{\text {th }}$ Symposium on Salt. Vol. 1. Northern Ohio Geological Society, Cleveland.

Kirkwood, D., Aminot, A., Pertilla, M. 1991. Report on the results of the fourth intercomparison exercise for nutrients in sea water. ICES Cooperative Research Report, $\mathrm{n}^{0} 174$. 
Krumbein, W.E. 1985. Applied an economic aspects of Sabkha systems-genesis of salt, ore and hydrocarbon deposits and bioechnology pp. 426 - 436. En: Hypersaline ecosystems. The Gavish Sabkha. Friedman, G.M. y Krumbein, W.E. (Eds). Springer-Verlag. Berlin.

Krumgalz, B. 1981. Salt effect on the pH of hypersaline solutions pp. 73 - 83. En Nissembaum, A. (Ed.). Hypersaline Brines and Evaporitic Environments, Elsevier.

Lacarra, J., Sánchez. X. y Jarque, F. 1996. Observaciones sobre la historia, geografía, agricultura, población y frutos del Reyno de Valencia. En: Las observaciones de Cavanilles 200 años después. Valencia. Bancaja. Obra social.

Lammens, E., van Luijn, F., Wessels, Y., Bouwhuis, H., Noordhuis, R., Portielje, R. y van der Molen, D. 2008. Towards ecological goals for the heavily modified lakes in the Ijsselmeer area, The Netherlands. Hydrobiologia 599: 239 - 247.

Landry, J.C. y Jaccard, J. 1982. Chimie des eaux libres dans le marais salant de Salin-deGiraud (Sud de la France). Géologie Mediterranéenne 9: 329 - 348.

Lazar, B., Starinsky, A., Katz, A. y Sass, E. 1983. The carbonate system in hypersaline solutions: alkalinity and $\mathrm{CaCO}_{3}$ solubility of evaporated seawater. American Society of Limnology and Oceanography 28: 978 - 986.

Ley 29/1985, de 2 de agosto, de Aguas. BOE nº 189, de 8 de agosto de 1985.

Ley 22/1988, de 28 de julio, de Costas. BOE nº 181, de 29 de julio de 1988.

Ley 11/1994, de 27 de diciembre, de la Generalitat Valenciana, de Espacios Naturales Protegidos de la Comunidad Valenciana. DOGV n ${ }^{2423}$, de 09 de enero de 1995.

Litchfield, C.D. y Gillevet, P.M. 2002. Microbial diversity and complexity in hypersaline environments: a preliminary assessment. Journal of Industrial Microbiology and Biotechnology 28: 48 - 55.

Litchfield, C.D., Irby, A. y Vreeland, R.H. 1999. The microbial ecology of solar salt plants pp. 39-52. En: Oren, A. (Ed). Microbiology and Biogeochemistry of Hypersaline Environments. CRC Press, Boca Raton, FL.

Litchfield, C.D., Irby, A., Kis-Papo, T. y Oren, A. 2000. Comparisons of the polar lipid and pigment profiles of two solar salterns located in Newark, California, USA, and Eilat, Israel. Extremophiles 4: 259 - 265.

Marcus, Y. 1989. Determination of $\mathrm{pH}$ in highly saline waters. Pure and Applied Chemistry 61: 1133 - 1138.

Margalef, R. 1983. Limnología. Ed. Omega. Barcelona.

Martí, E. 2000. Estudio medioambiental de las salinas de Calpe. Universidad Politécnica de Valencia. Escuela Politécnica Superior de Gandía. Proyecto Fin de Carrera. 
Martínez-Espinosa, R.M. 2003. Fisiología de la asimilación de nitrógeno en Haloferax mediterranei. Purificación y caracterización de nitrato y nitrito reductasas asimilativas. Tesis de Doctorado. Facultad de Ciencias Universidad de Alicante.

Migon, C. y Sandroni, V. 1999. Phosphorus in rainwater: Partitioning inputs and impact on the surface coastal ocean. Limnology and Oceanography 44: 1160 - 1165.

Ministerio de Medio Ambiente. 2007. Estudio general sobre la demarcación hidrográfica del Júcar. Programa A.G.U.A. (Actuaciones para la Gestión y Utilización del Agua). Ministerio de Medio Ambiente.

Ministerio de Medio Ambiente. 2009. Informe sobre la situación de la designación de HMWB y clasificación de su potencial ecológico en aguas costeras y de transición. Dirección General de Sostenibilidad de la Costa y del Mar. Secretaría General del Mar. Ministerio de Medio Ambiente y Medio Rural y Marino.

Miró, M. 1998. Estudio de aproximación al área de las salinas. Ayuntamiento de Calpe (no publicado).

Morillo, C. y Gómez-Campo, C. 2000. Conservation in Spain, 1980 - 2000. Biological Conservation 95: 165 - 174.

Mullin, J. y Riley, J. 1955. The spectrophotometric determination of silicate-silicon in natural waters with special reference to seawater. Analytica Chimica Acta 12: 162 - 170.

Murphy, J. y Riley, J.P. 1962. A modified single solution method for determination of phosphate in natural water. Analytica Chimica Acta 27: 31 - 36.

Nissembaum, A. 1969. Studies in the geochemistry of the Jordan River - Dead Sea system. Ph. D. Thesis Univ. California, Los Angeles.

Nixon, S.W. 1981. Remineralization and nutrient cycling in coastal marine ecosystems pp. 111 - 138. En: Neilson, B.J. y L.E. Cronin (Eds.). Estuaries and nutrients. Humana Press Inc., New Jersey.

Ollivier, B., Caumette, P., Garcia, J-L. y Mah, R.A. 1994. Anaerobic bacteria from hypersaline environments. Microbiological Review 58: 27 - 38.

Orden ARM/2656/2008, de 10 de septiembre, por la que se aprueba la intrucción de planificación hidrológica.

Oren, A. 1993. Ecology of extremely halophilic microorganisms pp. 25 - 53. En: Vreeland R.H. y L.I. Hochstein ( Eds). The Biology of Halophilic Bacteria. CRC Press, Boca Raton, FL.

Oren, A. 1999. Bioenergetic aspects of halophilism. Microbiology and Molecular Biology Reviews 63: 334-348. 
Oren, A. 2001. The bioenergetic basis for the decrease in metabolic diversity in increasing salt concentrations: implications for the functioning of salt lake ecosystems. Hydrobiologia 466: 61 - 72.

Oren, A. 2002. Molecular ecology of extremely halophilic archaea and bacteria. FEMS Microbial Ecology 39: 1 - 7.

Oren, A. 2005. A hundred years of Dunaliella research: 1905-2005. Saline systems 1:2, doi: 10.1186/1746-1448-1-2.

Oren, A. 2009. Saltern evaporation ponds as model systems for the study of primary production processes under hypersaline conditions. Aquatic Microbial Ecology 56: 193 204.

Oren, A. y Rodríguez-Valera, F. 2001. The contribution of halophilic Bacteria to the red coloration of saltern crystallizer ponds. FEMS Microbiology Ecology 36: 123 - 130.

Pachés, M. 2010. PHYMED: un sistema de indicadores ecológicos para la Directiva Marco del Agua basado en la composición de la comunidad fitoplanctónica. Ph. D Tesis. Universidad Politécnica de Valencia, Valencia, España.

Parsons, T.R., Maita, Y. y Lalli, C.M. 1984. A manual of chemical and biological methods for seawater analysis. Pergamon Press, New York.

Pavlova, P., Markova, K., Tanev, S. y Davis, J.S. 1980. Observations on a solar saltworks near Burgas, Bulgaria. International Journal of Salt Lake Research 7: 357 - 368.

Pedrós-Alió, C., Calderón-Paz, J.I., MacLean, M.H., Medina, G., Marrasé, C., Gasol, J.M. y Guixa-Boixereu, N. 2000. The microbial food web along salinity gradients. FEMS Microbiology Ecology 32: 143 - 155.

Planelles-Gomis, M. (ed.). 1999. Peces ciprinodóntidos ibéricos. Fartet y samaruc. Monografia de la Conselleria de Medi Ambient de la Generalitat Valenciana.

Ramos-Cormenzana, A. 1991. Halophilic organisms and the environment pp.15-21. En Rodríguez-Valera (Ed.). General and applied of halophilic microorganisms. Plenum Publishing Corporation. New York.

Real Decreto 1060/2007, de 20 de julio, por el que se prorroga y modifica la zona de reserva definitiva a favor del Estado para toda clase de yacimientos minerales y recursos geológicos que comprende el yacimiento de sal gema de El Pinoso, Alicante. BOE n ${ }^{\circ} 218$ de 11 septiembre 2007.

Revsbech, N.P., Jørgensen, B.B., Blackburn, T.H. y Cohen, Y. 1983. Microelectrode studies of the photosynthesis and $\mathrm{O}_{2}, \mathrm{H}_{2} \mathrm{~S}$ and $\mathrm{pH}$ profiles of a microbial mat. Limnology and Oceanography 28: 1062 - 1074.

Riley, J.P. y Chester, R. 1971. Introduction to marine chemistry. Academic Press, London. 
Rodríguez, J. 1982. Oceanografía del Mar Mediterráneo. Madrid, España. Ediciones Pirámide, 174p.

Rodríguez-Estrella, T. 1982. Paleogeografía de la zona Prebética durante el Cretácico. Cuadernos de Geología Ibérica 8: 615 - 633.

Rodríguez-Valera, F. 1988. Characteristics and microbial ecology of hypersaline environments pp. 3 - 30. En: Rodríguez-Valera, F. (Ed.). Halophilic Bacteria, Vol. 1. CRC Press, Boca Raton.

Romero, I. 2004. Tesis Doctoral: Comportamiento de nutrientes en la pluma del río Ebro. Ph. D Tesis. Valencia, España. Universidad Politécnica de Valencia.

Sadka, A., Lers, A., Zamir, A. y Avron, M. 1989. A critical examination of the role of the novo protein synthesis in the osmotic adaptation of the halotolerant alga Dunaliella. FEBS Letters 244: 93 - 98.

Sammy, N. 1983. Biological systems in north-western Australian solar salt fields. $6^{\text {th }}$ Symposium on Salt 1: 207 - 215.

Sanchis, E.J., Rodríguez, T. y Morell, I. 1989. Cap 9: Geología. Guía de la naturaleza de la Comunidad Valenciana. Ed. Levante-El Mercantil Valenciano.

Sass, E y Ben-Yaakov, S. 1977. The carbonate system in hypersaline solutions: Dead Sea brines. Marine Chemistry 5: 183 - 199.

Serra, J. 2005. Modelo morfológico-fotogramétrico de evolución, evaluación de la estabilidad y prognosis de evolución litoral. Universidad de Valencia.

Shiah, F.K., Kao, S.J., Gong G.C. y Liu, K.K. 1996. Spatial variability of phytoplankton production and the implications of its controlling mechanisms in the coastal zone near the river mouth of the Lanyang Hsi. Botanical Bulletin of Academia Sinica 37: 9 - 15.

Shinn, M. 1941. Colorimetric method for the determination of nitrite. Industrial and Engineering Chemistry Analytical Edition 13: 33 - 35.

Sierra, J.P., Sánchez-Arcilla, A., González del Río, J., Flos, J., Movellán, E., Mösso, C., Martínez, R., Rodilla, M., Falco S. y Romero, I. 2002. Spatial distribution of nutrients in the Ebro estuary and plume. Continental Shelf Research 22: 361 - 378.

Smayda, T.J. 1983. The phytoplankton of estuaries pp. 65-102. En: Ketchum, B. (Ed.) Ecosystems of the world, 26. Estuaries and enclosed seas. Elsevier Scientific Publishing Company, Amsterdam.

Soetaert, K., Hofmann, A.F., Middelburg, J.J., Meysman, F. y Greenwood, J. 2007. The effect of biogeochemical processes on $\mathrm{pH}$. Marine Chemistry 105: 30 - 51. 
Solórzano, L. 1969. Determination of ammonia in natural waters by the phenol hypoclorite method. Limnology and Oceanography 14: 799 - 801.

Sonnenfeld, P. 1984. Brines and evaporites. Academic Press. New York.

Stiller, M. y Nissembaum, A. 1999. Geochemical investigation of phosphorus and nitrogen in the hypersaline Dead Sea. Geochimica et Cosmochimica Acta 63: 3467 - 3475.

Strickland, J.D.H. y Parsons, T.R. 1965. A manual of seawater analysis (with special reference to the more common micronutrients and to particulate material). Journal of Fisheries Research Board Canada 125 2nd Ed., revised. Ottawa, Ont.

Strickland, J.D.H. y Parsons, T.R. 1972. A practical handbook of seawater analysis. Fisheries Research Board of Canada. Queens Printer, Ottawa.

Stumm, W. y Morgan, J.J. 1981. Aquatic Chemistry. Ed. John Wiley and sons, New York.

Tarapchak, S.J. 1983. Soluble reactive phosphorus measurements in lake water: Evidence for molibdate-enhanced hydrolisis. Journal of Environmental Quality 12:105 - 108.

Torralva, M., Oliva-Paterna, F.J., Andreu, A., García-Mellado, A., Miñano, P.A., Cardozo, V., García-Alonso, J. y Fernández-Delgado, C. 2001. Distribución y estado de conservación del fartet, Aphanius iberus (Valenciennes, 1846), en la región de Murcia (S.E. de la Península Ibérica). Establecimiento de grupos poblacionales operativos. Anales de Biología 23: 63 - 84.

Toumi, N., Ayadi, H., Abid, O., Carrias, J-F. y Sime-Ngando, T. 2005. Zooplancton in four ponds of different salinity: a seasonal study in the solar salterns of Sfax (Tunisia). Hydrobiologia 534: 1 - 9.

Treguer, P. y Le Corre. P. 1975. Manuel d'analyse des sels nutritifs dans l'eau de mer. Université de Bretagne Occidentale, Brest.

Valderrama, J.C. 1981. The simultaneous analysis of total nitrogen and total phosphorous in natural waters. Marine Chemistry 10: 109 - 122.

Van Gemerden, H. 1993. Microbial mats: A joint venture. Marine Geology 113: 3 - 25.

Venkatesh, M.G. 1982. Guidelines for the establishment of solar salt facilities from seawater, underground brines and salted lakes. United Nations Industrial Development Organization (UNIDO). UNIDO/IS. 330.

Ventosa, A, Nieto J.J. y Oren, A. 1998. Biology of moderately halophilic bacteria. Microbiology and Molecular Biology Reviews 62: 504 - 544.

Viñals, M.J. 2004. Los valores y funciones de los humedales. V Congrés Internacional de Medi Ambient d'Andorra: 14 - 17 Setembre 2004. Sant Julià de Lòria (Andorra). 
Vollenweider, R.A., Rinaldi, A., Viviani, R. y Todini, E. 1996. Assessment of the state of the eutrophication in the Mediterranean sea. MAP Technical Reports Series $n^{\circ} 106$ UNEP. Athens.

Webb, K.L. 1981. Conceptual models and processes of nutrient cycling in estuaries pp. 25 46. En: Neilson, B.J. y L.E. Cronin (Eds.). Estuaries and nutrients. Humana Press Inc., New Jersey.

Westall, J. y Stumm, W. 1980. The hydrosphere pp. 17-49. En: The Natural Environment and the Biogeochemical Cycles. The handbook of chemistry. Ed. O. Hutzinger. SpringerVerlag. Berlin-Heidelberg-New York.

WFD CIS. 2001. Common Implementation Strategy for the Water Framework Directive (2000/60/EC). Strategic document as agreed by the Water Directors under Swedish Presidency. 2 may 2001. Electronic document. Public WFD CIRCA library. http://forum.europa.eu.int/Public/irc/env/wfd/library:1-79. [Consulta: 02 de febrero de 2008].

WFD CIS. 2004. Common Implementation Strategy for the Water Framework Directive (2000/60/EC). Moving to the next stage in Common Implementation Strategy for the Water Framework Directive Progress and work programme for 2005 and 2006. Agreed by Water Directors. 2 - 3 December 2004. http://forum.europa.eu.int/Public/irc/env/wfd/library:1 84. [Consulta: 02 de mayo de 2008].

WFD CIS. 2009. European Workshop on Heavily modified water bodies: information exchange on designation, assessment of ecological potential, objective setting and measures. Key conclussions. Common Implementation Strategy, Brussels, 12 - 13 March 2009.

WFD CIS Guidance Document $n^{\circ}$ 4. 2003. Identification and Designation of Artificial and Heavily Modified Waterbodies. Published by the Directorate General Environment of the European Commission, Brussels, ISBN No. 92-894-5124-6, ISSN No. 1725 - 1087.

WWF/Adena. 2002. El litoral mediterráneo: importancia, diagnóstico y conservación. Propuesta de WWF/Adena. WWF/Adena. Madrid. 